MODELO DE TRANSFORMAÇÃO DE ENERGIA EÓLICA NUM FLUXO DE ÁGUA COM ALTA PRESSÃO PARA DESSALINIZAÇÃO POR OSMOSE REVERSA OU/E GERAÇÃO DE ELETRICIDADE

Tese apresentada à Escola Politécnica da

Universidade de São Paulo para obtenção

do título de Doutor em Engenharia.

São Paulo

2010 


\section{MODELO DE TRANSFORMAÇÃO DE ENERGIA EÓLICA NUM FLUXO DE ÁGUA COM ALTA PRESSÃO PARA DESSALINIZAÇÃO POR OSMOSE REVERSA, OU/E GERAÇÃO DE ELETRICIDADE}

Tese apresentada à Escola Politécnica da

Universidade de São Paulo para obtenção

do título de Doutor em Engenharia.

Área de concentração:

Engenharia Elétrica

Orientadora:

Professora Doutora

Eliane Aparecida Faria Amaral Fadigas

São Paulo

2010 
Este exemplar foi revisado e corrigido em relação à versão original, sob responsabilidade única do autor e com a anuência de seu orientador.

São Paulo, de de

Assinatura do autor:

Assinatura do orientador:

Dias, Juvenal Rocha

Modelo de transformação de energia eólica num fluxo de água com alta pressão para dessalinização por osmose reserva ou/e geração de letricidade / J. R. Dias -- versão corr. -- São Paulo, 2010. $221 \mathrm{p}$.

Tese (Doutorado) - Escola Politécnica da Universidade de São Paulo. Departamento de Engenharia de Energia e Automação Elétricas.

1.Energia eólica (Transformação) 2.Dessalinização 3.Osmose reserva 4.Geração de energia elétrica I.Universidade de São Paulo. Escola Politécnica. Departamento de Engenharia de Energia e Automação Elétricas II.t. 


\section{DEDICATÓRIA}

Aos meus pais:

João Batista Dias

Margarida Joana Lucas

Aos meus filhos:

Joselito Delgado Dias

Brenna Milena Lopes da Silva Dias.

Aos meus irmãos: Joaquim, José Carlos, Edna, Paulo e Nilton.

Igualmente dedico este trabalho ao meio ambiente e a todos que futuramente venham a "beber" do, ou ser "iluminados" pelo seu conteúdo, ou seu "produto", tendo em conta que água é vida ("leia" a figura) e luz deve ser para todos.

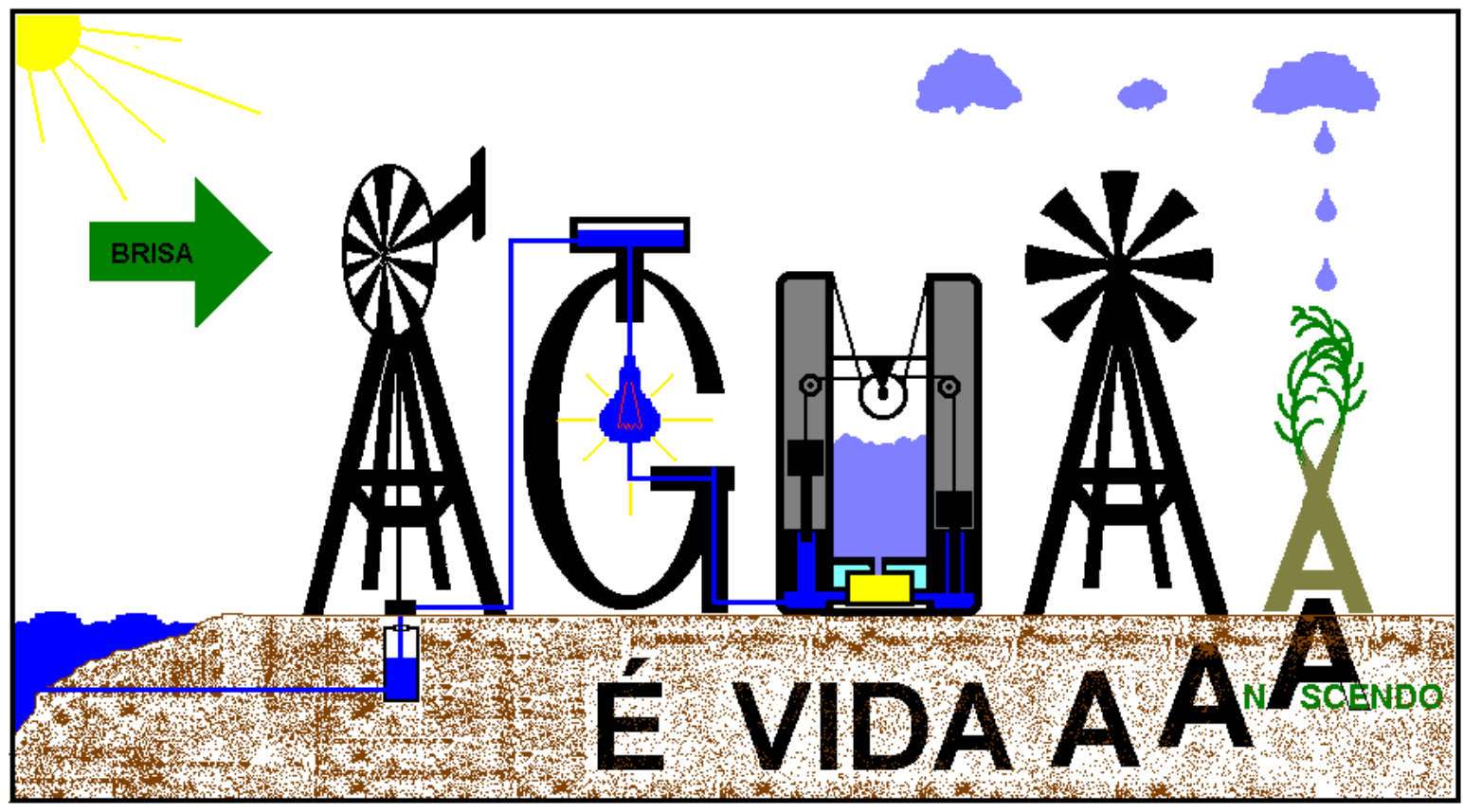

$\mathrm{O}$ autor

Juvenal Dias 


\section{AGRADECIMENTOS}

Agradeço à minha orientadora, Professora Doutora Eliane Aparecida Faria Amaral Fadigas, pela sua disponibilidade em colaborar, que tem demonstrado sempre. Faço questão ainda de agradecer aos colegas e Professores que, de uma forma ou outra tenham contribuído para que o trabalho tenha chegado até esta fase. Foram bem vindas, as questões levantadas durante a fase embrionária da idéia desenvolvida neste trabalho.

Não queria deixar de expressar, o meu agradecimento aos meus pais e irmãos que sempre me apoiaram de forma incondicional. De entre os irmãos, sublinho o suporte que me foi dado por José Carlos Rocha Dias que na companhia do colega Mário Biague, estabeleceu a ponte ( Brasil- Cabo Verde ) com a minha orientadora..

Aos Engenheiros e técnicos da ELECTRA (Empresa de Electricidade e Água), deixo registrado o meu agradecimento pelo apoio que me prestaram. De entre todos, cito os seguintes nomes dos Eng ${ }^{o s}$, Manuel Silva, Amílcar Moreira, Hipólito Gomes, Francisco Amaro, José Delgado e Kulla Cardoso. Igualmente agradeço ao meteorologista do instituto de meteorologia, Nilton Évora, pelos dados e informações que me concedeu.

Endereço meus agradecimentos à Câmara Municipal de Porto Novo ( Cabo Verde) com destaque ao Presidente, Sr Amadeu Cruz e ao Vereador Eng ${ }^{0}$ Manuel Baptista pelo seu empenho em apoiar este projeto. À FUSP, meu obrigado pela concessão da bolsa.

Aos técnicos das oficinas; Jaír, Raimundo, Gerson, Laércio e Gilberto, meu muito obrigado pelo apoio que me deram durante as fases de construção do protótipo.

Meus agradecimentos à todos os amigos que de alguma forma me apoiaram. Nesses estão incluídos aqueles que simplesmente me tenham escutado falar-lhes do projeto e para tal, tenham dispensado sua atenção e tempo.

Por fim, não menos importante, (aliás, de grande importância) foram as considerações e sugestões apresentadas pelo Professores Doutores Sílvio de Oliveira Júnior , José Carlos Mierzwa, Paulo César Marques de Carvalho e José Antônio Perella Balestieri, que enriqueceram o trabalho, e pelo fato, agradeço muito. 


\section{RESUMO}

Este trabalho apresenta uma configuração alternativa para a dessalinização de água e geração de energia elétrica com recurso à energia eólica. Trata-se de um modelo físico que permite armazenar água do mar ou água salobra sob a forma de energia potencial gravitacional, através do seu bombeamento até um reservatório a uma determinada altura. $\mathrm{O}$ bombeamento é feito com o recurso à energia do vento.

Uma vez, tendo a água sido acumulada no reservatório, sua energia potencial gravitacional EPG é usada para a sua dessalinização ou/e para a geração de eletricidade. O referido modelo é semelhante a um grupo de bombas de pistões. Os pistões possuem formato especial de modo que se consiga obter pressões elevadas suficientes quer para a dessalinização de água por osmose reversa, quer para a geração de eletricidade através de turbinas Pelton. Consegue-se o movimento alternado dos pistões a partir da transferência da energia da água acumulada (EPG) através dum sistema de roldanas e contrapesos.

Assim sendo, provar que o modelo é capaz de transformar a EPG de baixa pressão (inferior a 2 bar) em energia cinética de um fluxo com alta pressão (superior a 55 bar) se apresenta como o foco principal deste trabalho. Com esse foco em mira, construiu-se um protótipo com o objetivo de demonstrar a viabilidade técnica da proposta. Imagens do protótipo são apresentadas neste trabalho.

Em relação à osmose reversa, a referida configuração difere do que é convencional em plantas de dessalinização que usam esse processo, pelo fato de contemplar o uso de EPG. Com o modelo proposto, consegue-se um fluxo à entrada dos módulos de membrana (ou à saída do injetor da turbina Pelton) com pressão suficiente para a osmose reversa (ou para geração de eletricidade).

Em relação à captação da energia eólica para o bombeamento de água, o modelo é divido em dois sistemas. O primeiro (sistema 1) usa cataventos tradicionais e o segundo (sistema 2) aerogeradores. É feita a comparação qualitativa entre os dois sistemas com base em alguns parâmetros tais como área ocupada, versatilidade etc. 


\begin{abstract}
This work presents an alternative configuration for sea, and brackish water desalination by reverse osmosis and electricity generation, resorting to wind energy. It is a physical model that allows the storage of sea or brackish water as gravitational potential energy, through its pumping to a reservoir located at a certain height. The water pumping is done resorting to wind energy.

Once the water is stored in the reservoir, its gravitational potential energy GPE is used for its desalination or/and for electricity generation. The referred model is similar to a group of piston pumps. The pistons have a special shape so that it is possible to achieve the high pressures that are enough, either for water desalination by reverse osmosis or for electricity generation with Pelton turbines. The alternated movement of the pistons is achieved with the energy transfer from the stored water (GPE), through a system of pulleys and counterweights.
\end{abstract}

Thus, to prove that the model is capable of transforming the GPE at low pressure (below 2 bar) into kinetic energy of a flux with high pressure (over 55 bar) is the main focus of this work. Targeting that focus, a prototype was constructed with the objective of demonstrating the technical viability of the proposal. Images of the prototype will be shown in this work.

In respect of reverse osmosis, the referred configuration differs from the conventional in desalination plants that use the method, in that it incorporates the use of GPE. With the proposed model, one achieves a flux at the inlet of the membranes (or at the exit of the injector of the Pelton turbine) with enough pressure for reverse osmosis (or for electricity generation).

In respect of the harvesting of wind energy for water pumping, the model is divided into two systems. The first system (system 1), uses the traditional windmills and the second one (system 2), uses wind generators. It is carried out a comparison between the two systems based on some parameters such as occupied area, versatility and so on. 


\section{SUMÁRIO}

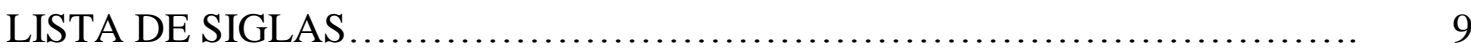

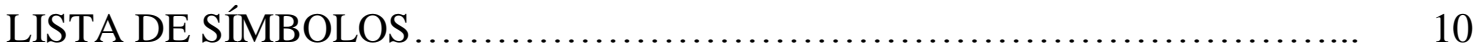

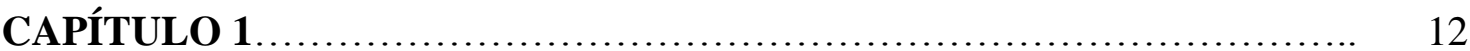

INTRODUÇÃ

1.1 Motivação......................................................... 12

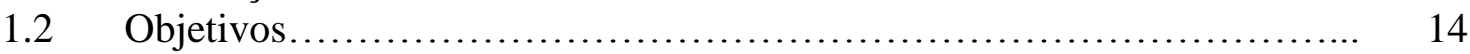

$1.3 \quad$ Estrutura do Trabalho.................................................. 15

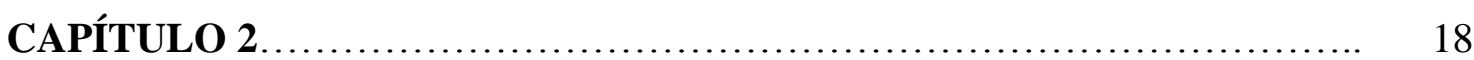

DESCRIÇÃO GERAL DO MODELO 18

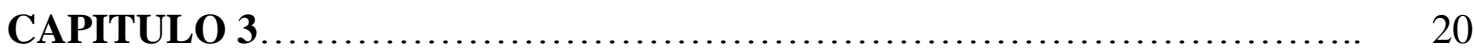

COLUNA DE POTÊNCIA HIDRÁULICA CPH............................... 20

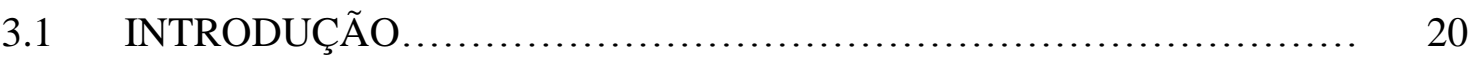

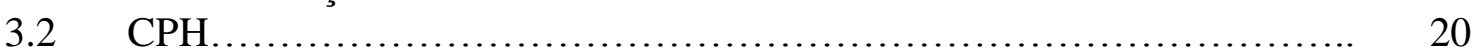

3.2.1 A bomba Clark e o Sistema de Recuperação de Energia.................... 22

3.3 Funcionamento da CPH.......................................... 27

3.3.1 Subsistemas complementares

para o funcionamento paralelo de duas colunas........................ 27

3.3.2 Funcionamento paralelo de duas colunas de potência hidráulica........... 33

3.4 Caráterísticas da CPH.................................................. 41

3.5 Pressão de Operação da CPH......................................... 42

3.6 Praticabilidade e Consumo Específico do modelo proposto................. 46

3.7 Etapas de construção do protótipo................................... 53

3.8 Comentários sobre os resultados do protótipo......................... 58

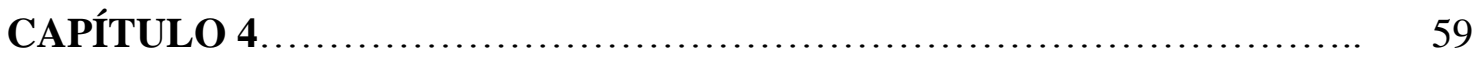

FONTE DE ENERGIA DO MODELO ................................. 59

$4.1 \quad$ INTRODUÇÃO ..................................................... 59

Fonte de Energia dos Sistemas
e bombeamento de água até o reservatório superior R1 ................... 59

$4.3 \quad$ Potencial eólico...................................................... 63

4.3.1 Estimativa do potencial eólico de um lugar.............................. 66

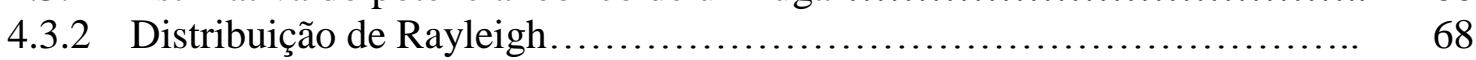

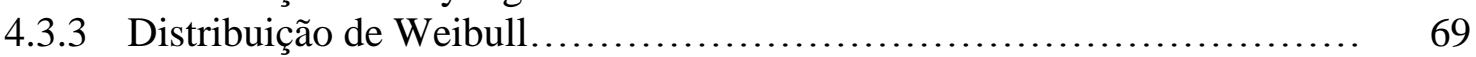

4.4 Potência real captada pela máquina eólica.............................. 70

4.5 Potência de bombeamento com cata-vento (Sistema 1).................. 73

4.6 Potência de bombeamento com aerogerador - bomba elétrica (Sistema 2).. 77

4.6.1 Estimativa da produção duma turbina através de técnicas estatísticas...... 78

4.6.1.1 Produtividade ideal de uma turbina usando a distribuição de Rayleigh..... 81

4.6.1.2 Produtividade real de uma turbina usando a distribuição de Weibull...... $\quad 84$

4.6.1.3 Produtividade real de uma turbina usando diretamente os dados coletados $\quad 86$

4.7 Conversão da potência de bombeamento em energia potencial gravitacional.................... 87

4.8 Comentários e comparação qualitativa dos dois sistemas................. 90 
CAPÍTULO 5

APLICAÇÕES DA CPH :

OSMOSE REVERSA E GERAÇÃO DE ELETRICIDADE...................... 95

$5.1 \quad$ Introdução......................................................... 95

5.2 Dessalinização..................................................... 95

5.2.1 Processos de Dessalinização........................................ 97

5.2.2 Osmose Reversa.................................................... 97

$5.3 \quad$ Geração de eletricidade.............................................. 100

5.3 .2 Tipos de turbinas................................................... 101

5.3.3 Potência gerada pela CPH........................................ 104

5.4 Diagramas de Sankey do modelo proposto............................ 111

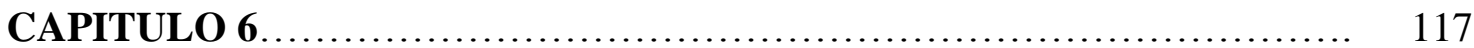

ESTUDO DE CASOS .................................................... 117

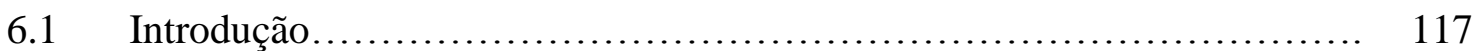

6.2 Estudo de caso 1: Produção de $5000 \mathrm{~m}^{3} /$ dia usando CPH e sistema $1 \ldots \ldots . .118$

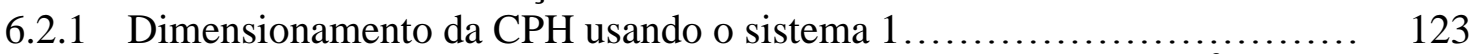

6.2.2 Resumo do dimensionamento da CPH para produção de $5000 \mathrm{~m}^{3} /$ dia..... $\quad 150$

6.2.3 Comparação da unidade convencional de Cabo Verde com a CPH......... 151

6.3 Caso 2: Dimensionamento da CPH para produzir $5 \mathrm{~m}^{3}$ de água por dia 153

6.3.1 Caráterísticas do protótipo Holandês............................... 154

6.3.2 Caso 2.1: Dimensionamento da CPH com o sistema S1 (cataventos)....... 155

6.3.3 Caso 2.2: Dimensionamento da CPH com o sistema S2 (Aerogeradores)... 166

6.3.4 Comparação entre o protótipo Holandês e a CPH (Sistemas 1 e 2)......... 168

6.4 Caso 3: Dimensionamento da $\mathrm{CPH}$

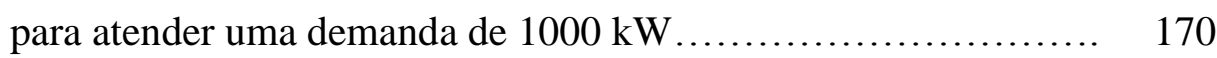

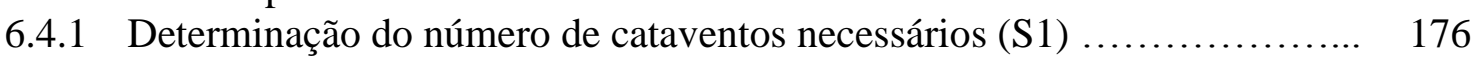

6.4.2 Determinação do número de aerogeradores necessários (S2) ............. 177

6.4.3 Comparação dos sistemas 1 e 2 para geração elétrica...................... 178

6.5 Diagramas de Sankey do modelo proposto............................ 179

6.6 Considerações sobre a viabilidade técnica ambiental e social do uso da CPH................... 185

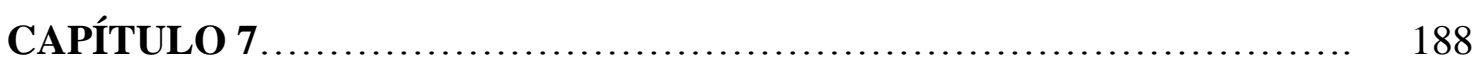

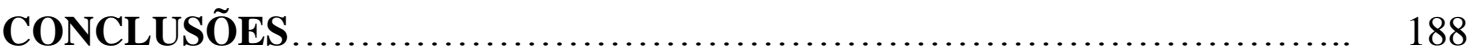

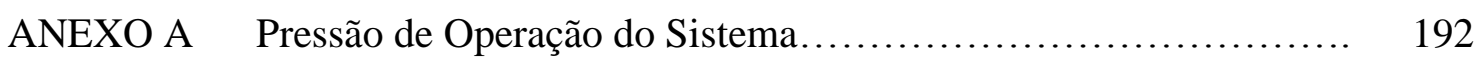

ANEXO B Consumo específico da CPH................................... 196

ANEXO C Práticas de manutenção aplicadas

a uma bomba de deslocamento positivo

de uma unidade de dessalinização água por osmose reversa........ 202

ANEXO D Extrato da divulgação do SEARASER ........................... 209

ANEXO E Uso de uma roda Pelton para a elevação do êmbolo especial....... 213

ANEXO F Alimentação de R1 com carneiro hidráulico...................... 215

ANEXO G Outros conceitos de turbinas eólicas............................. 217

REFERÊNCIAS ........................................................ 219 


\section{LISTA DE SIGLAS}

CPH Coluna de Potência Hidráulica

d.S Diagrama de Sankey

DWW Drinking with the wind

EPG Energia potencial gravitacional

ELECTRA Empresa de Electricidade e Água (Empresa que opera em Cabo Verde)

FMEA Failure Mode and Effect Analysis (Análise de modos e efeitos de falha)

MED Multiple-Effect Distillation (Destilação por Múltiplos-Efeitos)

MSF Multi-Stage-Flash (Múltiplas-Etapas)

MSFD Multi-Stage-Flash-Distillation (Destilação por múltiplas-Etapas)

MVC Mechanical Vapor Compression. (Compressão Mecânica de Vapor)

OMS Organização Mundial de Saúde

PSI Pound per Square Inch (libra por $\mathrm{cm}^{2}$, unidade inglesa de pressão)

RO Reverse Osmosis (Osmose Reversa)

OR Osmose Reversa

TDS Total Dissolved Solids. (Totalidade de sólidos dissolvidos) 


\section{LISTA DE SÍMBOLOS}

a Aceleração do conjunto contrapeso-êmbolo

$\mathbf{A}_{\mathbf{b}} \quad$ Área da base do êmbolo

$\mathbf{C}_{\mathbf{R} 3}$ Cilindrada da câmara de compressão (Volume de água que R3 comporta)

d Diâmetro interno do contrapeso

$\mathbf{d}_{\mathbf{e}} \quad$ Diâmetro da base do êmbolo

D Diâmetro de R1

Di Diâmetro interno do reservatório R2

$\mathbf{D}_{\mathbf{p}}$ Distância percorrida pelo contrapeso para elevar o êmbolo

Dr Distância percorrida pelo êmbolo ao ser elevado pelo contrpeso

E1 Êmbolo especial

$\mathbf{E}_{\text {el }} \quad$ Energia elétrica gerada pelo aerogerador

E Energia consumida

$\mathbf{E}_{\text {tra }}$ Energia transferida

F Peso do êmbolo

g Aceleração da gravidade

$\mathbf{H}_{\mathrm{m}} \quad$ Altura manométrica

$\mathbf{h}_{\mathbf{r}} \quad$ Altura do reservatório R1

J Fluxo de água dessalinizada através de uma membrana

m Massa

m Vazão mássica

$\mathbf{m}_{\mathbf{C P}}$ Massa do contrapeso

$\mathbf{m}_{\mathrm{E} 1} \quad$ Massa do êmbolo

n Nível de água no reservatório R2

$\mathbf{n}_{\text {cil }} \quad$ Número de ciclos

nd Número de dias

N Nível de água no contrapeso

$\mathbf{N}_{\mathbf{B}} \quad$ Número de partições de um intervalo de tempo $\Delta \mathrm{t}$

P Pressão

$\mathbf{P}_{\mathbf{0}} \quad$ Pressão atmosférica

$\mathbf{P}_{\mathbf{A} ; \mathbf{B}} \quad$ Pressão exercida pelo êmbolo especial A ou B

$\mathbf{P}_{\text {aço }}$ Peso do aço

$\mathbf{P}_{\text {água }}$ Peso da água contida em R2 
$\mathbf{P}_{\mathbf{C P}}$ Peso do contrapeso maciço

$\mathbf{P}_{\text {el }} \quad$ Potência elétrica da máquina eólica

$\mathbf{P}_{\text {elm }} \quad$ Potência elétrica média da máquina eólica

$\mathbf{P}_{\text {ench }}$ Peso do material de enchimento do êmbolo especial

$\mathbf{P}_{\mathbf{e v}} \quad$ Peso correspondente à massa sólida do êmbolo (peso do êmbolo vazio)

$\mathbf{P}_{\mathbf{g}} \quad$ Potência gerada pelo grupo turbina Pelton-Gerador

$\mathbf{P}_{\mathbf{b}} \quad$ Pressão na base de uma coluna de água

$\mathbf{P}_{\text {osm }} \quad$ Pressão osmótica

$\mathbf{P}_{\mathbf{o p}} \quad$ Pressão de operação

Pt Peso total do êmbolo especial

$\mathbf{Q}_{\mathbf{m}} \quad$ Vazão de água

Ri Reservatório de numeração i

T Tensão

t Tempo

$\rho_{\text {agua }}$ Densidade da água

$\rho_{\text {aço }}$ Densidade do aço

Vi Válvula de numeração i

$\mathbf{V}_{\mathbf{a C P}}$ Volume de água contida no contrapeso

$\mathbf{V}_{\text {agua }}$ Volume de água

$\mathbf{V}_{\mathrm{aR} 1}$ Volume de água no reservatório R1

$\mathbf{V}_{\text {bomb }}$ Volume bombeado

$\mathbf{v}_{\mathbf{e}}$ Velocidade de descida do êmbolo especial

$\mathbf{v}_{\mathbf{j}} \quad$ Velocidade do jato de água

$\mathrm{V}_{\mathrm{j}} \quad$ Velocidade média do vento no intervalo $\Delta \mathrm{t}$

$\mathbf{V}_{\mathbf{m}} \quad$ Velocidade média

$\mathbf{V}_{\mathbf{0}} \quad$ Volume inicial em R1 para a partida da $\mathrm{CPH}$

$\mathbf{V}_{1}$ Volume correspondente à m 1

$\mathbf{V}_{6} \quad$ Volume correspondente à ṁ6

$\mathbf{V}_{\mathbf{R} 1}$ Capacidade de R1

$\boldsymbol{\eta}_{\mathbf{T}}$ Rendimento da turbina Pelton

$\eta_{\mathbf{G}}$ Rendimento do gerador

W Trabalho realizado ao longo de um processo

$\mathbf{W}_{\mathbf{C P}}$ Trabalho realizado pelo contrapeso

w Trabalho por unidade de massa 


\section{CAPítulo 1:}

\section{INTRODUÇÃO}

\section{1 - Motivação}

Um dos primeiros aspectos que motivaram o autor deste trabalho a desenvolver este tema de pesquisa, é a sua origem como cidadão. Oriundo de um país insular (a República de Cabo Verde), sempre viveu cercado pelo mar. Apesar da quantidade imensa de água ao redor, o arquipélago de Cabo Verde, situado no Oceano Atlântico, sempre se debateu com a escassez de água potável, em várias das suas dez ilhas. Para ultrapassar esse problema, as ilhas mais afetadas dispõem de plantas de dessalinização.

No que concerne à geração de eletricidade, além da poluição gerada, o país se debate com o problema da dependência do petróleo, dado que a sua matriz elétrica é constituída essencialmente de grupos geradores movidos a diesel. A geração através de fontes renováveis é ainda incipiente.

Dessalinização é a designação do processo de extração de sais dissolvidos da água, para se obter água potável. Pela dessalinização, pode-se conseguir água potável, a partir de águas salobras, ou da água do mar. Em Cabo Verde cerca de $70 \%$ da água potável consumida pela população, é obtida da dessalinização da água do mar. Isso representa custos elevados para a Empresa de Eletricidade e Água (ELECTRA), dado que o processo de dessalinização é dispendioso. Em algumas ilhas, aproximadamente $30 \%$ da produção de energia elétrica da ELECTRA, são destinados para a dessalinização. Dado que, para a geração de energia elétrica as fontes mais usadas são os derivados do petróleo, a balança comercial do país é bastante e negativamente afetada devido à importação desses derivados.

Se por um lado, a Natureza não foi benevolente com esse país, onde o subsolo não tem minérios valiosos e chove pouco durante o ano, por outro compensou-lhe pela sua situação geográfica. Essa situação (Latitude $17^{0}-\mathrm{N}$, Longitude $25^{0}-\mathrm{W}$ ), permite à Cabo Verde dispor de uma abundância de ventos, de ondas e de radiação solar, cujo potencial, 
infelizmente, é ainda pouco explorado. As imagens da Fig. 1.1 dão uma impressão visual do que foi dito em relação à esse maravilhoso arquipélago.

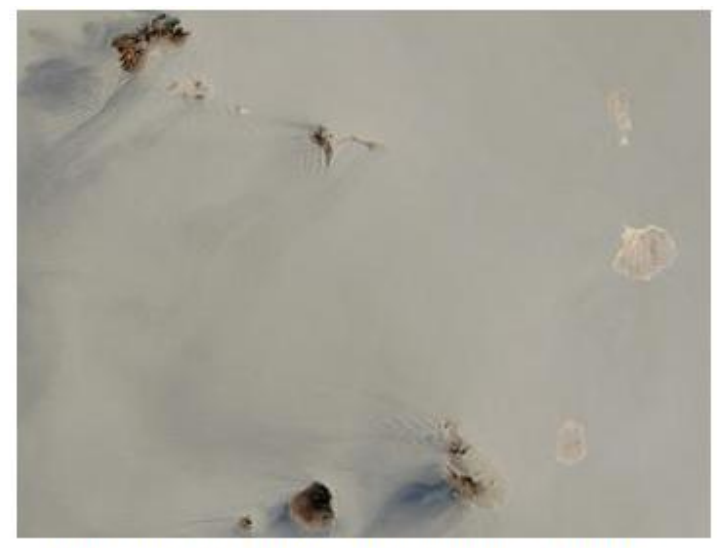

Ilhas de Cabo Verde parcialmente cobertas pela areia do Sahara trazida pelo vento.

( abundância de energia eólica)

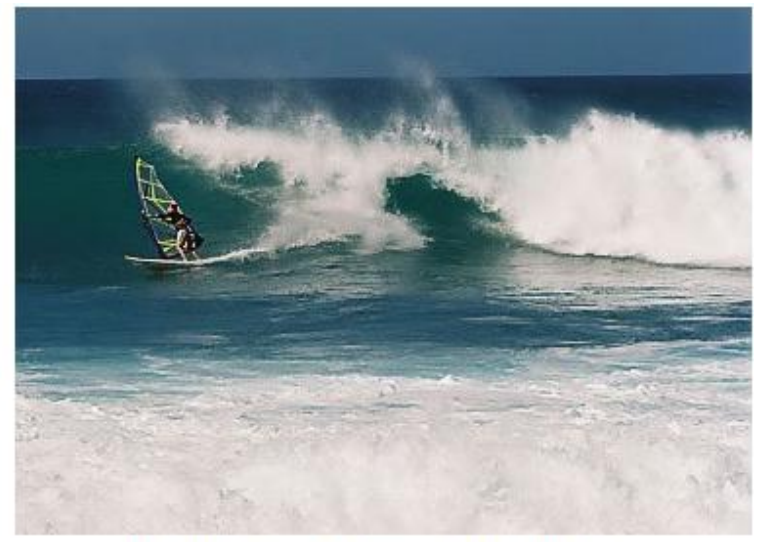

Manifestação das energias eólica e oceânica

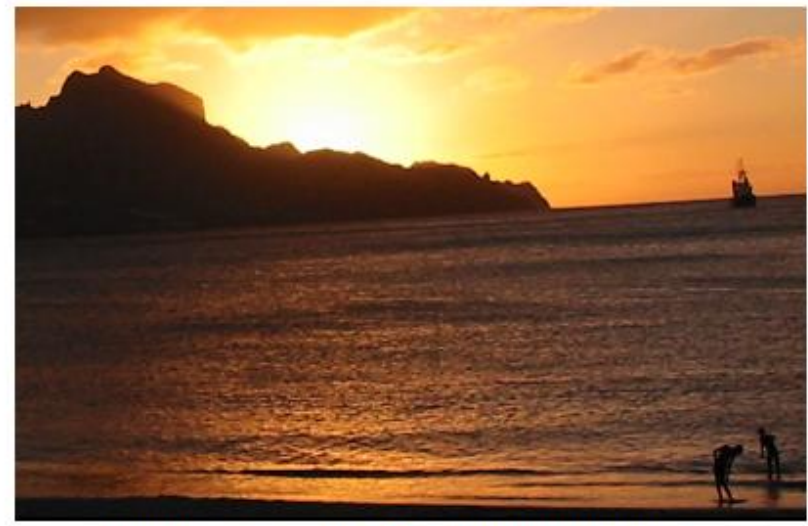

Energia solar: Pôr do sol no monte cara

Fig. 1.1: Ilustrações do potencial de energias renováveis de Cabo Verde.

O ensejo de ver ampliada a exploração desse potencial energético (energia solar, energia eólica e oceânica), motivou o autor a se dedicar ao estudo de fontes alternativas com o objetivo de ter sua aplicação tanto na dessalinização de água como na geração elétrica. A motivação é ainda acrescida, tendo em conta que a questão da escassez de água e da busca de alternativas sustentáveis para a geração elétrica terem abrangência mundial. Assim sendo, o modelo é concebido para satisfazer necessidades de outras regiões do Planeta onde as condições da fonte primária (o vento) forem propícias. 


\section{2- Objetivos}

O trabalho apresenta uma proposta alternativa para a satisfação da demanda crescente de água potável, e de energia elétrica existente em países carentes desses bens, como é o caso do arquipélago de Cabo Verde. Para tal, o objetivo do projeto é a dessalinização de água do mar ou água salobra através da osmose reversa e/ou geração de energia elétrica através de turbinas Pelton, tendo como recurso energético a energia potencial gravitacional da água, obtida a partir de bombeamento eólico (cataventos) ou eólicoelétrico (aerogeradores).

No caso do uso de cataventos (sistema 1), um dos principais objetivos é a total autonomia do sistema idealizado, dispensando o uso quer de eletricidade quer de combustíveis para o bombeamento da água que será armazenada num reservatório situado a uma determinada altura. No caso do uso de aerogeradores (sistema 2), além da autonomia, um dos objetivos é dispensar o uso de baterias para acumulação de energia, como geralmente é feito em sistemas convencionias. O diagrama de blocos representado na Fig. 1.2 dá uma visão global do modelo.

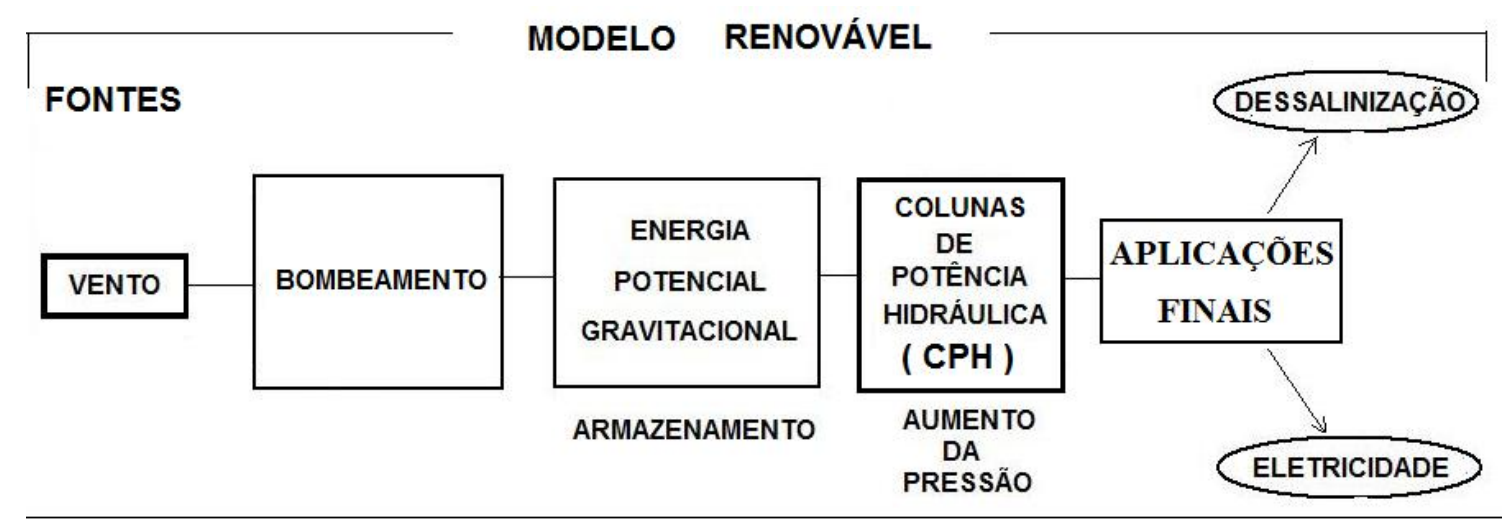

Fig. 1.2: Diagrama de blocos do modelo.

Após a captação da energia do vento, segue-se a sua transformação em energia potencial gravitacional (armazenamento de água num reservatório). As colunas de potência hidráulica $(\mathrm{CPH})$ usam essa EPG para gerar um fluxo de água de alta pressão. Essa geração é conseguida graças a um sistema mecânico constituído por êmbolos especiais, roldanas e contrapesos com controle hidráulico feito por atuadores e amortecedores. 
No caso da aplicação do modelo nas ilhas de Cabo Verde, dois objetivos fundamentais são o uso de um recurso abundante e renovável (o vento) e dispensar o uso de combustível fóssil (DIESEL).

O reservatório R1 permite a regularização da vazão de água obtendo-se uma energia firme, apesar do uso de um recurso energético intermitente. A proposta de estudo das fontes utilizando duas formas de energia: elétrica (aerogeradores) e mecânica (cataventos) para alimentar o reservatório com água, teve o objetivo de comparar estas duas tecnologias disponíveis, de tal forma a explorar as vantagens e desvantagens de cada uma neste tipo de aplicação.

\section{3- Estrutura do Trabalho}

Quanto à estrutura, o trabalho está dividido em sete capítulos incluindo este primeiro.

No segundo capítulo apresenta-se o modelo completo e a descrição geral de seu funcionamento. Neste capítulo apresenta-se os dois sistemas, o sistema 1 que capta a energia eólica com cataventos e o sistema 2, que o faz com aerogeradores.

No terceiro capítulo, que é o âmago do trabalho, apresenta-se o modelo da coluna de potência hidráulica, CPH. Nesse capítulo fica demonstrada a viabilidade técnica do modelo. No epílogo desse capítulo apresenta-se fotografias do protótipo.

No quarto capítulo faz-se a abordagem da fonte primária de energia do modelo e a correspondente modelagem matemática para atendimento de demandas de água e energia elétrica.

O quinto capítulo traz a abordagem das aplicações do modelo (dessalinização e geração elétrica). Faz-se uma subdivisão desse capítulo para abordar cada uma dessas aplicações. Apesar dessa subdivisão, não se exclui a possibilidade de se fazer, ao longo do texto, menção simultânea à dessalinização e à geração de eletricidade.

Nesse capítulo, quanto à obtenção de água potável, faz-se uma sucinta menção aos processos de dessalinização com ênfase para a osmose reversa e, quanto à geração de 
eletricidade, será feita uma abordagem às turbinas hidráulicas com maior ênfase à turbina Pelton, por ser o tipo que mais se adequa a transformação da energia de um jato de água.

No sexto capítulo, faz-se três estudos de caso:

O primeiro é feito com base no regime de vento de Cabo Verde. Os cálculos são feitos para o atendimento de uma demanda diária de $5000 \mathrm{~m}^{3}$ de água dessalinizada por dia. Este estudo constitui, em parte, um resgate do trabalho desenvolvido em (DIAS,2004) onde o estudo de caso foi baseado numa das unidades de dessalinização que operam em Cabo Verde.

Esse resgate se justifica não só pelo fato da dessalinização continuar a ser um objetivo da CPH mas também, porque os resultados obtidos em relação à energia firme no reservatório, servem para uma análise da geração elétrica. Infere-se isso dado que a pressão à entrada do injetor é imposta pela $\mathrm{CPH}$ e pode ser regulada pelo bico daquele.

No segundo caso o modelo é comparado com um protótipo desenvolvido na Holanda com a capacidade de produzir $5 \mathrm{~m}^{3}$ de água dessalinizada. Neste estudo, no decorrer do dimensionamento da CPH, aborda-se a questão da sua otimização.

No terceiro estudo, a CPH é dimensionada para atender uma demanda de $1000 \mathrm{~kW}$.

Um dos objetivos desse capítulo é demonstrar a viabilidade técnica da configuração proposta, em relação às duas aplicações: osmose reversa e geração de eletricidade.

As conclusões são apresentadas no capítulo 7. Ainda nesse capítulo adianta-se as perspectivas e propostas futuras. 


\section{CAPÍTULO 2:}

\section{DESCRIÇÃO GERAL DO MODELO}

A Fig. 2.1 ilustra a configuração geral do modelo proposto neste trabalho, que consiste na dessalinização por osmose reversa e geração de eletricidade com turbina Pelton, com recurso à energia eólica. O ineditismo do trabalho gira em torno da coluna de potência hidráulica, $\mathrm{CPH}$ (módulo em destaque na Fig. 2.1) que é a unidade que, no modelo, possibilita a transformação da energia do vento em fluxo de água com alta pressão, e que está demonstrado no capítulo 3.

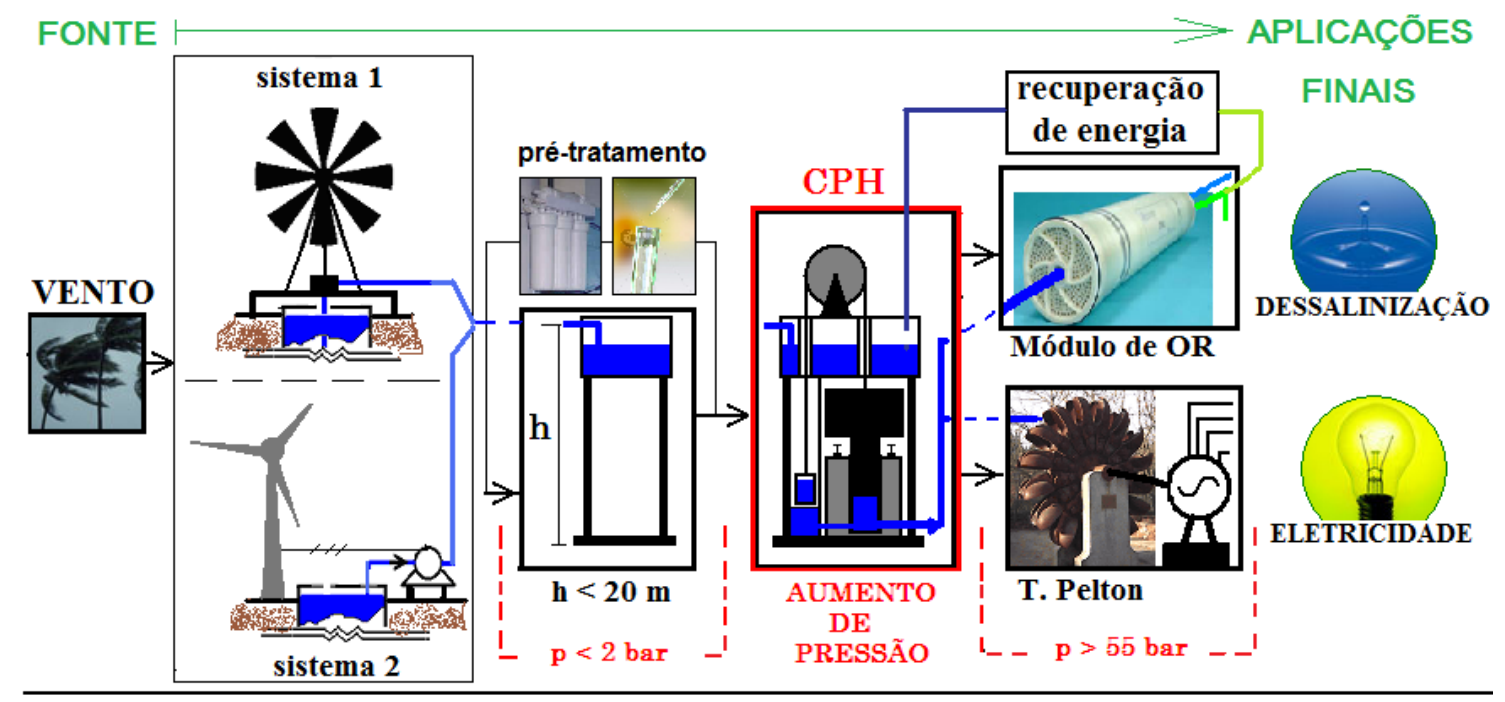

Fig. 2.1: Modelo renovável da coluna de potência hidráulica.

Em traços gerais, o modelo transforma a energia eólica em energia potencial gravitacional. Essa tranformação é conseguida através do bombeamento de água do mar ou de água salobra com um catavento convencional (sistema 1) ou com uma bomba elétrica alimentada por um aerogerador (sitema 2). A água bombeada é armazenada num reservatório situado a um altura inferior a vinte metros. Assim, no reservatório, tem-se energia potencial gravitacional com uma pressão de coluna de água inferior a 2 bar. Ao se referir à bomba elétrica, entenda-se como o conjunto usado para bombear água. formado por um motor elétrico e uma bomba centrífuga (ou moto-bomba).

A função específica da coluna de potência hidráulica $\mathrm{CPH}$ é transformar a água acumulada num fluxo de alta pressão, suficiente quer para a dessalinização por osmose 
reversa, quer para a geração de eletricidade usando uma turbina Pelton. A recuperação da energia da salmoura é feita por uma bomba Clark que converte essa energia em água bombeada até o reservatório da $\mathrm{CPH}$. Apesar do modelo comtemplar o uso de cataventos ou de aerogeradores, o objetivo fundamental é mostrar que a $\mathrm{CPH}$ funciona independentemente de como e quando a água foi bombeada até esse reservatório. Isso porque, uma vez garantida a energia firme no reservatório, $\mathrm{E}=\mathrm{mgh}$, estará garantido o funcionamento da CPH e a consequente obtenção dos bens finais, água potável e eletricidade. Esse funcionamento independente abre a possibilidade de se usar outras fontes de energia e outras tecnologias para o bombeamento de água até o reservatório, o que confere ao modelo uma desejável versatilidade.

$\mathrm{O}$ modelo de $\mathrm{CPH}$ pode, grosso modo, ser visto como um regresso ao passado, mas com os olhos para o futuro. Podemos caráterizá-lo como um regresso ao passado já que, apesar da era tecnológica em que vivemos, tem a pretensão de atingir dois objetivos principais:

- Dispensar o uso tanto da eletricidade (sistema 1) como o de combustíveis fósseis.

- Ser totalmente mecânico.

Trata-se de um projeto com uma visão do futuro, por pretender contornar duas evidências futuras:

- A escassez de água potável que tende a agravar com o decorrer dos anos.

- A prevista crise de fontes de energia convencionais.

Diante do quadro mundial de escassez de água potável e da prevista extinção das fontes convencionais de energia, o projeto proposto, pretende dar uma contribuição para a solução simultânea de três problemas:

- A questão da falta de água e o acesso à eletricidade

- Não usar recursos limitados e futuramente escassos, como os combustíveis fósseis ( exceção do carvão) ou a eletricidade derivada de tais combustíveis. 
O modelo visa a obtenção de água potável, a partir de água do mar ou de água salobra, através da dessalinização por RO ou/e a geração de eletricidade como ilustra o diagrama de blocos correspondente, Fig. 2.2.

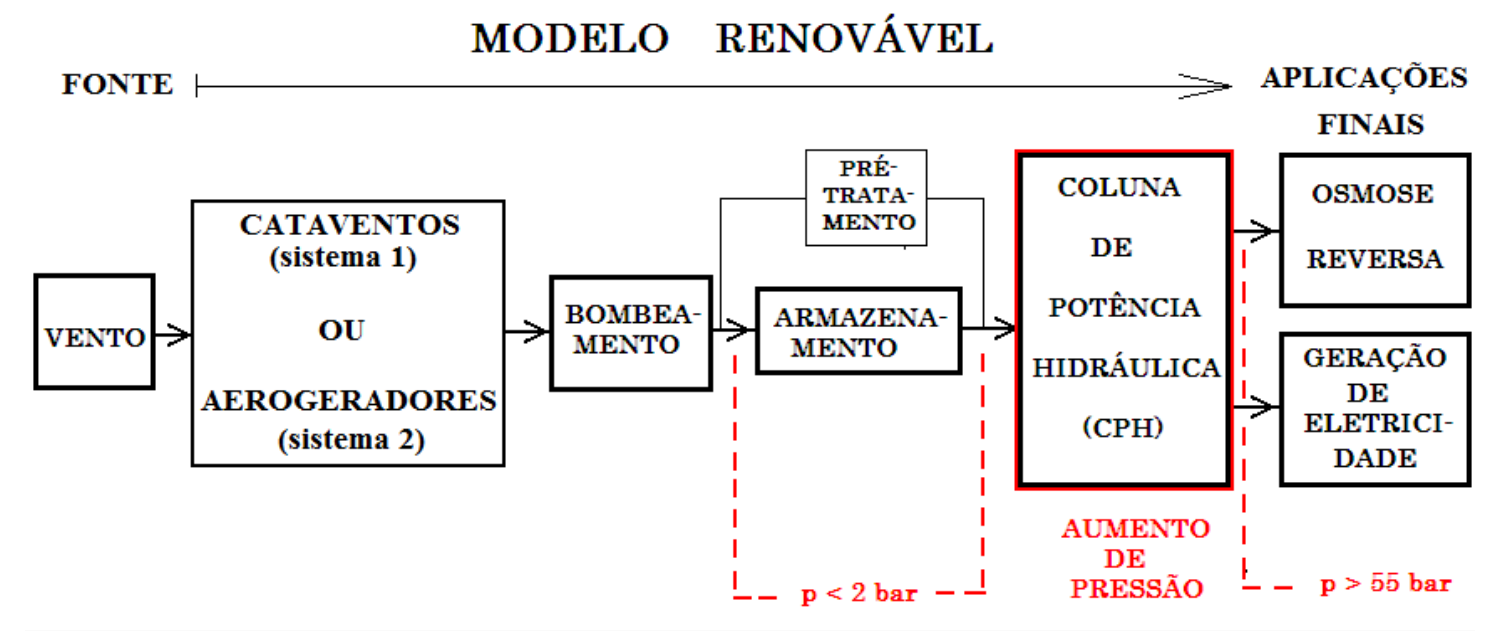

Fig. 2.2: Diagrama de blocos do modelo.

A concepção inicial do modelo prevê que a água bombeada para o reservatório superior Figs 2.1 e 2.2, passe por um pré-tratamento que protege os módulos de membranas. Geralmente, em plantas de dessalinização por osmose reversa, é necessário filtrar a água e adicionar produtos químicos. Esse tratamento prévio permite não só prolongar a vida das membranas, mas também manter um bom nível de produção de água dessalinizada. O pré-tratamento, em particular a filtração, também será benéfico para a turbina Pelton (TP) dado que reduz o possível desgaste das conchas que particulas em supensão poderiam provocar.

A qualidade da água dessalinizada dependerá essencialmente da capacidade de retenção das membranas. Existem módulos de membranas com capacidade para reter acima de 99\% dos sais dissolvidos. Em relação à osmose reversa, o modelo tanto poderá funcionar com módulos individuais como com uma bateria de módulos associados em série, em paralelo ou numa combinação série-paralelo. Em relação à geração de eletricidade, há também a possibilidade de se usar mais do que uma TP caso o projeto justifique. No capítulo seguinte apresenta-se a coluna de potência hidráulica. 


\section{CAPITULO 3:}

\section{COLUNA DE POTÊNCIA HIDRÁULICA CPH}

\section{1 - INTRODUÇÃO}

Como se constata no capítulo 2 (Fig. 2.1), as tecnologias que compõem o modelo são já consagradas: bombeamento eólico (cataventos, aerogeradores-bombas, membranas de osmose reversa, turbina Pelton. Assim, o componente que se apresenta neste capítulo se figura como o âmago do modelo: a coluna de potência hidráulica, $\mathrm{CPH}$. Na CPH ocorre a transformação da energia potencial gravitacional acumulada em energia cinética adequada para a osmose reversa e para a dessalinização de água. Seguem-se a apresentação da CPH, seus componentes, descrição do funcionamento e modelagem.

\section{2- CPH}

O primeiro esquema idealizado em 2002, (desenvolvido em (DIAS,2004)), para a coluna de dessalinização, designada agora por coluna de potência hidráulica $(\mathrm{CPH})$, encontrase representado nas Figs 3.1 e 3.2.

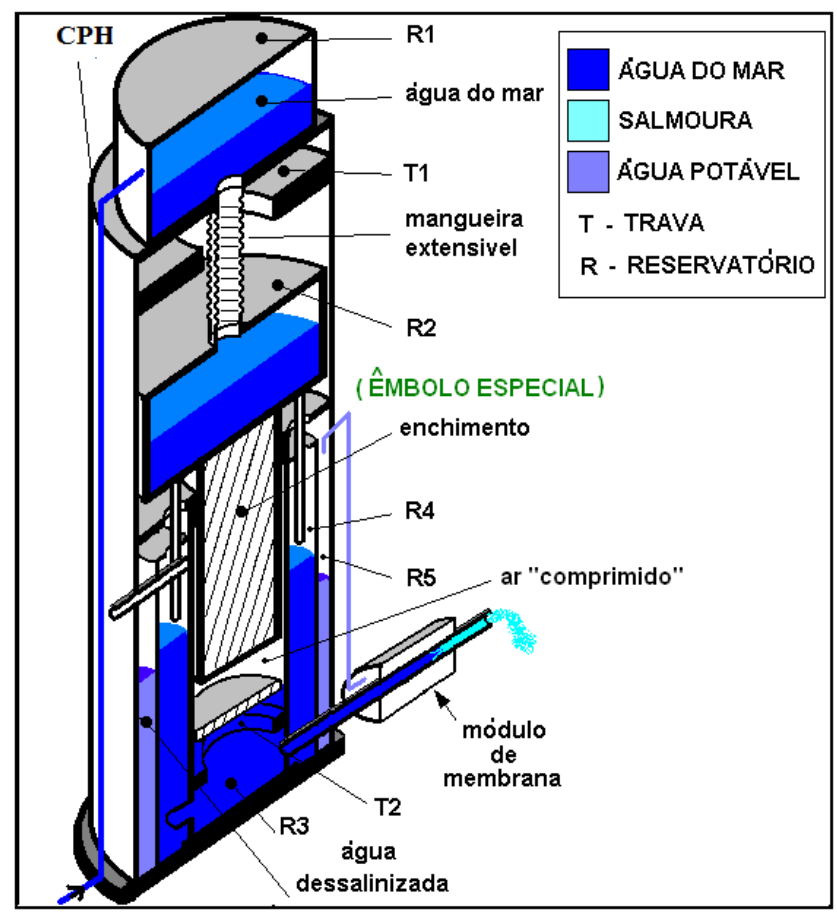

Fig. 3.1: Corte em perspectiva da Coluna de Potência Hidráulica, CPH. 
O princípio geral de funcionamento consiste em bombear a água do mar para o reservatório superior $\mathrm{R} 1$, onde fica armazenada. O bombeamento é feito através de cataventos ou de bomba elétrica alimentada por aerogeradores. A água de R1, ao passar para o reservatório intermediário $\mathrm{R} 2$, faz com que a pressão exercida pelo êmbolo especial sobre o ar comprimido aumente. A pressão aumenta até chegar ao valor necessário para se conseguir a dessalinização (cerca de 800 psi $=55$ bar). Ao atingir a referida pressão, o êmbolo realiza o trabalho de compressão à medida que a água do reservatório inferior R3 é forçada a passar pelo módulo de membrana. Após a realização do trabalho de compressão, R2 se esvazia e o êmbolo é elevado pela descompressão do ar na câmara C. O processo cíclico será descrito mais adiante porém, com base no modelo atual da CPH. Esse modelo funciona com duas colunas e um sistema de roldanas com contrapeso para elevar os êmbolos, (sem a câmara de ar portanto).

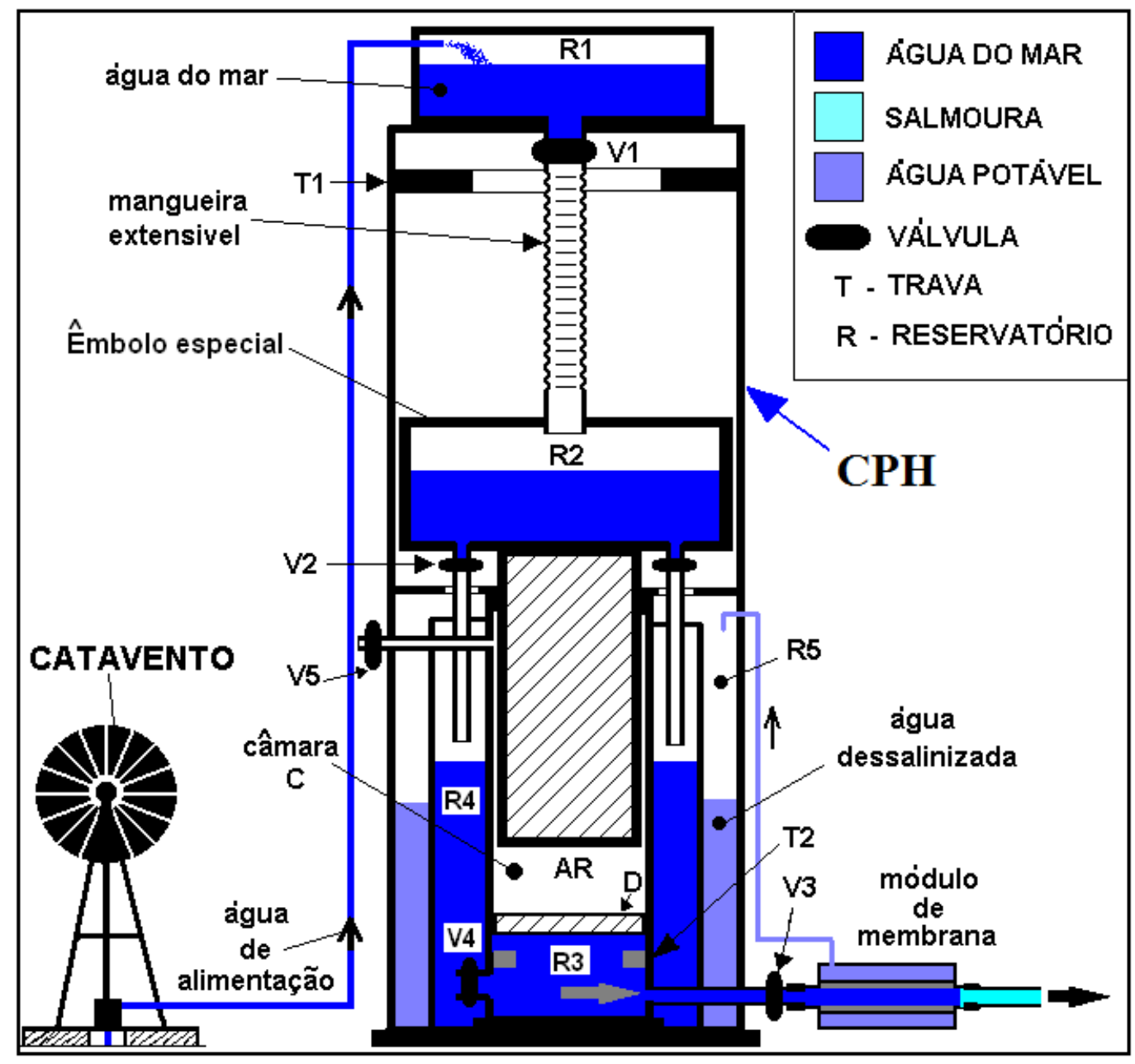

Fig. 3.2: Coluna de Potência Hidráulica, CPH. 
A salmoura ao sair do módulo de membrana, ainda contém grande quantidade de energia cinética devido à sua pressão. Parte dessa energia pode, e deve ser aproveitada para que se aumente o rendimento do sistema.

Em unidades de dessalinização de grande porte (produção acima de $1000 \mathrm{~m}^{3} /$ dia, por exemplo), esse aproveitamento pode ser feito, por exemplo, através de uma TP com a finalidade de conectar o seu eixo ao da bomba de alta pressão que envia a água para as membranas, ou de gerar eletricidade. Assim, se a CPH for dimensionada para grande porte, pode-se obter as duas aplicações finais (dessalinização e geração de eletricidade) em simultâneo e em série.

Em unidades de pequeno porte (produção abaixo de $100 \mathrm{~m}^{3} /$ dia, por exemplo), a utilização de uma turbina para esse fim resulta economicamente inviável. Essa inviabilidade se justifica pelo fato da quantidade de energia ainda disponível na salmoura, e susceptível de ser aproveitada, não ser suficiente para justificar o investimento na turbina. No modelo com a $\mathrm{CPH}$, a energia da salmoura é recuperada através de um dispositivo apresentado na seção seguinte, a bomba Clark.

Entretanto, é pertinente salientar que na CPH, há a possibilidade de se usar uma TP para recuperar a energia da salmoura. Nesse caso, o seu eixo seria conectado ao de uma bomba centrífuga que seria usada para bombear água até R1 (Fig. 3.2).

\subsection{1- A bomba Clark e o Sistema de Recuperação de Energia}

No presente projeto, para se recuperar parte da energia da salmoura, propõe-se a utilização de uma bomba Clark. A bomba Clark desenvolvida pela Spectra Watermakers of California, USA, é uma versão atual da unidade mencionada em (SOURIRAJAN, 1970), como "flow-work-exchanger". A função dessa bomba neste projeto é bombear água para o reservatório superior R1.

Uma bomba Clark foi usada num projeto de dessalinização com a capacidade de produção da ordem de $3 \mathrm{~m}^{3}$ por dia, descrito no trabalho BATTERYLESS[...]. Naquele projeto, a referida bomba foi usada para pressurizar água nas membranas auxiliando a bomba elétrica principal. 
O esquema da bomba pode ser visto na Fig. 3.3 (pode-se ver uma animação da figura no site indicado na referência). Na figura, percebe-se que a salmoura ao entrar na bomba Clark, provoca o movimento alternado do êmbolo duplo. Dispensamos aqui a descrição detalhada do funcionamento da bomba Clark por tal ter sido feito em (DIAS, 2004) com base na Fig. 3.4.

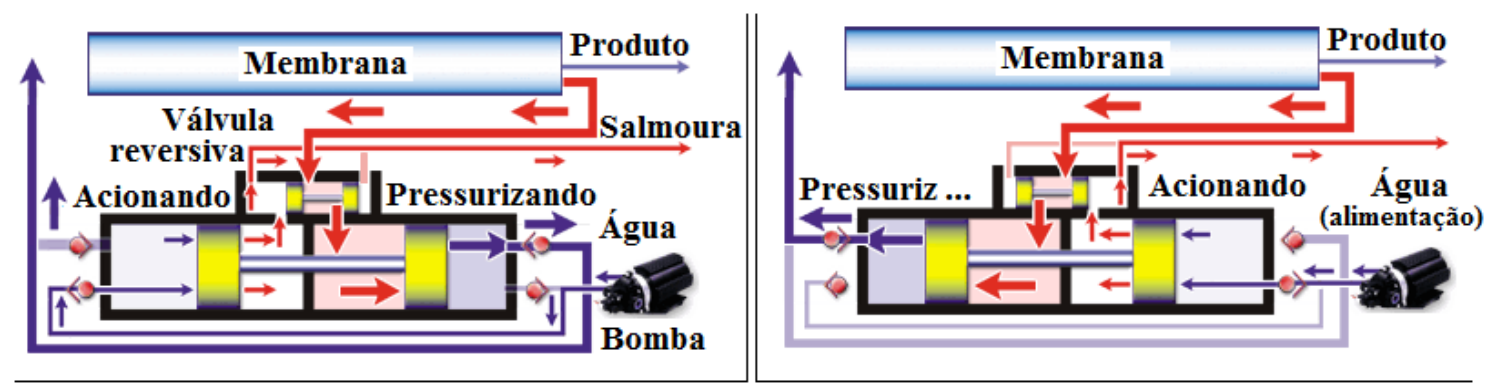

Fig. 3.3: Esquema da operação da bomba Clark.

Fonte: SPECTRA [...]

Em linhas gerais a bomba Clark tem um funcionamento idêntico ao de um motor à vapor sendo o fluído de trabalho a salmoura ao invés de vapor. Resumidamente, graças à válvula V (Fig. 3.4) a salmoura é conduzida alternadamente para as câmaras que contêm os cabeçotes do êmbolo E, fazendo com que este se mova alternadamente, bombeando água que sai pela tubulação 3 .

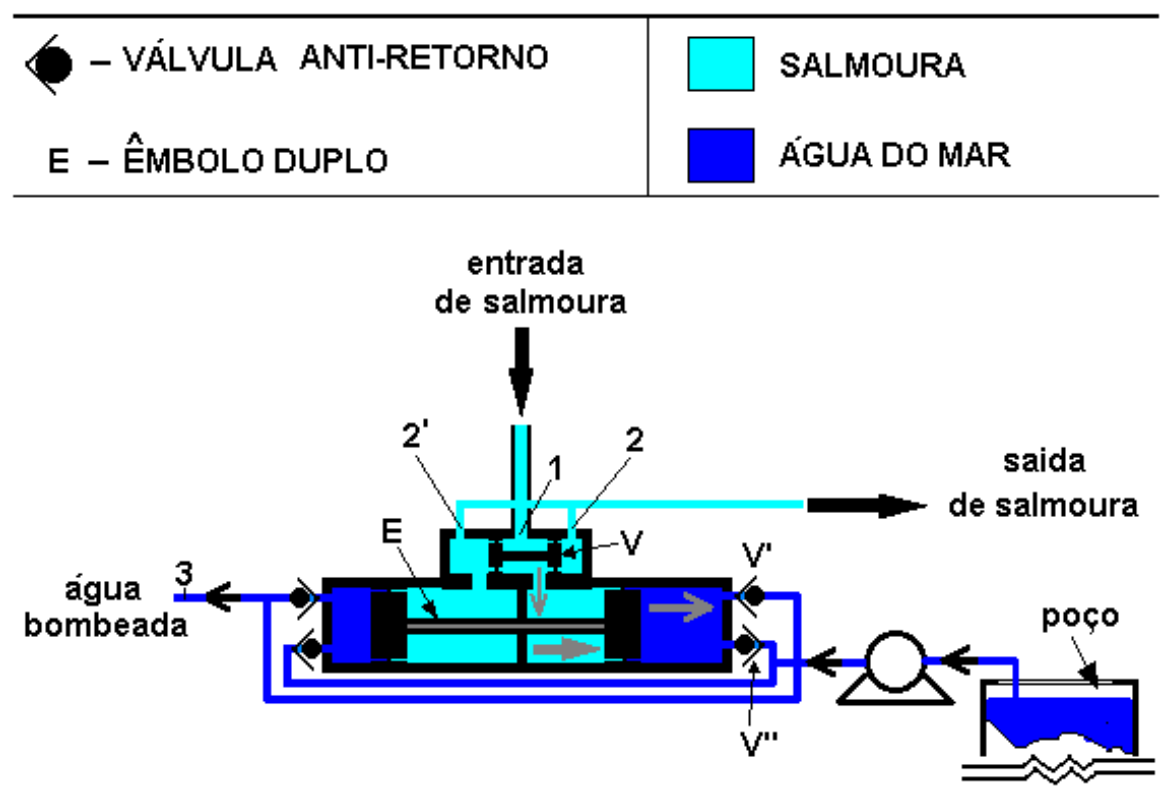

Fig. 3.4: Esquema da operação da bomba Clark. 
A salmoura entra na bomba com uma quantidade significativa de energia devida à sua pressão e velocidade e, sai dela com muito menos. Neste modelo, parte da parcela de energia "perdida" pela salmoura na bomba Clark é usada para bombear a água do mar até o reservatório superior. O processo é contínuo desde que haja entrada de salmoura, o que acontecerá sempre que houver osmose reversa ocorrendo nas membranas.

A inclusão da bomba Clark no projeto permitirá uma taxa de recuperação de energia da ordem dos $93 \%$ de acordo com os dados do projeto solar de dessalinização acima referido. Esses dados estão representados no esquema do diagrama de Sankey da Fig. 3.5, extraída de BATTERYLESS [...].

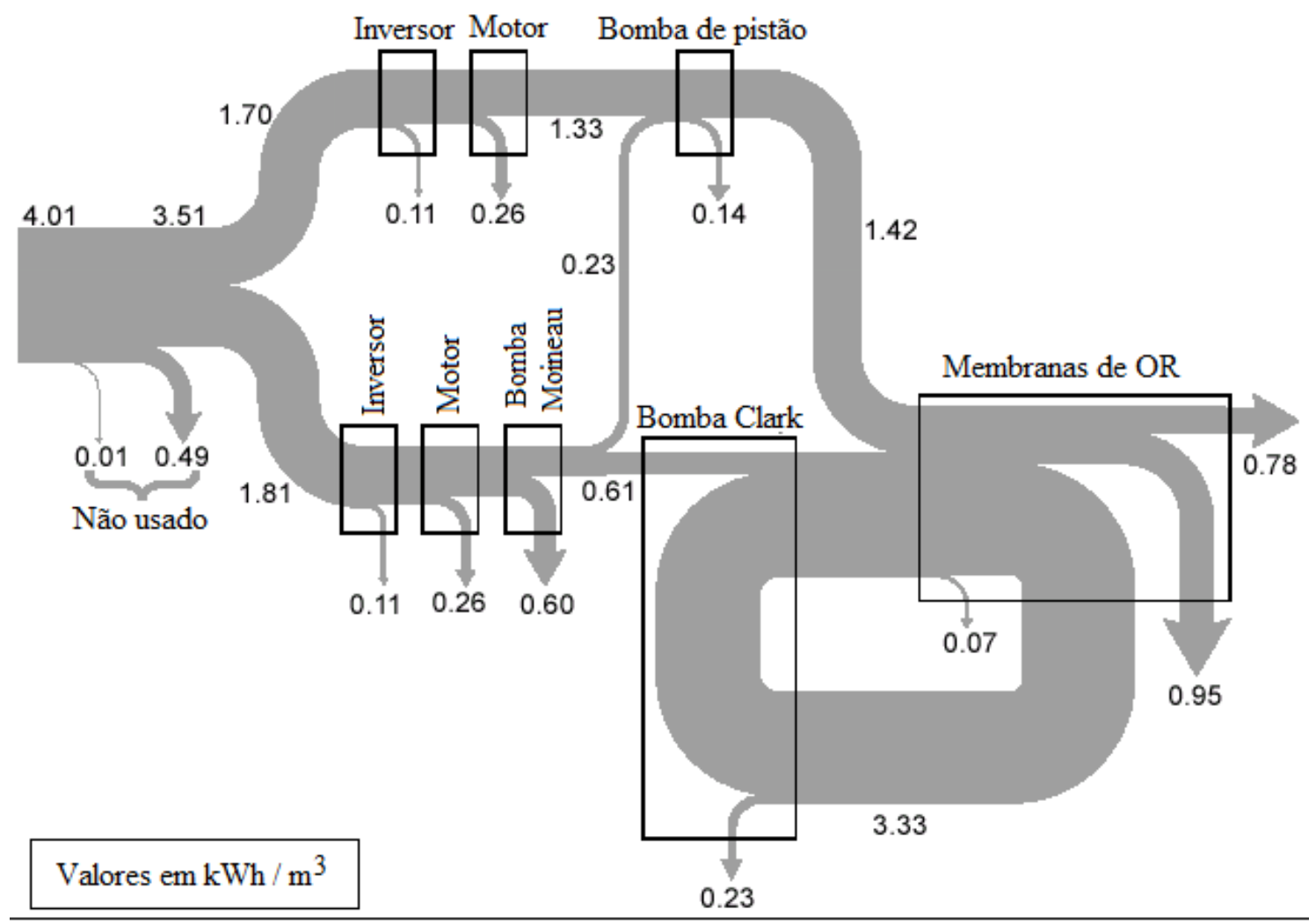

Fig. 3.5: Diagrama de Sankey do sistema de Dessalinização que usa energia solar fotovoltaica. Fonte: BATTERYLESS [...].

Caso a aplicação do modelo seja somente para geração de energia, é evidente que se dispensa o uso da bomba Clark. Comentando os valores do diagrama de Sankey, Fig. 3.5, diz-se em (BATTERYLESS [...], tradução nossa): 
"A quantidade de 3,33 $\mathrm{kWh} / \mathrm{m}^{3}$, saindo das membranas, representa a energia contida na salmoura. A bomba Clark recupera essa energia e a entrega diretamente ao fluxo de alimentação. A mesma atinge uma média anual de $93 \%$ que é verdadeiramente excelente."

De acordo com a interpretação do diagrama e do que é afirmado nesse trabalho, tem-se:

- $4,01 \mathrm{kWh} / \mathrm{m}^{3}$ são fornecidos pelos painéis solares. O consumo do sistema é de $3,51 \mathrm{kWh} / \mathrm{m}^{3}$ dado que $0,5 \mathrm{kWh} / \mathrm{m}^{3}$, $(0,01+0,49)$ não são usados para a dessalinização. As perdas ao longo do conjunto de membranas são pequenas, $0,07 \mathrm{kWh} / \mathrm{m}^{3}$ devido à queda de pressão e $0,95 \mathrm{kWh} / \mathrm{m}^{3}$ devido às perdas viscosas.

- A energia contida na salmoura $\left(3,33 \mathrm{kWh} / \mathrm{m}^{3}\right)$ corresponde à cerca de $95 \%$ $(3,33 / 3,51=0,948)$ do consumo específico do sistema. A recuperação da energia contida na salmoura é um dos aspectos importantes dos sistemas de dessalinização por osmose reversa. Essa recuperação proporciona a competitividade do processo.

- A inclusão da bomba naquele projeto permitiu recuperar em média 93\% dessa energia $((3,33-0,23) /(3,33) \times 100=93,1)$.

Segundo os autores do projeto os testes da bomba Clark em laboratório proporcionaram os resultados apresentados na Fig. 3.6, extraída do trabalho A SMALL-SCALE[...]. Tais resultados comprovam a alta eficiência da bomba em vários pontos de operação. 

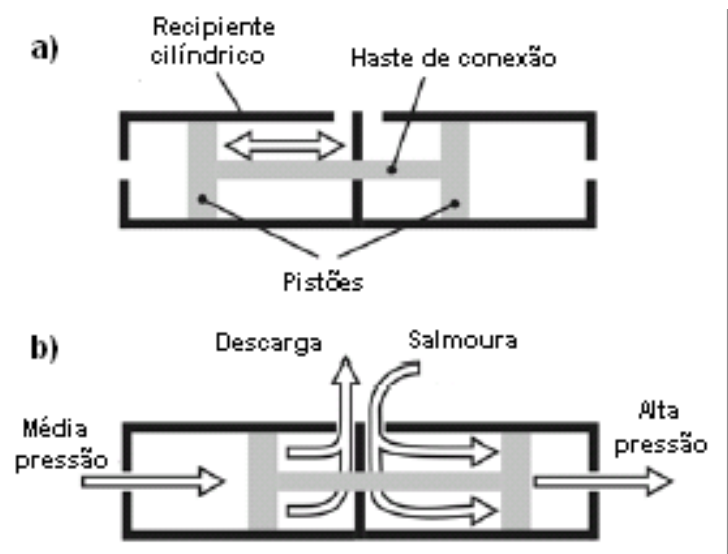

\section{Eficiência da bomba Clark}

\begin{tabular}{lccl}
\hline $\begin{array}{l}\text { @̂lta pressão } \\
\text { bar }\end{array}$ & $\begin{array}{c}\text { Pressão da } \\
\text { salmoura, bar }\end{array}$ & $\begin{array}{c}\text { Fluxo de } \\
\text { alimentaça } \\
\text { L/h }\end{array}$ & $\begin{array}{l}\text { Eficiência } \\
\text { \% }\end{array}$ \\
\hline 60 & 58 & 153 & 97.2 \\
50 & 48 & 153 & 97.2 \\
40 & 38 & 153 & 96.9 \\
60 & 58 & 458 & 95.9 \\
50 & 48 & 458 & 95.4 \\
40 & 38 & 458 & 94.8 \\
60 & 58 & 759 & 93.5 \\
50 & 48 & 759 & 92.4 \\
40 & 38 & 759 & 90.7 \\
\hline
\end{tabular}

Fig. 3.6: Esquema de operação da bomba Clark e respectiva eficiência.

Fonte: A SMALL-SCALE[...].

A Fig. 3.7 ilustra o esquema do projeto após a inclusão da bomba Clark para recuperação da energia da salmoura.

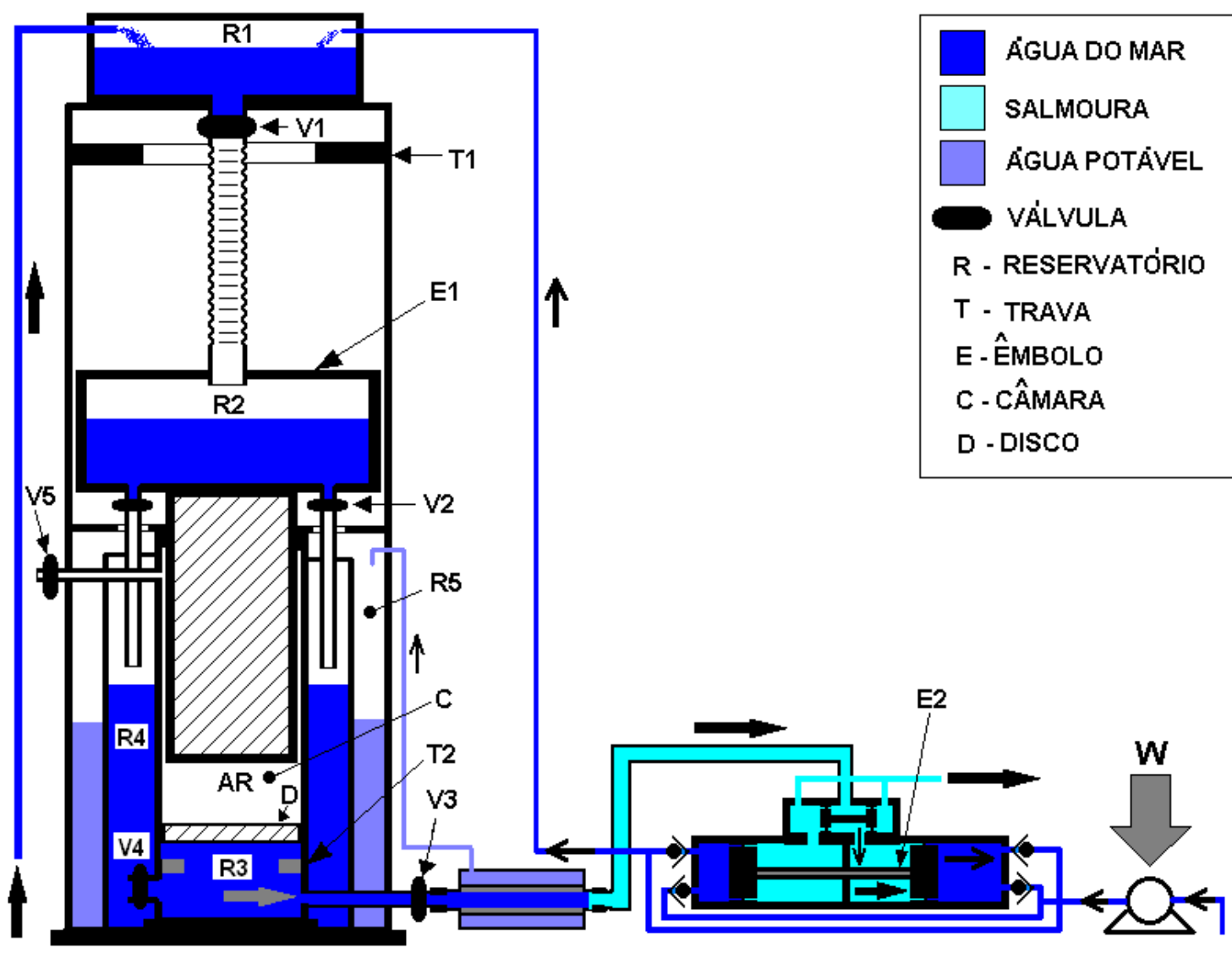

Fig.3.7: Bomba Clark acoplada à CPH. 


\section{3-Funcionamento da CPH}

Naturalmente, para que qualquer sistema funcione é necessário que haja energia envolvida nos processos. Posteriormente, apresenta-se a fonte de energia que está inicialmente prevista para abastecer o sistema. Mais à frente, questões relacionadas com o consumo de energia do sistema serão abordadas.

Para o automatismo do sistema, preconiza-se para a abertura e fechamento das válvulas, sistemas exclusivamente mecânicos. Para tal, foram idealizados mecanismos pneumáticos e/ou de alavancas, molas e engrenagens com rodas dentadas e roscas sem fim. Tem-se antecipadamente a certeza de se estar a pensar em sistemas possíveis de se concretizar. Essa certeza foi confirmada com a construção do protótipo. Esses

subsistemas são seguidamente apresentados, para melhor entendimento do funcionamento de duas CPH's em paralelo.

\subsection{1-Subsistemas complementares para o funcionamento paralelo de duas colunas}

O modelo de funcionamento paralelo de duas colunas proporciona algumas vantagens à $\mathrm{CPH}$, entre as quais pode-se citar as seguintes:

- Obtenção de um fluxo constante de água em direção aos módulos.

- Redução das dimensões do êmbolo especial E1.

- Facilidade na montagem de E1.

- Eliminar o tempo ocioso do sistema.

Essas vantagens estão relacionadas entre si sendo as últimas três consequência da primeira. Tendo um fluxo contínuo não haverá a necessidade de se ter um reservatório R3 de grandes dimensões para se conseguir uma determinada produção diária de água potável e, consequentemente, pode-se ter um êmbolo especial cujas dimensões não sejam gigantescas. Com um êmbolo de pequenas dimensões, depreende-se que a operação de sua montagem e inclusive a desmontagem para eventual manutenção seja mais fácil. 
Semelhantemente, com o funcionamento paralelo consegue-se eliminar o tempo em que não haveria fluxo em direção aos módulos correspondente à soma dos tempos de subida do êmbolo e de enchimento do reservatório R3. A eliminação desse tempo ocioso é conseguida dado que, quando um êmbolo de uma das colunas estiver "bombeando" água para os módulos, o outro da outra coluna estará sendo preparado para dar continuidade ao "bombeamento" e assim, ciclicamente haverá um revezamento no trabalho de compressão realizado pelos êmbolos.

Analisando as aplicações finais do modelo (osmose reversa e geração de eletricidade), é pertinente ainda enumerar mais duas vantagens do funcionamento sem intermitência:

- Em relação à dessalinização, a operação com fluxo constante permite que as membranas de osmose reversa não fiquem submetidas à pressão variável, o que prejudicaria o seu bom funcionamento.

- Em relação à geração de eletricidade, é desejável que se tenha um jato contínuo e com velocidade constante atuando na turbina Pelton. Assim, como será visto no capítulo 4, consegue-se que a turbina opere no ponto de máxima potência.

- Em ambas as aplicações, com a operação sem intermitência, consegue-se aumentar o desempenho do modelo.

Com a materialização do funcionamento paralelo de duas colunas abre-se a possibilidade de operar 2, 4, 6, 8 ... colunas à semelhança dos pistões de motores de veículos, podendo-se assim aumentar a produção diária de forma teoricamente ilimitada. As limitações práticas devem-se essencialmente à disponibilidade de vento e à viabilidade financeira (relação custo-benefício) de se ter um sistema com várias colunas.

Em relação à viabilidade financeira, cabe mencionar que, a redução das dimensões do êmbolo especial e, consequentemente da $\mathrm{CPH}$, proporciona uma redução substancial dos custos com o investimento e manutenção, o que representa mais uma vantagem de se ter um fluxo contínuo através do funcionamento paralelo de duas colunas. Os subsistemas idealizados que tornarão possível a materialização da obtenção de fluxo 
contínuo para os módulos, através do funcionamento paralelo de duas colunas de dessalinização, que serão apresentados a seguir, são (Fig. 3.8-A):

1) Grupo de roda dentada, cremalheira e mola para abertura e fechamento das válvulas $\mathrm{V} 1, \mathrm{~V} 2, \mathrm{~V} 5$ e V6.

2) Válvula de duas vias (V7) para interligar as colunas e módulos de membranas.

3) Atuador (AT) acionado por amortecedor (AM) para travar e destravar o êmbolo especial (E1).

4) Agrupamento de roldanas para elevar o êmbolo especial com um contrapeso.

5) Válvula anti-retorno, V3 na base do êmbolo especial para o enchimento de R3.

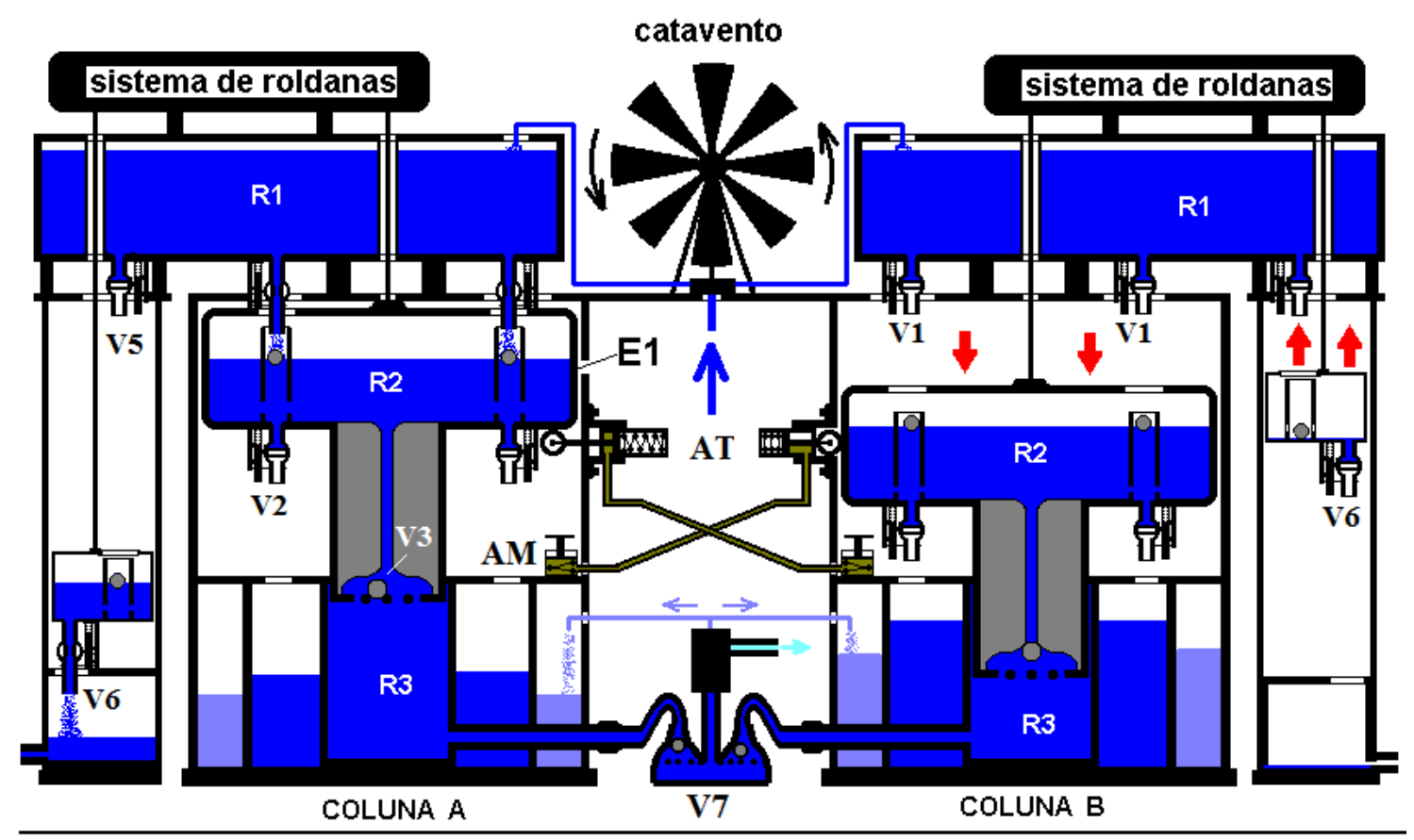

Fig. 3.8-A: Sistema de operação de duas CPH’s em paralelo.

As setas indicam o movimento do êmbolo especial e contrapeso da coluna B.

A representação de um só catavento na referida figura bem como a sua localização tem a ver essencialmente com questões estéticas. Na prática é muito provável que se tenha mais do que um catavento (número a ser determinado pelo dimensionamento), e que, para melhor captação do vento, estejam localizados ou por cima do reservatório superior R1, com ligação até o poço de captação de água ou ainda num local ao lado das colunas. Pode-se ao contrário, ter um único reservatório R1. 
A Fig. 3.8-B ilustra a CPH com êmbolos maciços. Naturalmente, o funcionamento da CPH com êmbolos maciços é mais simples dado que nessa configuração dispensa-se o uso de algumas válvulas. Nessa configuração a câmara de compressão R3 é alimentada com a água despejada pelo contrapeso através da abertura da válvula V6.

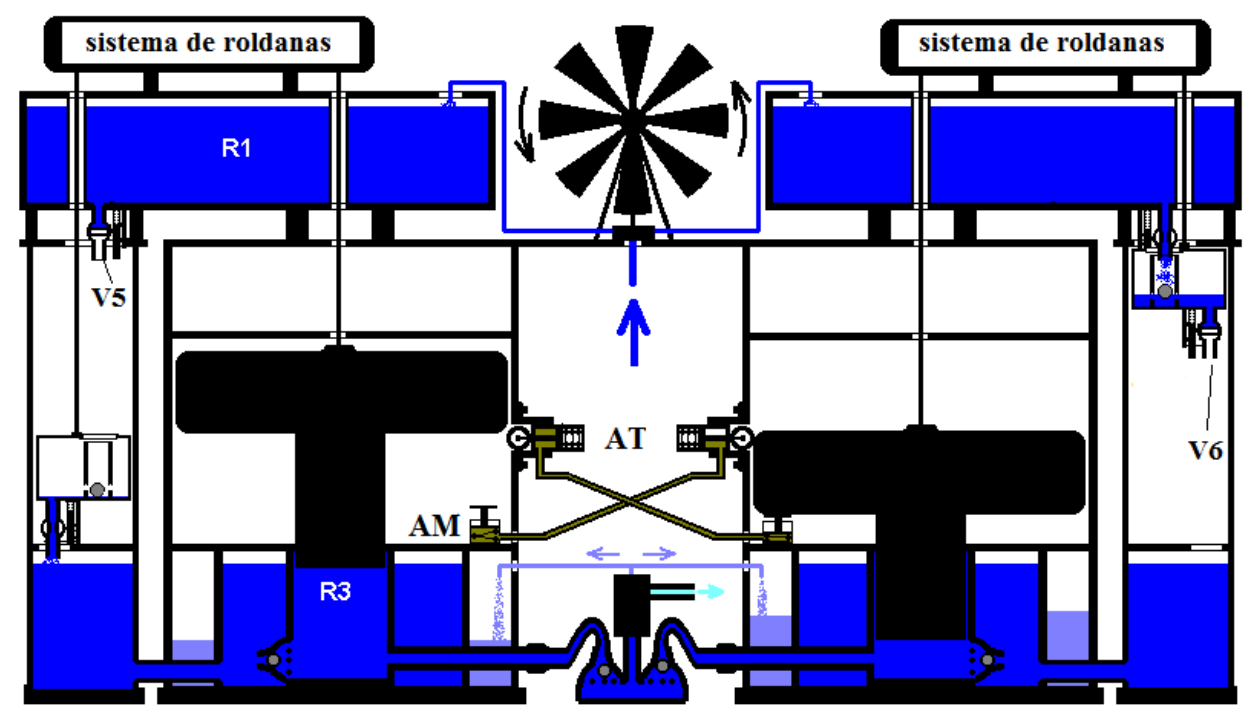

Fig. 3.8-B: Sistema de operação de duas CPH’s em paralelo com êmbolo maciço.

Em seguida, far-se-á a descrição dos subsistemas enumerados pelos itens de 1 a 5:

1) Com a engrenagem formada pela roda dentada, cremalheira e mola ilustrada na Fig. 3.9 consegue-se a abertura e fechamento automáticos da válvula acoplada à roda dentada. Além da função de abrir e fechar válvulas, essa engrenagem, devido à mola, tem a função de amortecer o impacto transmitido pela força $\mathbf{F}$ (parcela do peso do êmbolo especial).

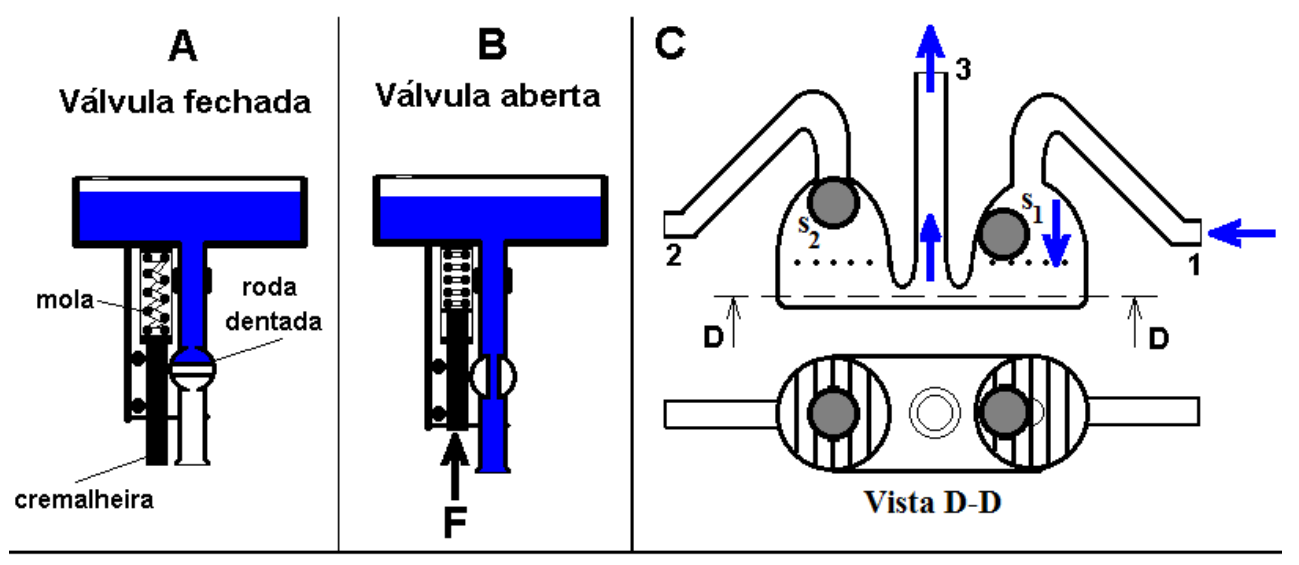

Fig. 3.9: A e B-engrenagem de roda dentada cremalheira e mola. C-válvula de duas vias. 
A válvula encontra-se normalmente fechada pela ação da mola, 3.9-A. Ao se aplicar a força $\mathbf{F}$ na direção axial da cremalheira, tem-se o seu deslocamento linear e o movimento correspondente é transmitido para a roda dentada, fazendo-a girar no sentido de abertura da válvula, Fig. 3.9-B. Ao se retirar a ação da força, impulsionada pela mola, a cremalheira volta à sua posição inicial correspondente à válvula fechada.

2) A válvula de duas vias (de 1 para 3 e de 2 para 3), Fig. 3.9- C, faz a interligação entre as duas colunas e os módulos de membranas de forma que, quer o fluxo provenha de uma coluna quer da outra, ele seja direcionado para os módulos e, não haja fluxo de uma coluna para a outra. O bloqueio e desbloqueio das vias são forçados pelo próprio fluxo ao impulsionar as esferas flutuantes $\mathrm{s}_{1}$ e $\mathrm{s}_{2}$. Assim, quando o fluxo provém do ponto 1 , a esfera $s_{2}$ bloqueia a via de 1 para 2 e vice-versa. Em ambos os casos, o fluxo seguirá para o ponto 3 onde a associação dos módulos ( em série, paralelo ou mista) será acoplada. O circuito hidráulico entre as colunas e os módulos poderá ser realizado com duas válvulas anti-retorno em substituição da válvula de duas vias proposta.

3) O conjunto amortecedor AM e atuador AT, Fig. 3.10, permite o envio de um sinal de uma coluna para outra de forma que quando o êmbolo de uma delas chegue ao seu fim de curso inferior, ao realizar o trabalho de compressão, o êmbolo da outra coluna comece a descer dando continuidade ao processo de compressão. O amortecedor, além da função de amortecer o impacto dos êmbolos, terá a função de enviar o sinal de pressão para o atuador para destravá-los, e o atuador terá a função de travá-los, de forma automática, quando atingem o seu fim de curso superior.

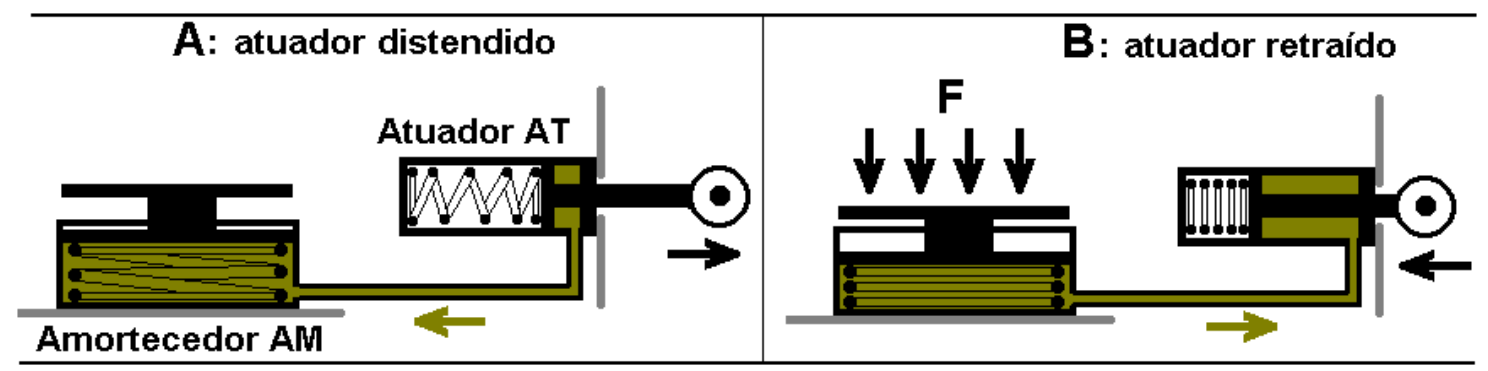

Fig. 3.10-conjunto atuador - amortecedor. O atuador é acionado pelo amortecedor.

O atuador encontra-se normalmente distendido pela ação da mola, Fig. 3.10-A. Ao se aplicar uma força no êmbolo do amortecedor, parte do fluído contido na sua câmara é 
forçado a entrar na câmara do atuador provocando assim a sua retração, Fig. 3.10-B. Ao se retirar a ação da força $\mathbf{F}$ as duas molas (a do atuador e a do amortecedor) agem no sentido de fazer o conjunto retornar à posição inicial. Na aplicação que este conjunto terá nas colunas de dessalinização, o movimento de avanço da haste do atuador poderá ser impedido até que chegue o momento propício em que a sua mola tenha liberdade para descomprimir.

4) Um subsistema de grande utilidade para o funcionamento paralelo de duas colunas é o grupo de estralheira representado na Fig. 3.11. Um conjunto de $\mathbf{n}$ roldanas formando uma estralheira, permite reduzir em $\mathbf{n}$ vezes o esforço $\mathbf{P}$ necessário para elevar a resistência $\mathbf{R}$ ( $\mathbf{P}=\mathbf{R} / \mathbf{n})$, Fig. 3.11-A $(\mathbf{n}=\mathbf{6})$. Se agruparmos $\mathbf{m}$ estralheiras, o referido esforço será reduzido em $\mathbf{n}^{\mathbf{m}}$ vezes $\left(\mathbf{P}=\mathbf{R} / \mathbf{n}^{\mathbf{m}}\right)$, Fig. 3-11-B.

Uma escolha adequada para $\mathbf{n}$ e $\mathbf{m}$ permite ter um sistema de roldanas que utilizado no modelo representa uma alternativa interessante para a elevação do êmbolo especial, com menor esforço. Para tal, o êmbolo (equivalente a $\mathbf{R}$ ) estará acoplado a um contrapeso CP (equivalente a $\mathbf{P}$ ) através do sistema de roldanas. Reza a história que, com um sistema de roldanas, Arquimedes, para assombro dos Siracusanos, levou um barco com a sua tripulação do estaleiro naval para o mar.

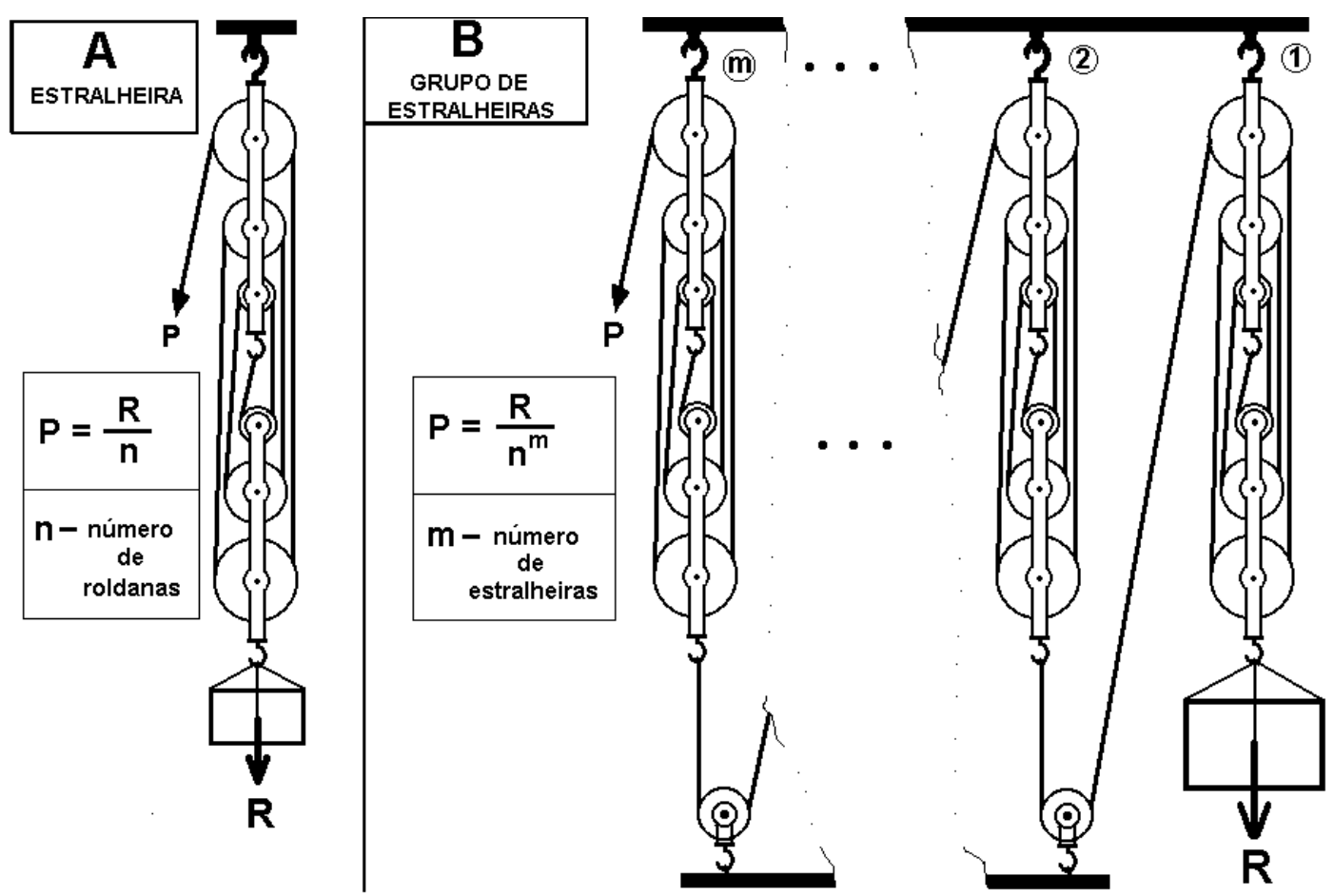

Fig. 3.11: Associação de roldanas. A: estralheira, B- grupo de estralheiras. 
Propõe-se que no modelo o esforço $\mathbf{P}$ seja feito por um reservatório cilíndrico que deverá ser enchido de água proveniente de R1 e deverá ser esvaziado quando o êmbolo for realizar o trabalho de compressão. Assim, dispõe-se de um contrapeso CP cujo peso é variável de acordo com a conveniência.

Esse subsistema deverá ser dimensionado de forma que o contrapeso cheio eleve o êmbolo vazio e vice-versa e quando um esteja no seu fim de curso superior, do outro esteja no seu fim de curso inferior. Para esvaziar e encher o contrapeso de forma automática, pode-se usar válvulas acopladas à rodas dentadas como ilustrado na Fig. 3.9-A e B.

5) A válvula anti-retorno V3 incorporada ao canal central do êmbolo especial, Fig. 3.8-A, permite que por aí seja feito o enchimento de R3, e que não haja fluxo de R3 para R2 durante o trabalho de compressão. O funcionamento dessa válvula é semelhante ao descrito anteriormente para a válvula de duas vias apresentada na Fig. 3-9-C.

\subsection{2-Funcionamento paralelo de duas colunas de potência hidráulica}

Com o intuito de se ter um fluxo de água do mar permanente em direção aos módulos de membranas, apresenta-se a alternativa para o funcionamento da $\mathrm{CPH}$ que, como já foi referido, tem vantagens em relação à apresentada no início deste capítulo.

O funcionamento proposto consiste em ter um sistema com duas CPH's operando em paralelo. Para se conseguir esse objetivo, são necessários os vários subsistemas previamente apresentados. Dispensou-se a inclusão da bomba Clark nas figuras dado que o seu funcionamento e função (recuperação de energia) são já conhecidos. Relembramos que, neste modelo, ela é usada para bombear água até o reservatório R1.

Nesse modo de operação, o enchimento e esvaziamento do reservatório R2 do êmbolo especial acontecem de forma automática devido à engrenagem, apresentada nos detalhes A e B das Figs 3.12 e 3.13. O fluxo de água que enche o reservatório R2 é bloqueado pela esfera flutuante s quando o nível desejado for atingido. Dá-se esse bloqueio devido à força de impulsão da água contida em R2. Quando o êmbolo é destravado e começa a 
descer, a engrenagem fecha a válvula V1. De forma idêntica tem-se o enchimento e esvaziamento do contrapeso CP cuja função é elevar o êmbolo especial E1 através do sistema de roldanas.

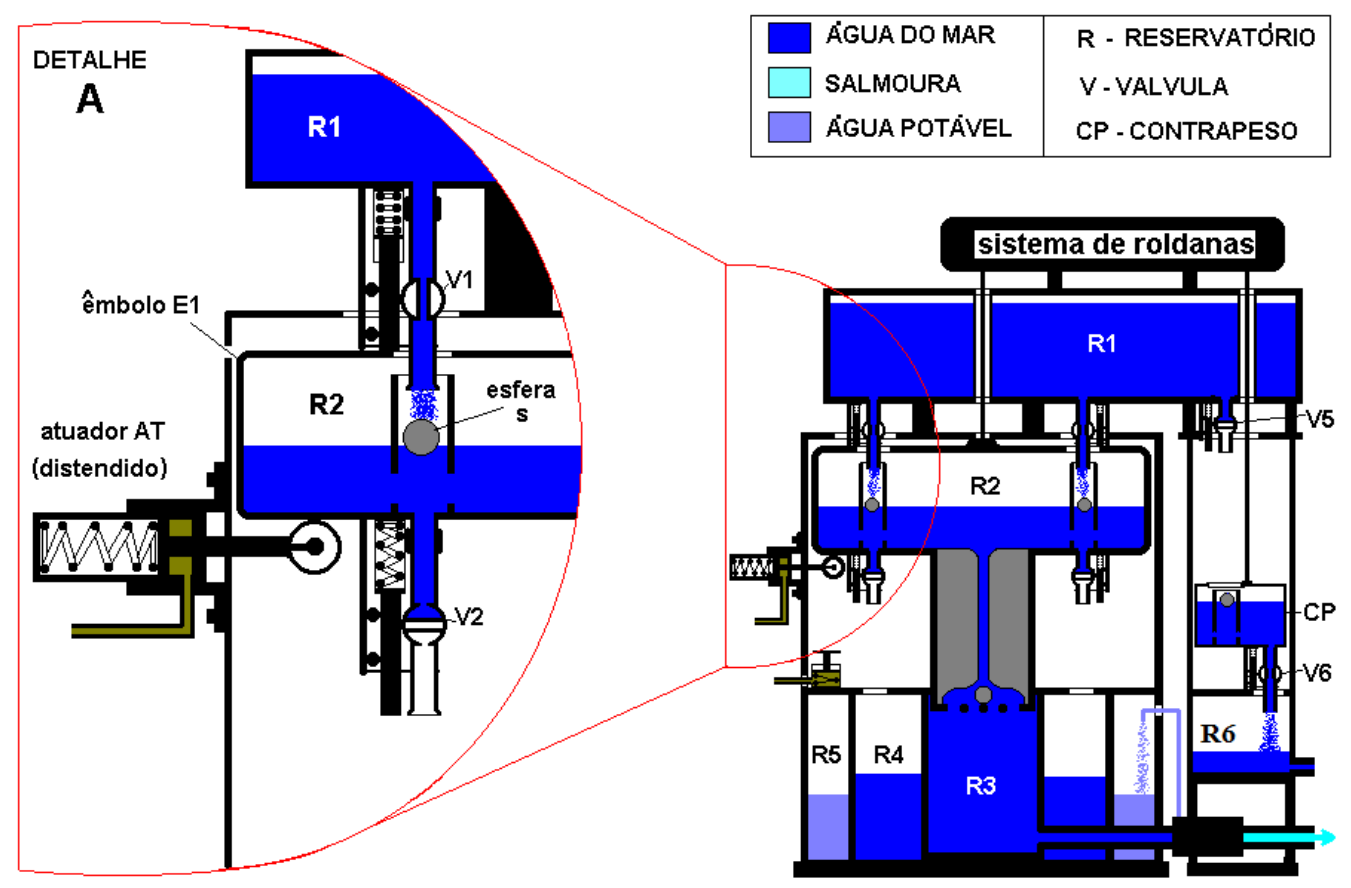

Fig. 3.12:Coluna de dessalinização com os subsistemas incorporados. A-detalhe da abertura da válvula V1, e do êmbolo E1 travado pelo atuador AT.

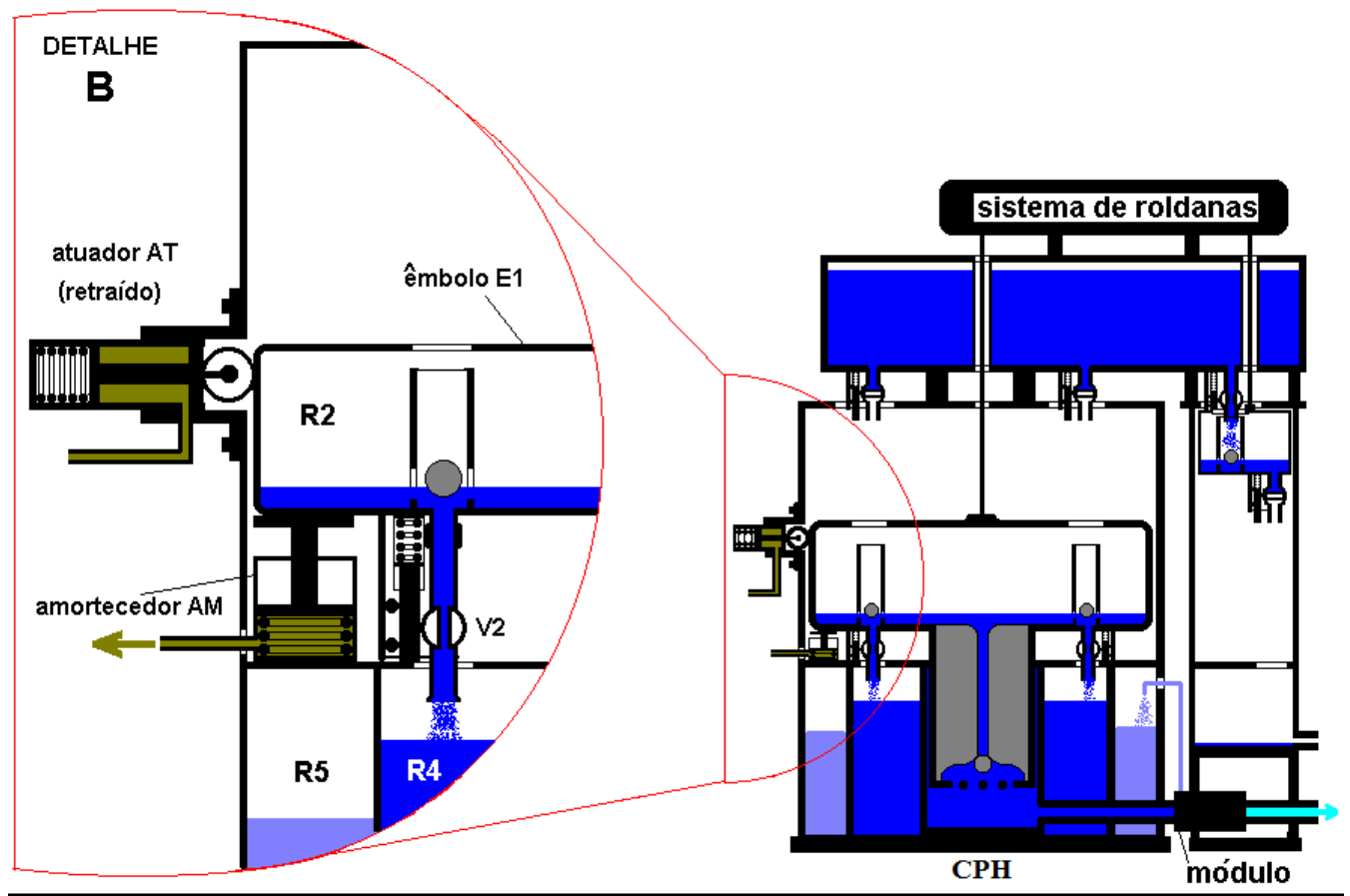

Fig. 3.13:Coluna de dessalinização com os subsistemas incorporados. B-detalhe da abertura da válvula V2, e do êmbolo E1 ativando o amortecedor AM. 
O diâmetro interno dos tubos de enchimento e esvaziamento dos diversos reservatórios deverá ser dimensionado para que, os tempos dessas operações estejam dentro dos limites compatíveis com a automação hidráulica do sistema. (FIALHO, 2004)

Durante o processo de compressão pela descida do êmbolo E1 de uma coluna (coluna A), o êmbolo da outra (coluna B), estará no seu fim de curso superior travado pelos atuadores AT, Fig. 3.12. Enquanto isso, o seu reservatório R2 deverá ser enchido a uma velocidade tal que, quando o êmbolo da coluna A chegue ao seu fim de curso inferior (fim da compressão), ele esteja cheio. Essa situação corresponde ao êmbolo preparado para dar início ao processo de compressão. Reciprocamente, ter-se-á um mecanismo idêntico durante o processo de compressão do êmbolo da coluna B.

Por questões relacionadas com o balanceamento do sistema prevê-se a utilização de pelo menos três atuadores e três amortecedores para cada coluna de dessalinização com uma localização desfasada de $60^{\circ}$ entre si num plano perpendicular ao da figura.

Quando o êmbolo da coluna A chega ao seu fim de curso inferior, Fig. 3.13 ele será amortecido pelos amortecedores AM e consequentemente, haverá um sinal enviado para os atuadores da coluna B que, em resposta, irão destravar o êmbolo dessa coluna. Enquanto isso, o contrapeso da coluna A estará sendo enchido para que o êmbolo seja elevado quando estiver vazio. Quando o êmbolo, elevado pelo contrapeso, chega ao fim de curso superior, ele será automaticamente travado pelos atuadores AT devido à descompressão de sua molas.

Enquanto o êmbolo sobe, a água que ainda estiver no seu reservatório R2 cai livremente no reservatório R3. Durante o funcionamento paralelo de duas colunas, o tempo de subida do êmbolo de uma coluna, acrescido dos tempos de enchimento e esvaziamento do seu reservatório, deverá ser inferior ao tempo de descida do êmbolo da outra coluna. Essa condição é necessária para que, quando termine o processo de bombeamento forçado por um êmbolo, o outro esteja preparado (cheio até o nível desejado) para dar continuidade ao processo.

Se o tempo necessário para elevar o êmbolo for insuficiente para que ele fique pronto para dar continuidade ao processo, uma opção para ultrapassar esse eventual 
constrangimento seria operar com 3, 4, 5 etc colunas à semelhança de uma prova de revezamento 4 por 4 em que há passagem do bastão entre os corredores.

Por analogia, o sinal de pressão dos amortecedores para os atuadores, corresponderia à passagem do bastão entre as colunas. Elas ficariam dispostas em círculo de forma que os atuadores de uma, fossem destravados pelo sinal de pressão vindo dos amortecedores da precedente. O sinal dos amortecedores daquela destravariam os atuadores da seguinte e assim sucessivamente até que o círculo se completasse.

O dimensionamento, e concepção da função do contrapeso $\mathbf{C P}$ deverão ter em conta os seguintes aspectos:

- Ele deverá estar cheio de água durante a sua descida e vazio durante a sua subida.

- O seu peso com água deverá ser suficiente para elevar o êmbolo especial através do sistema de roldanas e com a velocidade pretendida.

- O seu peso sem água deverá ser o mínimo possível de forma que ofereça pouca resistência durante a descida do êmbolo especial.

- Água despejada pelo contrapeso deverá ser encaminhada para um reservatório (R4 por exemplo) de onde será bombeada pela bomba Clark para o reservatório superior R1.

Satisfeitos os requisitos expostos, para a partida do sistema com duas colunas funcionando em paralelo, Figs. 3.14-A, B, C e D são necessários mais dois requisitos:

- O reservatório $\mathrm{R} 1$ deve ter água suficiente para que haja energia de acionamento da $\mathrm{CPH}$.

- A disponibilidade das fontes primárias deve ser suficiente para suprir o bombeamento de água para R1.

Para o caso de se optar por dois reservatórios superiores como ilustrado nas figuras, sugere-se que sejam interligados por um tubo de forma que o nível de água neles seja igual. Para visualizar o nível de água dos reservatórios em que haja esse interesse, 
propõe-se a utilização de tubos transparentes funcionando como um sistema de vasos comunicantes com os tais reservatórios.

A sequência de figuras 3.14 ilustra o funcionamento paralelo de duas colunas designadas por A e B. As setas representam os movimentos dos êmbolos E1 e dos contrapesos $\mathrm{CP}$.

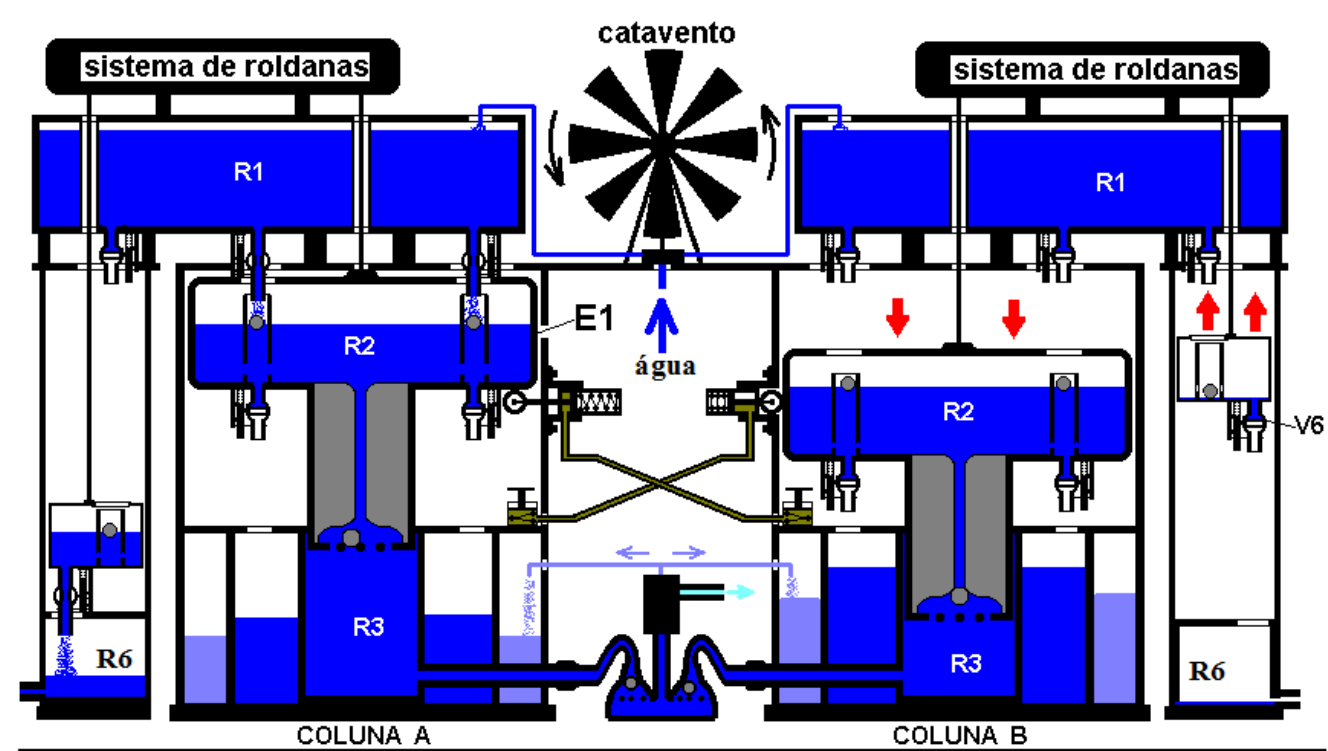

Fig. 3.14-A:êmbolo E1 da coluna B durante a compressão, e E1 da coluna A travado, sendo preparado enquanto o contrapeso da mesma coluna se esvazia em R6.

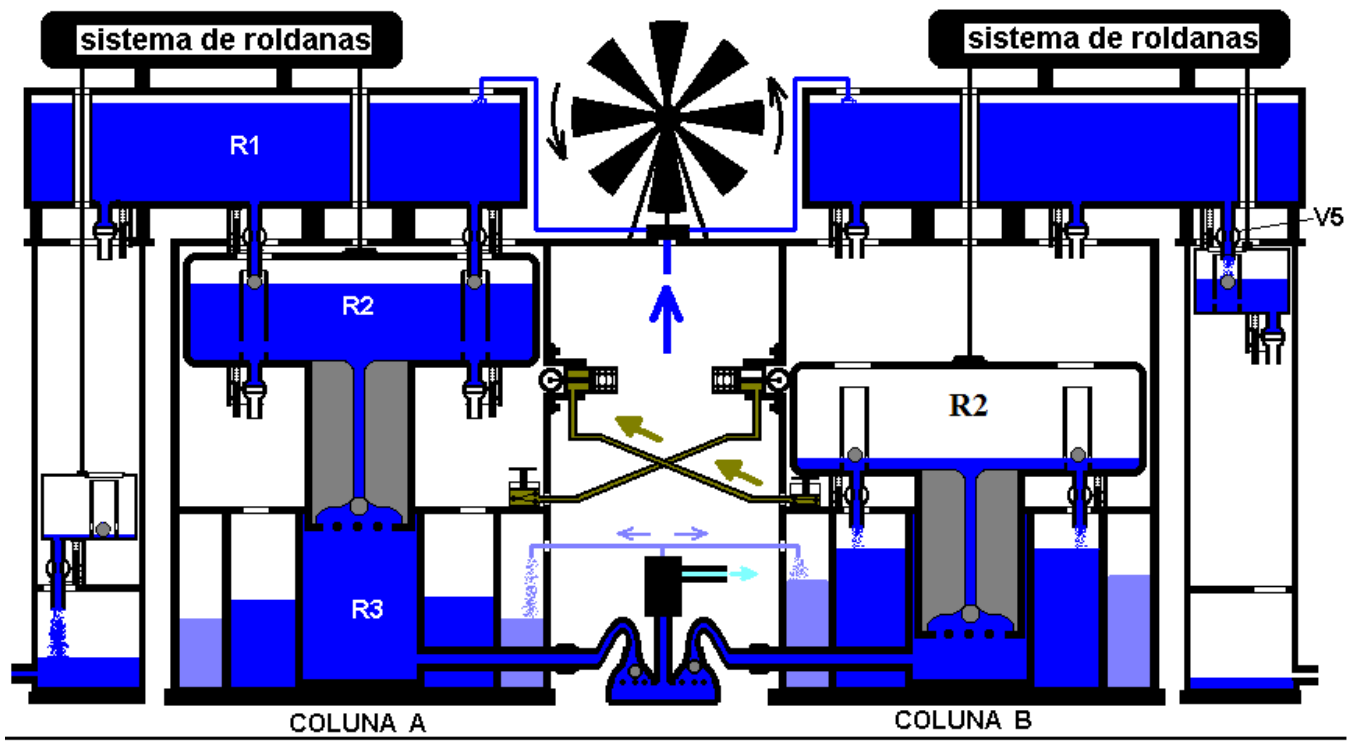

Fig. 3.14-B: êmbolo da coluna B no fim da compressão e enviando sinal para destravar o êmbolo da coluna A. R2 do êmbolo da coluna B se esvazia enquanto seu contrapeso se enche. 


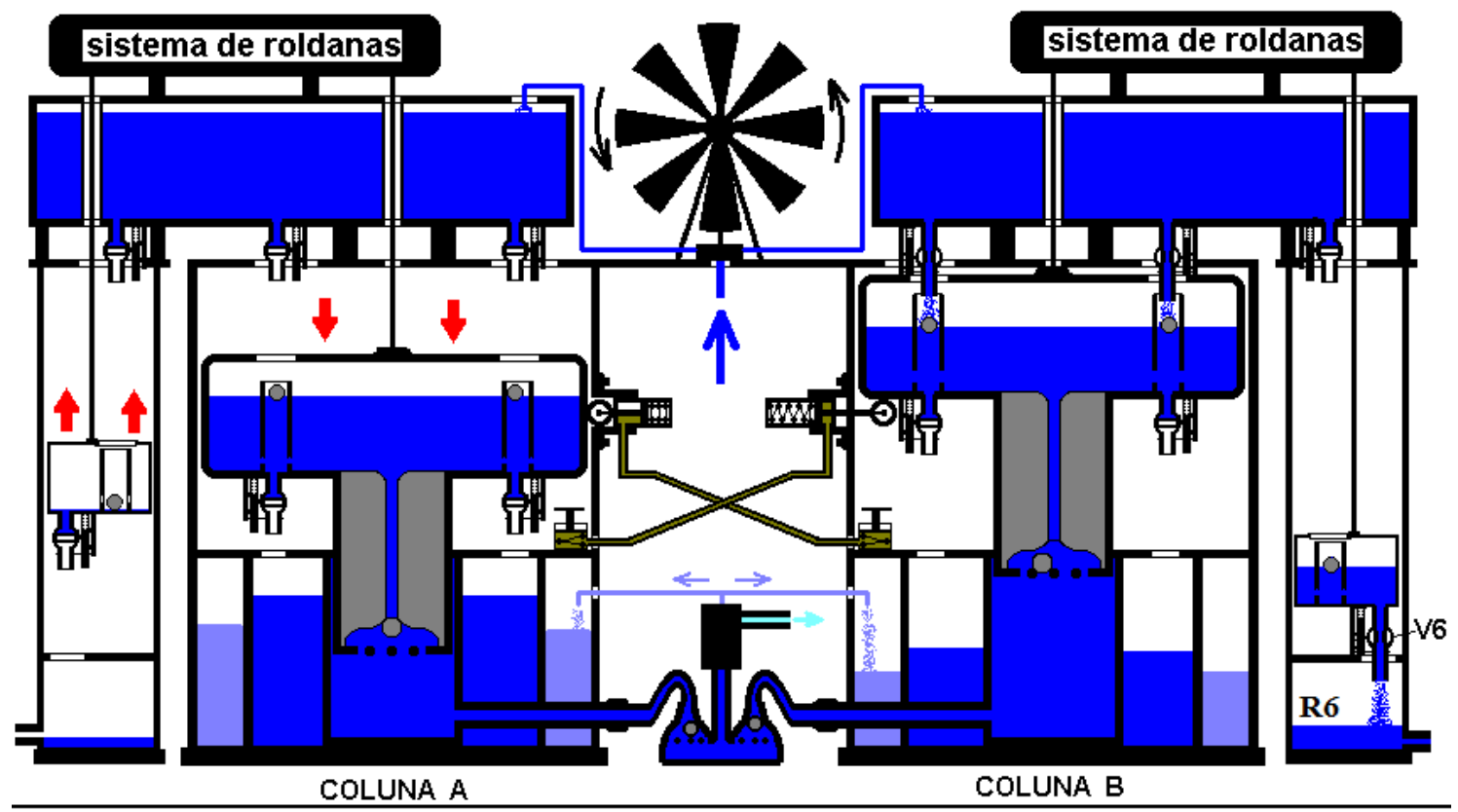

Fig. 3.14-C: êmbolo E1 da coluna A durante a compressão e E1 da coluna B travado, sendo preparado enquanto o contrapeso da mesma coluna se esvazia em R6.

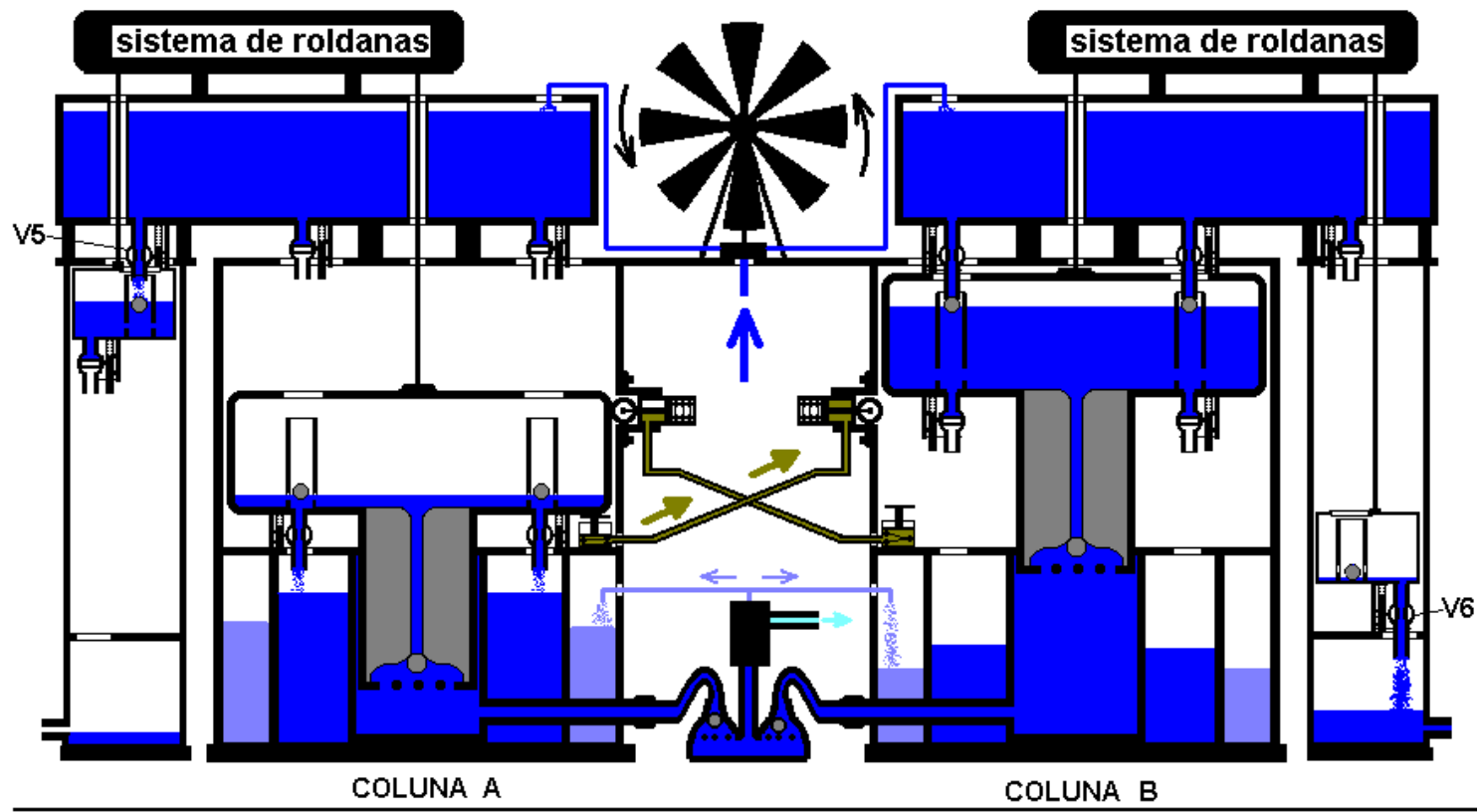

Fig. 3-14-D: êmbolo da coluna A no fim da compressão e enviando sinal para destravar o êmbolo da coluna B. O reservatório do êmbolo da coluna A se esvazia enquanto seu contrapeso se enche.

Satisfeitos os requisitos citados, resumidamente, durante a operação do sistema, tem-se os seguintes acontecimentos: 
1) Quando o êmbolo E1 da coluna B chega ao seu fim de curso inferior, Fig. 3.14-B ocorrem três eventos:

- O reservatório R2 se esvazia porque as válvulas V2 se abrem.

- O contrapeso se enche porque a válvula V5 se abre.

- A base do êmbolo se apoia nos amortecedores AM. Simultaneamente os atuadores da coluna A se retraem devido ao sinal recebido do AM, e o êmbolo E1 dessa coluna é destravado.

Reciprocamente, quando o êmbolo da coluna A chega ao seu fim de curso inferior, Fig. 3.14-D, três eventos idênticos acontecem.

2) Quando o êmbolo da coluna B chega ao fim de curso superior, Fig. 3.14-C, elevado pelo contrapeso, ocorrem três outros eventos:

- É travado pelos atuadores em cuja posição ficará até, após estar cheio, chegar o sinal de destravar vindo dos amortecedores da coluna A.

- O reservatório R2 começa a encher porque as válvulas V1 se abrem.

- O contrapeso se esvazia porque a válvula V6 se abre.

Processo idêntico ocorre quando o êmbolo da coluna A chega ao seu fim de curso superior, Fig. 3.14-A.

O automatismo hidráulico descrito nos itens 1 e 2 garante o funcionamento contínuo do sistema desde que haja água suficiente no(s) reservatório(s) superior(es) R1. Como referido anteriormente, o fluxo contínuo de água em direção aos módulos de membranas é garantido pela válvula de duas vias que faz a ligação entre as colunas A e B e os módulos, Figs 3.14 cujo funcionamento foi descrito previamente.

No sistema de funcionamento de duas colunas em paralelo, sugere-se que a(s) bomba(s) Clark seja(m) usada(s) para bombear água dos reservatórios $\mathrm{R} 4$ para o reservatório superior R1 através da recuperação da energia da salmoura, Fig. 3.15. Essa opção dispensa o uso de uma bomba auxiliar de média pressão como foi ilustrado nas 
Figs. 3.3 e 3.4, quando da apresentação da bomba Clark. Não obstante, a mesma sugestão pode ser usada também para o funcionamento de uma só coluna.

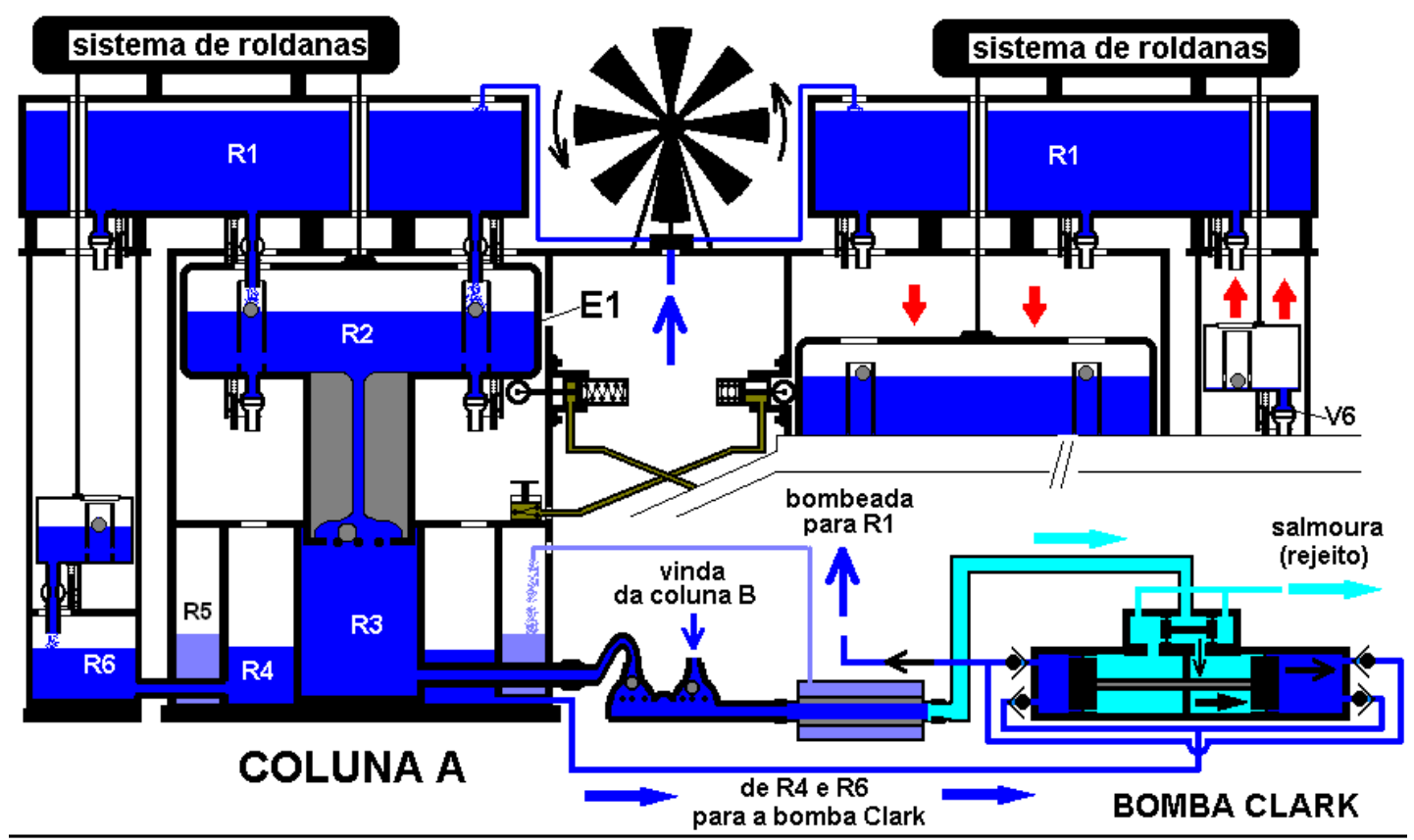

Fig. 3.15: uso da bomba Clark para bombear água dos reservatórios R4 e R6 para o reservatório superior R1.

Recorrendo à Fig. 3.8-B passamos a tecer alguns comentários sobre o funcionamento da $\mathrm{CPH}$ com êmbolos maciços. Como já foi avançado, o funcionamento nesse caso é mais simples dado que nessa configuração não existem as válvulas V1 e V2 para enchimento e esvaziamento do reservatório R2 do êmbolo especial.

Da observação dessa figura, depreende-se que o funcionamento é semelhante ao descrito anteriormente com e eliminação das etapas de espera para que R2 seja enchido e esvaziado. Por esse fato, dispensa-se aqui tal descrição detalhada. Em traços gerais tem-se:

1) Quando o êmbolo E1 da coluna B chega ao seu fim de curso inferior ocorrem dois eventos:

- O contrapeso se enche porque a válvula V5 se abre. 
- A base do êmbolo se apoia nos amortecedores AM. Simultaneamente os atuadores da coluna A se retraem devido ao sinal recebido do AM, e o êmbolo E1 dessa coluna é destravado.

Reciprocamente, quando o êmbolo da coluna A chega ao seu fim de curso inferior, dois eventos idênticos acontecem.

2) Quando o êmbolo da coluna B chega ao fim de curso superior, elevado pelo contrapeso, ocorrem dois outros eventos:

- Ele é travado pelos atuadores em cuja posição ficará até chegar o sinal de destravar vindo dos amortecedores da coluna A.

- O seu contrapeso se esvazia porque a válvula V6 se abre.

Processo idêntico ocorre quando o êmbolo da coluna A chega ao seu fim de curso superior.

\section{4-Caráterísticas da CPH}

Duas caráterísticas interessantes do núcleo do modelo proposto, a $\mathrm{CPH}$, são a sua relativa simplicidade e versatilidade. Podem ser citados, por exemplo, dois aspectos:

1-Há a possibilidade de se usar várias fontes de energia, além da eólica.

2-Dispõe-se de mais de uma alternativa para aumentar a produção de água potável e a potência elétrica.

Quanto ao primeiro aspecto, além das fontes renováveis mencionadas, pode-se, à moda dos sistemas convencionais, usar combustíveis fosseis, madeira, "lixo", eletricidade obtida a partir da sua transformação em termoelétricas etc. Nesse caso, a energia proveniente dessas fontes, seria usada para elevar a água até o reservatório R1.

No segundo aspecto, é referido um fator de extrema importância para o modelo. O aumento da capacidade do sistema permite estudar demandas adicionais resultando em 
economia de escala. Veja-se alternativas para se conseguir aumentar a capacidade do sistema:

- Aumentar as dimensões de R3.

- Diminuir o tempo de subida do êmbolo.

- Aumentar a pressão pelo aumento do nível de água em R2.

- Dispor de mais módulos de membrana ao longo do perímetro do reservatório R5.

- Trabalhar com mais de uma CPH.

A decisão por uma, ou por outra, alternativa para aumentar a produção, será tomada em função da relação custo-benefício tendo em conta a demanda e o tempo disponível para a sua satisfação.

Tendo em conta que uma das condições para que se consiga dessalinizar por RO é que a pressão da água junto à superfície da membrana seja bastante alta, urge apurar se, com o êmbolo especial, se consegue a pressão necessária (cerca de 55 bar). Essa pressão é adequada para a geração de eletricidade com uma turbina Pelton.

\section{5-Pressão de Operação da CPH}

A Fig. 3.16 ilustra os dois tipos de êmbolo especial que podem operar na CPH. Com o êmbolo especial A o aumento de pressão é conseguida graças ao peso da água. $\mathrm{O}$ êmbolo especial B é maciço. A pressão exercida pelo êmbolo especial na sua base cujo diâmetro é $\boldsymbol{d e}$, é função dos parâmetros geométricos (a,b,de etc.). 

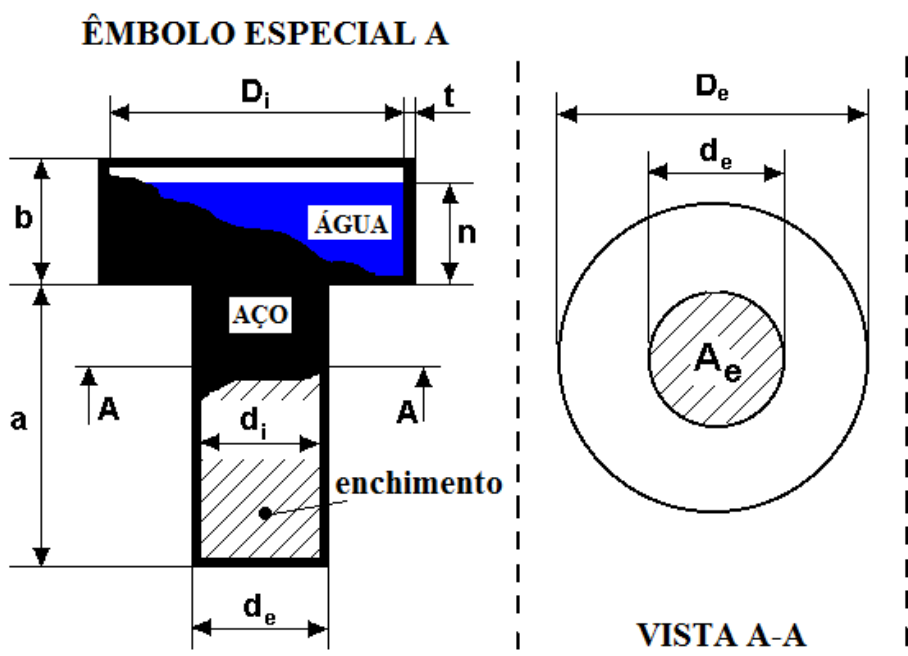

ÊMBOLO ESPECIAL B

Fig. 3.16: Esquema do êmbolo especial.

A pressão é dada pelo peso total $\boldsymbol{P t}$, do êmbolo dividido pela área circular $\mathbf{A}_{\mathbf{e}}$.

$\mathrm{P}=\boldsymbol{P t} / \mathrm{A}_{\mathrm{e}}$

Sendo $\mathbf{A}_{\mathbf{e}}=\pi / 4 \boldsymbol{d} \boldsymbol{e}^{2}$ vem,

$\mathrm{P}=4 P t /\left(\pi d e^{2}\right)$

O peso total do êmbolo A é dado pela soma dos pesos da estrutura de aço $\boldsymbol{P}_{\boldsymbol{a c ̧ o}}$, da água do mar contida no reservatório do êmbolo $\boldsymbol{P}_{\text {água }}$ e do enchimento $\boldsymbol{P}_{\text {ench }}$, ou seja,

$\boldsymbol{P t}=\boldsymbol{P}_{\text {aco }}+\boldsymbol{P}_{\text {agua }}+\boldsymbol{P}_{\text {ench }}$

Note-se que, sem que haja diferença apreciável no resultado final, desprezou-se o peso dos tubos que permitem o esvaziamento do reservatório do êmbolo. Substituindo a Eq. 3.3 na Eq. 3.2 e, após o tratamento algébrico (desenvolvimento apresentado no anexo A) que conduz às expressões para os pesos, chega-se à seguinte relação para a pressão:

$$
\left.P_{A}=\frac{g}{d e^{2}}\left[\rho_{a c ̧ o}\left(D e^{2} b+d e^{2} a\right)-D i^{2}(b-2 t)-d i^{2} a\right]+\rho_{a g u a} D i^{2} n+\rho_{e n c h} d i^{2} a\right]
$$


Sendo,

$\mathbf{P}_{\mathbf{A}} \quad$ é a pressão expressa em $\left[\mathrm{N} / \mathrm{m}^{2}\right]$

g é a aceleração da gravidade em $\left[\mathrm{m} / \mathrm{s}^{2}\right]$

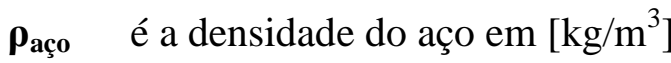

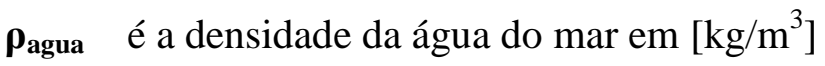

$\boldsymbol{\rho}_{\text {ench. }} \quad$ é a densidade do material de enchimento em $\left[\mathrm{kg} / \mathrm{m}^{3}\right]$

a, b, De , de, Di, di, n são os parâmetros geométricos da Fig. 3.16 expressos em [m]

e $\mathbf{D i}=\mathbf{D e}-2 \mathrm{t}$ em $[\mathrm{m}]$

Como se depreende da Eq. 3.4, a pressão na base do êmbolo, é função de vários parâmetros geométricos, como afirmado anteriormente, e das caráterísticas dos materiais escolhidos para a sua construção. Essa dependência da pressão tem a vantagem de permitir ao projetista, optar por uma decisão de construção, em função dos custos dos materiais e do espaço físico disponível.

Note-se que para o enchimento pode-se usar materiais reciclados ou de baixo custo como por exemplo areia do mar, pedras etc, como já foi feito na construção do protótipo. Consideramos ainda, para evitar a corrosão do aço, a hipótese de se usar material plástico nas superfícies que estarão em contato com a água. Com a mesma preocupação, sugere-se que as tubulações com água a baixa pressão, sejam de material plástico ou fibra.

A pressão exercida na base do êmbolo especial B em aço, cuja dedução também se encontra no anexo A, é dada por:

$$
P_{B}=\frac{g}{d e^{2}} \rho_{a c ̧ o}\left(D e^{2} b+d e^{2} a\right)
$$

Onde:

$\mathbf{P}_{\mathbf{B}} \quad$ é a pressão expressa em $\left[\mathrm{N} / \mathrm{m}^{2}\right]$ 
g é a aceleração da gravidade em $\left[\mathrm{m} / \mathrm{s}^{2}\right]$



a, b, De , de são os parâmetros geométricos expressos em [m]

A Eq. 3.4, inserida numa planilha do Excel, gerou os resultados apresentados a seguir na Tabela 3.1 (massa expressa em $[\mathrm{kg}]$ ).

Tabela 3.1: Resultados gerados a partir da equação da Pressão exercida pelo êmbolo.

\begin{tabular}{|c|c|c|c|c|c|c|c|c|c|c|}
\hline$\overline{4}$ & A & $B$ & C & D & $E$ & $\mathrm{~F}$ & G & $\mathrm{H}$ & 1 & $\mathrm{~J}$ \\
\hline 1 & $\begin{array}{c}\text { Aceleração } \\
\text { da gravidade } \\
{[\mathrm{m} / \mathrm{s} 2]}\end{array}$ & $\begin{array}{l}\text { Densidade } \\
\text { do Aço } \\
\text { [kg/m3] }\end{array}$ & \begin{tabular}{|c|} 
densidade \\
do \\
enchimento
\end{tabular} & $\begin{array}{l}\text { Densidade } \\
\text { da Água } \\
\text { [kg/m3] }\end{array}$ & $\begin{array}{l}\text { Dimensão } \\
\text { "a" [m] }\end{array}$ & $\begin{array}{l}\text { Dimensão } \\
\text { "b" [m] }\end{array}$ & $\begin{array}{c}\text { De } \\
\text { (diâmetro } \\
\text { externo }\end{array}$ & $\begin{array}{c}\text { de } \\
\text { (diámetro } \\
\text { externo }\end{array}$ & $\begin{array}{c}t \text { (espesura) } \\
{[\mathrm{m}]}\end{array}$ & $\begin{array}{r}\text { n (nivel de } \\
\text { água) [m] }\end{array}$ \\
\hline 2 & 9,8 & 7800 & 11400 & 1025 & 1 & 1 & 1 & 1,5 & 0,2 & 0,8 \\
\hline 3 & 9,8 & 7800 & 11400 & 1025 & 2,5 & 2,5 & 2,5 & 1,5 & 0,2 & 2 \\
\hline 4 & 9,8 & 7800 & 11400 & 1025 & 4 & 4 & 4 & 1,5 & 0,2 & 3,2 \\
\hline 5 & 9,8 & 7800 & 11400 & 1025 & 5,5 & 5,5 & 5,5 & 1,5 & 0,2 & 4,4 \\
\hline 6 & 9,8 & 7800 & 11400 & 1025 & 7 & 7 & 7 & 1,5 & 0,2 & 5,6 \\
\hline 7 & 9,8 & 7800 & 11400 & 1025 & 8,5 & 8,5 & 8,5 & 1,5 & 0,2 & 6,8 \\
\hline 8 & 9,8 & 7800 & 11400 & 1025 & 10 & 10 & 10 & 1,5 & 0,2 & 8 \\
\hline 9 & 9,8 & 7800 & 11400 & 1025 & 11,5 & 11,5 & 11,5 & 1,5 & 0,2 & 9,2 \\
\hline 10 & 9,8 & 7800 & 11400 & 1025 & 13 & 13 & 13 & 1,5 & 0,2 & 10,4 \\
\hline 11. & 9,8 & 7800 & 11400 & 1025 & 14,5 & 14,5 & 14,5 & 1,5 & 0,2 & 11,6 \\
\hline 13 & $\mathrm{Di}=\mathrm{De}-2 \mathrm{t}[\mathrm{m}]$ & \begin{tabular}{|l|} 
di (diâmetro \\
interno) [m]
\end{tabular} & \begin{tabular}{|c|} 
"Massa" \\
enchimento
\end{tabular} & $\begin{array}{c}\text { "Massa" de } \\
\text { Aço }\end{array}$ & $\begin{array}{c}\text { "Massa" de } \\
\text { Água }\end{array}$ & $\begin{array}{c}\text { "Massa" } \\
\text { total }\end{array}$ & Pressão $[\mathrm{Pa}]$ & $\begin{array}{c}\text { Pressão } \\
\text { [bar] }\end{array}$ & $\begin{array}{c}\text { Pressão } \\
\text { [PSI] }\end{array}$ & \\
\hline 14 & 0,6 & \begin{tabular}{|c|}
1 \\
\end{tabular} & 11400 & 15865,2 & 295,2 & 27560,4 & \begin{tabular}{|l|}
120040,8533 \\
\end{tabular} & $\frac{[\mathrm{Nur]}}{1,200408533}$ & \begin{tabular}{|c|}
17,41044927 \\
\end{tabular} & \\
\hline 15 & 2,1 & 1 & 28500 & 74014,2 & 9040,5 & 111554,7 & 485882,6933 & 4,858826933 & 70,47130831 & \\
\hline 16 & 3,6 & 1 & 45600 & 174283,2 & 42508,8 & 262392 & 1142862,933 & 11,42862933 & 165,7582113 & \\
\hline 17 & 5,1 & 1 & 62700 & 316672,2 & 117305,1 & 496677,3 & 2163305,573 & 21,63305573 & 313,7608648 & \\
\hline 18 & 6,6 & 1 & 79800 & 501181,2 & 250034,4 & 831015,6 & 3619534,613 & 36,19534613 & 524,9689754 & \\
\hline 19 & 8,1 & 1 & 96900 & 727810,2 & 457301,7 & 1282011,9 & 5583874,053 & 55,83874053 & 809,8722498 & \\
\hline 20 & 9,6 & 1 & 114000 & 996559,2 & 755712 & 1866271,2 & 8128647,893 & 81,28647893 & 1178,960395 & \\
\hline 21 & 11,1 & 1 & 131100 & 1307428,2 & 1161870,3 & 2600398,5 & 11326180,13 & 113,2618013 & \begin{tabular}{|l|}
1642,723116 \\
\end{tabular} & 809,9 \\
\hline 22 . & 12,6 & 1 & 148200 & 1660417,2 & 1692381,6 & 3500998,8 & 15248794,77 & 152,4879477 & 2211,650122 & osi \\
\hline 23 & 14,1 & 1 & 165300 & 2055526,2 & 2363850,9 & 4584677,1 & 19968815,81 & 199,6881581 & 2896,231117 & \\
\hline
\end{tabular}

Verifica-se pela análise dos resultados (células H19 e I19), que se obtém uma pressão de aproximadamente $\mathbf{8 0 9 . 9}$ psi (55,83 bar) com as seguintes dimensões:

$a=b=D e=8,5 m$ (células E7, F7, G7 respectivamente)

$D i=8,1 m$ (célula A19)

$d e=1,5 m$ (célula $\mathrm{H} 7$ )

di=1m (célula B19)

$\boldsymbol{t}=\mathbf{2 0} \mathrm{cm}$ (célula I7)

$n=6,8 m$ (célula K8)

Note-se que a pressão de operação das bombas utilizadas em plantas de dessalinização de água do mar por osmose reversa é cerca de 800 psi (aproximadamente 55 bar). Para 
se conseguir um êmbolo com uma altura menor $(a+b=17 m)$ dispõe-se de várias possibilidades, diminuir $\boldsymbol{a}$ ou $\boldsymbol{b}$ e aumentar $\boldsymbol{D} \boldsymbol{e}$, aumentar $\boldsymbol{t}$, diminuir $\boldsymbol{d e}$ etc.

Se a CPH funcionar com um êmbolo maciço, dependendo da densidade do material usado, consegue-se mais facilmente ter um êmbolo de menores dimensões como será mostrado no terceiro estudo de caso.

\section{6- Praticabilidade e Consumo Específico do modelo proposto}

Após constatar que é possível conseguir a pressão elevada (suficiente tanto para a dessalinização quanto para a geração elétrica), com dimensões que não inviabilizam a execução prática do projeto, surgem questões relacionadas essencialmente com a quantidade de energia envolvida nessa proposta de dessalinização, por osmose reversa. Três dessas questões são:

$1^{a}$-Será que a quantidade de energia necessária para elevar o êmbolo, não inviabiliza o projeto?

$2^{a}$ - Será que a quantidade de energia necessária para elevar a água até o reservatório R1 não inviabiliza o projeto?

$3^{a}$-A quantidade de energia usada para elevar água, não seria suficiente para conseguir a dessalinização fazendo-a passar diretamente pelo módulo de membrana?

Ao longo do mestrado desenvolvido pelo autor, trilhou-se caminhos para chegar às respostas, através de conceitos termodinâmicos, físicos e com suporte matemático. $\mathrm{O}$ que se provou para a dessalinização, poderá ser, em parte, aplicado para a geração de eletricidade.

Retoma-se aqui a análise da primeira das questões, que nos parece ser a mais pertinente para o projeto. As outras duas questões serão superficialmente abordadas. 


\section{Primeira Questão:}

Considere-se a dessalinização de um metro cúbico de água do mar, por osmose reversa, através do êmbolo especial. Vamos supor que a água está contida num reservatório cilíndrico de diâmetro de e altura $\boldsymbol{a}$, ilustrado na Fig. 3.17.

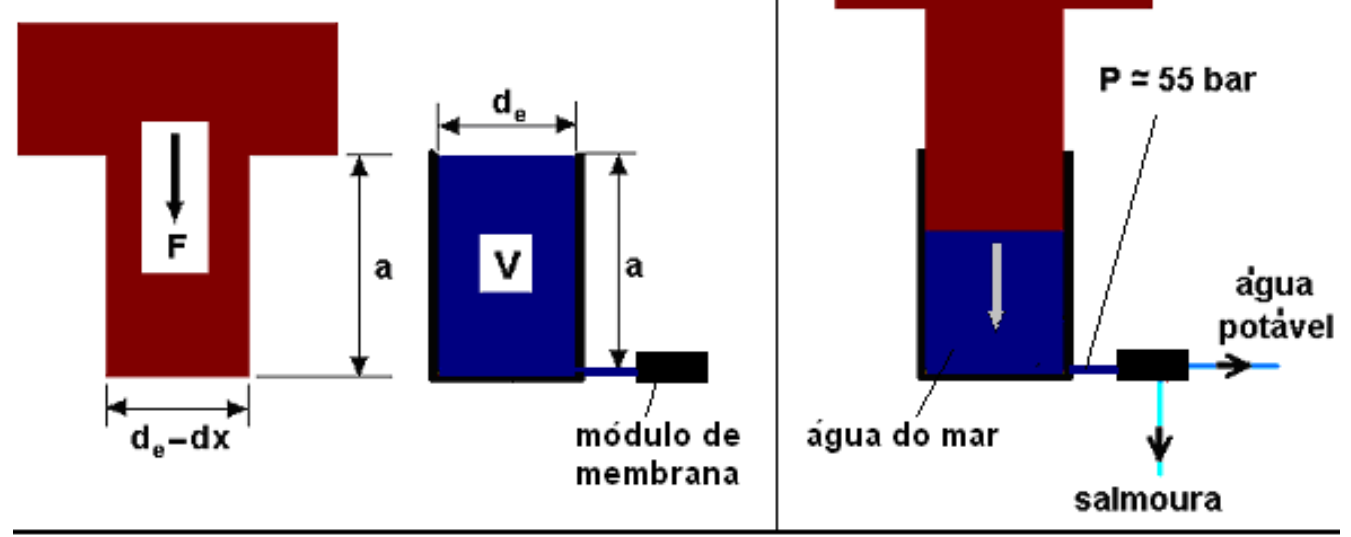

Fig. 3.17: Dessalinização por Osmose Reversa com o uso do Êmbolo Especial

Para dessalinizar a água dispõe-se de um módulo de membrana acoplada ao reservatório cilíndrico. Para exercer a pressão necessária para a dessalinização, dispõe-se de um êmbolo maciço, com a forma sugerida no projeto.

Note-se que a pressão mínima para se conseguir a dessalinização por osmose reversa é igual à pressão osmótica da solução que se quer dessalinizar.

No entanto, sem prejuízo para as conclusões a que se chegou, no decorrer das análises feitas, para se ter dados comparativos, foram usados valores diferentes para a pressão tais como:

55 bar, que corresponde à pressão usada em testes dos módulos de membranas para dessalinização de água do mar.

27,5 bar, pressão osmótica da água do mar de acordo com VIABILIDADE [...]. 
20,3 bar, pressão osmótica da água do mar de acordo com ISENTROPIC [...]

Nesta seção, com o mesmo objetivo usa-se as pressões de 55 bar e 20,3 bar.

A pressão $\mathbf{P}$ de dessalinização é dada pelo peso $\mathbf{F}$ do êmbolo dividido pela área $\mathbf{A}_{\mathbf{b}}$ da sua base,

$\mathrm{P}=\mathrm{F} / \mathrm{A}_{\mathrm{b}}$

Partindo desta relação, chegou-se à conclusão ( dedução no anexo B) que o peso do êmbolo $\mathbf{F}$ deve ser numericamente igual à pressão de dessalinização $\mathrm{P}$, ou seja $\mathbf{F}=\mathbf{P}$

Para a água do mar precisa-se de uma pressão igual a 800 psi ou 55 bar que corresponde a $55 \times 10^{5} \mathrm{~N} / \mathrm{m}^{2}$. Para que o êmbolo exerça pressão suficiente para dessalinizar o metro cúbico de água contida no reservatório, seu peso terá que ser igual a $55 \times 10^{5} \mathrm{~N}$.

Colocando esse êmbolo no topo do cilindro, ele forçará a água a atravessar a membrana plana. Dado que a membrana é semipermeável, ela permite a passagem da água, mas impede a da maior parte dos sais dissolvidos. Assim, consegue-se dessalinizar o metro cúbico de água contido no cilindro.

A quantidade de energia usada para o processo, equivale ao trabalho realizado para elevar o êmbolo até a altura a (Fig. 3.17), já que a sua descida se faz por ação da força de atração gravitacional.

Dado que $\mathbf{W}=\mathbf{F}$ a sendo, $\mathbf{F}$ o peso do êmbolo e a, a altura do reservatório cilíndrico, com os valores de a e $\mathbf{F}$ obtidos na dedução do anexo $\mathrm{B}(\mathrm{a}=1 \mathrm{~m} ; \mathrm{F}=\mathrm{P})$ tem-se:

$\mathrm{W}=55 \times 10^{5} \mathrm{~N} \times 1 \mathrm{~m}=55 \times 10^{5} \mathrm{~J}=5500 \mathrm{~kJ}$

Logo o consumo específico de energia (não computando as ineficiências dos processos da $\mathrm{CPH})$ é dado por:

$\mathrm{E} / \mathrm{V}=5500 \mathrm{~kJ} / 1 \mathrm{~m}^{3}=5500 \mathrm{~kJ} / \mathrm{m}^{3}$.

dado que $1 \mathrm{~kJ}=1 / 3600 \mathrm{kWh}$, vem 
$\mathrm{E} / \mathrm{V}=1,528 \mathrm{kWh} / \mathrm{m}^{3}$

Tendo em conta valores aceitáveis para os rendimentos dos processos, chegou-se ao valor $\mathbf{2 , 8 1 1} \mathbf{~ k W h} / \mathbf{m}^{3}$ (Dias, 2004) que corresponde à uma economia de cerca de $40 \%$ em relação ao consumo da unidade convencional em operação na cidade da Praia na República de Cabo Verde. Essa unidade convencional é apresentada no estudo de caso do capítulo 6.

Ainda com base na Fig. 3.17, generalizando o problema para qualquer valor de pressão do êmbolo, provou-se que (anexo B) a relação entre a energia $\mathbf{E}$ gasta para elevar o êmbolo e o volume $\mathbf{V}$ de água dessalinizada é dada por:

$\mathbf{E} / \mathrm{V}=\mathbf{P}$

( consumo específico da CPH )

O resultado encontrado sugere que:

-A energia específica consumida na dessalinização por osmose reversa, através da CPH, com a utilização da energia potencial gravitacional caráteriza-se pelos seguintes aspectos:

- É, numericamente, sempre igual à pressão P, necessária para que ocorra o processo de dessalinização (cerca de 55 bar para água do Mar, ou 20,3 bar isentropicamente).

- Não depende das dimensões do reservatório, que contém o volume de água por dessalinizar (Reservatório R3, no modelo proposto).

- Não depende, nem das dimensões do êmbolo (êmbolo especial E1, no modelo proposto), nem do material de que ele é feito.

O primeiro aspecto permite que se tenha um êmbolo com um peso menor se a pressão de operação for inferior a 55 bar resultando em economia de energia ( $\mathbf{W}=\mathbf{F}$ a ). O segundo aspecto permite o dimensionamento do diâmetro da coluna de dessalinização em função não só da demanda, mas também da área disponível para a construção e os 
custos envolvidos. O último aspecto referido possibilita economia na construção do êmbolo dado que pode-se escolher materiais de baixo custo para o enchimento. A construção do protótipo tem demonstrado essa afirmação.

O único requisito no dimensionamento do êmbolo, é que a pressão exercida na sua base de diâmetro de seja igual à pressão $\mathrm{P}$, necessária para a dessalinização (ou para geração elétrica) que como já foi referido, é aproximadamente igual a 55 bar para o caso da água do mar.

Note-se que um fluxo de água à 55 bar é suficiente para a geração de eletricidade com turbinas Pelton. Isso porque 55 bar corresponde aproximadamente à pressão exercida na base de uma coluna de água com 550 metros e a faixa de quedas para a operação das turbinas Pelton é sensivelmente entre 350 e 1100 metros.

Com base nas análises e a confrontação de resultados, conclui-se, portanto, que:

- O consumo específico de energia para dessalinização através da CPH, não contando com as irreversibilidades, é sempre igual ao mínimo que a Natureza permite. Conseqüentemente,

- O custo de produção de uma planta de dessalinização que venha a usar esse sistema seria, teoricamente, o mínimo atingível.

Para ilustrar o que foi afirmado, considere-se Fig. 3.18 que apresenta uma possibilidade de instalação da coluna de dessalinização sem que haja necessidade de bombear a água do mar para um reservatório superior. Como se percebe, essa configuração permite a alimentação direta do reservatório R3.

Na referida configuração, para se conseguir a osmose reversa, a energia gasta pelo sistema é fornecida pelo motor elétrico durante o processo de elevar o êmbolo (trabalho $\mathbf{W}$ ilustrado na Fig 3.18). 


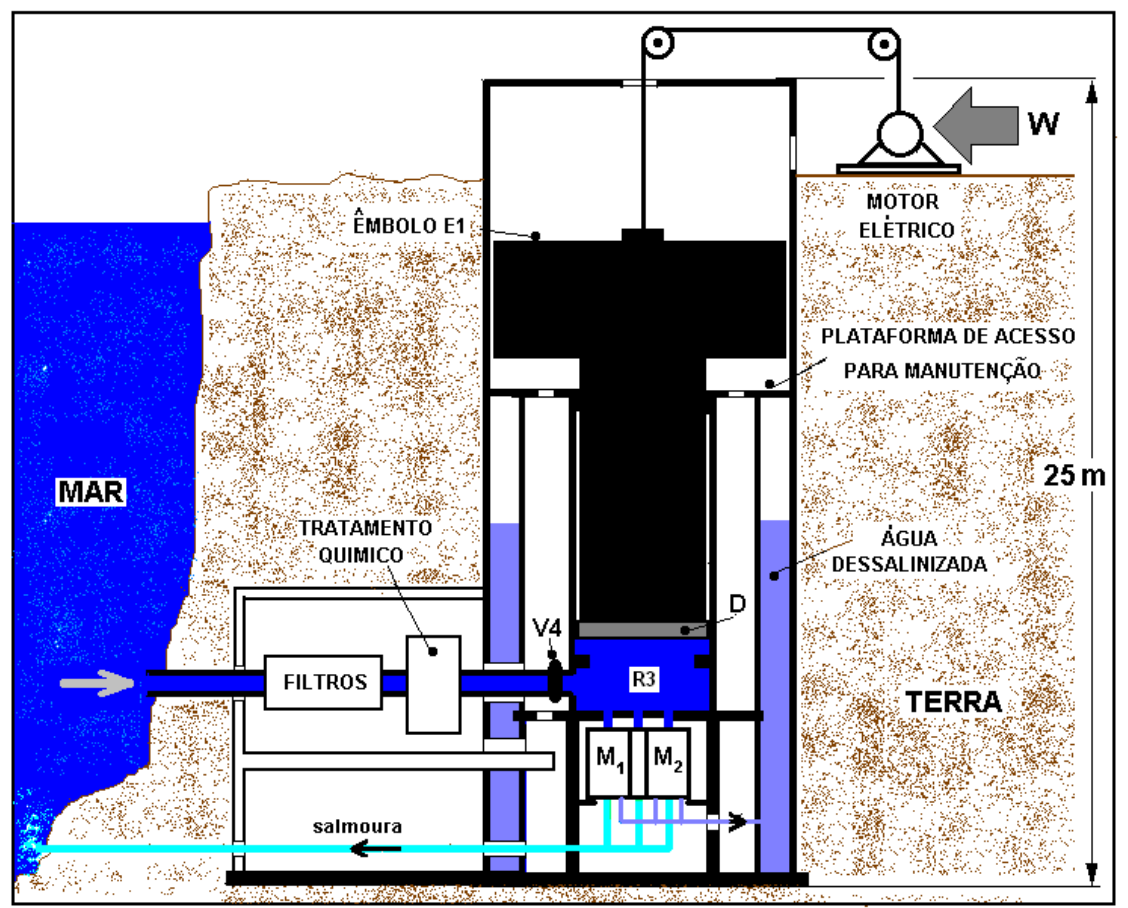

Fig. 3.18: CPH submersa no solo.

Suponha-se que a pressão exercida pelo êmbolo da CPH da Fig. 3.18 é 20,3 bar. Esse é o valor para dessalinização isentrópica (que equivale ao trabalho mínimo), de acordo com ISENTROPIC [...] Com esse valor, obtém-se o seguinte $\left(1 \mathrm{bar}=10^{5} \mathrm{~N} / \mathrm{m}^{2}\right)$ :

$\mathrm{E} / \mathrm{V}=\mathrm{P}=2030 \mathrm{~kJ} / 1 \mathrm{~m}^{3}$

dado que $1 \mathrm{~kJ}=1 / 3600 \mathrm{kWh}$, vem,

$\mathrm{E} / \mathrm{V}=0,564 \mathrm{kWh} / \mathrm{m}^{3}$

$\underline{\text { Esse valor confere com o calculado em ISENTROPIC [...] e corresponde à quantidade }}$ mínima de energia necessária para dessalinizar um metro cúbico de água do mar.

Quanto à segunda questão:

$2^{a}$ - Será que a quantidade de energia necessária para elevar a água até o reservatório Rl não inviabiliza o projeto? 
Ao longo do texto do mestrado (DIAS, 2004) mostrou-se que não. Resumidamente, basta afirmar que a energia usada no trabalho de bombeamento de água até R1 será "recuperada" através da sua descida no contrapeso ou/e no reservatório R2 do êmbolo especial.

Outra perspectiva de análise permite afirmar que durante a elevação da água até o reservatório $\mathrm{R} 1$ e da sua descida até o reservatório R3 tem-se simplesmente a transformação de energia cinética em energia potencial gravitacional e vice-versa. Pela primeira Lei da Termodinâmica, durante esse processo há conservação de energia.

\section{Quanto à terceira questão,}

\section{$3^{a}$-A quantidade de energia usada para elevar água, não seria suficiente para} conseguir a dessalinização fazendo-a passar diretamente pelo módulo de membrana?

Além do que já foi colocado em relação ao balanço de energia (trabalho realizado no bombeamento é "recuperado" na compressão exercida pelo êmbolo), um dos motivos que nos leva a adotar a estratégia de elevar água até o reservatório R1, fundamenta-se no seguinte:

A fonte de energia proposta para esse fim (eólica), não tem um caráter constante ao longo do dia ou do ano. Para contornar essa inconstância, recorremos à acumulação da energia proveniente da fonte, sob a forma de energia potencial gravitacional através da acumulação de água no reservatório R1. Trata-se de um aspecto de interesse relacionado com o bombeamento de água até o reservatório dado que isso permite que se tenha o sistema a operar livre das oscilações da energia eólica. Em suma, consegue-se a regularização da energia eólica através de armazenamento hidráulico.

As conclusões a que se chegou provam que, além de não ser mirabolante o que se propõe com o projeto, a energia específica consumida, em termos ideais, será o mínimo possível permitido pelas leis da Termodinâmica que é dado por:

$\mathrm{E} / \mathrm{V}=\mathrm{W} / \mathrm{V}=\mathbf{P}_{\mathbf{o s m}}$ 
O consumo específico real será maior do que o valor da pressão osmótica $\mathrm{P}_{\mathrm{osm}}$ da água, devido às irreversibilidades do processo de dessalinização. No processo de dessalinização que se propõe no projeto a maior fonte de irreversibilidade é o atrito entre o êmbolo e as superfícies em contato com ele.

Sobre isso, transcreve-se o que consta em (MEDINA, 2000, tradução nossa), no capítulo sobre bombas usadas nas unidades de osmose:

\section{“Bombas de pistões}

São bombas muito robustas e com uma alta eficiência hidráulica teórica de 90\%, tanto para bombas grandes como pequenas, derivada de una eficiência volumétrica de 100\%. Na pratica esta eficiência é algo inferior: 86-88\%."

É válida toda a análise anterior sobre o consumo específico para deduções sobre a eficiência de conversão da energia potencial gravitacional em energia elétrica com aumento da pressão de trabalho da TP a ser usada. No capítulo 5 abordar-se a questão da dessalinização e da geração de eletricidade com a CPH.

\section{7-Etapas de construção do protótipo}

A construção do protótipo passou por três fases (de 2006 a 2008) e encontra-se na terceira iniciada em outubro de 2009. Na primeira fase construiu-se um exemplar do protótipo em aço e alumínio cujas peças essenciais foram usinadas na oficina de projeto de fabricação do departamento da mecatrônica PMR. Outras peças foram construídas pelo autor deste trabalho. A segunda fase foi de pouca produção em termos de construção devido à falta de apoios em Cabo Verde. A terceira fase foi bastante produtiva. Ela aconteceu na oficina do departamento de eletrônica de potência. Seguemse, por ordem invertida, algumas fotos que ilustram esse processo.

Seguem-se as fotos (terceira fase ) dos componentes do modelo, Fig. 3.19, e uma visão global do mesmo, Fig. 3.20. Testes com o protótipo deram bons resultados qualitativos. No mínimo, conseguiu-se provar que o mecanismo idealizado para $\mathrm{CPH}$ funciona. 


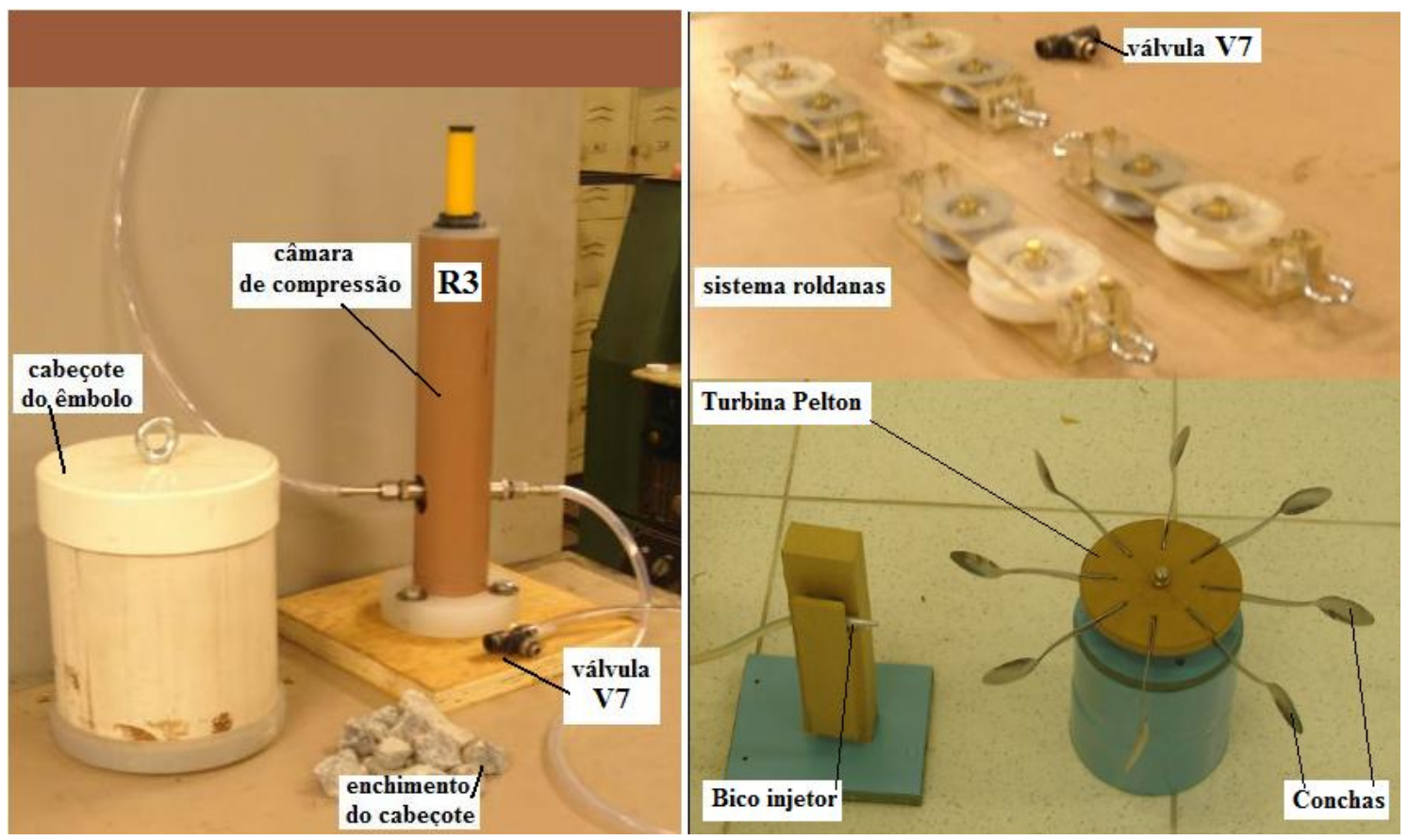

Fig. 3.19: Componentes do protótipo.

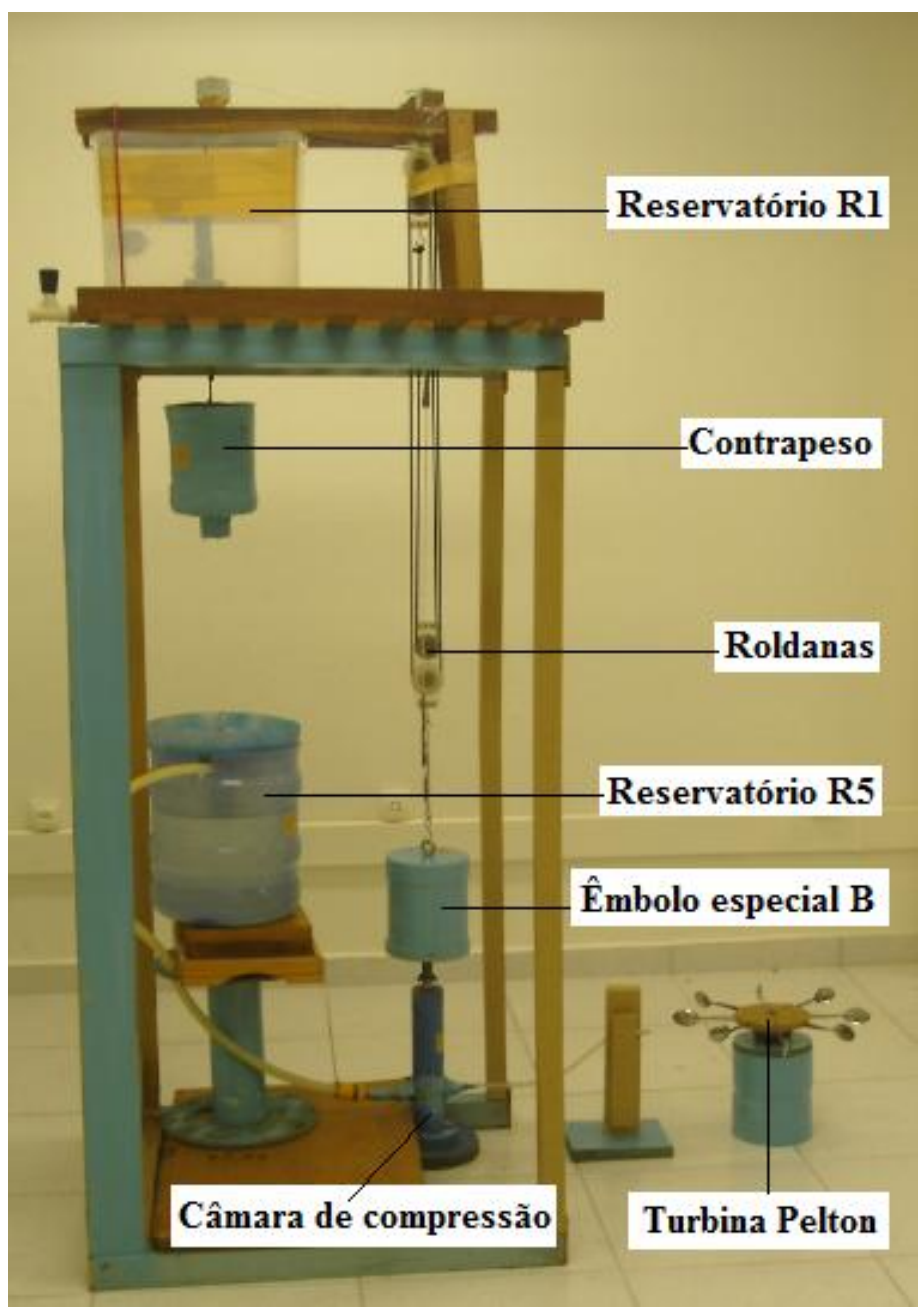

Fig. 3.20: Visão global do protótipo. 
Com base na Fig. 3.20, segue-se a descrição do funcionamento do protótipo :

1- O contrapeso ao se encher de água proveniente do reservatório $\mathrm{R} 1$, desce até o reservatório R5 onde despeja a água.

2-Durante a descida do contrapeso, o êmbolo especial é elevado até o seu curso superior enquanto a água proveniente de R5 entra na câmara de compressão.

3-Após o esvaziamento do contrapeso, o êmbolo desce e bombea a água da câmara de compressão para o TP que gira devido ao impacto do jato.

4-Quando o êmbolo chega ao fim do curso inferior, o contrapeso chega ao fundo do reservatório $\mathrm{R} 1$ e abre-se a válvula fazendo com que se encha novamente e que recomece o ciclo.

A Fig. 3.21 apresenta o êmbolo especial em fase de usinagem e pronto (construção do protótipo da CPH-primeira fase). O êmbolo foi feito de aço.

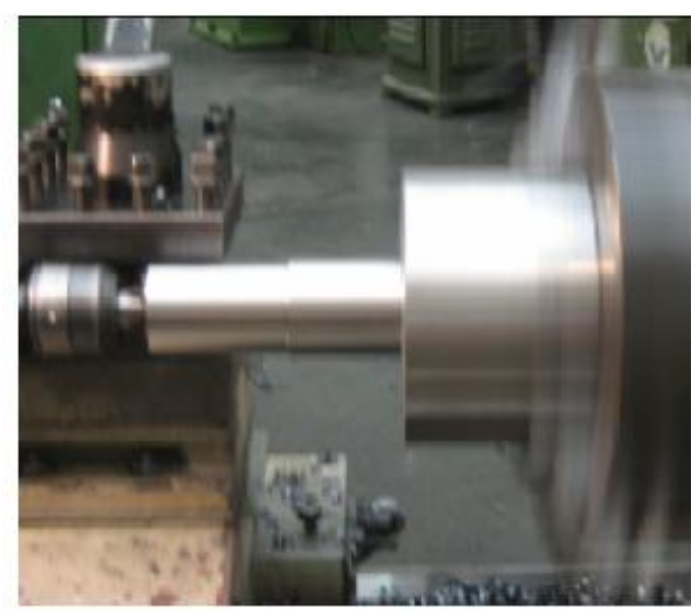

ÊMBOLO ESPECIAL EM FASE DE

USINAGEM NOTORNO

(Preparo da parte útil)

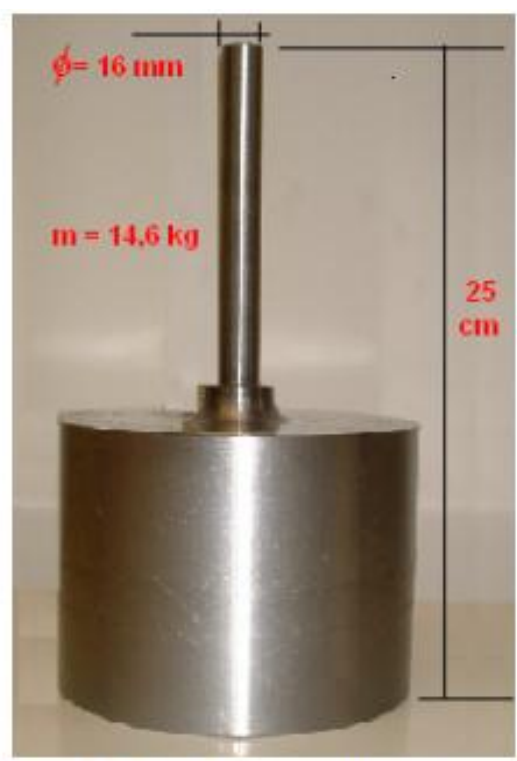

ÊMBOLO ACABADO

Fig. 3.21- êmbolo em usinagem e acabado.

Com as caráterísticas indicadas na Fig. 3.21 (massa =14,6 kg e diâmetro da parte útil= $16 \mathrm{~mm}$ )

o êmbolo é capaz de fornecer uma pressão de cerca de 7, 5 bar. As Figs. 3.22 e 3.23 
apresentam a câmara de compressão em construção e acabada. A câmara de compressão, feita de alumínio, corresponde a R3 no esquema da $\mathrm{CPH}$.

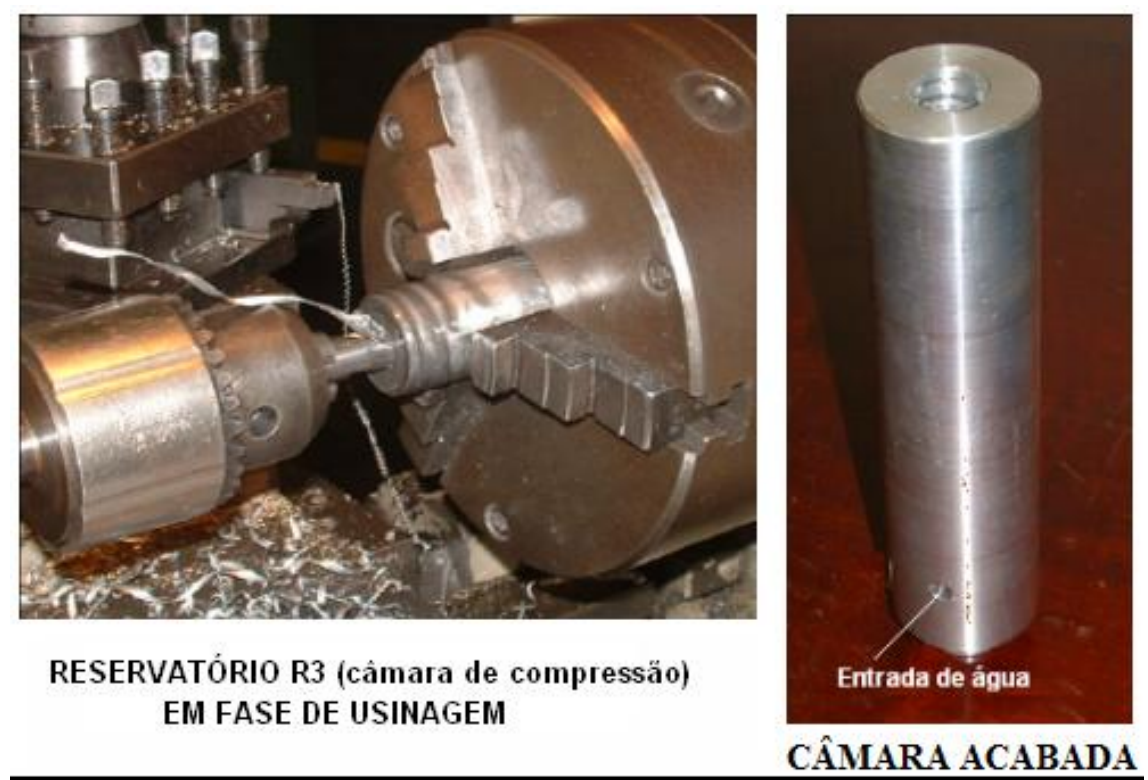

Fig. 3.22: Usinagem da câmara de compressão e câmara acabada.

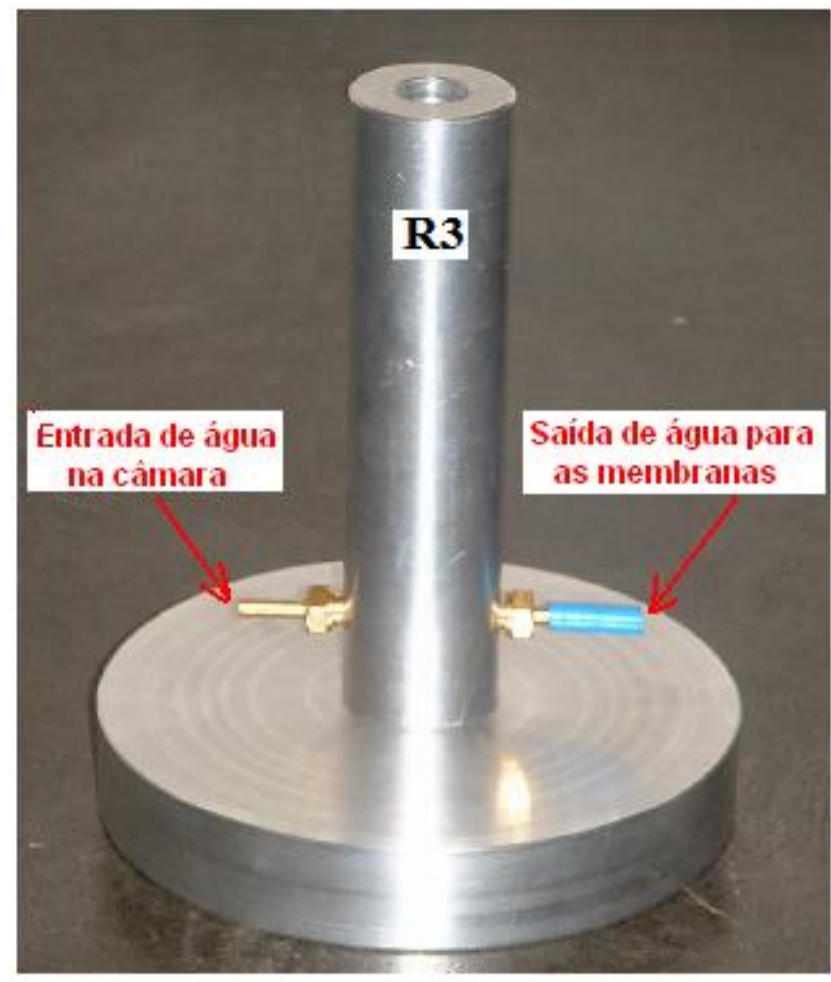

Fig. 3.23: Câmara de compressão com a sua base.

As Figs 3.24 e 3.25 mostram o sistema de roldanas e o cabo. Estes componentes foram construídos com a armadura em alumínio e as roldanas em aço. 


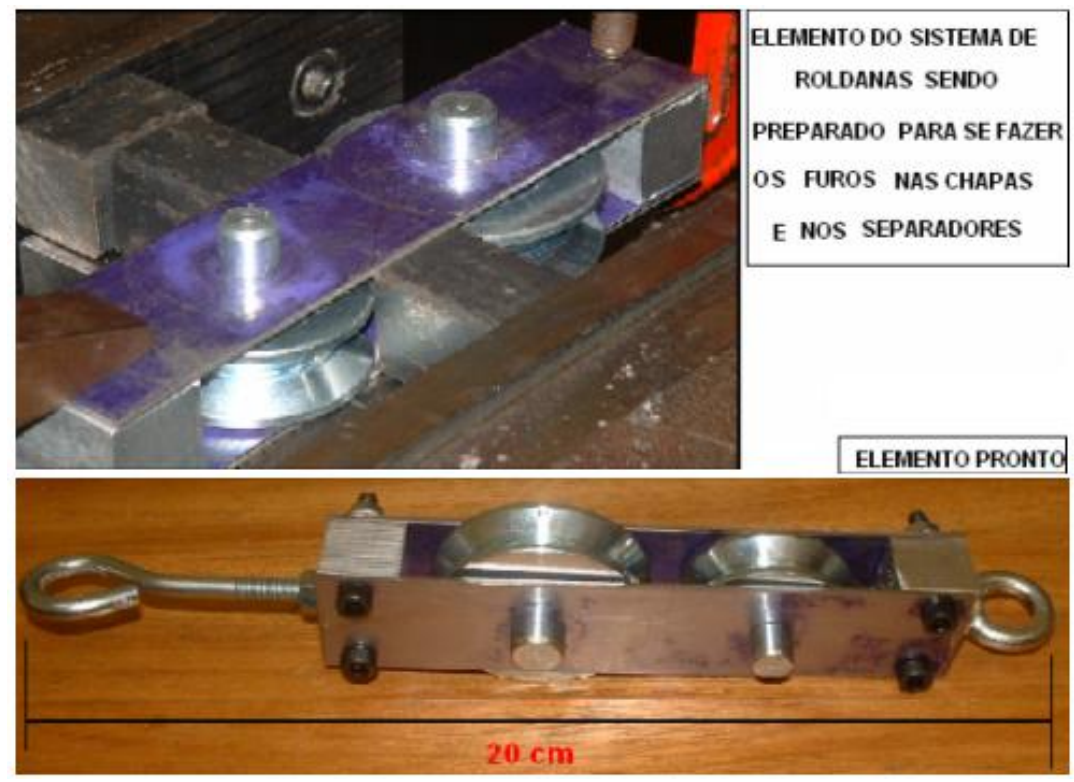

Fig. 3.24: Elemento do sistema de roldanas sendo preparado e pronto
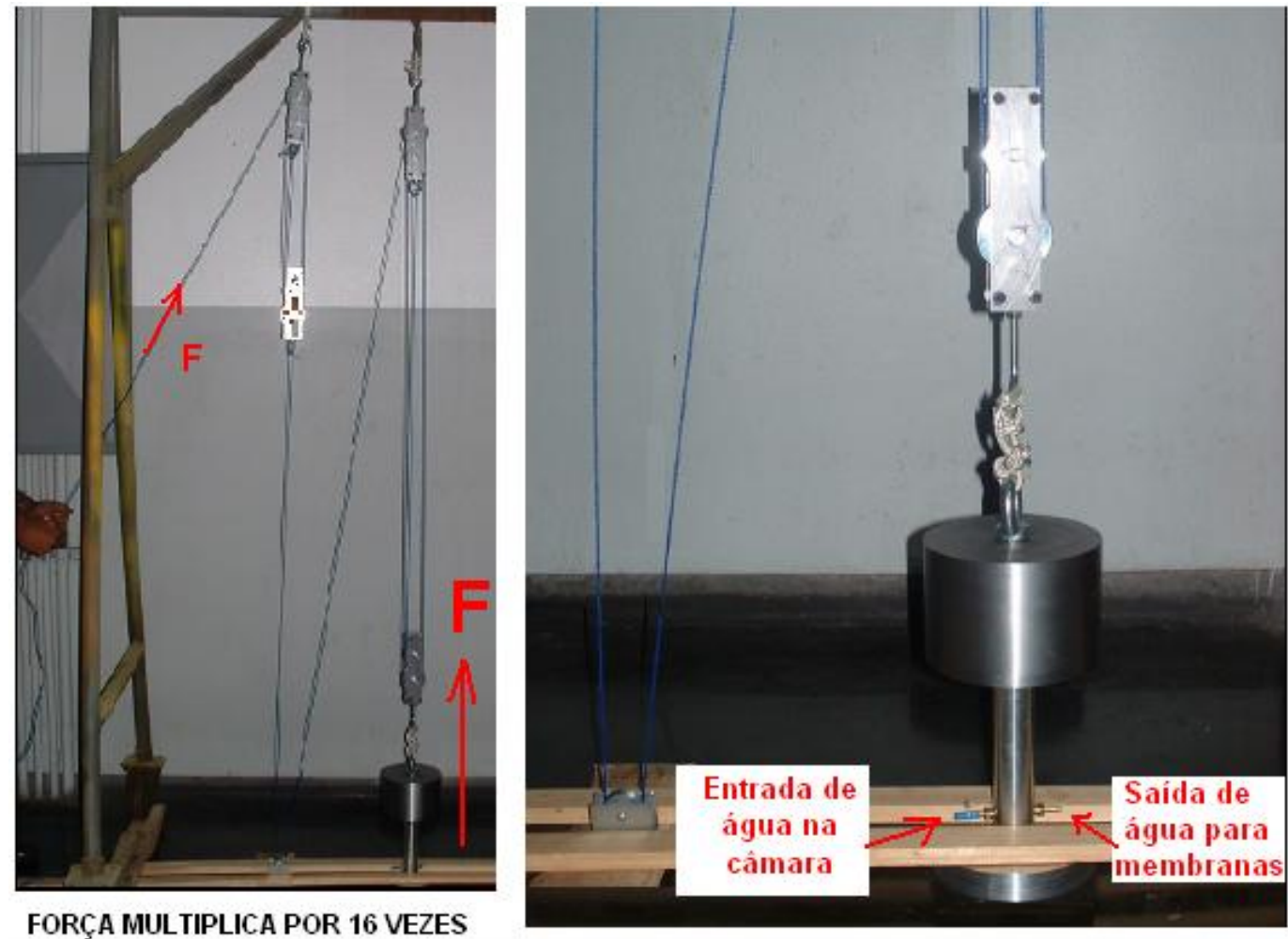

Fig. 3.25: Sistema em teste. Nesta fase dos testes, ainda não se tinha a ação do contrapeso para elevar o êmbolo.

O funcionamento do protótipo conseguido com a terceira fase de construção decorreu de acordo com o que foi projetado e descrito na seção 3.3.2. Entretanto, alguns componentes como as válvúlas V1, V2, V5 e V6 foram construídos com um princípio de funcionamento diferente do sistema cremalheira-roda dentada. 


\section{8-Comentários sobre os resultados do protótipo}

Dado que tanto a osmose reversa como a geração de eletricidade com TP são técnicas que já dão resultados sólidos, o foco do protótipo não foi obter água dessalinizada nem eletricidade, ainda que essas aplicações continuem sendo objetivos futuros.

Até esta fase, devido à alguns contrangimentos nomeadamente o tempo disponível, o foco foi provar que o mecanismo da $\mathrm{CPH}$ funciona. Assim, ficou provado com o protótipo que a $\mathrm{CPH}$ é capaz de transformar a energia potencial gravitacional obtida do reservatório R1 num fluxo de água com alta pressão. Além disso, provou-se também que ela pode ser usada como uma estação de elevação de água.

Dutrante o funcionamento, verificou-se que a $\mathrm{CPH}$ dispensa o uso de lubrificantes para o êmbolo especial e a camâra de compressão. A água bombeada desempenha a função de lubrificante.

O fluxo de água sob a pressão exercida pelo êmbolo especial, foi usado para acionar uma espécie de pequena turbina Pelton montada sob levitação magnética. Fez-se essa montagem para provar que a $\mathrm{CPH}$ tem condições práticas para a geração de eletricidade.

Embora para fins acadêmicos, a construção do protótipo possa ser dispensável, encarouse o desafio de fazê-lo funcionar pelo fato de a CPH ser uma inovação tecnológica que, sem uma prova prática, teria muito mais barreiras para sair do papel e ser transformado em realidade.

Além dessa motivação para construir o protótipo, essa opção se deve ao fato de esse modelo estar em desenvolvi mento desde 2002, tendo, uma vertente dele, sido já objeto da dissertação de mestrado (DIAS, 2004), e de duas publicações. uma na revista científica Desalination, (FADIGAS ; DIAS, 2009), e outra, nos anais do $10^{\circ}$ Congresso Brasileiro de Energia, onde foi apresentado em Outubro de 2004. 


\section{CAPÍTULO 4:}

\section{FONTE DE ENERGIA DO MODELO}

\section{1- INTRODUÇÃO}

Este capítulo tem como objetivo apresentar a modelagem matemática dos dois sistemas cuja fonte primária de energia é o vento definidos no capítulo 2. Serão abordadas as tecnologias adotadas para captar a energia contida na referida fonte. Dado que, para captar a energia eólica, o modelo é subdividido em dois sistemas: um que usa cataventos e outro que usa aerogeradores, far-se-á uma subdivisão na modelagem matemática, após a apresentação da parte teórica que é comum (potencial eólico contido numa corrente de ar). Seguidamente, apresenta-se o equacionamento, comum aos dois sistemas, referente à conversão da potência de bombeamento em energia potencional gravitacional (EPG) armazenada no reservatório superior R1.

No capítulo 6, faz-se uma comparação dos dois sistemas explorando as vantagens e desvantagens de cada um deles. Analisa-se, também, os pontos fortes e fracos desses sistemas em relação aos sistemas convencionais de dessalinização por osmose reversa $(\mathrm{OR})$ e de geração de eletricidade com turbina Pelton. No final deste capítulo faz-se uma comparação qualitativa dos dois sistemas.

\section{2 - Fonte de Energia dos Sistemas e bombeamento de água até o reservatório superior R1}

A energia que o sistema necessita, para ser autônomo, provém da energia potencial gravitacional $(\mathrm{EPG}=\mathrm{mgh})$ da água acumulada no reservatório superior R1, Fig. 4.1. Consegue-se essa EPG a partir da captação da energia eólica por cataventos (sistema 1S1) ou por aerogeradores (sistema 2 - S2), que é usada para o bombeamento da água retirada de um poço.

Note-se que se o poço em questão é cavado junto à costa para captação de água do mar, essa já terá uma salinidade ligeiramente inferior à que tem no oceano. Além dessa vantagem sutil, as paredes do poço e o solo já funcionam como um pré-filtro para retenção das impurezas de maior granularidade. 


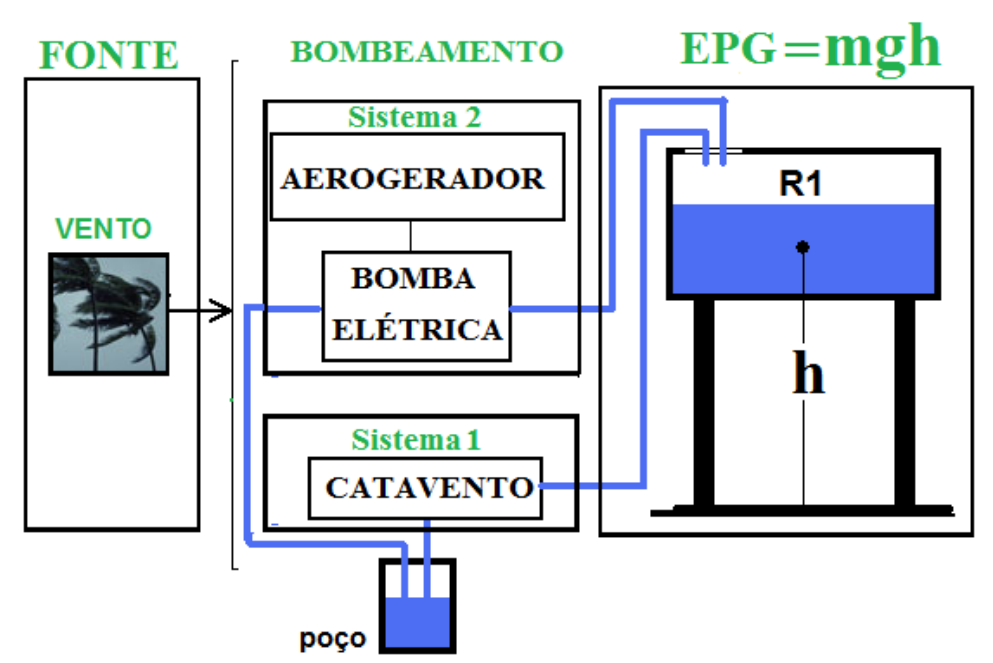

Fig. 4.1: esquema da fonte de energia do modelo.

Para garantir a energia firme no reservatório R1, é necessário que o mesmo seja dimensionado para uma reserva que permita atenuar o problema do regime intermitente da energia eólica. Tal dimensionamento é feito à semelhança do procedimento usado nas usinas hidroelétricas para a regularização da vazão dos reservatórios.

A Fig. 4.2 ilustra o bombeamento de água para o reservatório R1 através do sistema 1 (uso de cataventos) auxiliado pela bomba Clark através da recuperação de energia da salmoura.

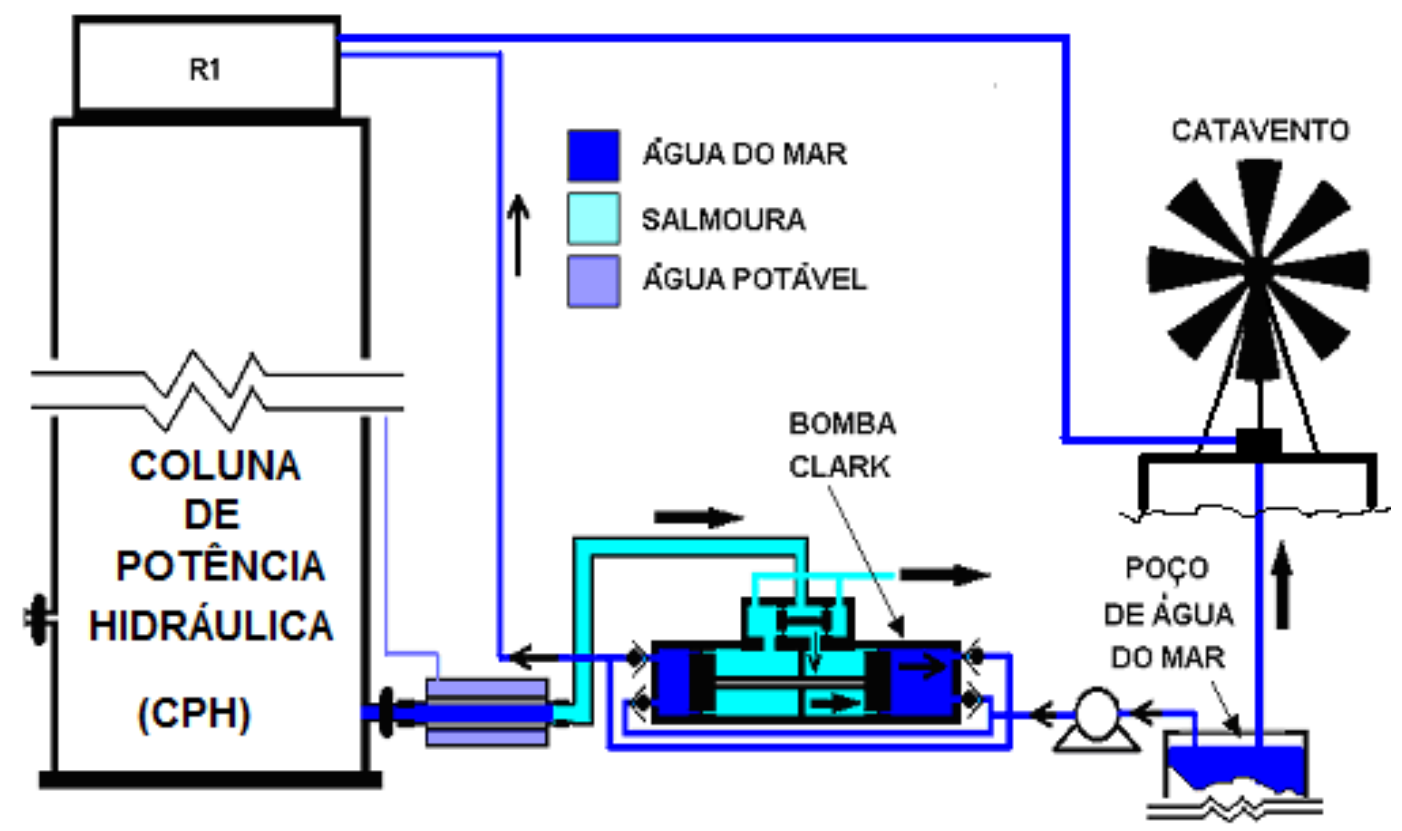

Fig. 4.2: Sistema de alimentação do reservatório superior R1. 
O esquema de bombeamento apresentado é atualmente factível, dado que as máquinas propostas estão disponíveis comercialmente, como se constata na Fig. 4.3. Em relação ao sistema 2 o estado da arte permite afirmar que há a disponibilidade comercial dos equipamentos escolhidos para o bombeamento (aerogeradores e bombas elétricas).

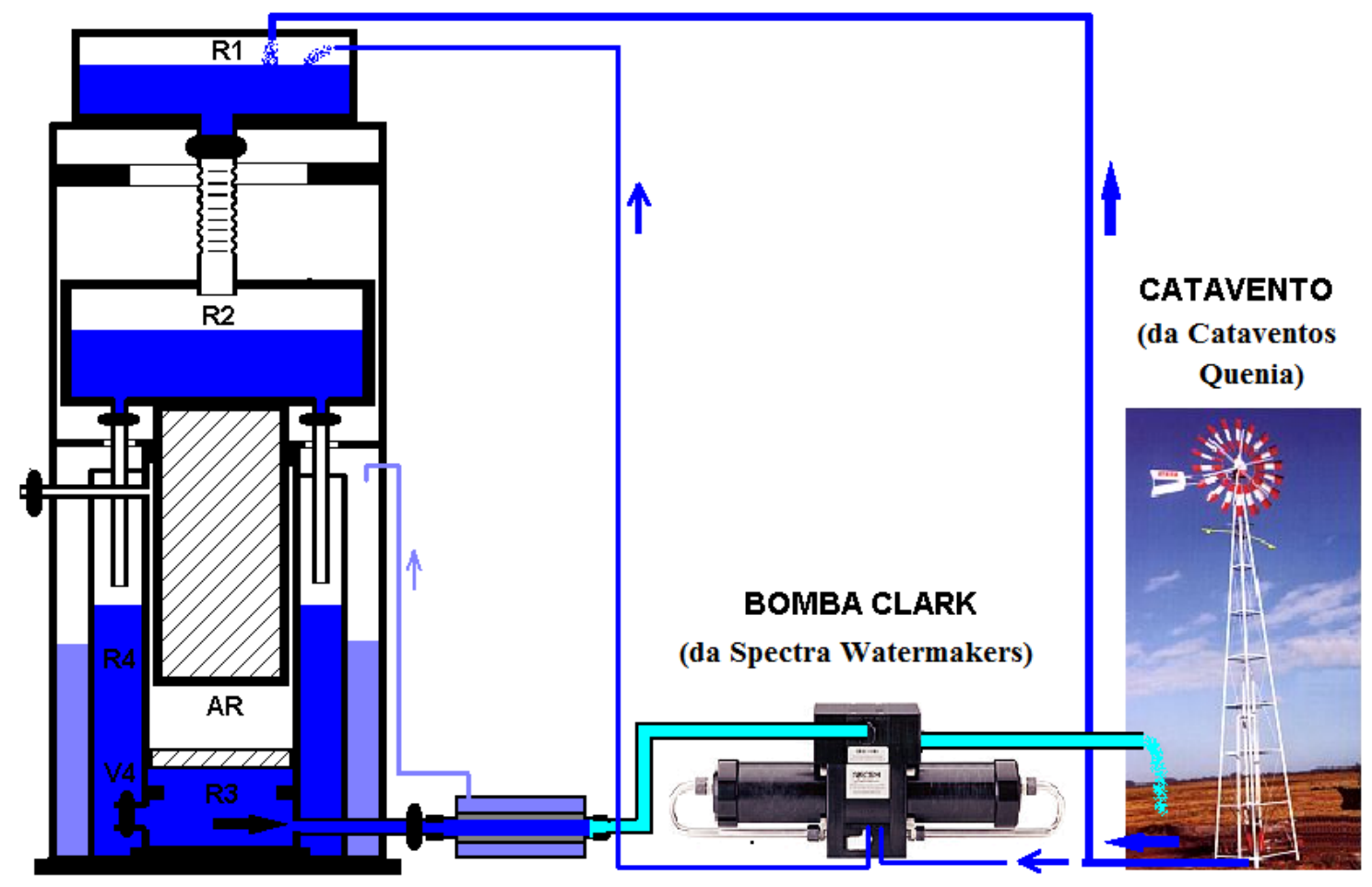

Fig. 4.3: Máquinas comerciais que se propõe para abastecer R1 de água.

Observa-se nas Figs 4.4 e 4.5 que no bombeamento feito através do sistema 1, com cataventos, há transformação da energia cinética do vento diretamente em energia mecânica usada para movimentar a água. No caso do sistema 2, com aerogeradores, após a transformação da energia cinética do vento em energia mecânica do rotor do aerogerador, há a tranformação desta em energia elétrica que é usada pela bomba que movimentará a água até R1. Nas Figs 4.4 e 4.5, além do destaque dado à aplicação dos dois sistemas na dessalinização, ilustra-se a recuperação de energia da salmoura através da bomba Clark. 


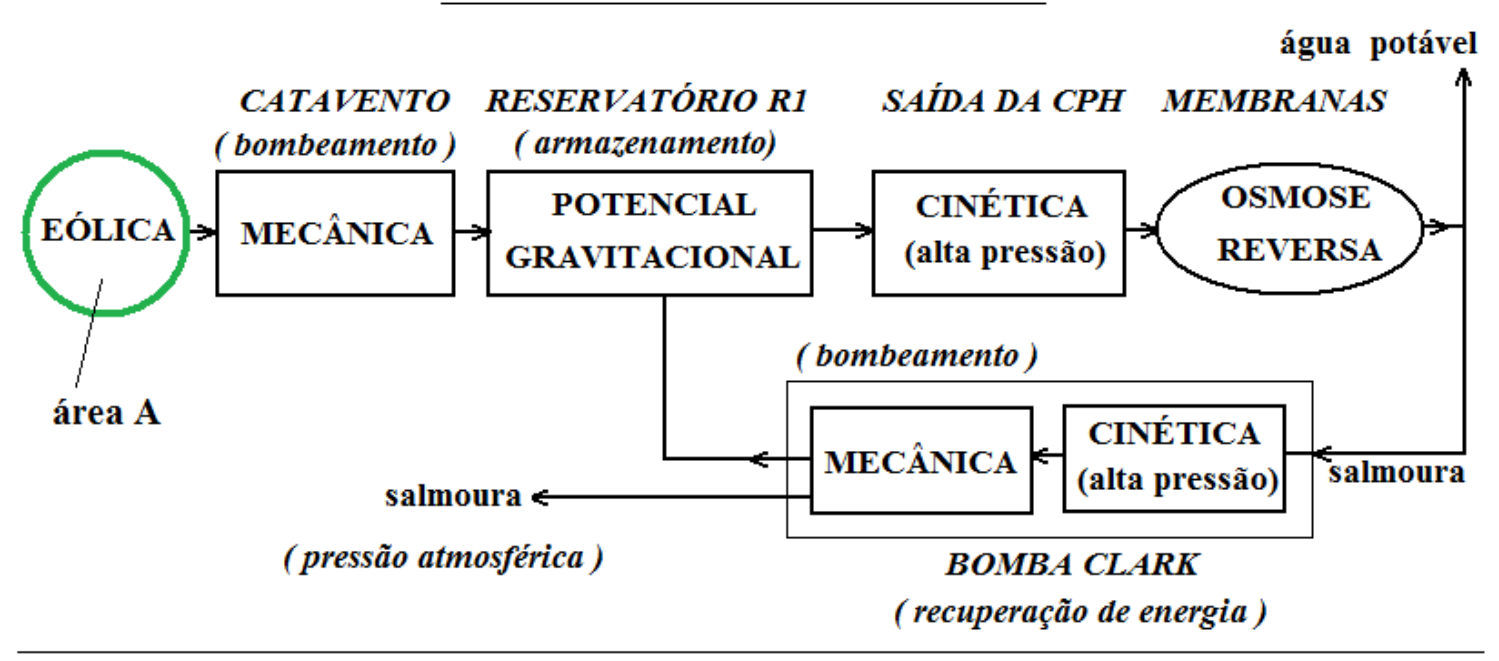

Fig. 4.4: Transformações de energia do sistema 1 aplicado para osmose reversa.

O uso da bomba Clark só se justifica se o modelo é usado para osmose reversa. Isso porque a perda de pressão do fluxo nas membranas é reduzida, havendo assim a necessidade de se recuperar essa energia para que o consumo específico não seja tão alto a ponto de inviabilizar economicamente o processo.

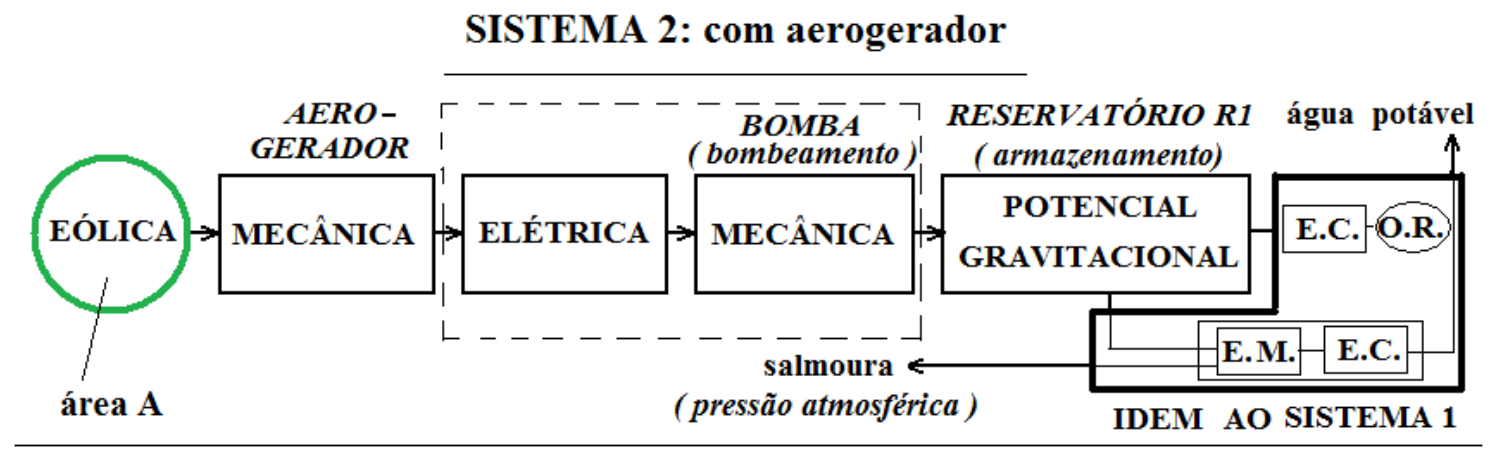

Fig. 4.5: Transformações de energia do sistema 2 aplicado para osmose reversa.

Note-se que (retângulo tracejado na Fig. 4.5 ) a configuração do sistema 2 apresenta mais transformações de uma forma de energia para outra do que o sistema 1. Assim, uma comparação qualitativa prévia dos dois sistemas permite deduzir que se os dois estiverem a operar com condições idênticas em relação à velocidade do vento (ex: velocidade constante de $7 \mathrm{~m} / \mathrm{s}$ ), exceto se o produto dos rendimentos das transformações a mais que ocorrem com o aerogerador seja superior ao rendimento do mecanismo de bombeamento do catavento é que o sistema 2 terá melhor desempenho que o sistema 1. 
Entretanto, se houver necessidade de se captar a energia eólica num local distante da coluna de potência hidráulica, é possível que o sistema 2 seja mais apropriado.

Em relação à dessalinização de água, pode-se a priori, mesmo sem efetuar o balanço energético da bomba Clark, esperar que o reservatório R1 tenha sempre água suficiente. Dois dados permitem-nos ter essa expectativa:

- A vazão dos cataventos pode chegar a 5000 litros por hora, ou seja, um catavento pode bombear para R1 cerca de 120000 litros de água por dia.

- Todas as vezes que o êmbolo descer, uma (ou mais) bomba Clark irá bombear água para R1 já que nela estará entrando salmoura com alta pressão transferida pela descida do êmbolo.

A primeira afirmação é feita com base em dados de fabricantes de cataventos. A segunda teve seu embasamento físico demonstrado em (DIAS,2004).

\section{3-Potencial eólico.}

No dimensionamento do modelo, para se determinar o número de cataventos (sistema 1) ou de aerogeradores (sistema 2) necessários, há que conhecer não só o regime dos ventos no local onde se pretende instalar o sistema, mas também a capacidade que essas máquinas têm de converter o potencial eólico disponível em energia mecânica. A análise da Fig. 4.6 permite avaliar teoricamente o potencial de energia contido num fluxo de ar.

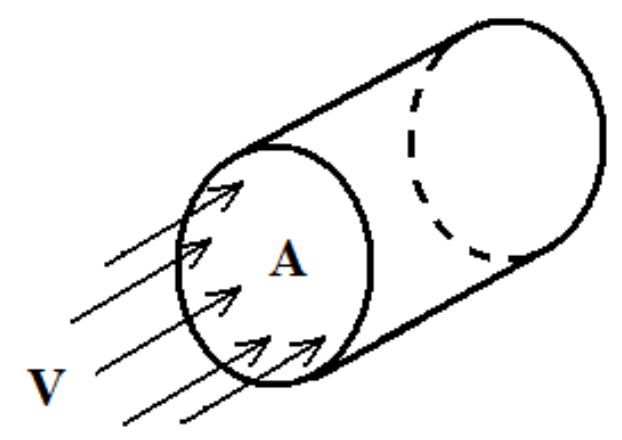

Fig. 4.6: Escoamento de ar com velocidade $\mathrm{V}$ através de um rotor de área $\mathrm{A}$. 
De acordo com (MANWELL et al, 2002), como ilustrado na Fig. 4.4, pode-se determinar o fluxo de massa de ar $d m / d t$ através do rotor de área $\mathrm{A}$. Da equação da continuidade (mecânica dos fluidos), o fluxo de massa de ar é uma função da densidade do ar, $\rho$, e da sua velocidade (considerada constante) V, e é dada por:

$\mathrm{dm} / \mathrm{dt}=\rho \mathrm{A} \mathrm{V}$

A energia cinética por unidade de tempo, ou potência do fluxo de ar é dada por (potência eólica $\mathrm{P}_{\mathrm{e}}$ ):

$\mathbf{P}_{\mathbf{e}}=1 / 2 \mathrm{dm} / \mathrm{dt} \mathrm{V}^{2}=\mathbf{1 / 2} \boldsymbol{\rho} \mathbf{A} \mathbf{V}^{\mathbf{3}}$

A potência eólica por unidade de área, $\mathrm{P}_{\mathrm{e}} / \mathrm{A}$ ou densidade de potência eólica é:

$$
\mathrm{P}_{\mathrm{e}} / \mathrm{A}=1 / 2 \rho \mathrm{V}^{3}
$$

Note-se que (Eqs 4.2 e 4.3):

- a densidade de potencia eólica é proporcional à densidade do ar. Para condições normais (nível do mar, $15^{\circ} \mathrm{C}$ ) a densidade do ar é $1,225 \mathrm{~kg} / \mathrm{m}^{3}$.

- A potência do vento é proporcional a área varrida pelo rotor (ou ao quadrado do diâmetro para uma máquina convencional de eixo horizontal).

- a densidade de potência do vento é proporcional ao cubo da velocidade do vento

A tabela 4.1 mostra que a velocidade do vento é um parâmetro importante e que influencia significativamente a potência por unidade de área disponível no vento. 
Tabela 4.1: Potência por unidade de área disponível no vento com velocidade constante. (densidade do ar $\left.=1,225 \mathrm{~kg} / \mathrm{m}^{3}\right)$.

\begin{tabular}{|c|c|}
\hline Velocidade do vento $[\mathbf{m} / \mathbf{s}]$ & Potência/Área $\left[\mathbf{W} / \mathbf{m}^{2}\right]$ \\
\hline 0 & 0 \\
5 & 80 \\
10 & 610 \\
15 & 2070 \\
20 & 4900 \\
25 & 9560 \\
30 & 16550 \\
\hline
\end{tabular}

A velocidade do vento varia em função da altura. Os anemômetros das estações são normalmente instalados a uma altura de, no mínimo, 10 metros (FADIGAS,2004). Para determinação da velocidade do vento a altura do rotor da máquina eólica (catavento ou aerogerador), há que corrigir os dados obtidos pelos anemômetros. Para tal dispõe-se de dois modelos denominados "Lei da potência" e a "Lei logarítmica" (FADIGAS,2004; MANWELL et al, 2002). A lei da potência é a mais simples de ser aplicada, contudo acarreta menos precisão. Apesar disso, utilizamo-la-emos nos nossos cálculos dado que, para fins de avaliação teórica da máquina eólica, ela satisfaz . Reforçando a justificação do seu uso, segundo (MANWELL et al, 2002), a lei da potência é usada por vários pesquisadores da área de energia eólica e ambas as leis estão sujeitas à incertezas devido à variável e complexa natureza de escoamentos turbulentos. A lei da potência é expressa por:

$V=V_{0}\left(H / H_{0}\right)^{n}$

sendo

V é a velocidade do vento na altura desejada

$\mathbf{V}_{\mathbf{0}} \quad$ é a velocidade do vento disponível na altura conhecida

H é a altura desejada

$\mathbf{H}_{\mathbf{0}} \quad$ é a altura conhecida

n é o fator de rugosidade do terreno 
Apresenta-se na tabela 4.2 alguns valores do fator " $n$ " para diferentes tipos de terrenos.

Tabela 4.2: Fator de rugosidade para terrenos planos. Fonte: (FADIGAS,2004).

\begin{tabular}{|l|l|}
\hline Descrição do terreno & n \\
\hline Terreno sem vegetação & 0,10 \\
Terreno gramado & 0,12 \\
Terreno cultivado & 0,19 \\
Terreno com poucas árvores & 0,23 \\
Terreno com: muitas árvores, cerca viva ou poucas edificações & 0,26 \\
Florestas & 0,28 \\
Zonas urbanas sem edificações & 0,32 \\
\hline
\end{tabular}

\subsection{1- Estimativa do potencial eólico de um lugar.}

Alguns aspectos relativos à caráterística do vento são aqui referidos antes de se apresentar ferramentas matemáticas que permitem avaliar a quantidade de energia disponível no vento e em determinado lugar. A velocidade do vento apresenta variações tanto temporais como espaciais sendo, portanto, um recurso energético com caráterística intermitente. Em relação ao tempo, as variações são convencionalmente divididas nas seguintes categorias (MANWELL et al, 2002) :

- inter-anuais

- anuais

- diárias

- de curta duração (turbulência e rajadas)

As variações inter-anuais ocorrem em escalas temporais superiores a um ano e podem ter um efeito importante na produção da máquina eólica a longo prazo. A Fig. 4.7 (dados da região Billings, Montana, EUA) mostra como há variações ao longo de um ano e de ano a ano que são significativas. Essa caráterística ocorre em quase todos os lugares do mundo (MANWELL et al, 2002) . 


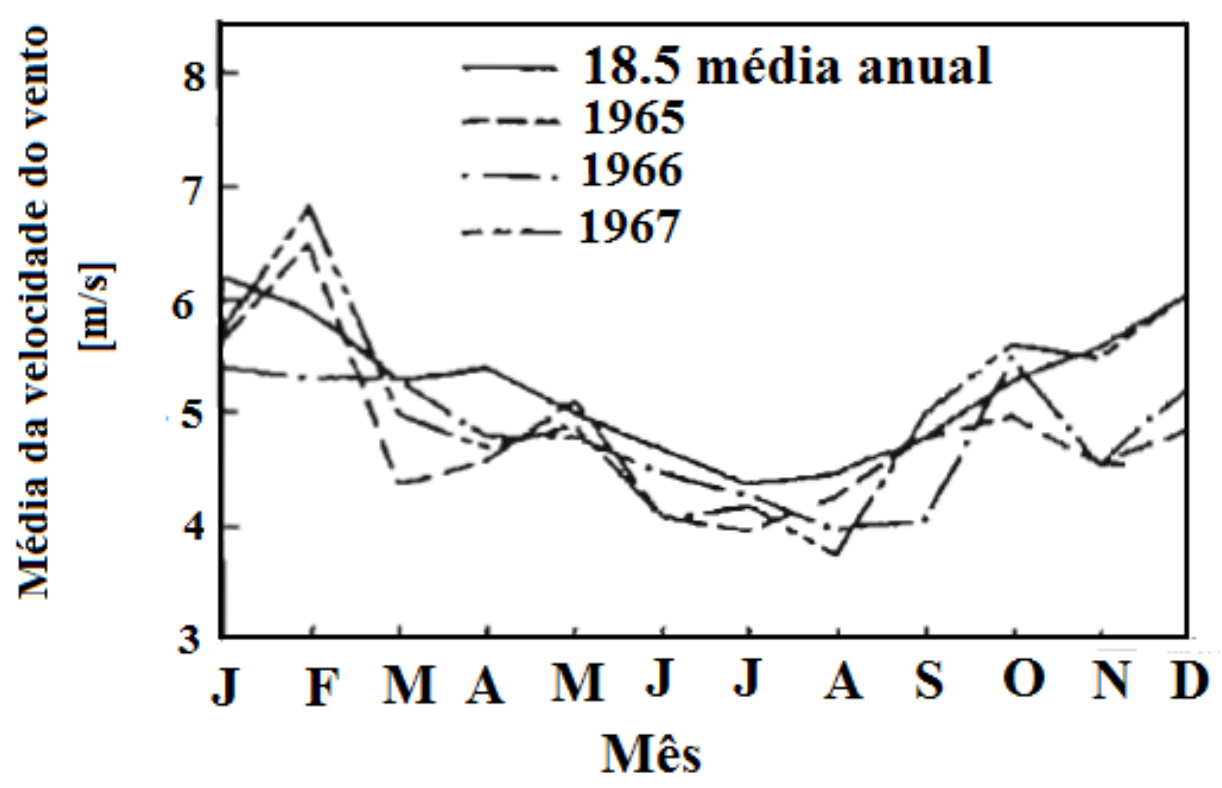

Fig. 4.7: Mudanças sazonais da média mensal da velocidade do vento.

Fonte: (MANWELL et al, 2002)

Nas regiões tropicais (caso de Cabo Verde) e nas latitudes temperadas ocorrem variações diárias da velocidade do vento que são devidas às diferenças de aquecimento da superfície da Terra durante o ciclo de radiação do Sol. Uma variação diurna típica é o aumento da velocidade do vento durante o dia e velocidades menores da meia noite ao nascer do Sol. A Fig. 4.8 ilustra variações repentinas da velocidade do vento típicas de rajadas e turbulências.

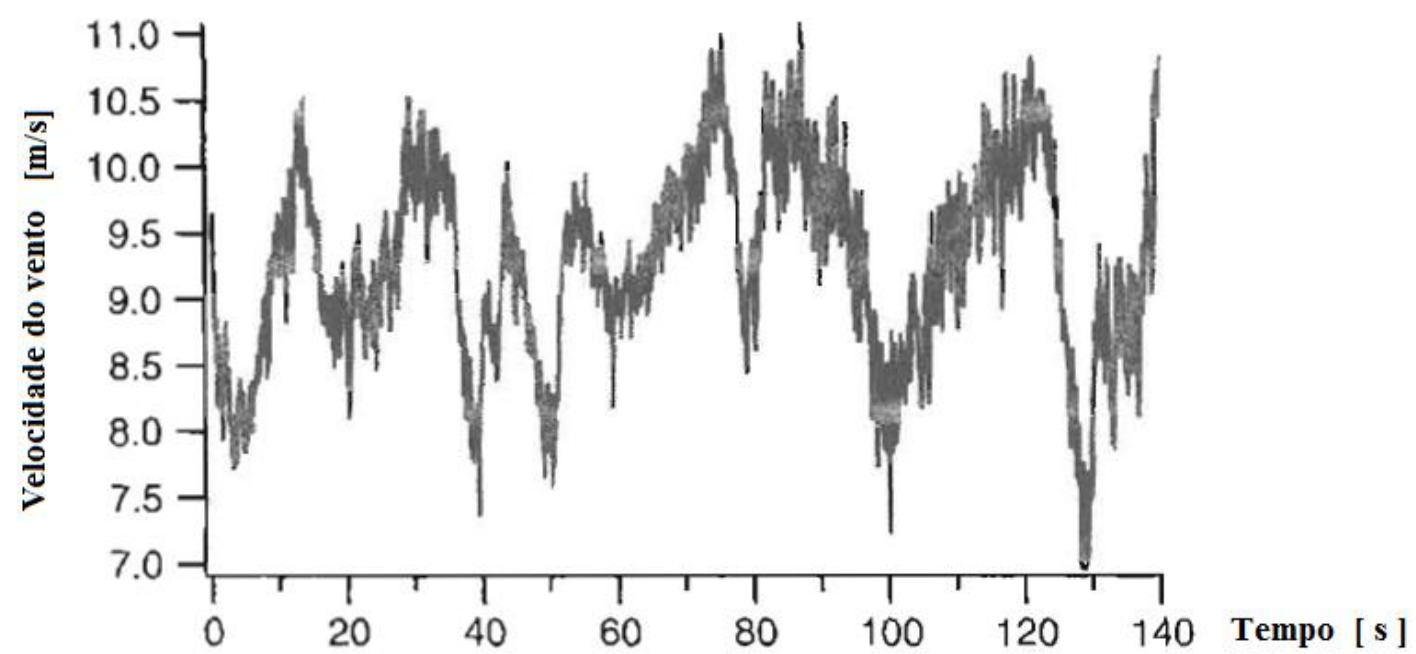

Fig. 4.8: Gráfico típico de variações da velocidade do vento versus tempo num curto período de tempo. Fonte: (MANWELL et al, 2002) . 
Além das variações temporais referidas há que ter em conta ainda as variações locais e de direção do vento quando se pretende implementar um projeto de aproveitamento eólico. As variações locais podem ser significativas devido à topografia e à cobertura do terreno. As variações da direção do vento podem ser pequenas (da ordem de 30 graus) ou as médias mensais podem ter variação de 180 graus (MANWELL et al, 2002) .

Em relação ao tratamento dos dados da velocidade do vento medidos num determinado lugar onde se pretende que uma máquina eólica opere, há um número de maneiras de sumariá-los numa forma compacta para que se possa avaliar o recurso eólico ou o potencial de produção. Tais formas incluem tanto técnicas diretas com técnicas estatisticas. Algumas dessas técnicas podem ser usadas com uma quantia limitada de dados (ex. somente velocidade média do vento) do lugar (MANWELL et al, 2002) .

Os métodos estatísticos são baseados em funções probabilísticas de densidade da velocidade do vento. A experiência tem mostrado que há maior tendência para que a velocidade do vento esteja próxima do seu valor médio do que longe dela (MANWELL et al, 2002). Assim, a função probabilística que melhor descreve esse comportamento é a de Gauss ou função normal. As funções mais usadas nos métodos estatísticos são as de Rayleigh e de Weibull.

\subsection{2- Distribuição de Rayleigh.}

Esta é a função de distribuição da densidade da velocidade do vento mais simples para representar o recurso eólico porque só se precisa ter conhecimento da velocidade média do vento (MANWELL et al, 2002). A função de densidade de probabilidade de Rayleigh é dada por:

$\mathrm{p}(\mathrm{V})=\pi / 2\left(\mathrm{~V} / \mathrm{V}_{\mathrm{m}}{ }^{2}\right) \exp \left[-\pi / 4\left(\mathrm{~V} / \mathrm{V}_{\mathrm{m}}\right)^{2}\right]$

A figura 4.9 ilustra a função de Rayleigh para diferentes valores de velocidade média. Como se vê, um maior valor de velocidade média dá uma maior probabilidade para velocidades maiores. 


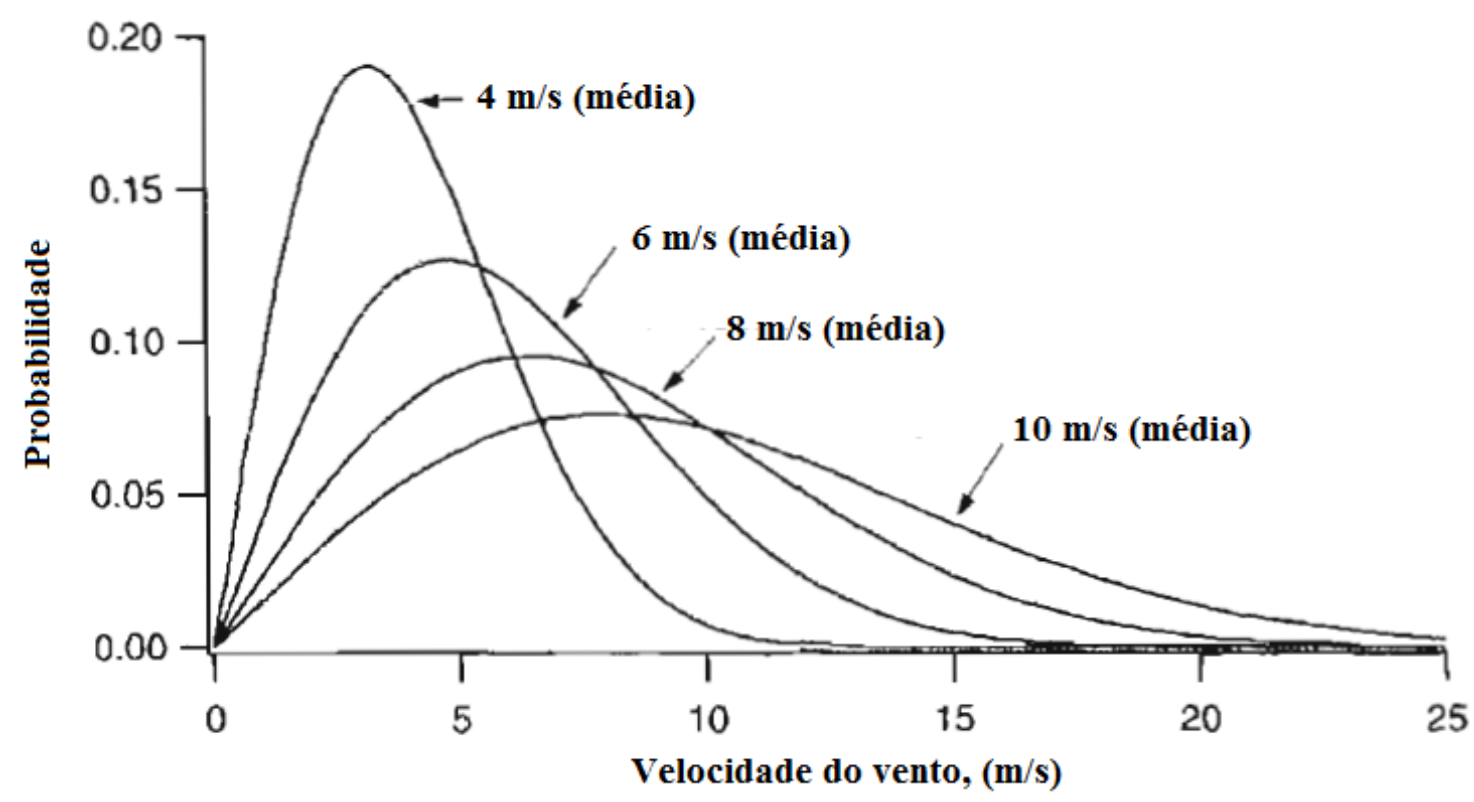

Fig. 4.9: Exemplos da distribuição de Rayleigh. Fonte: (MANWELL et al, 2002) .

\subsection{3- Distribuição de Weibull.}

A determinação da função de densidade de probabilidade de Weibull requer o conhecimento de dois parâmetros: $\boldsymbol{k}$, um fator de forma e $\boldsymbol{c}$ um fator de escala. Ambos os fatores são função da velocidade média e do desvio padrão. A função de densidade de probabilidade de Weibull é dada por:

$\mathrm{p}(\mathrm{V})=(\mathrm{k} / \mathrm{c})(\mathrm{V} / \mathrm{c})^{\mathrm{k}-1} \exp \left[-(\mathrm{V} / \mathrm{c})^{\mathrm{k}}\right]$

Exemplos da função densidade de probabilidade de Weibull para vários valores de $k$ são mostrados na Fig. 4.10. Como se vê, quando o valor de $k$ aumenta, a curva tem uma concavidade mais pronunciada indicando que há menos variação da velocidade do vento. Métodos analíticos e empíricos para a determinação de $k$ e $c$ podem ser encontrados em (MANWELL et al, 2002) . Na seção 4.6 (estimativa do potencial de produção de uma turbina), apresenta-se um dos métodos para se determinar $k$ e $c$. 


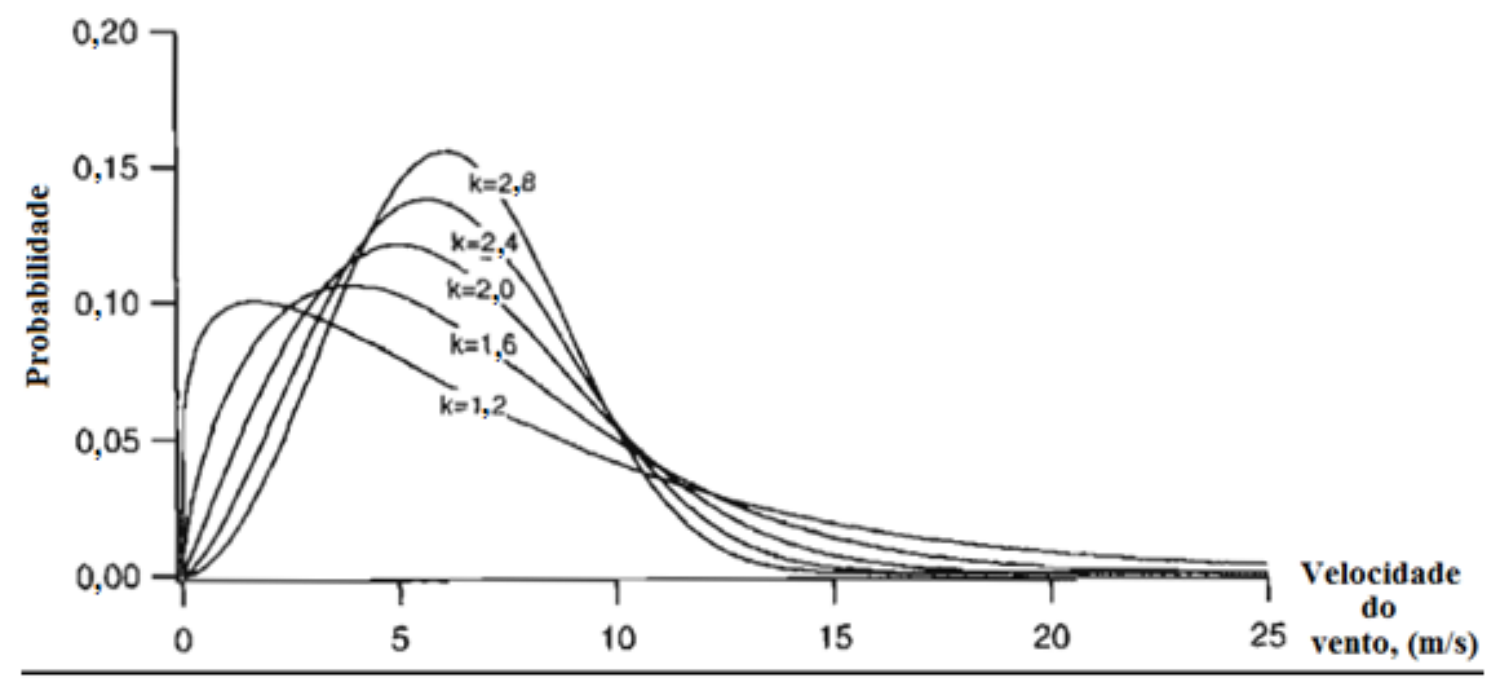

Fig. 4.10: Exemplo da distribuição de Weibull para velocidade média de $8 \mathrm{~m} / \mathrm{s}$.

Fonte: (MANWELL et al, 2002).

\section{4- Potência real captada pela máquina eólica}

A potência real captada por uma máquina eólica é afetada pela mecânica do fluido que por ela passa, pela aerodinâmica e pela eficiência das combinações rotor-bomba (catavento) ou rotor-caixa de redução-gerador (aerogerador).

$\mathrm{Na}$ avaliação da conversão da potência eólica $\mathrm{P}_{\mathrm{e}}$ em potência mecânica do rotor $\mathrm{P}_{\mathrm{r}}$ da máquina eólica (catavento ou aerogerador) definem-se dois coeficientes:

- $\mathrm{O}$ coeficiente de potência $\mathrm{C}_{\mathrm{p}}$, que relaciona diretamente a potência eólica com a potência do rotor.

- A razão de velocidade da ponta da pá $\lambda$ (tip speed ratio), ou velocidade específica que relaciona o $\mathrm{C}_{\mathrm{p}}$ com a velocidade do vento que atravessa a área varrida pelo rotor, e a velocidade da ponta da pá.

$\mathrm{O}$ coeficiente de potência $C_{p}$ representa a percentagem da potência eólica $P_{e}$ que é captada pela máquina e convertida em potência do seu rotor $\mathrm{P}_{\mathrm{r}} \cdot \mathrm{C}_{\mathrm{p}}$ caráteriza, portanto, o desempenho aerodinâmico da máquina eólica e é dado por (MANWELL et al, 2002) :

$\mathrm{C}_{\mathrm{p}}=\mathrm{P}_{\mathrm{r}} / \mathrm{P}_{\mathrm{e}}=\mathrm{P}_{\mathrm{r}} /\left(1 / 2 \rho \mathrm{A} \mathrm{V}^{3}\right)$ 
$O$ coeficiente de potência $C_{p}$ é geralmente expresso em função da razão de velocidade ) da ponta da pá $\lambda$ que é definida por:

$\lambda=\omega \mathrm{R} / \mathrm{V}=($ velocidade da ponta da pá) / (velocidade do vento)

onde $\omega$ é a velocidade angular do rotor e R é o seu raio.

A Fig. 4.11 ilustra a eficiência aerodinâmica, (caráterizada pelo seu coeficiente de potência $\mathrm{C}_{\mathrm{p}}$ ) de diversos tipos de máquinas eólicas em função de $\lambda$.

Em relação à conversão da potência eólica em potência do rotor, Betz demonstrou que um rotor ideal tem a capacidade de captar no máximo até $59,3 \%\left(\mathrm{C}_{\mathrm{p}}\right.$ máximo $)$ da potência disponível do vento (MANWELL et al, 2002) .

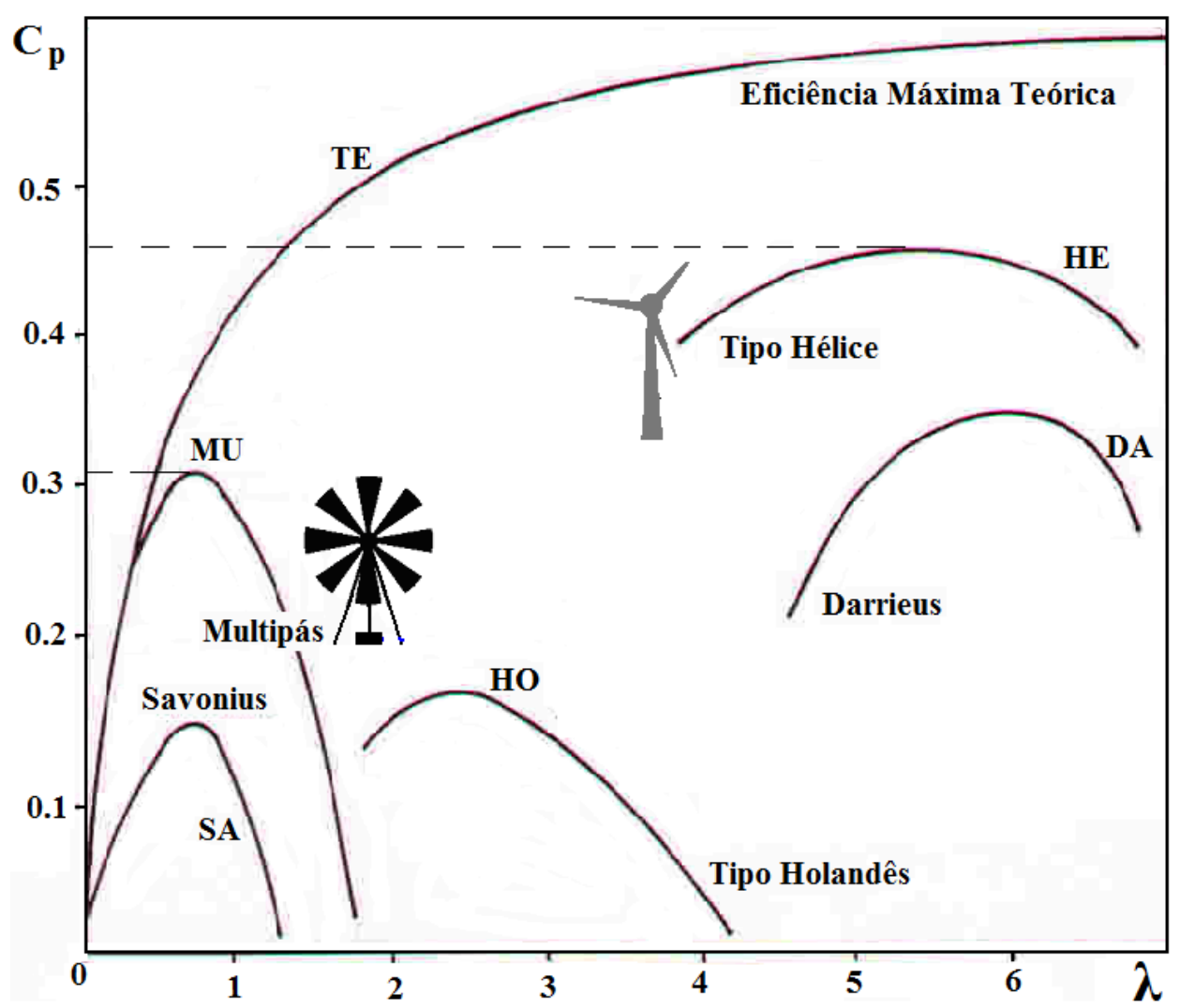

Fig. 4.11: Eficiências aerodinâmicas dos diversos tipos de rotores.

Fonte: (MANWELL et al, 2002) com adaptação nossa.

Da definição do coeficiente de potência (Eq. 4.7: $P_{r}=C_{p} \times P_{e}$ ) depreende-se que o ideal, se fosse atingível, seria ter $C_{p}=1$. No entanto, na prática, busca-se operar a máquina 
eólica numa faixa próxima ao seu máximo valor $\left(\mathrm{C}_{\mathrm{p}}\right.$ máximo da máquina $)$ para que se consiga o melhor desempenho. Essa busca pela otimização é mais comum com turbinas eólicas que dispõem de controle do ângulo de ataque do vento através da rotação das pás em torno dos seus respectivos eixos.

Da Eq. 4.7 obtém-se para a potência do rotor da máquina eólica $\mathrm{P}_{\mathrm{r}}$ o seguinte:

$$
\mathbf{P}_{\mathbf{r}}=\mathbf{C}_{\mathbf{p}} \mathbf{1 / 2} \boldsymbol{\rho} \mathbf{A} \mathbf{V}^{\mathbf{3}} \quad \text { em }[\mathrm{kg} \mathrm{m} / \mathrm{s}]
$$

Na qual (FARRET,1999):

$\mathbf{C}_{\mathbf{p}}$ é o coeficiente de potência

$\boldsymbol{\rho}$ é a densidade específica do $\operatorname{ar}\left(=1,225 \mathrm{~kg} / \mathrm{m}^{3}\right.$ à $15^{\circ} \mathrm{C}$ e ao nível do mar)

A é a área varrida pelas hélices ou pás do rotor $\left[\mathrm{m}^{2}\right]$.

V é a velocidade do vento $[\mathrm{m} / \mathrm{s}]$.

$1 \mathrm{~kg} \mathrm{~m} / \mathrm{s}=9,81 \mathrm{~W}$

Se a altitude $\mathrm{H}$ (em metros) for conhecida, a densidade do ar pode ser estimada por (FARRET,1999):

$\rho=1,1225-\left(1,194 \times 10^{-4}\right) \mathrm{H}$

A transformação da potência mecânica do rotor $\left(\mathrm{P}_{\mathrm{r}}=\mathrm{C}_{\mathrm{p}} 1 / 2 \rho \mathrm{A} \mathrm{V}^{3}\right)$ em potência de bombeamento $\mathrm{P}_{\mathrm{b}}$ dependerá dos rendimentos $\boldsymbol{\eta}_{\mathbf{c o m b}}$ das combinações que fazem parte do sistema 1 (catavento-bomba de pistão) ou do sistema 2 (turbina eólica-gerador-bomba elétrica). Levando esse fator à equação 4.9 , tem-se:

$$
P_{b}=C_{p} 1 / 2 \rho A V^{3} \eta_{c o m b}
$$

Nas próximas seções aborda-se separadamente as adaptações que a Eq. 4.10 terá quando aplicada à cada um dos sistemas. Inicia-se com o sistema de bombeamento com cataventos (sistema 1), passando, em seguida, ao de bombeamento com bomba elétrica alimentada por aerogerador. O Coeficiente de potência que figura na Eq. 4.10 é caráterístico do tipo de máquina eólica usado na captação da energia eólica. Assim, em 
relação aos sistema 1 e 2, verifica-se na Fig. 4.11 que os cataventos podem atingir um $\mathrm{Cp}$ de 0,3 (curva MU) e os aerogeradores um $\mathrm{Cp}$ de 0,45 (curva HE).

Devido à tais caráterísticas específicas de cada tipo de máquina eólica, e resultados práticos obtidos quer pelos fabricantes quer por pesquisadores, há equações expeditas que computam a potência fornecida pela máquina em função da velocidade do vento e da área varrida pelo rotor. Para que se tenha como ferramenta que permite avaliar de forma rápida o potencial de um catavento ou de um aerogerador, apresenta-se nas seções respectivas as referidas equações do gênero $P_{r}=f(A ; V)$.

Entretanto, avança-se que (FARRET,1999), recorrendo ao conceito de coeficiente de potência máximo de Betz $\left(\mathbf{C}_{\mathbf{p}, \text { Betz }}=59,3 \%\right)$, inserido na equação $\mathbf{P}_{\mathbf{e}}=\mathbf{C}_{\mathbf{p}} \mathbf{1} / \mathbf{2} \mathbf{\rho} \mathbf{A} \mathbf{V}^{\mathbf{3}}$, e

com $\rho_{\mathrm{ar}}=1,2929 \mathrm{~kg} / \mathrm{m}^{3}$ (nível do mar e $0^{\circ} \mathrm{C}$ ), a densidade de potencia máxima de vento que pode ser obtido pela máquina eólica (sem levar em conta as perdas aerodinâmicas no rotor, as variações de velocidade do vento nos vários pontos da área de captação, o tipo de rotor, etc.) é dado por: $\mathbf{P}_{\mathbf{e}} / \mathbf{A}=\mathbf{0 , 3 8 3 1} \mathbf{V}^{\mathbf{3}}$ expresso em $\left[\mathrm{W} / \mathrm{m}^{2}\right]$, sendo $\mathrm{V}$ a velocidade do vento. Numa próxima seção, baseando-se em dados da bibliografia ( MANWEL et al, 2002; FARRET,1999) faz-se a dedução da densidade de potencia máxima de vento captado por aerogeradores de pequeno, médio e grande porte, porém, levando em conta o seu rendimento prático.

Com essa equação, é fácil estimar a potência fornecida por uma máquina eólica (catavento ou aerogerador) colocada num local onde se conhece a velocidade média do vento desde que se saiba, de acordo com resultados práticos, qual é a percentagem do potencial máximo que a máquina em questão é capaz de fornecer e o diâmetro do rotor.

\section{5 -Potência de bombeamento com cata-vento (Sistema 1).}

Como mostrado na seção anterior (Eq. 4.9), a potência do rotor do catavento é dado por

$$
P_{r}=C_{p} 1 / 2 \rho A V^{3}
$$


Na Fig. 4.12 visualiza-se as etapas de transformação a que a potência do rotor $\mathrm{P}_{\mathrm{r}}$ (extraída da potência eólica $\mathrm{P}_{\mathrm{e}}$ ) passará até a conversão em potência de bombeamento $\mathrm{P}_{\mathrm{b}}$ usada para colocar água no reservatório R1 ( armazenamento de energia potencial gravitacional E.P.G).

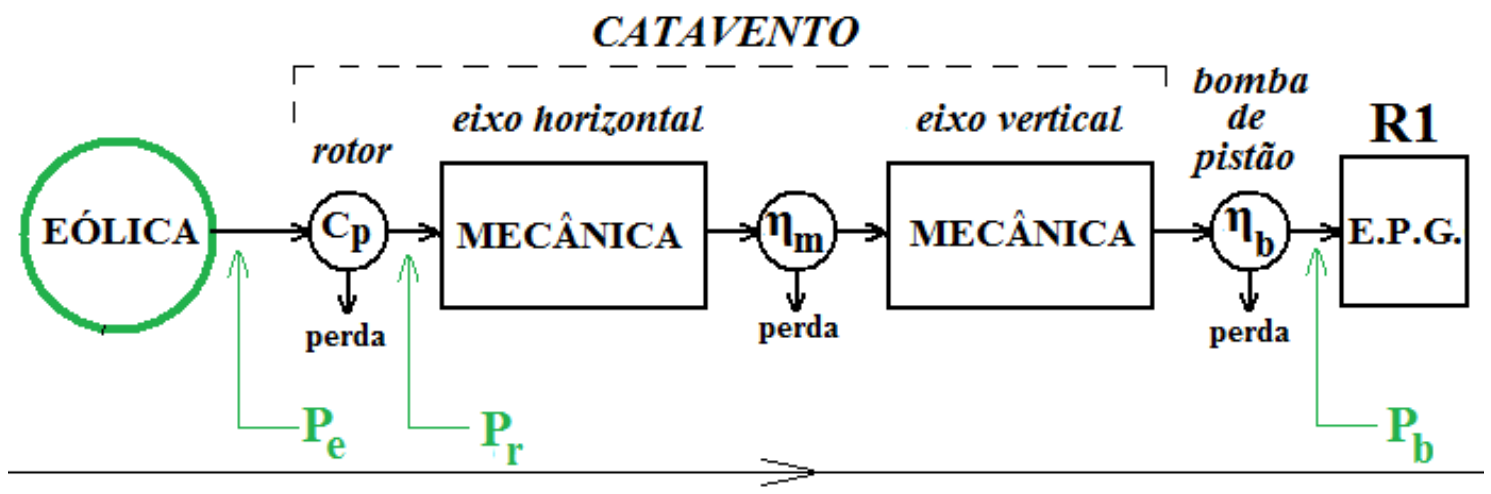

Fig. 4.12: Etapas de transformação da potência eólica em potência de bombeamento.

Tendo em conta os rendimentos da engrenagem $\eta_{\mathrm{m}}$ e da bomba de pistão $\eta_{\mathrm{b}}$ na cadeia de transformações, a potência de bombeamento será dada por:

$P_{b}=\operatorname{Pr} \cdot \eta_{m} \cdot \eta_{b}$

Ou seja, a potência de bombeamento do sistema com catavento é:

$P_{b}=C_{p} 1 / 2 \rho A V^{3} \eta_{m} \cdot \eta_{b}$

Em termos teóricos, a Eq. 4.11 traduz a potência de bombeamento no fim da cadeia do sistema 1. Entretanto, na prática, o produto $\mathbf{C}_{\mathbf{p}} \boldsymbol{\eta}_{\mathbf{m}} \cdot \boldsymbol{\eta}_{\mathbf{b}}$ poderá ser convertido num único valor obtido de testes com cataventos.

Seguindo essa linha prática, apresenta-se a seguir a modelagem matemática referente ao uso de cataventos que permitirá determinar o número necessário dessas máquinas para o abastecimento do reservatório superior R1 do sistema. A anunciada modelagem foi apresentada em (DIAS,2004) com base em (SILVA, et al, 2000).

De acordo com (SILVA, et al, 2000), a densidade de potencia eólica $\mathbf{P}_{\mathbf{e}} / \mathbf{A}$ disponível do vento é obtida por ( adaptação da Eq. 4.3): 
$\mathrm{P}_{\mathrm{e}} / \mathrm{A}=k \mathrm{~V}^{3}\left[\mathrm{~W} / \mathrm{m}^{2}\right]$

onde,

$\boldsymbol{k} \quad$ é um valor tabelado que depende das unidades de $\mathrm{P}_{\mathrm{e}}, \mathrm{A}$ e $\mathrm{V}$,

$\mathbf{V}$ é a velocidade do vento $[\mathrm{m} / \mathrm{s}]$.

Indica-se em (SILVA, et al, 2000). o valor $k=0,0006449924$ para $\mathrm{P}_{\mathrm{e}}[\mathrm{kW}], \mathrm{A}\left[\mathrm{m}^{2}\right]$, e V $[\mathrm{m} / \mathrm{s}]$. Com menor precisão, indica-se para a constante eólica $k$ o valor 0,00064 (ACIOLA,1993) para as mesmas unidades de $\mathrm{P}_{\mathrm{e}}, \mathrm{A}$ e V.

De acordo com o referido trabalho, o coeficiente de potência máxima $\mathbf{C p}$, para cataventos, não ultrapassa o valor 0,3 (veja-se a curva MU na Fig. 4.11 ). Tendo em conta esse valor, na prática a potencia eólica $\mathrm{P}_{\mathrm{e}}$ reduz-se ao valor dado por:

$\mathrm{P}_{\mathrm{e}}=0,3 \quad \mathrm{~A} \quad k \quad \mathrm{~V}^{3} \quad[\mathrm{~W}]$

A conversão da potência obtida pela Eq. 4.13 em potência de bombeamento $\mathrm{P}_{\mathrm{b}}$ resulta numa redução que depende das eficiências da transmissão e da bomba. Assim, segundo resultados práticos, num dado local com uma velocidade média do vento, a potência $\mathrm{P}_{\mathrm{b}}$ de saída média é calculada através da equação seguinte (SILVA,C.D et al):

$\mathbf{P}_{\mathrm{b}}=\mathbf{0 , 1}$ A $\quad \mathbf{V}^{3}$

$\mathbf{P}_{\mathbf{b}}$ é a potência de bombeamento [W]

A é a área varrida pelo rotor do catavento $\left[\mathrm{m}^{2}\right]$

$\mathbf{V}$ é a velocidade média do vento [m/s]

Tendo em conta que geralmente os rotores têm um diâmetro externo $\mathbf{D}$ e outro interno d, a área varrida é dada por $A=\pi / 4\left(D^{2}-d^{2}\right)$. Assim, a Eq. 4.14 toma o seguinte formato:

$P_{b}=0,1 \pi / 4\left(D^{2}-d^{2}\right) V^{3}$ 
A Eq. 4.15 dá, portanto, potência de bombeamento obtida a partir da transformação da potência do rotor de um catavento (função do vento que move suas pás, Eq. 4.9). Após a determinação da potência de bombeamento, há que conhecer a vazão de água bombeada em função da altura manométrica $\mathrm{H}_{\mathrm{m}}$. A vazão é dada por (SILVA,C.D et al):

$Q_{m}=\left(3600 . P_{b}\right) /\left(\rho_{\text {agua }} \cdot g \cdot H_{m}\right)$

sendo,
Qm é a vazão
$\left[\mathrm{m}^{3} / \mathrm{h}\right]$.
$\mathbf{P}_{\mathbf{b}}$ é a potência de bombeamento [W].

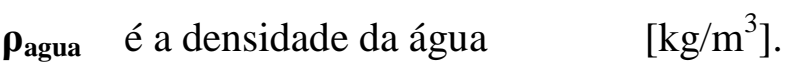
g é a aceleração da gravidade $\left[9,8 \mathrm{~m} / \mathrm{s}^{2}\right]$.
$\mathbf{H}_{\mathbf{m}} \quad$ é altura manométrica $\quad[\mathrm{m}]$.

Com $\rho_{\text {agua }}=1025 \mathrm{~kg} / \mathrm{m}^{3}$ correspondente à densidade da água do mar a ser bombeada para o reservatório superior R1, a equação 4.15 reduz-se à:

$\mathbf{Q}_{\mathrm{m}}=\mathbf{P}_{\mathrm{b}} /\left(\mathbf{2 , 7 9 0} \mathbf{H}_{\mathrm{m}}\right)$

De posse da Eq. 4.17, conhecendo a altura a que estiver o reservatório superior R1 reune-se duas condições que permitem determinar o número de cataventos necessários, em função da demanda diária de água dessalinizada ou de eletricidade.

Além dos dados necessários para a Eq. 4.17, à semelhança de sistemas eólicos para geração de energia elétrica (FADIGAS,2004), "é importante que a determinação do regime dos ventos seja feita com a maior exatidão possível" para que se disponha de dados que permitam o dimensionamento adequado do sistema de bombeamento de água para R1.

A dedução das Eqs 4.16 e 4.17 será apresentada na seção 4.6 na qual se mostra como a potência de bombeamento é convertida em energia potencial gravitacional armazenada no reservatório R1. Tais equações aparecem na referida seção como Eqs 4.32 e 4.33 respectivamente. 


\section{6 -Potência de bombeamento com aerogerador - bomba elétrica (Sistema 2)}

À semelhança do tratamento que se deu ao sistema 1, a potência do rotor do aerogerador é dado por: $P_{r}=C_{p} \mathbf{1 / 2} \rho A \mathbf{V}^{3}$.

$\mathrm{Na}$ Fig. 4.13 visualiza-se as etapas de transformação a que a potência do rotor $\mathrm{P}_{\mathrm{r}}$ passará até sua conversão em potência de bombeamento $\mathrm{P}_{\mathrm{b}}$.

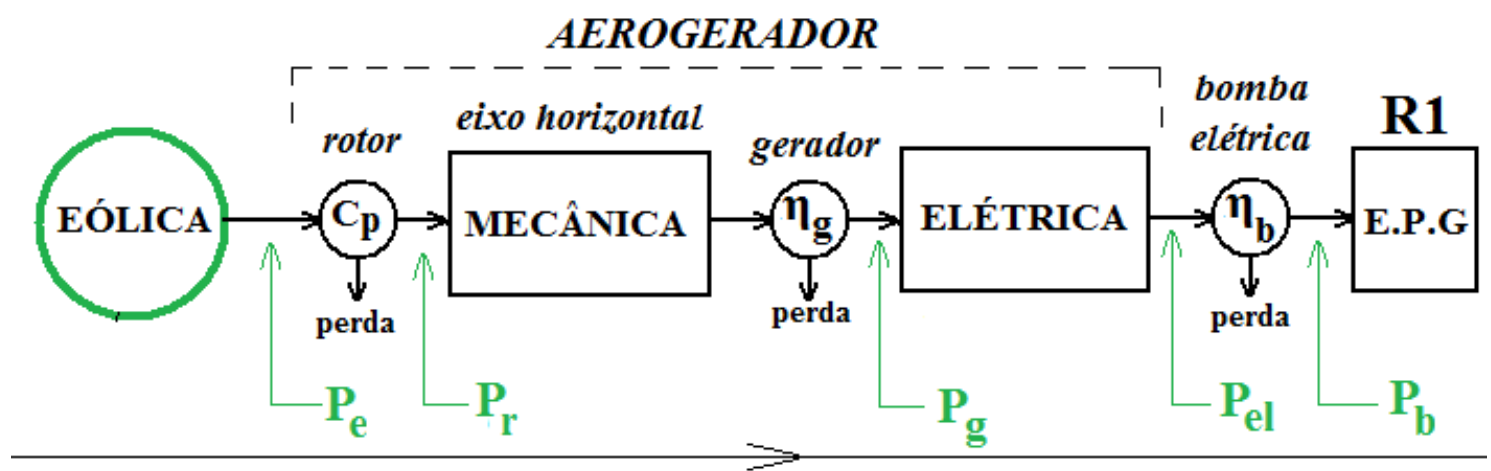

Fig. 4.13: Transformações de potência na cadeia de bombeamento eólico com aerogerador.

Tendo em conta os rendimentos do gerador $\eta_{\mathrm{g}}$ e da bomba elétrica $\eta_{\mathrm{b}}$ na cadeia de transformações, Fig. 4.13, a potência de bombeamento será dada por:

$\mathrm{P}_{\mathrm{b}}=\operatorname{Pr} . \eta_{\mathrm{g}} \cdot \eta_{\mathrm{b}}$

Ou seja, a potência de bombeamento do sistema com aerogerador é:

$P_{b}=C_{p} 1 / 2 \rho A V^{3} \eta_{g} \cdot \eta_{b}$

Em termos teóricos, a Eq. 4.19 traduz a potência de bombeamento no fim da cadeia do sistema 2. Entretanto, na prática, a agregar ao $\boldsymbol{\eta}_{\mathbf{g}} \cdot \boldsymbol{\eta}_{\mathbf{b}}$, ainda existe mais um fator $\boldsymbol{\eta}_{\mathbf{m}}$ (não usado em pequeno porte) que corresponde ao rendimento da caixa de redução de velocidade. Essa caixa geralmente é necessária para que a velocidade de rotação do rotor da turbina seja multiplicado para se atingir valores da ordem de 1800 a $3600 \mathrm{rpm}$ necessários para a rotação do eixo do gerador. 
Para efeito de cálculos, não há necessidade de se conhecer nem o rendimento da caixa de redução nem do gerador elétrico e demais componentes, dado que os fabricantes já fornecem a curva de potência do aerogerador na qual já estão implícitos os rendimentos das engrenagens que conectam o eixo da turbina ao do gerador.

Assim, apesar de se ter apresentado a Eq. 4.18, pode-se proceder de outra forma para determinar a potência de bombeamento $\mathrm{P}_{\mathrm{b}}$ nos cálculos que serão feitos para dimensionar o sistema para atender a demanda de água dessalinizada.

Seguindo essa alternativa, há que primeiramente avaliar a performance da máquina eólica, registrar a potência elétrica por ela fornecida e, em seguida, de posse dessa potência, avaliar o desempenho da conexão com a bomba elétrica que irá colocar a água no reservatório superior R1.

A potência, fornecida por uma turbina eólica, varia com a velocidade do vento e cada turbina tem uma caráterística de desempenho designada curva de potência. Com tal curva é possível prever a produção de energia duma turbina sem ter em conta os detalhes técnicos dos seus vários componentes (MANWELL et al, 2002). A curva de potência dá a potência elétrica fornecida como função do vento à altura do eixo do rotor (MANWELL et al, 2002). A Fig. 4.14 apresenta um exemplo de uma curva de potência de uma turbina hipotética.

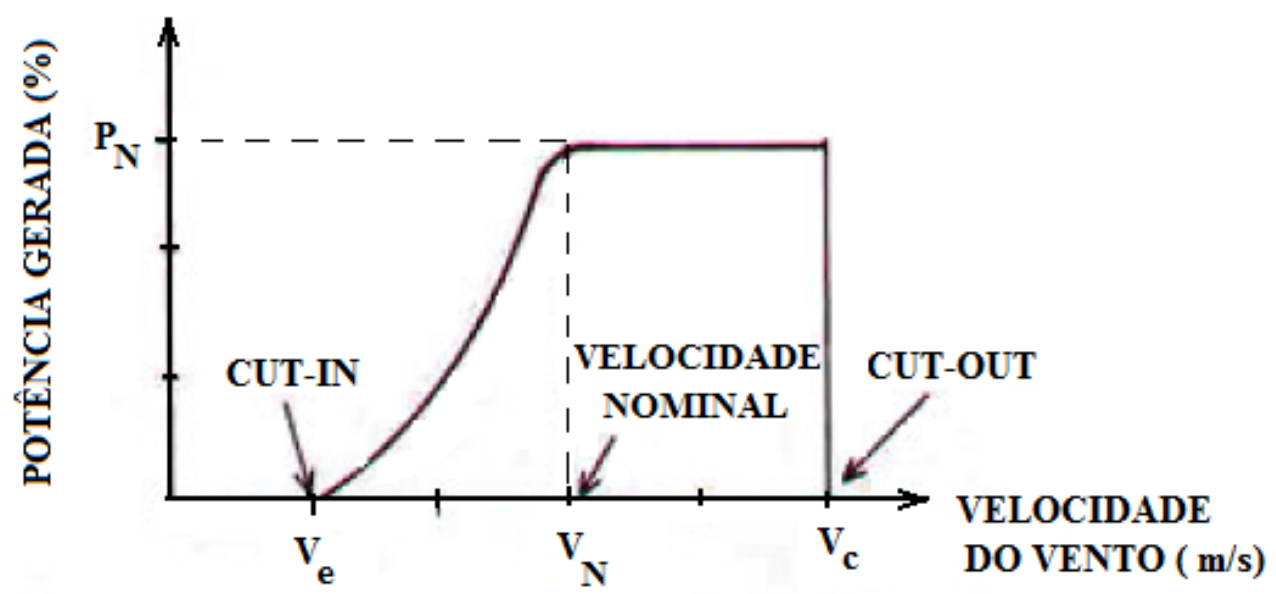

Fig. 4.14: Curva de potência típica de uma turbina eólica. 
O desempenho de um dado gerador de uma turbina eólica pode ser relacionado com três pontos chave na escala de velocidade (MANWELL et al, 2002) :

- A velocidade de entrada $V_{\text {e }}($ Cut-in): velocidade mínima a partir da qual a turbina fornecerá potência útil (entre 2,5 a 3,5 m/s ).

- Velocidade nominal do vento $\mathbf{V}_{\mathbf{N}}$ : Velocidade do vento a que a se atinge a potência nominal (geralmente a máxima potência fornecida pelo gerador elétrico).

- Velocidade de corte $\mathbf{V}_{\mathbf{c}}$ (Cut-out): Velocidade do vento a partir da qual a turbina é desligada para evitar probemas estruturais.

Curvas de potência de turbinas são fornecidas pelos fabricantes. As curvas são construídas a partir de testes de campo, através de métodos padronizados. Também é possível estimar a forma aproximada da curva de potência de uma dada máquina. Esse processo não é uma tarefa fácil porque envolve a determinação da potência caráterística do rotor e do gerador elétrico, razões da caixa de velocidades, e a eficiência dos componentes (MANWELL et al, 2002) .

Nas próximas seções, faz-se três abordagens para a estimativa da produção de eletricidade obtida com uma turbina eólica operando num lugar com um determinado regime de vento:

1- usando técnica estatística ( distribuição de Rayleigh para turbina ideal ).

2- usando técnica estatística ( distribuição de Weibull para turbina real ).

3- uso direto de dados coletados (velocidade média) como variável de entrada para curva de potência da turbina.

A primeira abordagem permite avaliar a máxima potência elétrica que se poderia conseguir com uma turbina, conhecendo a velocidade média do lugar. A segunda e a 
terceira abordagens dão aproximações bastante razoáveis da potência elétrica real fornecida pelo aerogerador.

\subsection{1 -Estimativa da produção duma turbina através de técnicas estatísticas}

Para uma regime de distribuição probabilística p (V), e uma curva de potência de uma turbina $\mathrm{P}_{\mathrm{el}}(\mathrm{V})$, a potência média da máquina eólica $\mathrm{P}_{\mathrm{elm}}$ é dada por (MANWELL et al, 2002) :

$\mathrm{P}_{\mathrm{elm}}=\int_{0}^{\infty} \mathrm{P}_{\mathrm{el}}(\mathrm{V}) \mathrm{p}(\mathrm{V}) \mathrm{dV}$

A expressão para $\mathrm{P}_{\mathrm{el}}(\mathrm{V})$, é dada por:

$\mathrm{P}_{\mathrm{el}}(\mathrm{V})=1 / 2 \rho \mathrm{A} \mathrm{C}_{\mathrm{p}} \eta \mathrm{V}^{3}$

onde:

- $\boldsymbol{\eta}$ é a eficiência da transmissão (potência do gerador/potência do rotor)

- $C_{p}$ é o coeficiente de potência do rotor.

- $\boldsymbol{\rho}$ é a densidade do ar

- $\boldsymbol{A}$ é área varrida pelo rotor

- $\boldsymbol{V}$ é a velocidade do vento

Assumindo um valor constante para a eficiência da transmissão $\boldsymbol{\eta}$, outra expressão para a potência média de uma turbina é dada por:

$\mathrm{P}_{\mathrm{elm}}=\frac{1}{2} \rho \mathrm{A} \eta \int_{0}^{\infty} \mathrm{C}_{\mathrm{p}}(\lambda) \mathrm{V}^{3} \mathrm{p}(\mathrm{V}) \mathrm{d}(\mathrm{V})$

onde $\lambda$ é a razão de velocidade de ponta da pá (definida pela Eq. 4.8, $\lambda=\Omega \mathrm{R} / \mathrm{V}$ ) de que depende o coeficiente de potência $\boldsymbol{C}_{\boldsymbol{p}}$.

De posse da Eq. 4.17, está-se em condições de usar os métodos estatísticos (distribuições $\boldsymbol{P}(\boldsymbol{V})$ de Rayleigh e de Weibull) para estimar a produção de energia de 
uma dada turbina eólica num determinado lugar com um mínimo de informação (MANWELL et al, 2002) .

\subsubsection{1-Produtividade ideal de uma turbina usando a distribuição de Rayleigh}

Uma medida da máxima produção média anual possível com um dado diâmetro de rotor, pode ser calculado assumindo uma turbina ideal e usando a função de densidade de probabilidade de Rayleigh (MANWELL et al, 2002). Segundo (MANWELL et al, 2002), a análise baseada no trabalho de Carlin (1997), assume o seguinte:

- Turbina ideal $(\boldsymbol{\eta}=1)$, sem perdas, coeficiente de potência da máquina igual ao limite de Betz, $\boldsymbol{C}_{\boldsymbol{p} \text { Betz }}=16 / 27$.

- A distibuição de probabilidade da velocidade do vento é dada pela distribuição de Rayleigh

A potência média da turbina é dada pela Eq. 4,17, e para a distribuição de Rayleigh tem-se:

$\mathrm{P}_{\mathrm{elm}}=\frac{1}{2} \rho \mathrm{A} \eta \int_{0}^{\infty} \mathrm{C}_{\mathrm{p}}(\lambda) \mathrm{V}^{3}\left\{\frac{2 \mathrm{~V}}{\mathrm{~V}_{\mathrm{c}}^{2}} \exp \left[-\left(\frac{\mathrm{V}}{\mathrm{V}_{\mathrm{c}}}\right)^{2}\right]\right\} \mathrm{dV}$

onde $\mathbf{V}_{\mathbf{c}}$ é uma velocidade caráterística dada por:

$V_{c}=2 \frac{V_{m}}{\sqrt{\pi}}$

Segundo (MANWELL et al, 2002), Carlin prossegue a análise a partir da Eq. 4.23 tendo em conta as premissas assimidas e que $\mathrm{A}=\pi \mathrm{D}^{2} / 4$, e chega a seguinte equação para a potência produzida pela turbina :

$P_{\text {elm }}=\rho(2 / 3 D)^{2} V_{m}^{3}$ 
De acorco com (MANWELL et al, 2002), Carlin chamou a Eq. 4.24 de equação umdois-três! (a densidade está elevada à primeira potência).

Para um exemplo numérico, pode-se calcular a produção anual média de uma máquina eólica Rayleigh-Betz com diâmetro de 18 metros ao nível do mar com uma velocidade do vento média anual de $6 \mathrm{~m} / \mathrm{s}$. Usando Eq. 4.24 tem-se:

$P_{\text {elm }}=\left(1.225 \mathrm{~kg} / \mathrm{m}^{3}\right)(2 / 3 \times 18 \mathrm{~m})^{2}(6 \mathrm{~m} / \mathrm{s})^{3}=38,1 \mathrm{~kW}$

Multiplicando esse valor por 8760 horas/ano tem-se uma previsão da produção anual de energia elétrica de 334000 kWh.

Conhecendo o rendimento da conexão do aerogerador com a bomba elétrica, poder-se-ia traduzir essa produção anual, se fosse real, numa potência anual de bombeamento de água até o reservatório superior $\mathrm{R} 1$, ou seja poder-se-ia determinar a quantidade de água bombeada ao longo do ano.

Retomando a Eq. 4.24, tendo em conta que $\mathrm{A}=\pi \mathrm{D}^{2} / 4$, manipulando-a algebricamente, obtem-se, uma equação do tipo $\mathrm{P}=\mathrm{f}(\mathrm{A} ; \mathrm{V})$ que permite avaliar de forma expedita a máxima potência média teórica de um aerogerador que será dado por:

$\mathrm{P}_{\mathrm{elm}}=\rho / \pi(4 / 3)^{2} \mathrm{AV}_{\mathrm{m}}^{3}$

Note-se que a Eq. 4.25 é semelhante à equação $\mathbf{P}_{\mathrm{e}} / \mathbf{A}=\mathbf{0 , 3 8 3 1} \mathbf{V}^{\mathbf{3}}$ apresentada no penúltimo parágrafo da seção 4.4, pelo que comentários idênticos podem ser feitos em relação à mesma. Assim, com essa equação, é fácil estimar a potência fornecida pelo aerogerador colocado num local onde se conhece a velocidade média do vento desde que se saiba, de acordo com resultados práticos, qual é a percentagem do potencial máximo que ele é capaz de fornecer e a área varrida pelo seu rotor.

De forma genérica, ao se considerar o rendimento prático do aerogerador como sendo $\boldsymbol{\eta}$ e computando esse fato na Eq. 4.19-B tem-se:

$\mathrm{P}_{\mathrm{elm}}=\eta \rho / \pi(4 / 3)^{2} \mathrm{AV}_{\mathrm{m}}{ }^{3}$ 
Seguidamente, propõe-se desenvolver a Eq. 4.26 com base em valores prováveis para o rendimento de aerogeradores de pequeno médio e grande porte. Faz-se isso recorrendo à informações que constam na bibliografia especializada na área.

Assim, para máquinas de pequeno porte cita-se (FARRET,1999):

“O rendimento aerodinâmico de uma máquina primária de pequeno tamanho varia, no máximo, entre 40 e 45\%, atingindo, na prática, uma média de 35\%. Além disso, o rendimento de um gerador de corrente contínua é da ordem de 55 a 60\%. Portanto, o rendimento total de um sistema de pequeno porte (poucas centenas de Watts) será na ordem de $20 \%$."

Em relação às máquinas de maior tamanho cita-se (MANWELL et al, 2002, tradução nossa) :

"O rendimento da melhor turbina eólica de eixo horizontal é de $45 \%$ "

Deduz-se que sejam turbinas eólicas de médio e grande porte por serem tais turbinas com alto rendimento, as que as melhores empresas do ramo produzem para atender o mercado que já é competitivo.

Retornando à Eq.4.26, inserindo nela a informação sobre máquinas de pequeno porte $(\eta=20 / 100)$, obtém-se:

$\mathrm{P}_{\mathrm{elm}}=16 / 45 \rho / \pi \mathrm{AV}_{\mathrm{m}}^{3}$

Com $\rho=1,2929$ e $\pi=3,14$, a equação anterior fica:

$P_{\text {elm }}=0,146 \mathrm{AV}_{\mathrm{m}}{ }^{3}$

sendo:

A é a área varrida pelo rotor do aerogerador de pequeno porte

$\mathbf{V}_{\mathbf{m}}$ a velocidade média do vento que faz suas hélices girar. 
Analogamente, levando a informação $(\boldsymbol{\eta}=45 / 100)$ à Eq. 4.26, obtem-se:

$\mathrm{P}_{\mathrm{elm}}=16 / 20 \rho / \pi \mathrm{AV}_{\mathrm{m}}{ }^{3}$

E com $\rho=1,2929$ e $\pi=3,14$, a equação anterior fica:

$P_{\text {elm }}=0,329 \mathrm{AV}_{\mathrm{m}}^{3}$

Concluindo, as Eqs 4.28 e 4.30 permitem, com poucos dados e rapidamente, avaliar o potencial "real" de um aerogerador de pequeno porte ( Eq. 4.28 ) ou de médio e grande porte ( Eq. 4.30 ) operando, com rendimentos de $20 \%$ e $45 \%$ respectivamente, num local cuja velocidade média do vento a altura do rotor é conhecida. Caso o rendimento seja outro, sugere-se usar a Eq. 4.26 para essa avaliação prática.

\subsubsection{2-Produtividade real de uma turbina usando a distribuição de Weibull}

De forma semelhante ao que se apresentou na seção anterior, a potência média de uma turbina usando a Eq. 4.20 é dada por:

$\mathrm{P}_{\mathrm{elm}}=\int_{0}^{\infty} \mathrm{P}_{\mathrm{el}}(\mathrm{V}) \mathrm{p}(\mathrm{V}) \mathrm{dV}$

Com base na função de distribuição cumulativa e a distribuição de Weibull, pode-se calcular a potência média através da seguinte expressão (MANWELL et al, 2002) :

$\mathrm{P}_{\mathrm{elm}}=\sum_{\mathrm{j}=1}^{\mathrm{N}_{\mathrm{B}}}\left\{\exp \left[-\left(\frac{\mathrm{V}_{\mathrm{j}-1}}{\mathrm{c}}\right)^{\mathrm{k}}\right]-\exp \left[-\left(\frac{\mathrm{V}_{\mathrm{j}}}{\mathrm{c}}\right)^{\mathrm{k}}\right]\right\} \mathrm{P}_{\mathrm{el}}\left(\frac{\mathrm{V}_{\mathrm{j}-1}+\mathrm{V}_{\mathrm{j}}}{2}\right)$

sendo:

$\mathbf{N}_{\mathbf{B}}$ é o número de partições do intervalo,

V é a velocidade do vento,

$\mathbf{k}$ é o fator de forma,

c é o fator de escala. 
De acordo com (MANWELL et al, 2002), para valores de $\boldsymbol{k}$ entre um e dez, pode-se determiná-lo através da seguinte expressão:

$k=\left(\frac{\sigma_{V}}{V_{m}}\right)^{-1,086}$

Sendo $\boldsymbol{\sigma}_{\mathbf{v}}$ o desvio padrão, e $\mathbf{V}_{\mathbf{m}}$ a velocidade média. Com o valor de $\boldsymbol{k}$ calculado com a Eq. 4.22, acha-se o valor de $\boldsymbol{c}$ usando a seguinte aproximação:

$\frac{c}{V_{m}}=(0,568+0,433 / k)^{\frac{-1}{k}}$

Retomando a análise da Eq. 4.22, ela é equivalente à seguinte:

$\mathrm{P}_{\mathrm{elm}}=\frac{1}{N} \sum_{\mathrm{j}=1}^{\mathrm{N}_{\mathrm{B}}} \mathrm{P}_{\mathrm{el}}\left(m_{j}\right) \cdot f_{j}$

onde :

$\mathbf{m}_{\mathbf{j}}$ é o ponto médio do intervalo entre as velocidades $\mathrm{V}_{\mathrm{j}-1}$ e $\mathrm{V}_{\mathrm{j}}$.

$\mathbf{f}_{\mathbf{j}}$ é a frequência relativa, de forma que $\mathbf{N}$ é igual ao somatório de 1 até $\mathrm{N}_{\mathrm{B}}$ de $\mathrm{f}_{\mathrm{j}}$.

Conhecendo a potência elétrica fornecida pelo aerogerador e, tendo em conta o rendimento $\boldsymbol{\eta}_{\mathbf{b}}$ da bomba elétrica que será alimentada por esse aerogerador obtém-se a seguinte expressão para a potência de bombeamento:

$P_{b}=\left[\frac{1}{N} \sum_{j=1}^{N_{B}} P_{e l}\left(m_{j}\right) \cdot f_{j}\right] \eta_{b}$

O rendimento $\boldsymbol{\eta}_{\mathbf{b}}$ da bomba, que figura na Eq. 4.26, será, naturalmente, dependente da altura a que estiver o reservatório R1. De posse da curva de rendimento da bomba elétrica pode-se determinar o ponto ótimo de operação dado que durante o bombeamento até o reservatório as condições da carga (altura manométrica e caudal) podem ser mantidas constantes. 


\subsubsection{3-Produtividade real de uma turbina usando diretamente os dados coletados}

De posse de uma série de $\mathrm{N}$ observações da velocidade do vento, sendo $\mathrm{V}_{\mathrm{j}}$ a velocidade média no intervalo $\Delta \mathrm{t}$, esses dados podem ser usados para determinar os seguintes parâmetros úteis (MANWELL et al, 2002) :

- A velocidade média do vento ao longo de todo o período de coleta de dados é:

$V_{m}=\frac{1}{N} \sum_{j=1}^{N} V_{j}$

- A densidade de potência eólica é a média disponível da velocidade do vento por unidade de área e é dada por:

$\frac{P_{m}}{A}=\frac{1}{2} \rho \frac{1}{N} \sum_{j=1}^{N} V_{j}^{3}$

- A potência média da máquina eólica é dada por:

$P_{e l m}=\frac{1}{N} \sum_{j=1}^{N} P_{e l}\left(V_{j}\right)$

Onde, $\mathrm{P}_{\mathrm{elm}}\left(\mathrm{V}_{\mathrm{j}}\right)$ é a potência definida pela curva de potência do aerogerador.

- A energia elétrica $E_{\text {el }}$ gerada pelo aerogerador é dada por:

$\mathrm{E}_{\mathrm{el}}=\sum_{\mathrm{j}=1}^{\mathrm{N}} \mathrm{P}_{\mathrm{el}}\left(\mathrm{V}_{\mathrm{j}}\right)(\Delta \mathrm{t})$

Conhecendo a potência elétrica média da máquina eólica, Eq. 4.29 e, tendo em conta o rendimento $\boldsymbol{\eta}_{\mathbf{b}}$ da bomba elétrica obtém-se a seguinte expressão para a potência de bombeamento:

$\mathrm{P}_{\mathrm{b}}=\left[\frac{1}{\mathrm{~N}} \sum_{\mathrm{j}=1}^{\mathrm{N}} \mathrm{P}_{\mathrm{el}}\left(\mathrm{V}_{\mathrm{j}}\right)\right] \eta_{\mathrm{b}}$ 
Na prática, a aplicação das Eqs 4.26 e 4.31 que dão a conversão da potência elétrica obtida pelo aerogerador em potência de bombeamento $\mathbf{P}_{\mathbf{b}}$, há que ter em conta alguns detalhes de projeto para que se tenha um sistema de bombeamento otimizado. Dentre esses aspectos destacam-se os seguintes:

- Se a geração da turbina é em corrente contínua, é conveniente ter um motor de corrente contínua. Essa escolha evita a necessidade de conversão para corrente alternada.

- Se a geração da turbina é em corrente alternada, é conveniente ter um motor de corrente alternada (motor de indução por exemplo). Essa escolha evita a necessidade de retificação da energia gerada.

- No caso da geração ser em corrente alternada, dependendo do porte da unidade, o aerogerador a ser escolhido poderá ser de ímã permanente. Essa escolha dispensa o consumo de corrente pelo circuito de excitação.

Além desses aspectos, outros mais influenciam a decisão pela melhor combinação aerogerador-bomba elétrica tais como o custo dos equipamentos e regime de vento do local da instalação. Especificamente em relação ao bombeamento, uma opção razoável, para se ter uma boa combinação entre o aerogerador e a bomba, é a consulta de projetos desse tipo já testados que tenham apresentado bons resultados. Essa opção é sensata dado que a tecnologia de bombeamento elétrico é já consagrada e o funcionamento da coluna de potência hidráulica só depende da existência de água no reservatório R1.

\section{7-Conversão da potência de bombeamento em energia potencial gravitacional}

Após a determinação da potência de bombeamento, há que se conhecer a vazão de água bombeada em função da altura manométrica $\mathrm{H}_{\mathrm{m}}$, bem como o volume $\mathrm{V}$ de água armazenado no reservatório superior R1, Fig. 4.15. 


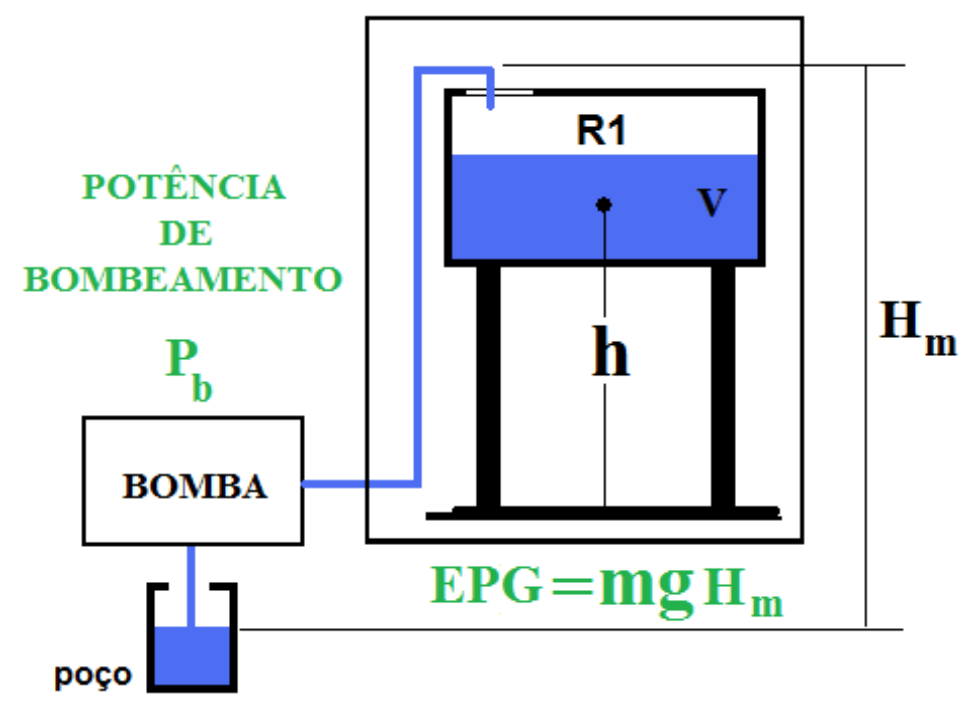

Fig. 4.15: Armazenamento de energia no reservatório R1

A energia $\mathrm{E}_{\text {tra }}$ transferida para a água durante o bombeamento é dada por:

$\mathrm{E}_{\mathrm{tra}}=\mathrm{P}_{\mathrm{b}} \cdot \Delta \mathrm{t}$.

onde $\Delta$ t é o tempo (expresso em segundos) correspondente ao período de operação da bomba considerado.

Essa energia transferida será armazenada sob a forma de energia potencial gravitacional, EPG no reservatório R1. A relação de conversão é dada por:

$\mathrm{E}_{\text {tra }}=\mathrm{EPG}$

ou seja,

$\mathrm{P}_{\mathrm{b}} \cdot \Delta \mathrm{t}=\mathrm{m} \cdot \mathrm{g} \cdot \mathrm{H}_{\mathrm{m}} \cdot$

onde $\mathrm{H}_{\mathrm{m}}$ é a altura manométrica a ser vencida pela bomba para conduzir a água do poço ao reservatório $\mathrm{R} 1$, Fig. 4.15. Na avaliação de $\mathrm{H}_{\mathrm{m}}$ desprezaram-se as perdas hidráulicas na tubulação e na bomba.

Dado que a massa de água bombeada é o produto da sua massa específica pelo seu volume $\left(\mathrm{m}=\rho_{\mathrm{a}} \mathrm{V}\right)$, a Eq. 4.34 transforma-se em: 
$P_{b} \cdot \Delta t=\rho_{a}$ V.g. $H_{m}$.

Resolvendo a Eq. 4.35 para se obter o volume de água bombeado tem-se:

$V=P_{b} \cdot \Delta t /\left(\rho_{a} \cdot g \cdot H_{m}\right)$

onde:

V é o volume de água bombeado $\left[\mathrm{m}^{3}\right]$

$\mathbf{P}_{\mathbf{b}} \quad$ é a potência de bombeamento [W]

$\boldsymbol{\rho}_{\mathbf{a}}$ é a densidade da água. $\quad\left[\mathrm{kg} / \mathrm{m}^{3}\right]$

g é a aceleração da gravidade. $\left[\mathrm{m} / \mathrm{s}^{2}\right]$

$\mathbf{H}_{\mathbf{m}}$ é altura manométrica. [m]

Considerando o tempo de bombeamento de uma hora, a Eq. 4.36 fica:

$\mathrm{V}=3600 \mathrm{P}_{\mathrm{b}} \cdot /\left(\rho_{\mathrm{a}} \cdot \mathrm{g} \cdot \mathrm{H}_{\mathrm{m}}\right)$

Com $\rho_{a}=1025 \mathrm{~kg} / \mathrm{m}^{3}$ correspondente à densidade da água do mar a ser bombeada para $\mathrm{o}$ reservatório superior R1, e $g=9,81 \mathrm{~m} / \mathrm{s}^{2}$, a Eq. 4.37 reduz-se à:

$\mathrm{V}=\mathbf{P}_{\mathrm{b}} /\left(2,790 \mathbf{H}_{\mathrm{m}}\right)$

Da análise da Eq. 4.38 conclui-se que:

- O volume de água V armazenado no reservatório superior R1 (EPG armazenada) é diretamente proporcional à percentagem do potencial eólico $\% \mathrm{P}_{\mathrm{e}}$ convertido em potência de bombeamento $P_{b}$.

- V é inversamente proporcional à altura manométrica $H_{m}$ (não contabilizando as perdas hidráulicas na tubulação e na bomba).

De posse da Eq. 4.38, conhecendo a altura a que estiver o reservatório superior R1, e o nível da água no poço reúne-se duas condições que permitem determinar o número de 
cataventos ou de aerogeradores necessários, em função da demanda diária de água dessalinizada ou de eletricidade. Esse procedimento será seguido no capítulo 6, no qual apresenta-se estudos de caso.

Além dos dados necessários para a Eq. 4.38, à semelhança de sistemas eólicos para geração de energia elétrica (FADIGAS,2004), "é importante que a determinação do regime dos ventos seja feita com a maior exatidão possível" para que se disponha de dados que permitam o dimensionamento adequado do sistema de bombeamento de água para R1.

\section{8-Comentários e comparação qualitativa dos dois sistemas}

Para seguir a análise, retorna-se às Figs 4.4 e 4.5 que apresentam os diagramas dos sistemas 1 e 2. Tendo em conta a Eq. 4.38 [ $\mathbf{V}=\mathbf{P}_{\mathbf{b}} /\left(\mathbf{2 , 7 9 0} \mathbf{H}_{\mathbf{m}}\right)$ ], que dá o volume de água armazenado no reservatório $\mathrm{R} 1$ da $\mathrm{CPH}$, infere-se que um catavento (sistema 1S1) e um aerogerador (sistema 2 - S2), com a mesma área varrida pelas pás, operando num mesmo regime de vento, para alimentar o reservatório $\mathrm{R} 1$ da $\mathrm{CPH}$, será mais eficiente o sistema cuja cadeia de transformação da energia eólica em potência de bombeamento fornecer melhor resultado.

S1 apresenta a vantagem de ser mais simples e de manutenção menos especializada. Para um sistema de médio e grande porte o catavento apresenta a vantagem de poder operar com velocidades de vento inferiores à velocidade de partida do aerogerador. Além disso, geralmente os cataventos continuam operando com velocidades superiores às de corte para as quais os aerogeradores são travados por questões mecânicas e para proteger o gerador.

Deduz-se que o custo de instalação e de operação de S1 seja menor do que o de S2. Isso porque um aerogerador de porte igual ao de um catavento ( mesma área varrida pelas pás), além de ser mais caro, sua manutenção exige mão de obra especializada.

S2 apresenta a vantagem de se poder situar a máquina eólica num local apropriado com maior potencial eólico não havendo a necessidade de se tê-la junto do poço de captação de água. Além disso, se o sistema for de grande porte, com S2 não há a necessidade de 
se furar vários poços (como o caso de um por catavento) dado que facilmente se conectam eletricamente as turbinas eólicas para alimentar uma única bomba situada junto a um único poço. Em suma S2 é mais versátil do que S1.

Em relação à geração de eletricidade com a $\mathrm{CPH}$ alimentando uma turbina Pelton, o uso de um aerogerador $(\mathrm{S} 2)$ para abastecer R1 parece ser um retrocesso uma vez que já se tem eletricidade fornecida pelo aerogerador. Entretanto, o recurso a esse sisetema, permite contornar o problema da intermitência do vento através do armazenamento de água em R1 dispensando o uso de baterias. Consegue-se assim uma regularização da energia eólica através do armazenamento hidráulico.

A alternativa de armazenar água em R1, ao invés de armazenar eletricidade em baterias, além de ser mais simples, tem um custo menor de instalação, operação e manutenção.

Face a essa aparente ineficiência de S2 para a geração de eletricidade (o citado “retrocesso"), é interessante vislumbrar uma variante S2'. Nessa variante, a potência mecânica do eixo do rotor da turbina eólica $\mathrm{P}_{\mathrm{r}}$ seria usada diretamente para $\mathrm{o}$ bombeamento de água até R1. Posteriormente, com a energia potêncial armazenada, a CPH geraria a pressão e vazão para alimentar a turbina Pelton. As vantagens da variante S2’ seriam:

- Tirar proveito do maior coeficiente de potência $C_{p}$ da turbina eólica em relação ao catavento.

- Não haver a necessidade de travar a turbina quando a velocidade do vento atingir a de corte (cut-out). Assim, aproveitar-se-ia mais o potencial eólico.

Como citado previamente, se S1 e S2 estiverem a operar com condições idênticas em relação à velocidade do vento (ex: velocidade constante de $7 \mathrm{~m} / \mathrm{s}$ ), exceto se o produto dos rendimentos das transformações a mais que ocorrem com o aerogerador seja superior ao rendimento do mecanismo de bombeamento do catavento S2 terá melhor desempenho que S1.

De acordo com a empresa Southwest Windpower, o estado da arte a que chegaram permite-lhes colocar no mercado (o equivalente a S2) um sistema de bombeamento 
eólico-elétrico (wind-electric water pumper) capaz de bombear um volume de água quatro vezes superior ao de um catavento (S1) nas mesmas condições de vento. $\mathrm{O}$ sistema usa uma bomba centrífuga trifásica submersível ou de superfície com 3/4 HP de potência conectada à 230 VAC. O diâmetro do rotor é de $3 \mathrm{~m}$ e a velocidade de arranque da turbina é de $3,1 \mathrm{~m} / \mathrm{s}$ e o pico de potência de $1000 \mathrm{~W}$ é atingido à velocidade do vento de $10,5 \mathrm{~m} / \mathrm{s}$.

Em relação à área ocupada, suponha-se que, nas mesmas condições do vento, com a S2 se consegue (de acordo com a Southwest Windpower ) bombear quatro vezes mais água do que com $\mathrm{S} 1$. Significa assim ter quatro vezes mais água em R1 com S2 do que com $\mathrm{S} 1$, ou seja, mais energia potêncial gravitacional disponível. Se se quiser compensar essa diferença através de alterações no projeto de $\mathrm{S}$ 1, bastaria aumentar o diâmetro do rotor do catavento para que ele captasse mais energia eólica. Contudo, visto que a área varrida pelo rotor é proporcional ao quadrado do diâmetro do rotor, seria necessário um pequeno aumento que não teria uma alteração apreciável na base da torre em termos de ocupação do terreno. Em relação volume de água em R1, seria suficiente aumentar a altura do mesmo para que comportasse quatro vezes mais água. Deduz-se assim que, não é significativa a diferença de área ocupada entre os dois sistemas S1 e S2.

Ainda para fins comparativos de caráter quantitativo e qualitativo, retoma-se, neste ponto, as equações apresentadas que expressam a potência de bombeamento de cataventos (S1) e a potência elétrica de um aerogerador (S2) com rendimento de $45 \%$ :

$\mathrm{P}_{\mathrm{b}}=0,1 \quad \mathrm{~A} \mathrm{~V} \mathrm{~V}^{3}$

$\mathrm{P}_{\mathrm{elm}}=0,329 \mathrm{~A} \mathrm{~V}_{\mathrm{m}}^{3}$

Constata-se que tem-se em torno de 3,3 vezes mais potência elétrica fornecida pelo aerogerador do que a potência de bombeamento do catavento. Se se admitir um rendimento de $85 \%$ da bomba elétrica que seria alimentada pelo aerogerador, ter-se-ia uma potência de bombeamento do sistema S2 cerca de 3 vezes maior do que a do sistema S1. Isso significa que, nessas condições, S2 bombearia para o reservatório R1 um volume de água cerca de 3 vezes maior do que o que S1 bombearia. 
Embora esses cálculos não confirmem a afirmação da empresa a Southwest Windpower (quatro vezes mais água com S2 do que com S1 para o mesmo vento) é prudente avançar que, na prática, é possível que isso se confirme.

Finda a avaliação qualitativa dos dois sistemas, apresenta-se novamente na Fig. 4.16 o esquema geral do modelo com o intuito de se ter uma visão global do que até aqui foi abordado e do que será apresentado no capítulo 5.

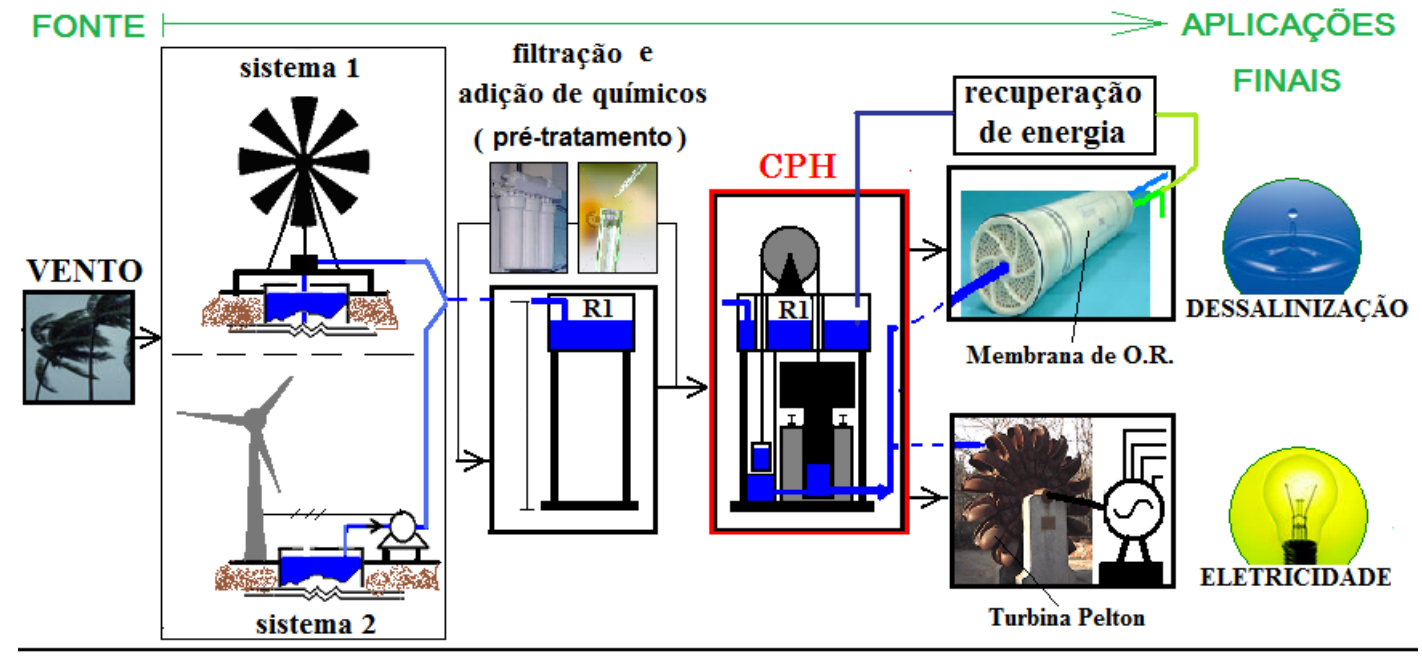

Fig. 4.16: Modelo da CPH.

Este capítulo teve o objetivo de apresentar uma abordagem (modelagem matemática) do recurso eólico e das duas tecnologias usadas pelo sistema (catavento-sistema 1 e aerogerador-sistema 2) para captar a energia do vento e armazená-la sob forma de energia potencial gravitacional no reservatório superior R1. Após a apresentação das equações referentes à potência de bombeamento conseguida através dos dois sistemas, mostrou-se como tal potência é convertida em volume de água armazenado em R1 durante um determinado período de tempo (dia, mês etc). Esse volume de água acumulado traduz-se em energia que será usado pela CPH para proporcionar um fluxo de água com alta pressão.

O referido fluxo com alta pressão que equivale a uma potência hidráulica terá duas aplicações: dessalinização por osmose reversa (O.R) através de membrans e geração de energia elétrica através de turbina Pelton são as aplicações do sistema que serão abordadas no próximo capítulo. 
A recuperação de energia ( necessária só para a O.R) é feita através da bomba-Clark. A filtração (pré-tratamento) é projetada para ser por gravidade junto à R1 e a adição de químicos, se necessária, também será feita em R1. Refere-se que foi divulgado em 2008 um projeto denominado "drinking with the wind" (RABINOVITCH, 2008) desenvolvido na universidade tecnológica holandesa Delft, com capacidade de dessalinizar $10 \mathrm{~m}^{3} \mathrm{de}$ água por dia, no qual, não há adição de químicos no pré-tratamento devido à baixa taxa de recuperação de água (cerca de 20 litros de água potável por 100 litros de água do mar). 


\section{CAPÍTULO 5}

\section{APLICAÇÕES DA CPH : OSMOSE REVERSA E GERAÇÃO DE ELETRICIDADE}

\section{1- Introdução}

Neste capítulo, retoma-se a apresentação da configuração alternativa para a dessalinização por osmose reversa ou/e geração de energia elétrica com recurso ao modelo renovável apresentado no capítulo 2, e retomado no final do capítulo 4 (Figs 2.1 e 4.16). Em relação à produção de água potável, faz-se uma breve menção dos processos mais usados em plantas de dessalinização de água com destaque para a osmose reversa. Em relação à geração de eletricidade, faz-se uma abordagem das turbinas hidráulicas, com especial referência às Pelton por melhor se adaptarem ao modelo.

Além da apresentação e desenvolvimento do modelo concebido, encerrando o capítulo, faz-se referência aos fluxos de energia que acompanham os processos que ocorrem no sistema. Essa abordagem será feita com base nos diagramas de Sankey do sistema 1 (bombeamento com cataventos) e do sistema 2 (bombeamento com o grupo aerogerador-bomba elétrica).

\section{2- Dessalinização}

O panorama mundial da distribuição de água potável no planeta Terra atesta a escassez desse bem tão precioso. Uma solução para atender às necessidades das populações é o recurso à dessalinização quer de águas subterrâneas, quer da água do mar. Os oceanos contêm cerca de $95 \%$ de toda a água do planeta. A percentagem dos sais dissolvidos na água do mar encontra-se esquematizado na Fig. 5.1. 


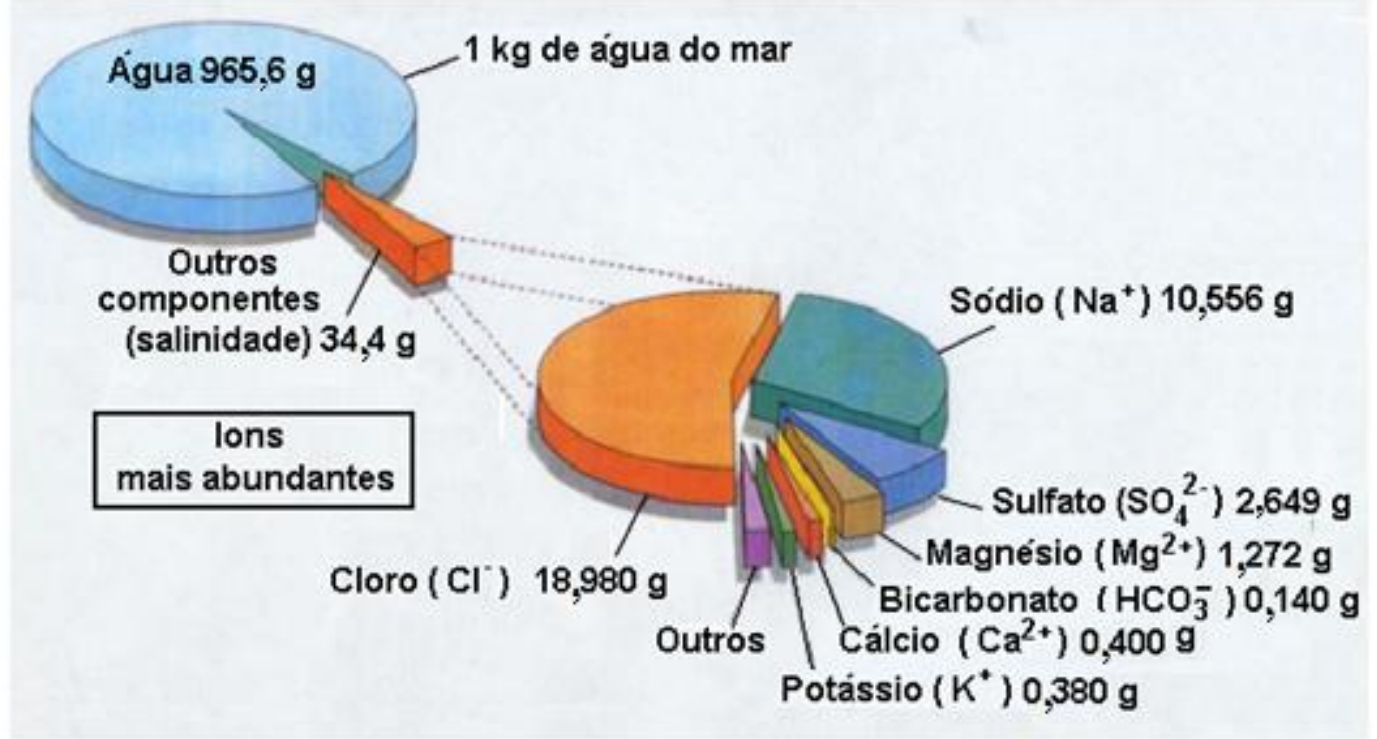

Fig. 5.1: Composição da água do mar. Fonte: PROPERTIES [...].

Para que se possa extrair os sais dissolvidos na água, é necessária uma determinada quantidade de energia. Por outras palavras, para se dessalinizar a água "paga-se" com o dispêndio de energia. A Fig. 5.2 esquematiza o processo de obtenção de água potável a partir de água salina.

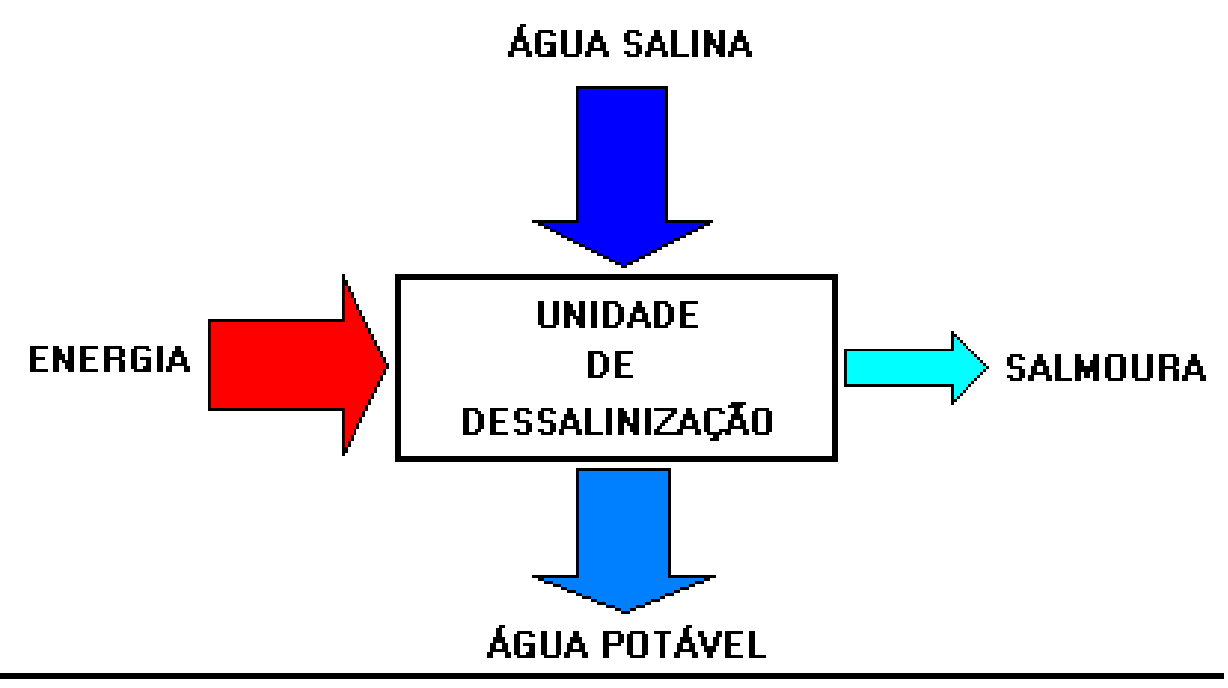

Fig. 5.2: Esquema simplificado de uma unidade de dessalinização.

A quantidade de energia utilizada para dessalinizar um metro cubico de água (consumo específico, $\mathrm{kWh} / \mathrm{m}^{3}$ ), varia de acordo com a capacidade de produção da unidade (economia de escala), e com o processo de dessalinização usado. 


\subsection{1- Processos de Dessalinização}

Dessalinização é um processo através do qual, a partir de água com elevada concentração de sais (água salobra ou água do mar), obtém-se água com muito menor concentração e própria para o consumo (água potável). Em traços gerais, tem-se um fluxo de água salina (água salobra ou água do mar) à entrada e dois à saída, Fig. 5.2. Um dos fluxos de saída (salmoura) tem uma concentração superior à do fluxo de entrada e o outro (água potável) tem concentração bem menor. Existem vários processos de dessalinização, sendo os mais usados atualmente, os seguintes:

- MSFD- Multi-Stage-Flash-Distillation (Destilação Instantânea por MúltiplasEtapas) ou simplesmente MSF.

- MED-Multi-Efect-Destilation (Destilação por Múltiplos-Efeitos )

- MVC-Mechanical Vapor Compression (Compressão Mecânica de Vapor).

- ELETRODIÁLISE.

- OSMOSE REVERSA (RO, de Reverse Osmosis).

Os três primeiros (MSFD, MED e MVC) são processos térmicos e os dois últimos são processos em que se utilizam membranas.

Dado que uma descrição desses processos foi apresentada em (DIAS, 2004), nesta tese, de forma sucinta, aborda-se só a osmose reversa devido à importância desse processo para o modelo.

\subsection{2-Osmose Reversa}

A osmose reversa (OR) é a inversão de um processo que acontece naturalmente, denominado osmose. A osmose ocorre, quando dois líquidos separados por uma membrana permeável não têm a mesma pressão osmótica. A pressão osmótica é causada pela diferença de concentração de sais existente de um lado e outro da referida membrana, Fig. 5.3. 


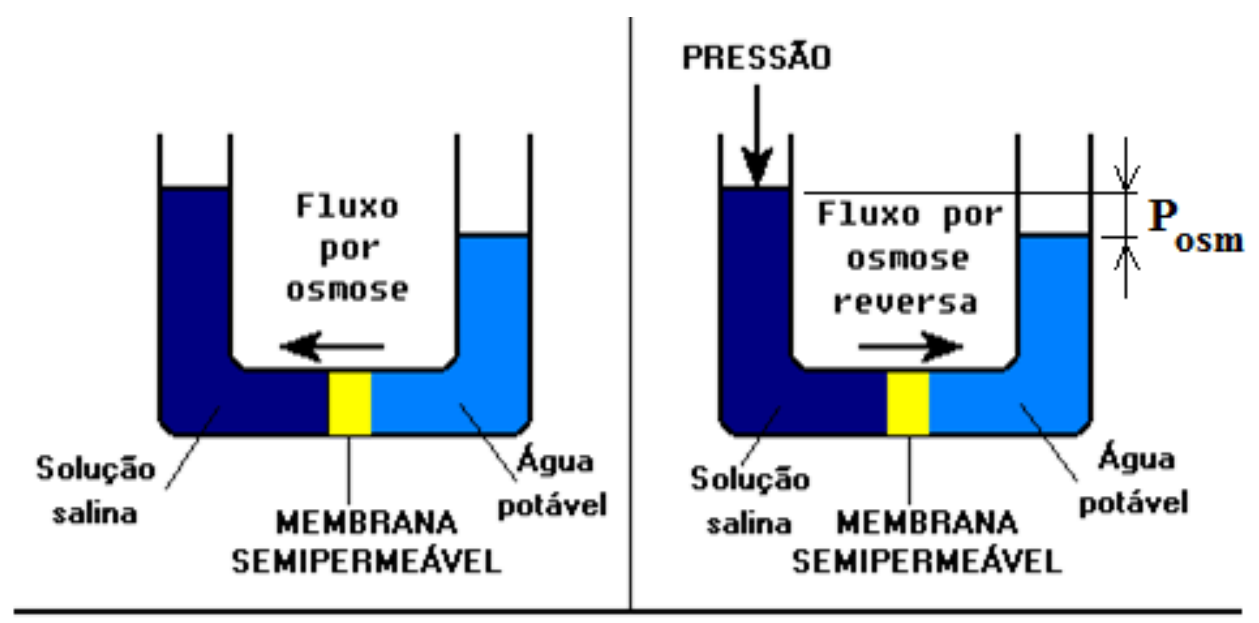

Fig. 5.3: Fluxos por osmose, e por osmose reversa

Em tal situação, há uma tendência natural para que haja um equilíbrio químico. Assim sendo, o líquido atravessa a membrana do lado de menor para o de maior concentração. Consegue-se a inversão desse processo ao submeter o líquido a uma pressão suficientemente elevada (superior à pressão osmótica, $\mathrm{P}_{\mathrm{osm}}$ ) capaz de forçar o seu fluxo no sentido inverso. A membrana usada na osmose reversa tem a capacidade de reter o soluto existente na água, o que permite a obtenção de água potável. A Fig. 5.4 esquematiza uma das possíveis formas de se realizar a osmose reversa.

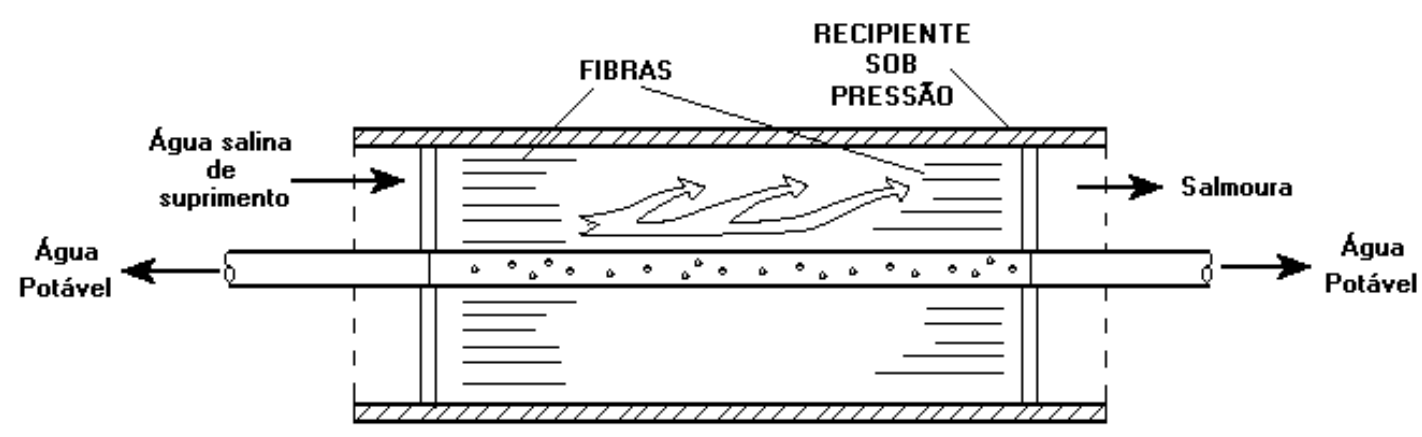

Fig. 5.4: Osmose Reversa.

A água salina entra no módulo com uma pressão alta. Essa pressão força o fluxo de água potável através da membrana que se encontra disposta convenientemente nas paredes externas do tubo central. O referido tubo faz a coleta da água dessalinizada.

Comercialmente, as membranas são encapsuladas em unidades designadas por módulos. Existem três tipos de módulos comerciais: 
- Módulos com placas de membrana

- Módulos tubulares

- Módulos espirais

- Módulos com fibras ocas

Já estão a ser desenvolvidas membranas que prometem uma redução de $30 \%$ do custo de produção de água dessalinizada. Trata-se de membranas obtidas a partir da aglomeração de nanopartículas. Na Fig. 5.5 pode-se ver os principais componentes de uma planta de dessalinização que usa a OR.

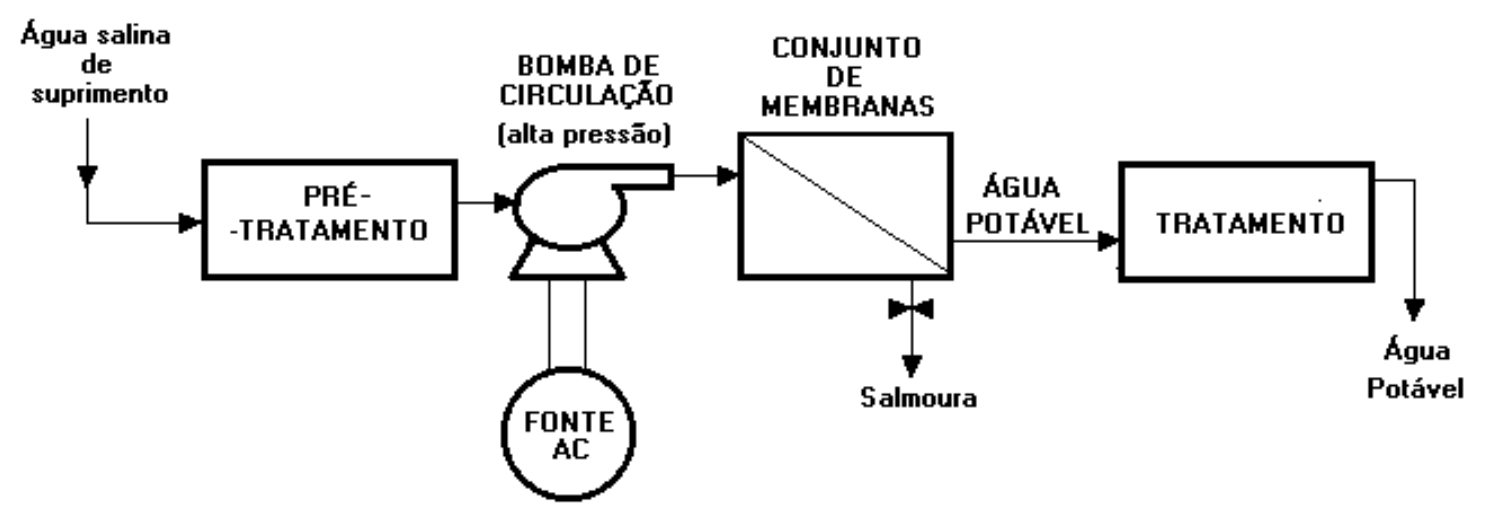

Fig. 5.5: Esquema de uma planta de dessalinização que usa a osmose reversa.

Repare-se que, na configuração convencional de plantas de dessalinização que usam a OR, figura uma bomba de alta pressão, Fig. 5.5. Essa bomba é indispensável porque a pressão da água à entrada do conjunto de membranas deve ultrapassar a pressão osmótica $\mathrm{P}_{\text {osm }}$, para que se consiga osmose reversa. Apesar da pressão mínima para se conseguir a dessalinização da água do mar ser em média 27,5 bar (de acordo com VIABILIDADE [...] ), para que se aumente a produção, as bombas em plantas de dessalinização por OR operam na faixa entre 55 a 70 bar. Para a dessalinização de águas salobras, tem-se sensivelmente metade desse valor. A necessidade de trabalhar com pressões tão elevadas acarreta altos custos de investimento e de operação, destacando-se o alto consumo de energia.

Da comparação entre processos de dessalinização, a OR é o que apresenta um menor consumo específico de energia. Isso, em parte, justifica a escolha desse processo para a dessalinização usando energias renováveis. 


\section{3 -Geração de eletricidade}

No que toca à geração de eletricidade através da Coluna de Potência Hidráulica, CPH, o modelo pode ser visto como uma pequena central hidrelétrica. Para tal, a turbina hidráulica que melhor se adapta é a Pelton pelas caráterísticas de funcionamento nomeadamente de altas pressões. Pelo fato da geração elétrica com tais turbinas ser uma tecnologia há muito consagrada, deduz-se que o essencial é que a CPH garanta um fluxo com uma determinada pressão (compatível com a exigência da turbina) direcionado para as conchas. Segue-se uma breve referência às turbinas com destaque para a Pelton.

As turbinas hidráulicas são projetadas para transformar a energia mecânica (a energia de pressão e a energia cinética) de um fluxo de água, em potência de eixo. Atualmente são mais encontradas em usinas hidrelétricas, onde são acopladas a um gerador elétrico, o qual é conectado à rede de energia. Contudo, também podem ser usadas para geração de energia em pequena escala, para as comunidades isoladas. Em suma, turbina hidráulica refere-se a para máquinas que convertem a energia de um fluxo de água em energia mecânica dada pela rotação de um eixo.

As turbinas hidráulicas dividem-se entre quatro tipos principais: Pelton, Francis, Kaplan, Bulbo. Cada um destes tipos é adaptado para funcionar em usinas, com uma determinada faixa de altura de queda. As vazões volumétricas podem ser igualmente grandes em qualquer uma delas, mas a potência será proporcional ao produto da queda (H) pela vazão volumétrica $(\mathrm{Q})$.

Em todos os tipos há alguns princípios de funcionamento comuns. A água entra pela tomada de água, a montante da usina hidrelétrica que está num nível mais elevado, e é levada através de um conduto forçado até a entrada da turbina. Nas turbinas Pelton, há um bocal injetor com uma agulha móvel, semelhante a uma válvula. O controle da vazão é feito por este dispositivo. Por transferência de quantidade de movimento parte da energia do fluxo é transferida para o rotor na forma de torque e velocidade de rotação.

As turbinas hidráulicas podem ser montadas com o eixo no sentido vertical. Um mancal de escora suporta todo o peso das partes girantes da turbina e do gerador que é montado 
logo acima dela. Em pequenas centrais hidrelétricas $(\mathrm{PCH})$, turbinas são montadas com eixo na horizontal.

A potência $\mathbf{P}$ de uma turbina pode ser calculada por:

$\mathbf{P}=(\rho \mathbf{Q H g}) \eta$

[W]

onde:

$\boldsymbol{\rho}$ é a massa específica da água. $\quad\left[\mathrm{kg} / \mathrm{m}^{3}\right]$

Q é o caudal de água que chega à turbina. $\left[\mathrm{m}^{3} / \mathrm{s}\right]$

H é a altura de queda. [m]

g é a aceleração da gravidade. $\quad\left[\mathrm{m} / \mathrm{s}^{2}\right]$

$\eta$ é a eficiência total da turbina.

Tipicamente turbinas modernas têm uma eficiência entre $85 \%$ e $99 \%$, que varia conforme a vazão de água e a potência gerada.

Para o caso do modelo de CPH a potência pode ser avaliada através do jato de água bombeado com a pressão imposta pelo êmbolo especial. A dedução da equação é apresentada numa próxima seção.

\subsection{1: Tipos de turbinas}

Turbinas podem ser classificadas em dois grupos básicos:

\section{De impulso ou ação}

Em condições ideais, há apenas mudança da direção do fluxo ao passar pelo rotor da turbina, sem variação de pressão. Portanto, a magnitude da velocidade do fluxo é constante. 


\section{De reação}

O fluxo sofre variação de velocidade ao passar pelo rotor da turbina.

\section{Turbina Pelton.}

Inventada pelo americano Lester Allan Pelton na década de 1870, é uma típica turbina de impulso. A Fig. 5.6 contém partes da imagem de domínio público da ilustração da patente original e mostra o esquema de funcionamento da turbina Pelton.

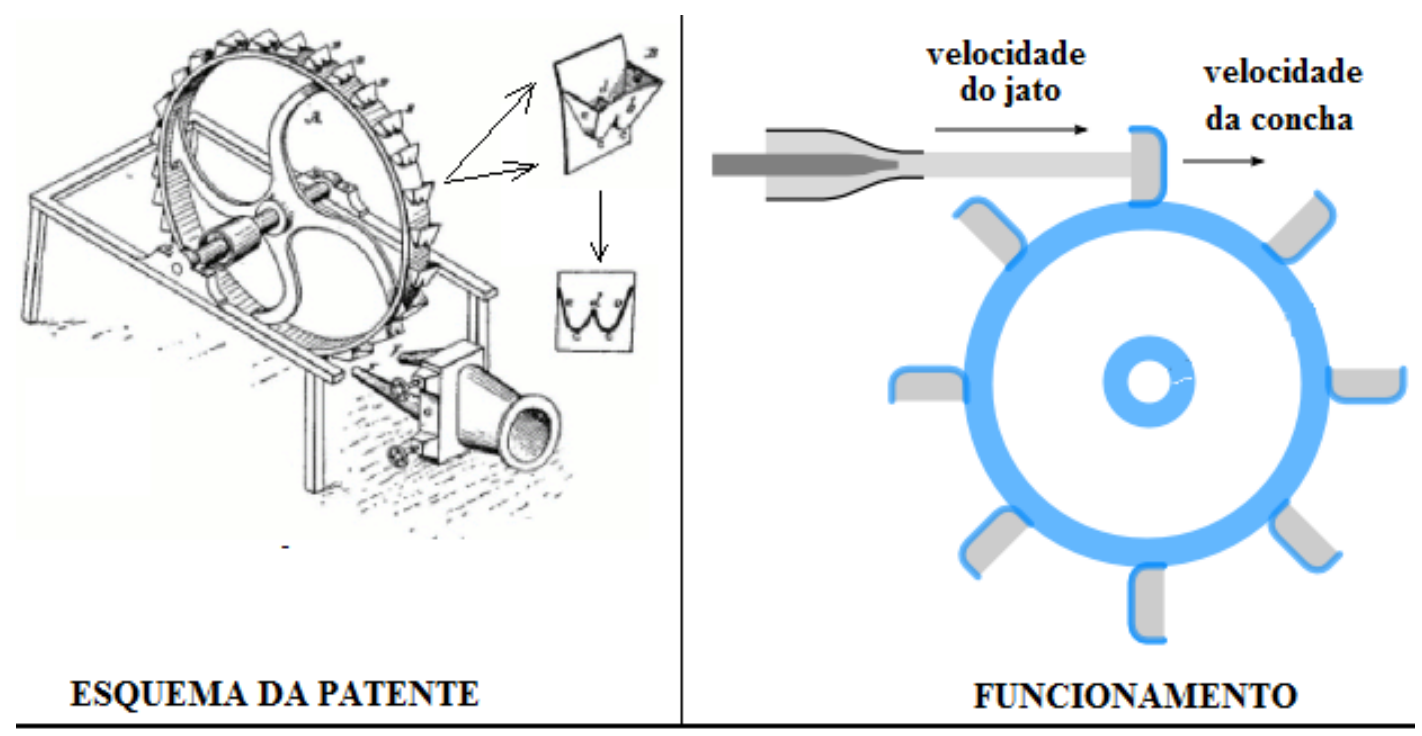

Fig. 5.6: Turbina Pelton.

A operação é simples: um rotor em forma de anel é dotado de conchas, que são arrastadas sob ação de um fluxo tangencial de água, proporcionado por um bocal injetor. O injetor é normalmente dotado de uma agulha para regulagem. Turbinas práticas podem ter mais de um injetor (6 por exemplo).

O formato das conchas desvia o fluxo para uma direção quase oposta à direção original, resultando em uma variação de momento linear e, por conseqüência, em uma força tangencial que aciona o rotor.

As conchas têm cavidades duplas para distribuir igualmente o fluxo para cada lado, de modo que os esforços axiais se anulem. 
A própria forma construtiva permite deduzir que é uma turbina adequada para altas pressões de água e vazões relativamente baixas. É considerada uma das mais eficientes.

São adequadas para operar entre quedas de $350 \mathrm{~m}$ até $1100 \mathrm{~m}$, sendo por isto muito mais comuns em países montanhosos. Essas alturas de queda de 350 a $1100 \mathrm{~m}$ em termos de coluna de água, correspondem a pressões na base de aproximadamente 35 e 110 bar, respectivamente.

Este modelo de turbina opera com velocidades de rotação maiores que os outros, e tem o rotor de caráterística bastante distintas. Os jatos de água ao se chocarem com as "conchas" do rotor geram o impulso. Dependendo da potência que se queira gerar podem ser acionados até 6 injetores simultaneamente, ou apenas cinco, quatro, etc... $\mathrm{O}$ número normal de bocais injetores varia de dois a seis, igualmente espaçados angularmente para garantir um balanceamento dinâmico do rotor.

Um dos maiores problemas destas turbinas, devido à alta velocidade com que a água se choca com o rotor, é a erosão provocada pelo efeito abrasivo da areia misturada com a água, comum em rios de montanhas. Esse problema não se coloca no caso do acionamento da turbina com a jato de água proveniente da $\mathrm{CPH}$ devido ao prétratamento. As turbinas Pelton, devido à possibilidade de acionamento independente nos diferentes injetores, têm uma curva geral de eficiência plana, que lhes garante boa performance em diversas condições de operação.

Após a abordagem geral sobre as duas aplicações do modelo (dessalinização e geração de eletricidade) e, apontadas as tecnologias adotadas no modelo (osmose reversa e turbina Pelton), faz-se, na seção seguinte, uma avaliação da potência fornecida pela $\mathrm{CPH}$.

$\mathrm{Na}$ anunciada seção, apesar de se fazer uma análise visando avaliar o potencial de geração de eletricidade a partir da transformação da energia cinética de um jato de água, os resultados obtidos permitem inferir sobre a osmose reversa. A recíproca é igualmente 
válida, ou seja, com resultados sobre a osmose reversa pode-se inferir sobre a geração de eletricidade.

\subsection{2-Potência gerada pela $\mathrm{CPH}$}

Quanto ao modelo da CPH, como já foi referido, a turbina que a ele melhor se adapta é a Pelton. A pressão do jato de água ao entrar no bico do injetor é imposta pelo êmbolo especial. Com base na Fig. 5.7, faz-se a dedução da potência do jato que será entregue à entrada do bico do (s) injetor (es).

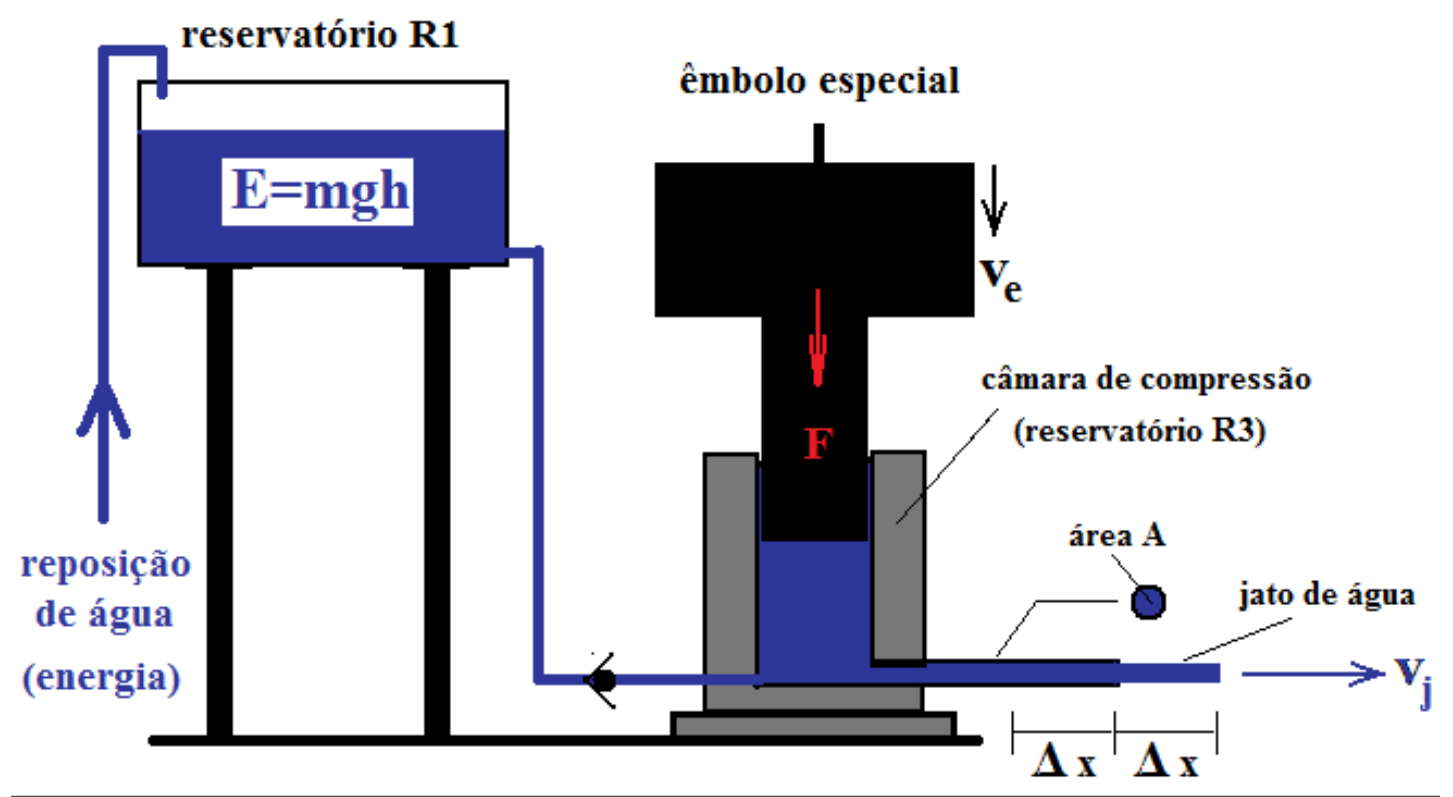

Fig. 5.7: Conversão de energia potencial gravitacional em potência de um jato de água gerada pela $\mathrm{CPH}$.

A potência é dada pelo quociente do trabalho pelo tempo gasto em realizá-lo isto é:

$\mathrm{P}=\mathrm{W} / \mathrm{t}$

Dado que trabalho é o produto da força $F_{2}$ ( a que faz a água sair pelo tubo) pelo deslocamento $\Delta \mathrm{x}$ vem:

$\mathrm{P}=\mathrm{F}_{2} \Delta \mathrm{x} / \mathrm{t}$ 
Entretanto, a força $\mathbf{F}_{2}$ (que faz a água sair pelo tubo) é dada pela pressão $\mathbf{p}$, multiplicada pela área $\mathbf{A}$ isto é,

$$
\mathrm{F}_{2}=\mathrm{p} \mathrm{A}
$$

Substituindo a Eq. 5.3 na Eq. 5.2 tem-se:

$\mathrm{P}=\mathrm{pA} \Delta \mathrm{x} / \mathrm{t}$

Contudo, o produto $\mathbf{A} \Delta \mathbf{x}$ dá o volume $\mathbf{V}$ do "cilindro" de água que sai do tubo. Portanto, a Eq. 5.4 transforma-se em:

$\mathrm{P}=\mathrm{p} \mathrm{V} / \mathrm{t}$

Mas, V / t é a vazão volumétrica $\mathbf{Q}$. Logo, obtém-se finalmente que:

$$
\mathbf{P}=\mathbf{p} \mathbf{Q} \quad[\mathrm{W}]
$$

onde,

$\mathbf{P}$ é a potência em [ W ],

p é a pressão do fluxo de água que sai da câmara de compressão expressa em [ N/m² ]

$\mathbf{Q}$ é a vazão volumétrica por unidade de tempo expressa em $\left[\mathrm{m}^{3} / \mathrm{s}\right]$

Conclui-se então que na $\mathrm{CPH}$ a potência é o produto da pressão pela vazão volumétrica.

Na Eq. 5.6, uma vez definida a pressão p, fixada pela geometria e material do êmbolo especial, é possível variar a vazão $\mathbf{Q}$ através da regulação do bico injetor que direciona o jato para a turbina Pelton. O cálculo da pressão exercida pelo êmbolo especial foi desenvolvido na seção 3.5 (Eqs 3.4 e 3.6). Designando a pressão exercida pelo êmbolo por pressão de operação $\mathbf{P}_{\mathbf{o p}}$, e a potência por potência gerada $\mathbf{P}_{\mathbf{g}}$, reescreve-se a Eq. 5.6 assim: 
Prosseguindo, de acordo com a equação da continuidade, considerando a velocidade $\mathbf{v}_{\mathbf{e}}$ de descida do êmbolo especial durante o trabalho de compressão e a velocidade $\mathbf{v}_{\mathbf{j}}$ do jato de água à saída, tem-se:

$v_{e} A_{b}=v_{j} A$

sendo $\mathbf{A}_{\mathbf{b}}$ é a área da base do êmbolo especial.

Sabe-se também que a potência de um jato de água é dado pelo produto da força motriz pela velocidade isto é:

$\mathrm{P}=\mathrm{F}_{2} \mathrm{v}_{\mathrm{j}}$

Resolvendo a Eq. 5.8 para $\mathbf{v}_{\mathbf{j}}$ e substituindo o resultado na Eq. 5.9 tem-se:

$\mathrm{P}=\mathrm{F}_{2} \mathrm{v}_{\mathrm{e}} \mathrm{A}_{\mathrm{b}} / \mathrm{A}$.

Da Eq. 5.3 tem-se $F_{2}=$ p A, logo a equação anterior fica:

$\mathrm{P}=\mathrm{p} \mathrm{v}_{\mathrm{e}} \mathrm{A}_{\mathrm{b}}$

Tendo em conta que a pressão $\mathbf{p}$ é a pressão exercida pelo êmbolo especial na sua base, ela é dada por $\mathrm{p}=\mathrm{F} / \mathrm{A}_{\mathrm{b}}$. Levando esse resultado à Eq. 5.11, resulta em:

$\mathbf{P}=\mathbf{F} \mathbf{v}_{\mathbf{e}} . \quad[\mathrm{W}]$

F é o peso do êmbolo especial expresso em [ $\mathrm{N}]$.

$\mathbf{v}_{\mathbf{e}}$ é a sua velocidade de descida do êmbolo expressa em [ m/s ].

A Eq. 5.12 sugere que, uma vez tendo o peso do êmbolo definido, a potência pode ser regulada através da regulação da velocidade de descida do êmbolo. Essa velocidade é 
também controlada pela bico do injetor variando-se a área. Verifica-se isso se se retoma a Eq. 5.12, substituindo $\mathbf{v}_{\mathbf{e}}$ pelo resultado obtido da Eq. 5.8. Tem-se assim:

$\mathrm{P}=\mathrm{FA} / \mathrm{A}_{\mathrm{b}} \mathrm{V}_{\mathrm{j}}$

Inserindo os rendimentos da turbina Pelton $\eta_{\mathrm{T}}$ e do gerador $\eta_{\mathrm{G}}$ na Eq. 5.13 obtem-se a potência gerada $\mathbf{P}_{\mathbf{g}}$ pelo grupo CPH-Turbina-Gerador que é dada por:

$\mathrm{P}_{\mathrm{g}}=\eta_{\mathrm{T}} \eta_{\mathrm{G}} \mathrm{FA} / \mathrm{A}_{\mathrm{b}} \mathrm{v}_{\mathrm{j}} \quad[\mathrm{W}]$

Dado que o quociente $\mathbf{F} / \mathbf{A}_{\mathbf{b}}$ é a a pressão de operação $\mathbf{P}_{\mathbf{o p}}$ exercida pelo êmbolo especial, a Eq. 5.14 toma o seguinte forma:

$\mathbf{P}_{\mathrm{g}}=\boldsymbol{\eta}_{\mathbf{T}} \boldsymbol{\eta}_{\mathbf{G}} \mathbf{P}_{\mathbf{o p}} \mathbf{A} \quad \mathbf{v}_{\mathbf{j}}$

onde,

$\boldsymbol{\eta}_{\mathbf{T}}$ é o rendimento da TP

$\eta_{\mathbf{G}}$ é o rendimento do gerador elétrico.

$\mathbf{P}_{\mathbf{o p}}$ é a pressão exercida pelo êmbolo $\left[\mathrm{N} / \mathrm{m}^{2}\right]$

A é a area do bico do injetor em $\left[\mathrm{m}^{2}\right]$

$\mathbf{v}_{\mathbf{j}}$ é a velocidade do jato de água que se dirige às conchas da TP em $[\mathrm{m} / \mathrm{s}]$.

A conversão da energia potencial gravitacional $(\mathrm{EPG}=\mathrm{mgH})$ em potência elétrica será governada pela Eq. 5.14 mediante a regulação da velocidade do jato de água. Conforme a potência desejada (função da demanda), dimensiona-se tanto o reservatório R1 de armazenamento de água como a taxa de reposição de água pelo bombeamento (veja-se a Fig. 5.8) com cataventos ou aerogeradores. Entende-se assim que o dimensionamento, feito em (DIAS,2004), para o caso da dessalinização no mestrado (que será parcialmente apresentado no capítulo 6) é válido para o caso da geração de eletricidade.

Para tal, basta multiplicar o consumo específico, expresso em $\left[\mathrm{kWh} / \mathrm{m}^{3}\right]$ pela vazão volumétrica expressa em [ $\mathrm{m}^{3} / \mathrm{s}$ ] e pelo fator 3600 [ s] para convertê-lo em potência, 
expressa em [ kW ]. Será necessário então, conhecer a vazão volumétrica de água que passa pelas membranas. Esse dado aparece no capítulo 6 ao longo de um estudo de caso.

A velocidade do jato $\mathbf{v}_{\mathbf{j}}$ na Eq. 5.14 pode ser estimada a partir da aplicação do teorema de Torricelli à CPH como ilustra a Fig. 5.8.

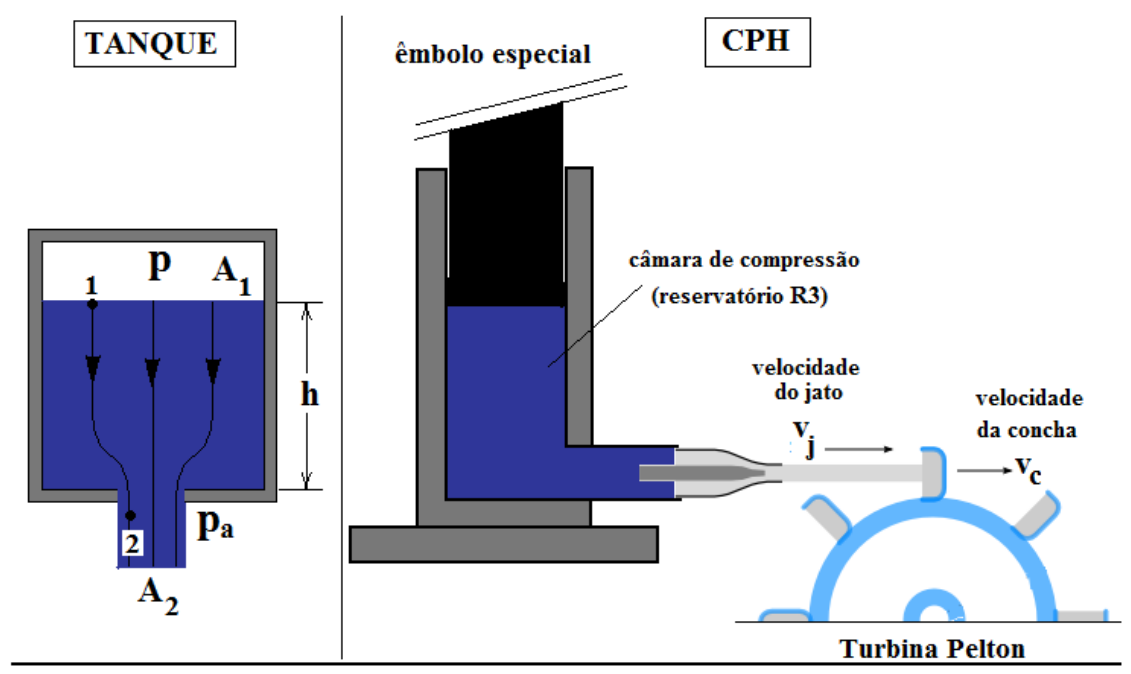

Fig. 5.8: Velocidade de descarga e o teorema de Torricelli aplicados à CPH.

À esquerda da figura representa-se um tanque com área transversal igual a $\mathbf{A}_{1}$, cheio de um líquido (água do mar por exemplo) de densidade $\boldsymbol{\rho}$ até uma altura $\mathbf{h}$. $\mathrm{O}$ espaço acima da superfície do líquido contém ar a uma pressão p. O líquido escoa através de um orifício de área transversal A2. Aplicando a equação de Bernoulli aos pontos 1 e 2 e tomando como nível de referência o fundo do tanque, obtem-se (SEARS F.W.; ZEMANSKY M.W.,1980):

$\mathrm{v}_{2}^{2}=\mathrm{v}_{1}^{2}+2\left(\mathrm{p}-\mathrm{p}_{\mathrm{a}}\right) / \rho+2 \mathrm{gh}$

Da equação de continuidade,

$\mathrm{v}_{2}=\mathrm{A}_{1} / \mathrm{A}_{2} \mathrm{v}_{1}$

Devido à convergência das linhas de corrente à medida que se aproximam do orifício, a seção transversal da corrente líquida continua a diminuir até uma pequena distância fora do tanque. A área a ser usada na Eq. 5.17 é a da menor seção transversal conhecida 
como vena contracta (veia contraída). Para um orifício circular de borda bem aguçada, a área da veia contraída é cerca de $65 \%$ da do orifício.

Considere-se alguns casos especiais. Suponha-se que o tanque esteja aberto para a atmosfera de maneira que:

$\mathrm{p}=\mathrm{p}_{\mathrm{a}}$ ou seja $\mathrm{p}-\mathrm{p}_{\mathrm{a}}=0$

Suponha-se também que $A_{1}$ é muito maior do que $A_{2}$. Então $v_{1}^{2}$ é muito menor do que $\mathrm{v}_{2}{ }^{2}$ e pode ser desprezado. Com tais pressupostos, da Eq. 5.16, tira-se:

$\mathbf{v}_{2}=(2 \mathrm{gh})^{1 / 2}$

Conclui-se que a velocidade de descarga ou velocidade de escoamento é igual à velocidade final de um corpo em queda livre a partir da altura $\mathbf{h}$. Esse é o teorema de Torricelli que não se restringe à orifícios na base do tanque, sendo aplicado também para os que são feitos nas paredes laterais a uma profundidade $\mathbf{h}$ abaixo da superfície (situação similar à apresentada pela $\mathrm{CPH}$ ).

Suponha-se novamente que a relação de áreas seja tal que $\mathrm{v}_{1}{ }^{2}$ seja desprezível e que a pressão p (num tanque fechado) seja tão grande que o termo $2 \mathrm{gh}$ na Eq. 5.16 possa ser considerado nulo, comparado com o termo $2\left(p-p_{a}\right) / \rho$. A velocidade de descarga é, então, (SEARS F.W.; ZEMANSKY M.W.,1980):

$\mathrm{v}_{2}=\left[2\left(\mathrm{p}-\mathrm{p}_{\mathrm{a}}\right) / \rho\right]^{1 / 2}$

Adaptando os conceitos anteriores à $\mathrm{CPH}$, a velocidade do jato (ver Fig. 5.8 ) é dada por:

$\mathbf{v}_{\mathbf{j}}=\left[2\left(\mathbf{P}_{\mathrm{op}}-\mathbf{p}_{\mathrm{a}}\right) / \rho_{\text {água }}\right]^{1 / 2} \quad[\mathrm{~m} / \mathrm{s}]$

sendo

$\mathbf{P}_{\mathbf{o p}}$ é a pressão de operação exercida pelo êmbolo. 
$\mathbf{p}_{\mathbf{a}}$ é a pressão atmosférica.

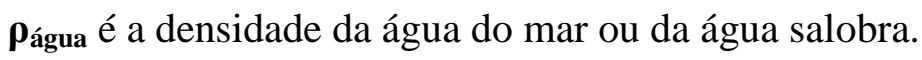

Demonstra-se que para se ter a TP operando no ponto de máxima potência, a velocidade do jato $\mathrm{v}_{\mathrm{j}}$ deve ser o dobro da velocidade das conchas $\mathrm{v}_{\mathrm{c}}$, ou seja $\mathbf{v}_{\mathbf{j}}=\mathbf{2} \mathbf{v}_{\mathbf{c}}$.

Continuando a discussão sobre geração elétrica através da $\mathrm{CPH}$, anuncia-se que um projeto dum Engenheiro britânico, Sr Alvin Smith, cujo fundamento é o mesmo do apresentado neste trabalho evidenciou a simplicidade da proposta em relação à geração de eletricidade. Pela sua semelhança com a proposta da $\mathrm{CPH}$, o referido projeto é apresentado no anexo D. Essa apresentação, acompanhada de alguns comentários, elucida não só a importância deste trabalho (projeto da $\mathrm{CPH}$ ), mas também demonstra que a proposta é factível. Abrimos aqui parênteses para expor o seguinte raciocínio:

A propósito de se basear em resultados obtidos por outros para sustentar afirmações, recordemos o que disse Sir Isaac Newton à respeito do seu trabalho:

\section{"Se vi mais longe, foi por estar de pé sobre ombros de gigantes"}

Numa clara alusão aos seus predecessores, "os gigantes" , Newton confessa que o recurso à resultados de um trabalho, para fundamentar outro, não retira mérito a este, mas sim, pode dar-lhe alicerces e directrizes que o conduzam a bons resultados. Isso tem acontecido ao longo da história do desenvolvimento científico e não há razões para se pensar que deixará de assim ser. Afinal, não é mais necessário esforçar-se para reinventar a roda, mas sim para lhe dar outras aplicações.

Em relação ao potencial do projeto proposto pelo engenheiro Alvin Smith (anexo D), afirma-se que 11000 SEARASER'S com 1,2 m de diâmetro do pistão, seriam capazes de suprir a demanda de todas as casas do Reino Unido. Isso com um custo da eletricidade (cerca de 0,042 Reais $/ \mathrm{kWh}$ ) competitivo em relação às outras formas de geração, além de ser limpa e renovável.

Note-se as semelhanças da proposta de geração com SEARASER'S com a proposta apresentada em (DIAS,2004): 
-Armazenamento da energia através do bombeamento de água até um reservatório.

-Bomba de pistão com um cabeçote para aumentar a pressão (êmbolo especial versus SEARASER)

-possibilidade de geração de eletricidade.

\section{4-Diagramas de Sankey do modelo proposto}

Nesta seção apresenta-se a interpretação dos processos através do diagrama de Sankey. O dito diagrama, Figs 5.10 e 5.11, dá um panorama geral das quantidades de energia envolvidas nos diversos processos do sistema. Para simplificar tal interpretação, optouse por usar uma configuração idêntica à da figura 5.9 com um êmbolo maciço (êmbolo especial B) e o reservatório superior R1 a uma altura de 12,8 metros em relação ao nível do mar. Com essa configuração evita-se contabilizar o fluxo de energia correspondente ao volume de água que se teria no reservatório R2 do êmbolo especial A. Na referida configuração, além do fato do êmbolo ser maciço, é caráterizada pelos seguintes aspectos:

- O reservatório R3 é alimentado com a água despejada pelo contrapeso através de um sistema de vasos comunicantes (reservatórios R4 e R5) e da válvula V4.

- Tem um menor número de válvulas (válvulas V1 e V2 eliminadas).

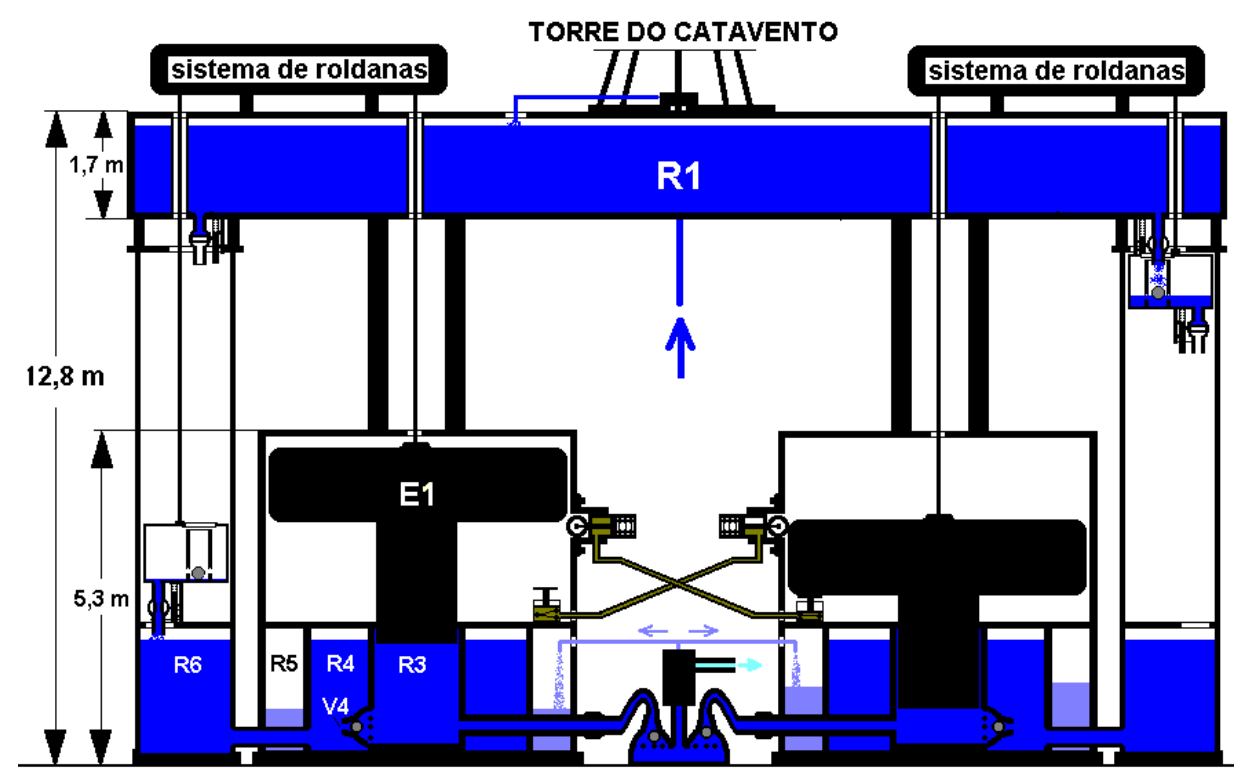

Fig. 5.9: CPH com êmbolos maciços. 
O diagrama de Sankey correspondente, representado na Fig. 5.10 para osmose reversa e na Fig. 5.11 para geração de eletricidade tem uma aparência ligeiramente diferente da habitual dado que além de ilustrar os fluxos de energia inerentes aos processos que ocorrem no sistema, semioticamente apresenta a forma de energia associada aos referidos fluxos. Os diagramas apresentados nesta seção ilustram os fluxos de energia sem contudo apresentar os correspondentes valores. Esse complemento virá no próximo capítulo (estudos de casos), no qual tem-se os dados obtidos a partir do dimensionamento da $\mathrm{CPH}$ para atender demandas diárias.

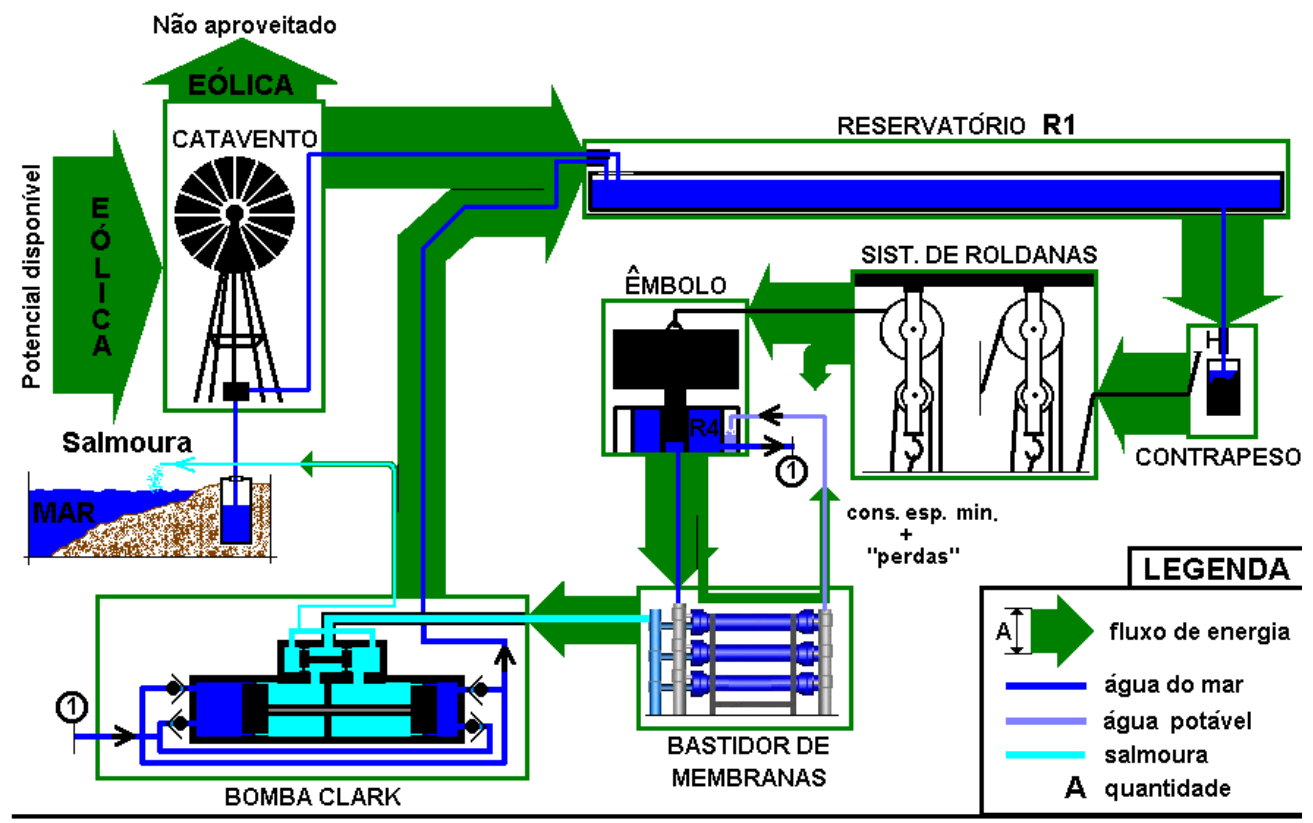

Fig. 5.10: Diagrama de Sankey do sistema 1 para osmose reversa com base na configuração da Fig. 5.9.

No diagrama de Sankey da Fig. 5.10 "lê-se" que:

O reservatório R1 é alimentado graças ao fluxo de energia eólica captada pelo catavento e ao que, proveniente da salmoura, é recuperado pela bomba Clark.

$\mathrm{O}$ contrapeso recebe um fluxo de energia de R1 da qual transfere uma percentagem (cerca de 75\%) ao sistema de roldanas para a elevação do êmbolo especial.

O êmbolo especial transfere parte da energia para o bastidor de membranas onde ocorre osmose reversa. Deste processo saem dois fluxos de energia sendo um correspondente ao consumo mínimo para a dessalinização mais as "perdas" e o correspondente à 
energia da salmoura que sai do bastidor com acima de $95 \%$ da pressão recebida pelo êmbolo especial.

A Fig. 5.11 representa o diagrama de Sankey para a geração de eletricidade com o sistema 1 (catavento). A leitura deste diagrama dispensa uma descrição pela semelhança com o anterior.

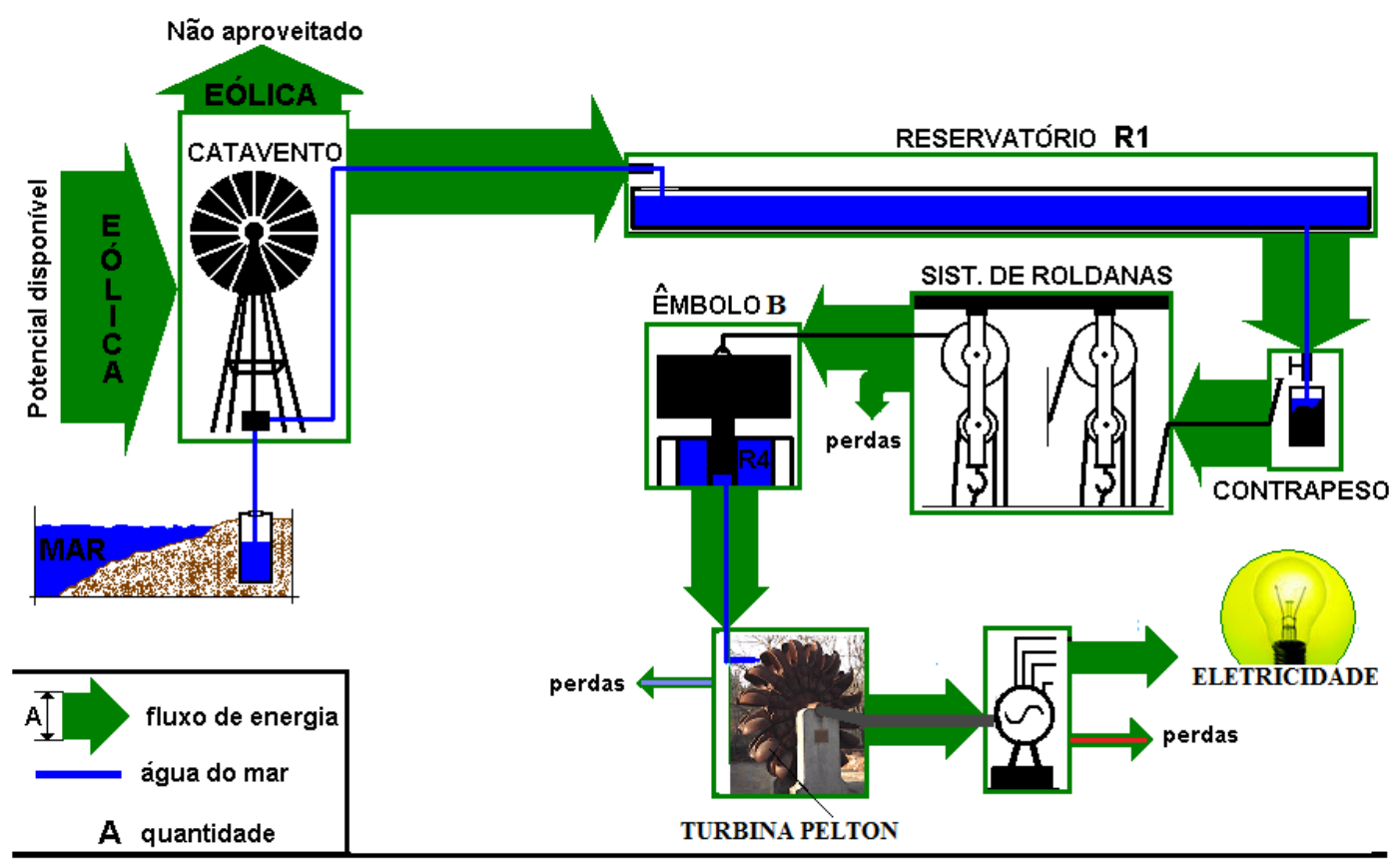

Fig. 5.11: Diagrama de Sankey do sistema 1 para geração de energia elétrica com base na configuração da figura 5.9.

No próximo capítulo faz-se referência aos diagramas de Sankey baseados no sistema de bombeamento com aerogeradores alimentando bombas (sistema 2). De seguida, com o suporte das Figs 5. 12 a 5.16 faz-se uma interpretação mais detalhada das etapas que compõem os diagramas de Sankey.

No diagrama de Sankey (d.S.) da coluna de potência hidráulica, Fig. 5.12, "lê-se" que do reservatório R1 saem "pacotes" de energia potencial gravitacional, EPG, na forma de água que vai para o contrapeso. 


\section{COLUNA DE POTÊNCIA HIDRÁULICA}

( $\mathrm{CPH})$

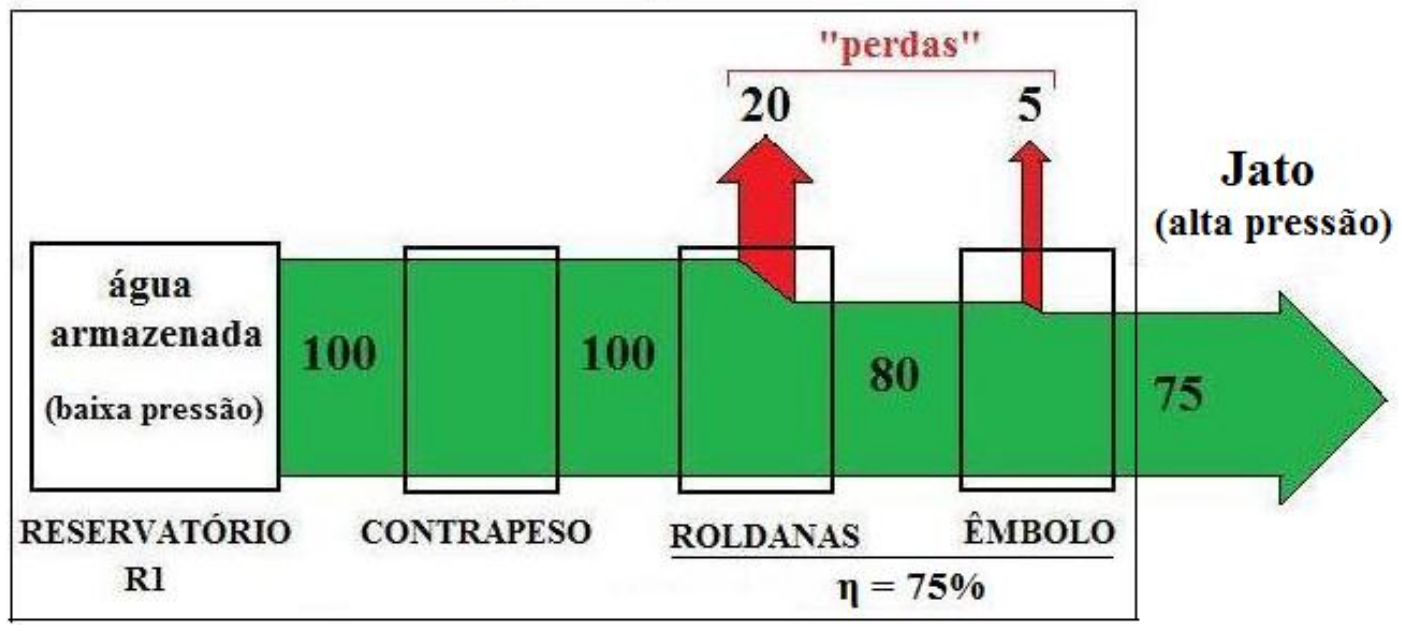

Fig. 5.12-Diagrama de Sankey da CPH.

Através do sistema de roldanas, a EPG do contrapeso com água é transferida para êmbolo. Por sua vez, a EPG do êmbolo é transferida ao fluxo de água que sai da coluna de potência hidráulica $\mathrm{CPH}$ com alta pressão e em forma de jato.

Nesses processos de transferência de energia assumiu-se $20 \%$ de "perdas" por atrito no sistemas de roldanas e de 5\% no êmbolo (atrito na câmara de compressão e "perdas" hidráulicas).

Assim, por cada "pacote" de 100 unidades de EPG que sai de R1 (baixa pressão), são aproveitadas 75 unidades correspondentes à energia cinética do fluxo que sai da $\mathrm{CPH}$. Portanto, nessas condições, o rendimento da $\mathrm{CPH}$ é de $75 \%$. O citado fluxo é usado para as duas aplicações da CPH (dessalinização de água ou/e geração de eletricidade).

De acordo com o d.S. da Fig. 5.13, a EPG armazenada em R1 é obtida do vento através de cataventos (sistema S1) que bombeiam água até o reservatório R1. Se R1 é alimentado com cataventos, tem-se uma "perda" de cerca de $90 \%$ do potencial eólico disponível fazendo com que o rendimento global do sistema seja muito baixo. Se R1 é alimentado através de aerogeradores (sistema S2) a "perda" é de cerca de 70\%. 


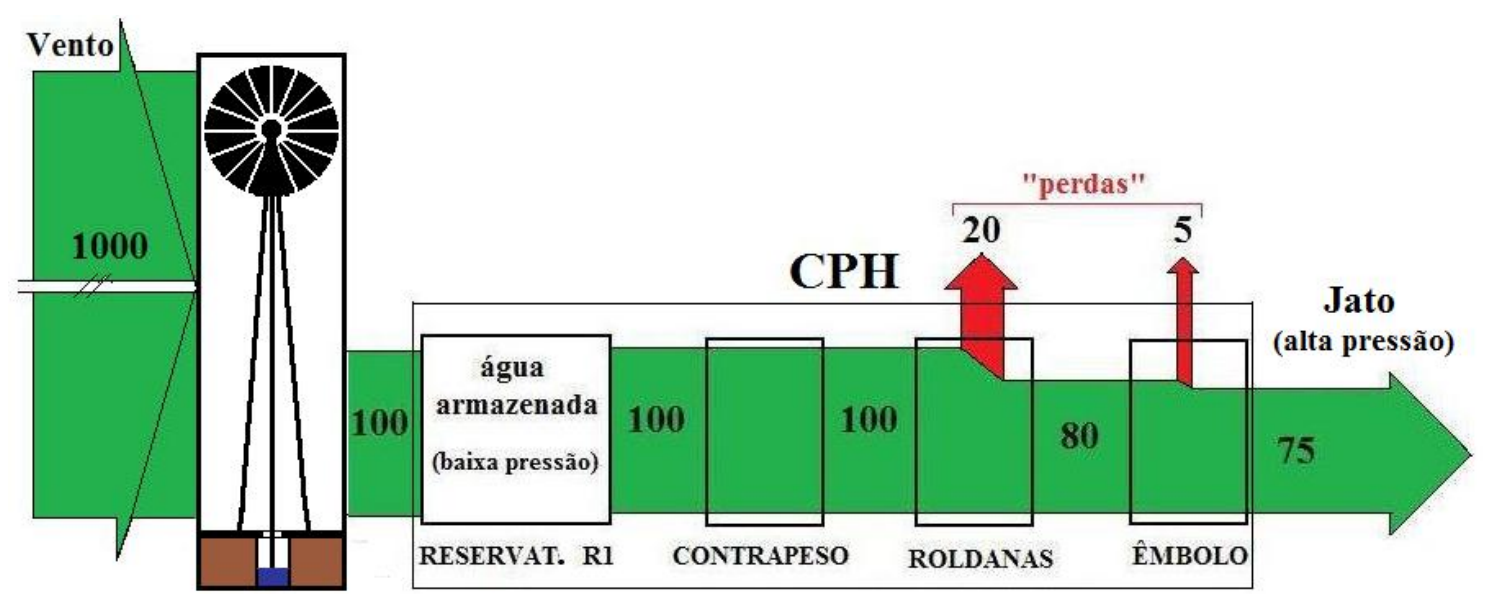

Fig. 5.13-Diagrama de Sankey da CPH alimentada com cataventos.

O d.S. da Fig. 5.14 ilustra a conversão da energia do fluxo que sai da CPH em eletricidade com um rendimento de $48 \% \quad(0,80 \times 0,60)$. Para uma comparação com centrais hidrelétricas, se a análise do rendimento for feita a partir da EPG armazenada em R1, tem-se um rendimento da ordem de $36 \%(0,75 \times 0,80 \times 0,60)$.

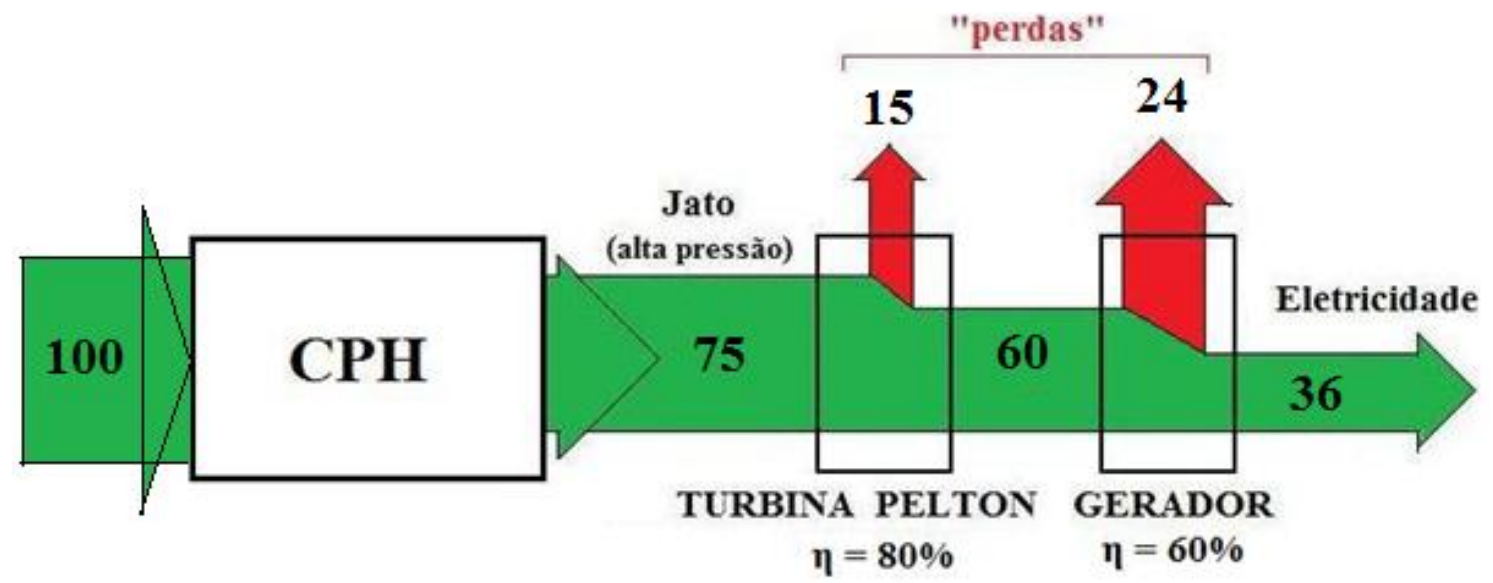

Fig. 5.14-Diagrama de Sankey da conversão da energia do jato em eletricidade.

O d.S. da Fig. 5.15 ilustra a aplicação da energia do fluxo que sai da CPH para osmose reversa. Note-se que as perdas hidráulicas no bastidor de membranas são de 5\%. Assim, o fluxo que sai do bastidor contém $95 \%$ da energia do jato proveniente da CPH. É necessário recuperar essa energia para que o consumo específico não seja muito alto. A recuperação dessa energia é feita pela bomba Clark com um rendimento de $93 \%$ através do bombeamento de água até o reservatório $\mathrm{R} 1$ da $\mathrm{CPH}$. 


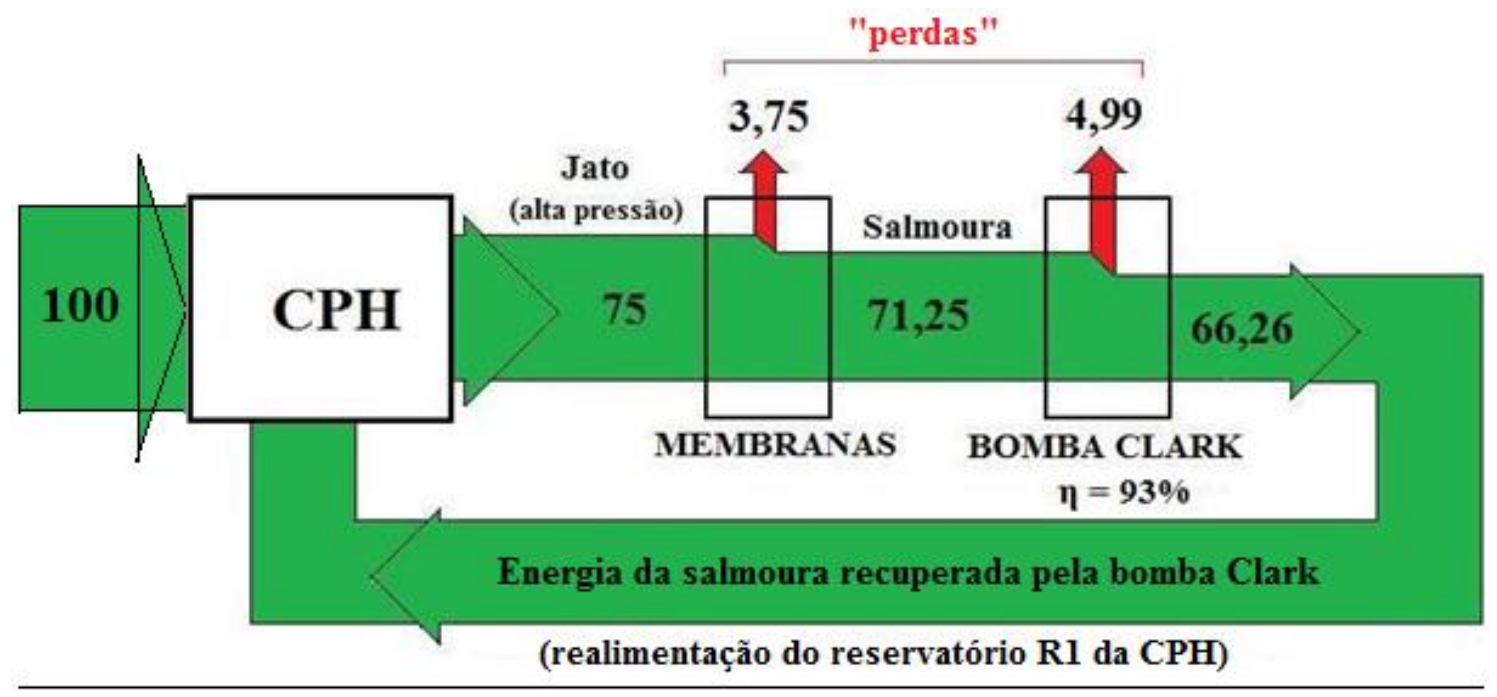

Fig. 5.15-Diagrama de Sankey da aplicação da energia do jato para osmose reversa.

Em relação à aplicação do modelo para a osmose reversa, é de frisar que apesar do rendimento global dos sistemas S1 e S2 ser baixo (devido ao rendimento da conversão do potencial eólico), esse fator não inviabiliza o projeto dado que a fonte de energia é "gratuita" e o consumo específico "real" da CPH é de aproximadamente $2,811 \mathrm{kWh} / \mathrm{m}^{3}$.

O d.S. da Fig. 5.16 ilustra a aplicação (simultânea e em série) da energia do fluxo que sai da CPH para osmose reversa e geração de eletricidade. Ao invés do uso da bomba Clark para recuperar a energia da salmoura, usa-se o grupo turbina Pelton-Gerador que converte essa energia em eletricidade com um rendimento de $48 \%$. Note-se que apesar do rendimento global da conversão da EPG ser de 34,2\% nessa configuração, tem-se a obtenção de dois produtos (água dessalinizada e eletricidade).

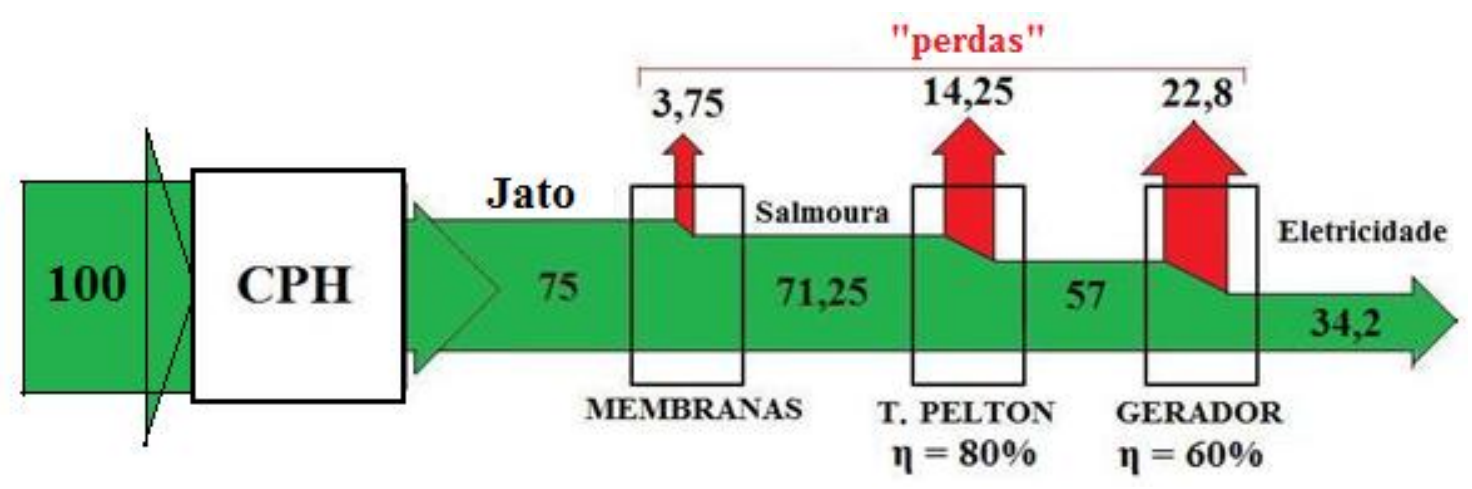

Fig. 5.16-Diagrama de Sankey da aplicação em série da energia do jato para osmose reversa e geração de eletricidade. 


\section{CAPITULO 6:}

\section{ESTUDO DE CASOS}

\section{1-Introdução}

Neste capítulo objetiva-se fazer a análise da CPH e suas aplicações para atendimento de demandas de água potável e de energia elétrica. Para tal, apresentam-se três estudos de casos. Nesses estudos não serão usados os métodos estatísticos apresentados (distribuições de Rayleigh e Weibull) pelo fato de, para uma estimativa, ser suficiente usar o método direto com base na velocidade média do vento. Note-se que tais métodos são mais adequados porque permitem uma maior aproximação de resultados reais.

No primeiro estudo de caso, tendo com referência uma unidade convencional de dessalinização por osmose reversa que epera em Cabo Verde, com uma produção diária de $5000 \mathrm{~m}^{3}$ de água potável, dimensiona-se a $\mathrm{CPH}$ usando somente o sistema 1 (cataventos) para a produção da mesma quantidade de água dessalinizada. Pela capacidade de produção, este pode ser considerado um sistema de grande porte. Após o dimensionamento, faz-se uma análise comparativa entre o sistema e a unidade convencional.

No segundo caso, utiliza-se como referência um sistema de pequeno porte relativo a um protótipo desenvolvido na Holanda, cuja capacidade de produção diária de água dessalinizada é de $5 \mathrm{~m}^{3}$. Também neste caso, dimensiona-se a CPH para a mesma capacidade, porém usando os dois sistemas: sistema 1 (cataventos) e sistema 2 (aerogeradores-bomba elétrica). Analogamente, após o dimensionamento, faz-se uma análise comparativa entre a CPH e o protótipo holandês.

No terceiro caso, a $\mathrm{CPH}$ é dimensionada para atender uma demanda hipotética de potência elétrica de $1000 \mathrm{~kW}$. Neste caso, a CPH também é dimensionada com base nos sistemas 1 e 2.

Ainda neste capítulo, de posse de resultados do estudo de caso 1, retomam-se os diagramas de Sankey. 


\section{2-Estudo de caso 1: Produção de $5000 \mathrm{~m}^{3} /$ dia usando CPH e sistema 1}

Faz-se previamente, uma apresentação do arquipélago de Cabo Verde, (Fig. 6.1) e são mostrados na Fig. 6.2 dados do clima que dão suporte às análises e comentários.

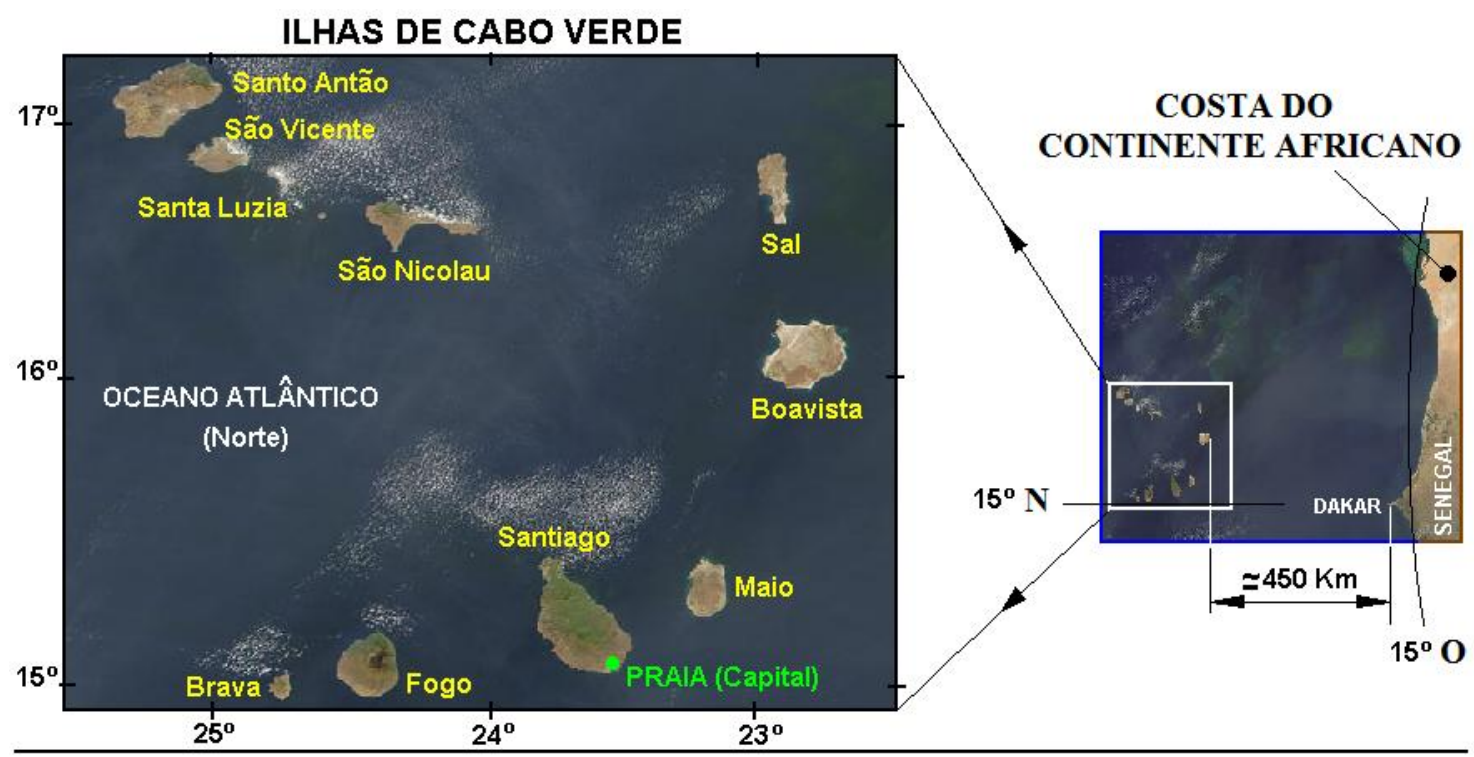

Fig. 6.1: Fotos de satélite das ilhas de Cabo Verde com adaptação do autor.

Fonte: VISIBLE EARTH.

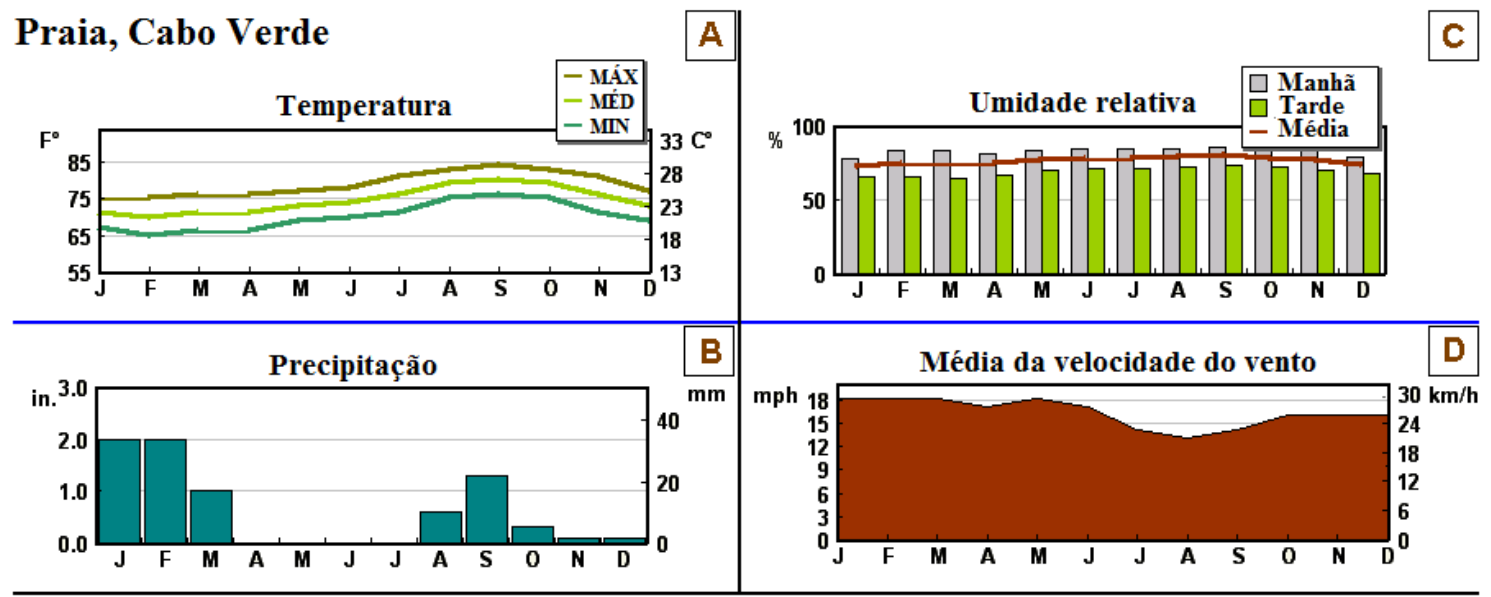

Fig. 6.2: Dados climatológicos da capital da República de Cabo Verde.

Fonte: FREE-WEATHER.COM.

Nota: $1[\mathrm{~km} / \mathrm{h}]=5 / 18[\mathrm{~m} / \mathrm{s}$.

De acordo com registros estatísticos colhidos no aeroporto internacional da ilha do Sal e em outras estações meteorológicas do país, os ventos caráterizam-se por uma relativa 
estabilidade no que respeita à direção predominante. $\mathrm{O}$ mesmo acontece com a velocidade, Fig. 6.2-D. De seguida apresenta-se a planta de dessalinização da Praia.

Essa planta tem como principais caráterísticas uma produção diária de $5000 \mathrm{~m}^{3}$ de água dessaslinizada, com uma taxa de conversão de $45 \%$, sendo a pressão de operação da bomba cerca de 67 bar e o consumo específico de $4,12 \mathrm{kWh} / \mathrm{m}^{3}$, que engloba o processo e o bombeamento a partir dos pontos de captação da água do mar.

A unidade de dessalinização instalada na cidade da Praia, ilha de Santiago, opera desde Janeiro de 2002. A Fig. 6.3 ilustra os componentes que realizam as principais etapas do processo de osmose reversa dessa unidade com indicação, através das setas, da sequência em que elas ocorrem.

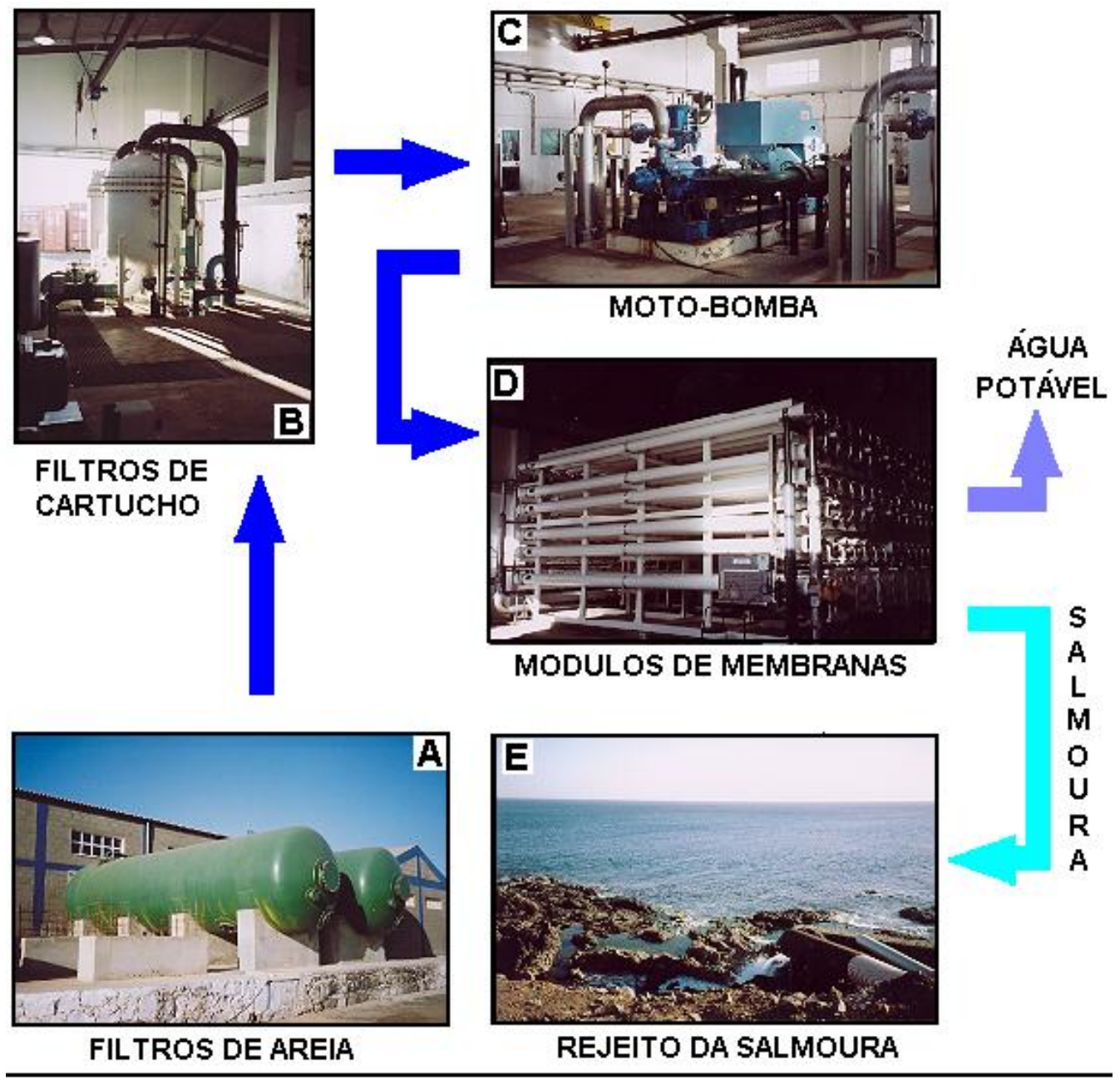

Fig. 6.3: Alguns dos equipamentos da unidade de dessalinização por osmose reversa da cidade da Praia em Cabo Verde. 
A unidade produz água potável com uma salinidade (TDS-Total Dissolved Solids) inferior a 500 ppm, após remineralização, a partir da água do mar com uma salinidade de aproximadamente 36000 ppm.

A unidade em questão comporta os seguintes equipamentos:

- Três furos de captação de água do mar com cerca de $40 \mathrm{~m}$ de profundidade. Cada um desses furos está munido de uma bomba submersível de $300 \mathrm{~m}^{3} / \mathrm{h}$. Geralmente duas dessas bombas estão em funcionamento enquanto a outra fica em "stand by".

- Um conjunto de tubulações que ligam os furos de captação com os filtros de areia.

- Dois filtros de areia horizontais e dois filtros de cartucho verticais.

- Pré-tratamento e dosagem de reagentes.

- Dois grupos de bombeamento compostos por bombas centrífugas com fluxo de, em média, $500 \mathrm{~m}^{3} / \mathrm{h}$ e pressão de $67 \mathrm{kgf} / \mathrm{cm}^{2}$ (cerca de $65,7 \mathrm{bar}$ ).

- Motor elétrico com uma potência de $800 \mathrm{~kW}$ e tensão de $6300 \mathrm{~V}$.

- Turbina do tipo "Pelton" em aço inox para recuperação de energia com um caudal de $290 \mathrm{~m}^{3} / \mathrm{h}$ e pressão de $65 \mathrm{kgf} / \mathrm{cm}^{2}$ (cerca de 63,7 bar ).

- Um bastidor com 80 tubos de pressão contendo cada um 7 módulos de membranas montados em série, totalizando 560 módulos do tipo espiral.

Além dos equipamentos apontados, fazem ainda parte da unidade equipamentos para limpeza dos filtros e para pré-tratamento químico da água captada do mar e pós-tratamento da água produzida, bem como equipamentos elétricos e equipamentos de comando e controle.

Através das Figs 6.4 a 6.7 tem-se a visão global da unidade dessalinizadora cujo funcionamento pode, em traços gerais, ser descrito assim:

A água é captada de dois dos três poços ilustrados na Fig. 6.4 (pelo registro momentâneo do computador, cerca de $478 \mathrm{~m}^{3} / \mathrm{h}$ ) e, após primeiro tratamento químico, é bombeada, a cerca de 3,5 bar, para os filtros de areia, Fig.6.5. Dos filtros de areia, após 
segundo tratamento químico (adição de dispersantes), a água segue para os filtros de cartucho, Fig. 6.5 e destes segue para um dos dois conjuntos motor-bomba da Fig. 6.6. Daí a água é forçada pela bomba a uma pressão de aproximadamente 67 bar em direção ao bastidor de membranas onde se dá a osmose reversa. A água dessalinizada segue para um reservatório após tratamento químico (adição de cal), Fig. 6.7, e a salmoura, a cerca de 65 bar, é encaminhada para a turbina Pelton, cujo eixo está acoplado ao eixo da bomba, Fig. 6.6. Assim consegue-se a recuperação da sua energia. Após passar pela turbina a salmoura é lançada ao mar, Fig. 6.3-E.

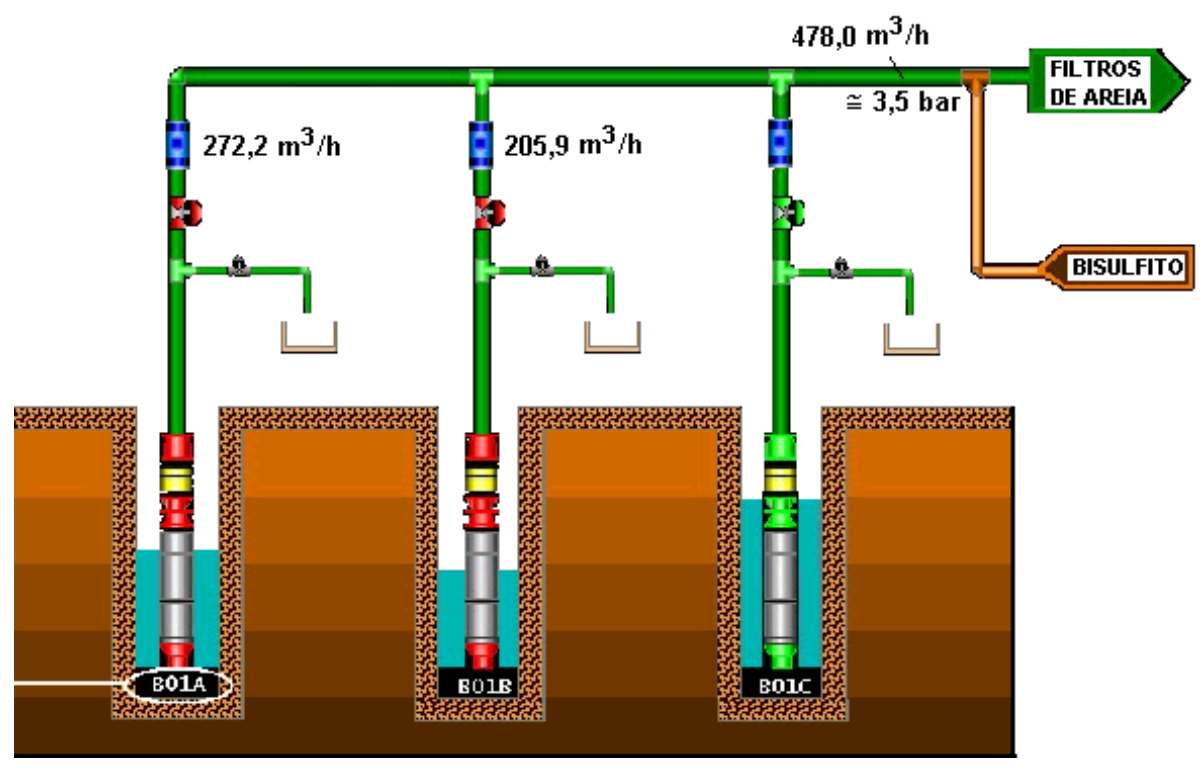

Fig. 6.4: Poços de captação de água do mar.

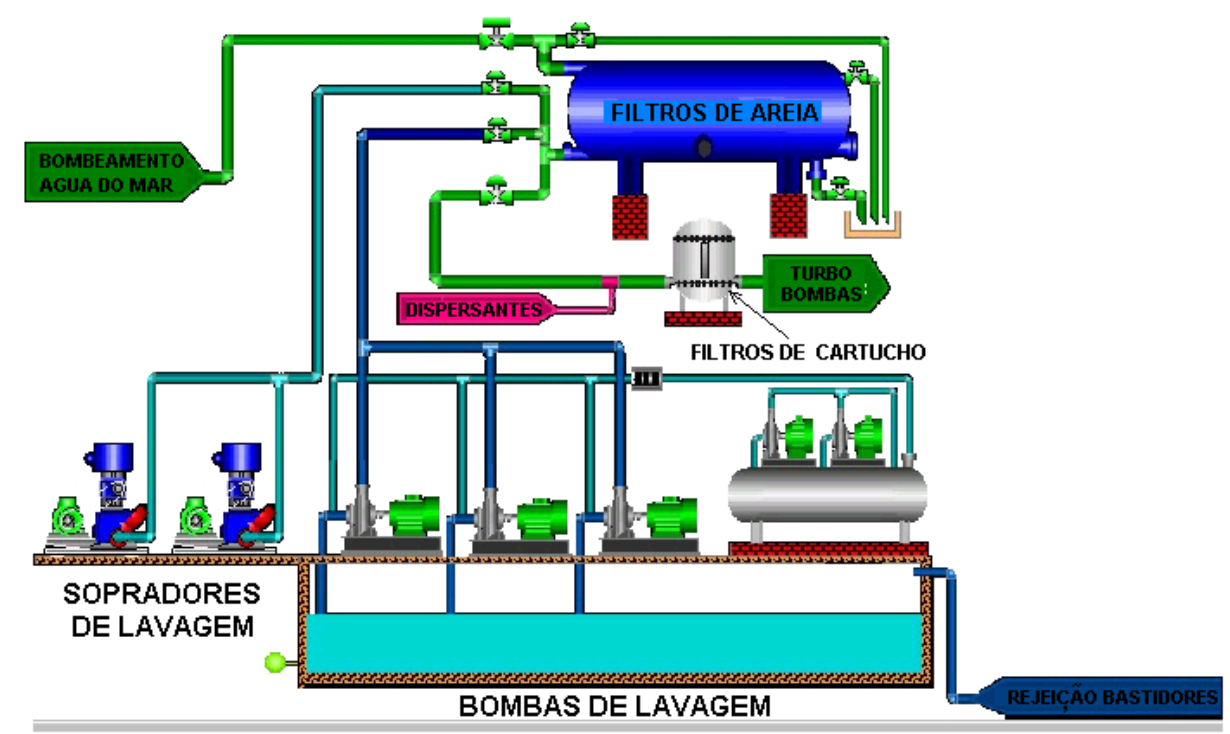

Fig. 6.5: Filtros de areia, filtros de cartucho e respectivo sistema de lavagem. 


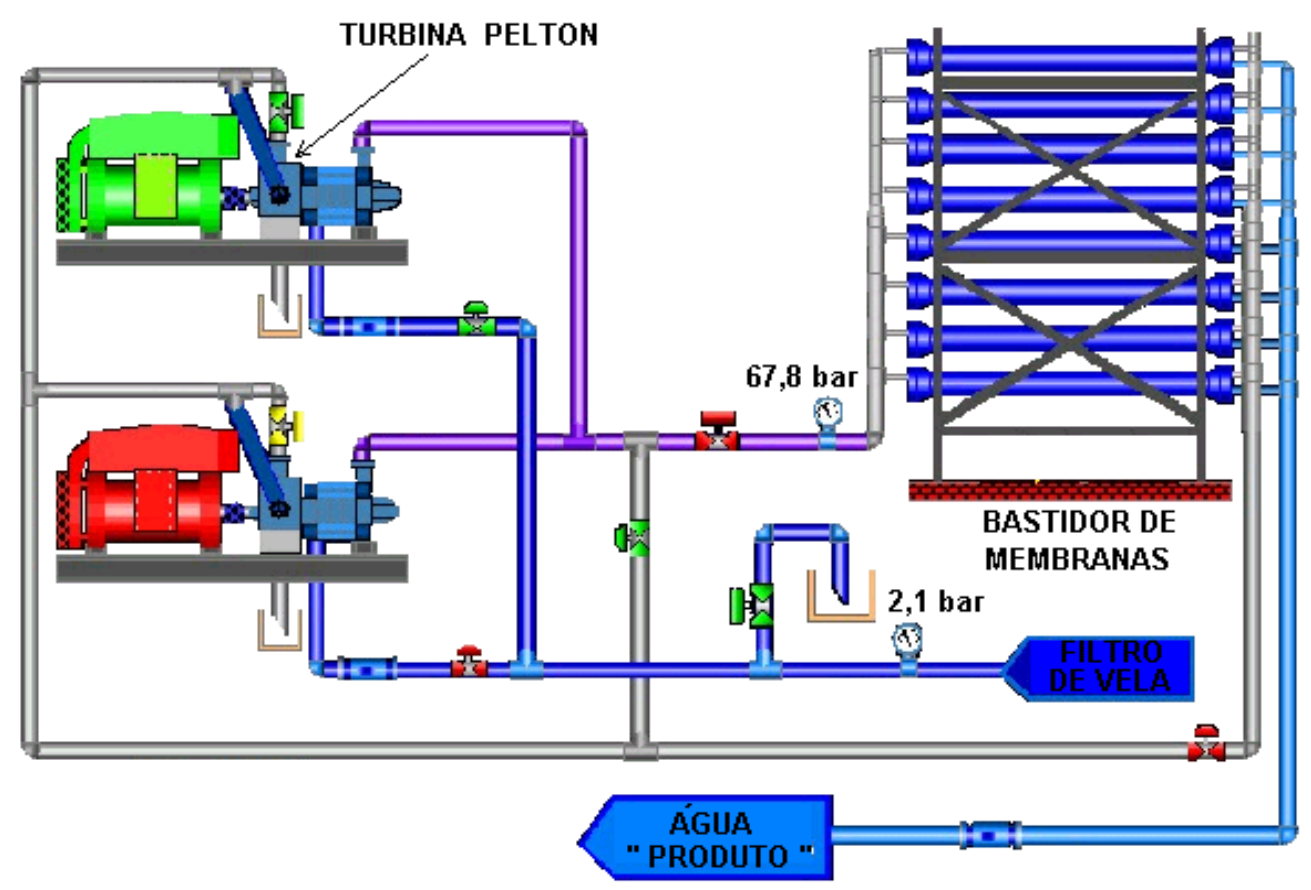

Fig. 6.6: Conjuntos motor-bomba e bastidor de membranas.

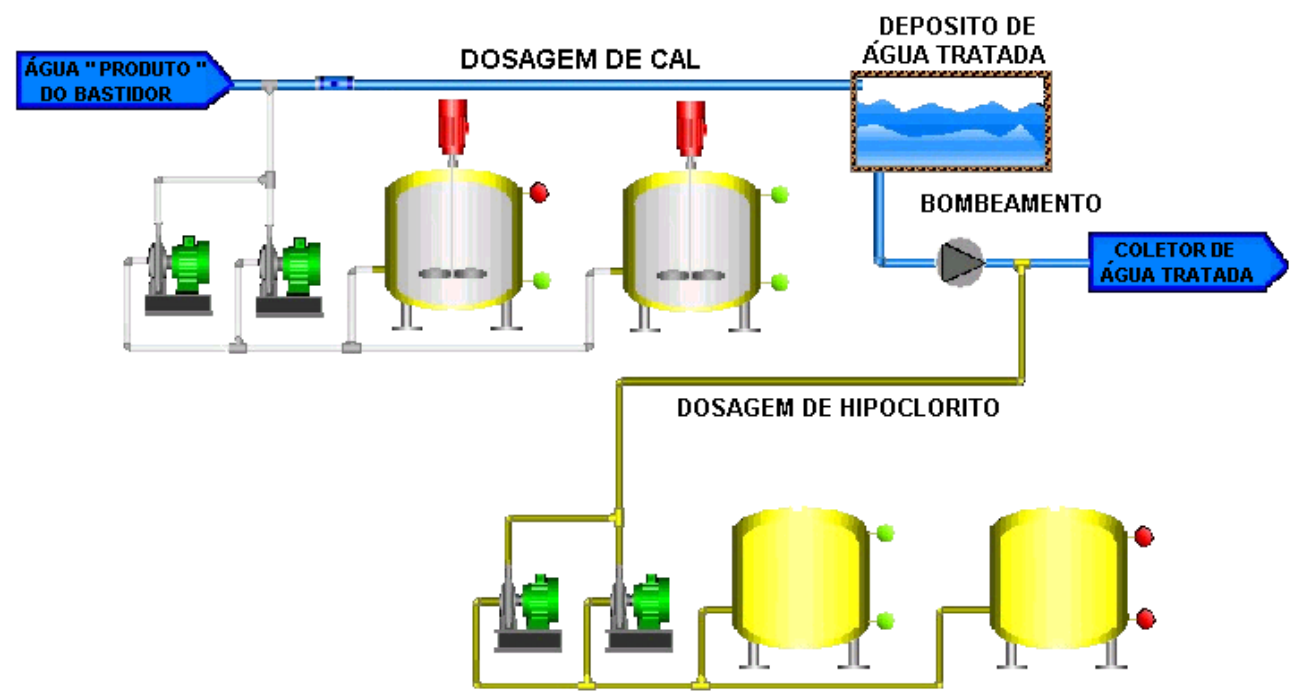

Fig. 6.7: Armazenamento e tratamento químico da água dessalinizada.

A seguir apresentam-se as etapas que conduzem ao dimensionamento do sistema proposto nesta tese (veja-se o sistema na Fig. 3.15) para que se tenha uma produção idêntica à da referida unidade convencional. 


\subsection{1 -Dimensionamento da CPH usando o sistema 1}

\section{Dimensionamento dos êmbolos}

Como visto no capítulo 4, a pressão P exercida pelo êmbolo especial E1 (representado no esquema anexado à tabela 6.1) na sua base é função do nível $\boldsymbol{n}$ de água no reservatório $\mathrm{R} 2$ e dos parâmetros geométricos $\boldsymbol{a}, \boldsymbol{b}, \boldsymbol{t}, \boldsymbol{d e}, \boldsymbol{d i}, \boldsymbol{D e}, \boldsymbol{D i}$. Essa função é dada por (a dedução da função encontra-se no anexo A):

$$
\left.P=\frac{g}{d e^{2}}\left[\rho_{a c ̧ o}\left(D e^{2} b+d e^{2} a\right)-D i^{2}(b-2 t)-d i^{2} a\right]+\rho_{\text {agua }} D i^{2} n+\rho_{e n c h} d i^{2} a\right]
$$

Com a Eq. 6.1, inserida numa planilha do Excel, e tendo presente o gráfico de sensibilidade da pressão em relação aos parâmetros geométricos e o nível de água em R2 (Fig. A2 do anexo A), consegue-se dimensionar o êmbolo de acordo com restrições do projeto que podem ser físicas ou/e econômicas. A tabela 6.1 apresenta várias possibilidades de se ter um êmbolo cuja pressão na sua base seja 67 bar (pressão média de operação da unidade da Praia, células H14 a H22) e um dimensionamento para o valor de 55 bar (pressão de teste das membranas, célula H23). Os valores dos parâmetros foram obtidos tendo em conta o que foi colocado em relação ao dimensionamento dos êmbolos.

Decidiu-se manter o dimensionamento dos êmbolos com base no êmbolo especial A ainda que isso acarrete ter um êmbolo de maiores dimensões do que as que se teria se fosse usado o êmbolo especial B maciço.

Justificando tal decisão, relembra-se que o consumo específico teórico e ideal só depende da pressão exercida pelo êmbolo $(\mathrm{E} / \mathrm{V}=\mathrm{P})$ como foi demonstrado no anexo $\mathrm{B}$. 
Tabela 6.1: Resultados gerados a partir da Eq.6.1.

\begin{tabular}{|c|c|c|c|c|c|c|c|c|c|c|}
\hline & A & $\mathrm{B}$ & C & $\bar{D}$ & $E$ & $\mathrm{~F}$ & $\mathrm{G}$ & $\overline{\mathrm{H}}$ & 1 & $\bar{J}$ \\
\hline 1 & $\begin{array}{c}\text { Aceleração } \mathbf{g} \\
\text { [m/s2] }\end{array}$ & $\begin{array}{c}\text { Densidade do } \\
\text { aço [kgin } 3]\end{array}$ & $\begin{array}{c}\text { Densidade do } \\
\text { enchimento }\end{array}$ & $\begin{array}{c}\text { Densidade da } \\
\text { água [kgin3] }\end{array}$ & $\begin{array}{c}\text { Dimensẫo "a" } \\
\text { [m] }\end{array}$ & $\begin{array}{c}\text { Dimensẫo "b" } \\
\text { [m] }\end{array}$ & $\begin{array}{c}\text { De (diâm. ext. } \\
\text { maior) [m] }\end{array}$ & $\begin{array}{l}\text { de (diam. ext. } \\
\text { menor) [m] }\end{array}$ & $\begin{array}{c}\mathbf{t} \text { (espesura) } \\
{[\mathrm{m}]}\end{array}$ & $\begin{array}{l}\text { n (nivel em } \\
\text { R2) [m] }\end{array}$ \\
\hline 2 & 9,8 & 7800 & 11400 & 1025 & 2 & 2,8 & 5,5 & 0,5 & 0,1 & 2,601 \\
\hline 3 & 9,8 & 7800 & 11400 & 1025 & 2 & 2,1 & 5 & 0,29 & 0,01 & 1,884 \\
\hline 4 & 9,8 & 7800 & 11400 & 1025 & 2,5 & 2,1 & 5 & 0,29 & 0,01 & 1,86 \\
\hline 5 & 9,8 & 7800 & 11400 & 1025 & 3 & 2,5 & 6 & 0,41 & 0,01 & 2,702 \\
\hline 6 & 9,8 & 7800 & 11400 & 1025 & 3 & 1,5 & 6 & 0,5 & 0,15 & 1,389 \\
\hline 7 & 9,8 & 7800 & 11400 & 1025 & 1,71 & 2 & 5 & 0,3 & 0,015 & 1,95 \\
\hline 8 & 9,8 & 7800 & 11400 & 1025 & 3,5 & 1,5 & 8 & 0,41 & 0,01 & 1,467 \\
\hline 9 & 9,8 & 7800 & 11400 & 1025 & 4 & 3 & 5 & 0,35 & 0,01 & 2,758 \\
\hline 10 & 9,8 & 7800 & 11400 & 1025 & $\frac{7}{4}$ & 3,2 & 4 & 0,3 & $\begin{array}{l}0,01 \\
0,01 \\
\end{array}$ & 3,15 \\
\hline 11 & 9,8 & 7800 & 11400 & 1025 & 1,8 & 2 & 4,5 & 0,3 & 0,015 & 1,928 \\
\hline 12 & & & & & & & & \multirow{2}{*}{$\begin{array}{c}\text { Pressão } \\
\text { [bar] }\end{array}$} & & \\
\hline 13 & $\mathrm{Di}=\mathrm{De}-2 \mathrm{t}[\mathrm{m}]$ & $\begin{array}{l}\text { di (diânnetro } \\
\text { interno) }\end{array}$ & $\begin{array}{c}\text { Massa } \\
\text { enchiment }[k g]\end{array}$ & $\begin{array}{c}\text { Massa de Aço } \\
{[\mathrm{kg}]}\end{array}$ & $\begin{array}{l}\text { Massa de } \\
\text { Água }[\mathrm{kg}]\end{array}$ & $\begin{array}{l}\text { Massa total } \\
{[\mathrm{kg}]}\end{array}$ & Pressẫo [Pa] & & Pressẫo [PSI] & \begin{tabular}{|l|} 
Massa de E1 \\
sem água [kg]
\end{tabular} \\
\hline 14 & 5,30 & 0,40 & 3648,00 & 92398,80 & 74888,64 & 170935,44 & 6700669,34 & 67,01 & 971,85 & 96046,80 \\
\hline 15 & 4,98 & 0,40 & 3648,00 & 5954,27 & 47892,05 & 57494,32 & 6699695,17 & 67,00 & 971,71 & 9602,27 \\
\hline 16 & 4,98 & 0,40 & 4560,00 & 5658,26 & 47281,96 & 57500,22 & 6700382,70 & 67,00 & 971,81 & 10218,26 \\
\hline 17 & 5,98 & 0,40 & 5472,00 & 10440,36 & 99040,22 & 114952,58 & 6701578,03 & 67,00 & 971,98 & 15912,36 \\
\hline 18 & 5,70 & 0,40 & 5472,00 & 119199,60 & 46256,83 & 170928,43 & 6700394,27 & $\frac{67,02}{67,00}$ & 971,81 & 124671,60 \\
\hline 19 & 4,97 & 0,29 & 1639,45 & 10524,66 & 49370,92 & 61535,03 & 6700481,49 & 67,00 & 971,82 & 12164,11 \\
\hline 20 & 7,98 & 0,27 & 2908,71 & 16272,42 & 95754,63 & 114935,76 & 6700597,42 & 67,01 & 971,84 & 19181,13 \\
\hline 21 & 4,98 & 0,30 & 4104,00 & 9553,50 & 70109,49 & 83766,99 & 6701359,45 & 67,01 & 971,95 & 13657,50 \\
\hline 22 & $\begin{array}{l}4,90 \\
3,98\end{array}$ & $\begin{array}{l}0,100 \\
0,28\end{array}$ & 3575,04 & 6816,64 & 51144,69 & 61536,37 & 6700626,94 & 67,01 & |971,84 & 10391,68 \\
\hline 23 & 4,47 & 0,40 & 3283,20 & 7890,69 & 39486,25 & 50660,15 & 5516326,92 & 55,16 & 800,08 & 11173,89 \\
\hline & & & & & & $\mathbf{D}_{\mathbf{i}}$ & ENCHIMI & 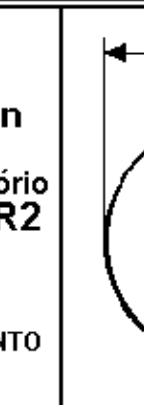 & $\overline{D_{\mathrm{e}}}$ & \\
\hline
\end{tabular}

Das várias possibilidades apresentadas na tabela 6.1, destacaram-se três que estão reunidas na tabela 6.2. Os valores correspondentes a essas possibilidades poderão ser adotadas para cálculos que conduzam ao dimensionamento do sistema para atendimento da demanda equivalente à da unidade dessalinizadora da ilha de Santiago, cidade da Praia.

Tabela 6.2: Resultados extraídos da tabela 6.1.

\begin{tabular}{|c|c|c|c|c|c|c|}
\hline $\begin{array}{c}\mathbf{a}[\mathrm{m}] \\
(\mathrm{col} . \mathrm{E})\end{array}$ & $\begin{array}{c}\mathbf{b}[\mathrm{m}] \\
(\mathrm{col} . \mathrm{F})\end{array}$ & $\begin{array}{c}\text { De }[\mathrm{m}] \\
(\mathrm{col} . \mathrm{G})\end{array}$ & $\begin{array}{c}\mathbf{d e} \\
{[\mathrm{cm}]} \\
(\mathrm{col} . \mathrm{H})\end{array}$ & $\begin{array}{c}\mathbf{t}[\mathrm{cm}] \\
(\mathrm{col} . \mathrm{I})\end{array}$ & $\begin{array}{c}\mathbf{n}[\mathrm{m}] \\
(\mathrm{col} . \mathrm{J})\end{array}$ & $\begin{array}{c}\text { "Massa" de E1 sem água } \\
{[\mathrm{kg}]}\end{array}$ \\
\hline 2 & 2,8 & 5,5 & 50 & 10 & 2,601 & $\mathbf{9 6 0 4 6 , 8 0} \mathrm{J14}, \mathrm{J19}$ e J22) \\
\hline 1,71 & 2 & 5 & 30 & 1,5 & 1,95 & $\mathbf{1 2 1 6 4 , 1 1}$ \\
\hline 4 & 3,2 & 4 & 30 & 1 & 3,15 & $\mathbf{1 0 3 9 1 , 6 8}$ \\
\hline
\end{tabular}


Pelos valores da tabela 6.2 percebe-se que se tem êmbolos cuja altura (soma de a com b) não ultrapassa os 8 metros, tendo-se inclusive um cuja altura é de 3,71 metros. Este pode funcionar numa $\mathrm{CPH}$ de 5,3 metros. Comparativamente, recorde-se que o êmbolo dimensionado para 55 bar tem 17 metros de altura podendo funcionar numa CPH de 25 metros.

A Fig. 6.8 apresenta dois dos êmbolos com as respetivas dimensões obtidas pelo dimensionamento. Os valores indicados foram obtidos da segunda linha da tabela 6.2 (êmbolo com pressão de 67 bar) e das linhas 11 e 23 da tabela 6.1 (êmbolo com pressão de 55,16 bar).

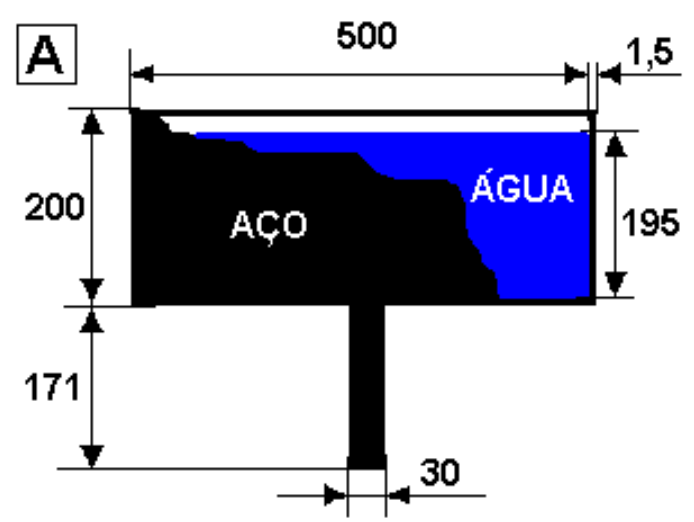

Dimensões em [cm]

Pressão na base: 67,00 bar

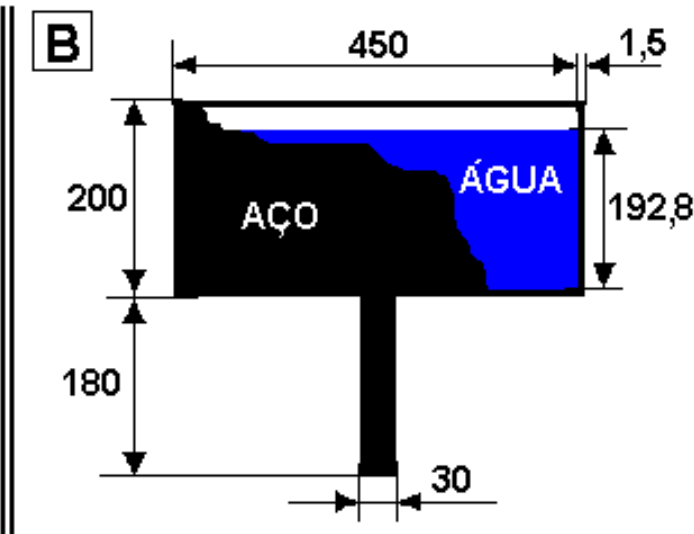

Dimensões em [cm]

Pressão na base: $\mathbf{5 5 , 1 6}$ bar $(800,08$ psi)

Fig. 6.8: Êmbolos de dimensões relativamente pequenas. A-êmbolo que com nível de água igual a $195 \mathrm{~cm}$, exerce na sua base uma pressão de 67 bar. B-êmbolo que com nível de água igual a 192,8 cm, exerce na sua base uma pressão de 55,16 bar.

Note-se que se o dimensionamento for feito com base num êmbolo maciço (êmbolo B do anexo A), consegue-se dimensões menores para a e b.

\section{Determinação do número de cataventos}

Nesta secão retomam-se algumas das equações apresentadas no capítulo 4 na seção 4.4 [Potência de bombeamento com cata-vento (Sistema 1) ]. Numa primeira análise, referese que a determinação do número de aerogeradores seria feita de forma análoga tendo em conta a potência de bombeamento com essas máquina eólicas (sistema 2). 
Os cálculos terão como base não só o que foi exposto no capítulo 4 mas também outros estudos análogos sobre bombeamento eólico realizados e publicados.

Como já foi referido na seção 4.3, para a determinação do número de cataventos ou de aerogeradores necessários, há que conhecer não só o regime dos ventos no local onde se pretende instalar o sistema, mas também a capacidade que essas máquinas têm de converter o potencial eólico disponível em energia mecânica.

Retomando a Eq. 4.11, o potencial eólico por unidade de área $\mathbf{P}_{\mathbf{e}} / \mathbf{A}$ disponível do vento é obtido por (SILVA,C.D et al):

$\mathrm{P}_{\mathrm{e}} / \mathrm{A}=k \mathrm{~V}^{3}$

A partir da recomendação segundo a qual a velocidade mínima que viabiliza o aproveitamento da energia eólica para bombeamento de água é de $3 \mathrm{~m} / \mathrm{s}$ (SILVA,C.D et al), deduz-se que Cabo Verde é um país privilegiado nessa matéria dado que o seu potencial eólico é acima do dobro desse valor (veja-se a Fig. 6.2-D).

De acordo com o exposto na seção 4.3 e representado pela Eq. 4.12, na prática, o potencial eólico $\mathrm{P}_{\mathrm{e}}$ reduz-se ao valor dado por:

$\mathrm{P}_{\mathrm{e}}=0,3 \quad \mathrm{~A} \quad k \quad \mathrm{~V}^{3} \quad[\mathrm{~W}]$

A conversão do potencial obtido pela Eq. 6.3 em potência de bombeamento (potência hidráulica, $\mathrm{P}_{\mathrm{b}}$ ) resulta numa redução que depende das eficiências da transmissão mecânica e da bomba. Assim, num dado local com uma velocidade média do vento, a potência hidráulica de saída média é calculada através da equação (SILVA,C.D et al):

$P_{b}=0,1 \quad A \quad V^{3}$

$\mathbf{P}_{\mathbf{b}} \quad$ é a potência de bombeamento [W]

A é a área varrida pelo rotor do catavento $\left[\mathrm{m}^{2}\right]$

V é a velocidade média do vento [m/s] 
Tendo em conta que geralmente os rotores dos cataventos têm um diâmetro externo $\mathbf{D}$ e outro interno d, a área varrida é dada por $A=\pi / 4\left(D^{2}-d^{2}\right)$. Assim, a Eq. 6.4-A toma o seguinte formato:

$P_{b}=0,1 \pi / 4\left(D^{2}-d^{2}\right) V^{3}$

Para a correção da velocidade do vento para a altura do rotor usaremos a lei da potência representada pela Eq. 6.6 (detalhes na Eq.4.4) :

$\mathrm{V}=\mathrm{V}_{\mathrm{o}}\left(\mathrm{H} / \mathrm{H}_{\mathrm{o}}\right)^{\mathrm{n}}$

Após a determinação da potência hidráulica, a vazão de água bombeada em função da altura manométrica é dada por (consultar detalhes nas Eqs 4.30 a 4.32):

$Q_{m}=\left(3600 \cdot P_{b}\right) /\left(\rho_{a} \cdot g \cdot H_{m}\right)$

Com $\rho_{\mathrm{a}}=1025 \mathrm{~kg} / \mathrm{m}^{3}$ correspondente à densidade da água do mar a ser bombeada para $\mathrm{O}$ reservatório superior R1, a Eq. 6.7 reduz-se à:

$\mathbf{Q}_{\mathrm{m}}=\mathbf{P}_{\mathrm{b}} /\left(2,790 \mathbf{H}_{\mathrm{m}}\right)$

De posse da Eq. 6.8, conhecendo a altura a que estiver o reservatório superior R1 reúnese duas condições que permitem determinar o número de cataventos necessários, em função da demanda diária de água dessalinizada. Assim, antes do cálculo do número de cataventos, faz-se de seguida a determinação da vazão necessária para suprir R1.

\section{Determinação da vazão necessária para abastecimento do reservatório $R 1$}

Foram feitas duas abordagens para determinar o volume de água que deve ser bombeado diariamente para o reservatório $\mathrm{R} 1$, para que se tenha uma determinada reserva que permita atender a produção diária de água dessalinizada. A primeira abordagem leva em conta a taxa de conversão (45\%), e a segunda usa o conceito de consumo específico "real" da CPH $\left(2,811 \mathrm{kWh} / \mathrm{m}^{3}\right)$. 
- Primeira abordagem: determinação do volume de água a ser bombeado com base na taxa de conversão.

A unidade de osmose reversa da Praia (República de Cabo Verde) cuja produção diária é de $5000 \mathrm{~m}^{3}$ trabalha com uma taxa de conversão de $45 \%$. Esse dado significa que de cada $100 \mathrm{~m}^{3}$ de água captada do mar obtém-se $45 \mathrm{~m}^{3}$ de água potável e os restantes $55 \mathrm{~m}^{3}$ retornam ao mar na forma de salmoura.

Numa primeira etapa, os cálculos foram feitos com base na taxa de conversão de $45 \%$ e os dados da velocidade média do vento da ilha de São Vicente, tabela 6.3. Com esses dados obteve-se o número de cataventos necessários (resultados da tabela 6.4) para bombear o volume de água do mar de $11111 \mathrm{~m}^{3}\left(45 \%\right.$ de $\left.11111 \mathrm{~m}^{3}=5000 \mathrm{~m}^{3}\right)$ suficiente para se conseguir $5000 \mathrm{~m}^{3}$ de água dessalinizada na unidade convencional da Praia.

Tabela 6.3: Dados da velocidade do vento, colhidos, a $10 \mathrm{~m}$ de altura, pela estação meteorológica da ilha de São Vicente.

\begin{tabular}{|c|c|c|c|c|c|c|c|c|c|c|c|c|c|c|c|}
\hline 2 & \multicolumn{10}{c|}{ Velocidade média do vento em [km/h] de São Vicente, período 1990/1997 } \\
\hline 3 & Ano & & Jan. & Fev. & Mar. & Abr. & Mai. & Jun. & Jul. & Ago. & Set. & Out. & Nov. & Dez. & Média \\
anual \\
\hline 4
\end{tabular}

O uso dos dados da ilha de São Vicente deve-se ao fato de ter sido menos difícil conseguí-los do que conseguir os dados da Praia. Contudo a avaliação não será afetada substancialmente dado que os dados da Praia não são significativamente diferentes dos de São Vicente, como se constata na Fig. 6.2-D.

Além das equações usadas na tabela 6.4 para a determinação da potência de bombeamento (Eqs 6.2, 6.3 e 6.4 ), as células da planilha dessa tabela contêm as seguintes: 
-A Eq. 4.4 que permite determinar o potencial eólico a uma dada altura $\mathbf{H}$ (célula C2).

-A Eq. 4.17 que determina a vazão diária $\mathbf{Q}_{\mathbf{m}}$ em função da altura manométrica $\mathbf{H}_{\mathbf{m}}$. A altura manométrica $\mathrm{H}_{\mathrm{m}}$ é inserida na célula B20.

O volume a ser bombeado para o reservatório superior R1 é introduzido na célula M12 como sendo a demanda diária de água do mar no referido reservatório.

Tabela 6.4: Número de cataventos (Fortuna, Kenya e Farroupilha, altura da torre igual a $25 \mathrm{~m}$ ) necessário para bombear $11111 \mathrm{~m}^{3} /$ dia de água do mar até uma altura manométrica de $7 \mathrm{~m}$.

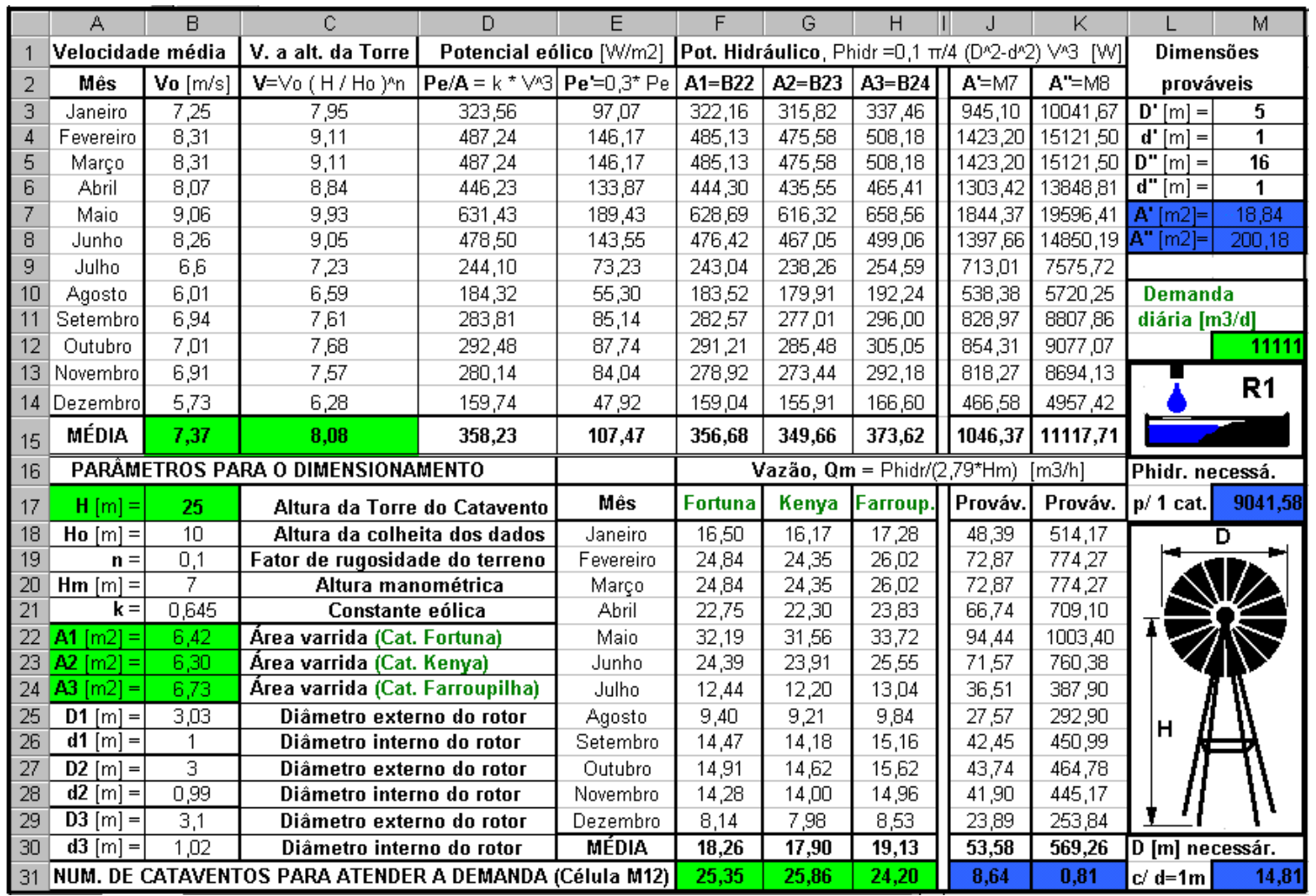

Da interpretação dos resultados da tabela 6.4, verifica-se que são necessários cerca de 25 cataventos Farroupilha (célula F31 da planilha) para atender a demanda diária de $11111 \mathrm{~m}^{3}$ de água do mar para o reservatório R1 que deverá estar a altura Hm. Para os cataventos Fortuna e Kenya tem-se em torno de um catavento a mais para se conseguir o mesmo objetivo.

As células J31 e K31 apresentam resultados obtidos com cataventos cujas pás têm as dimensões indicadas nas colunas $\mathrm{L}$ e $\mathrm{M}$ e linhas de 3 a 6 . Verifica-se que com um 
diâmetro externo de $5 \mathrm{~m}$ e interno de $1 \mathrm{~m}$ seriam precisos cerca de 9 cataventos (célula J31), e que há ainda a possibilidade de reduzir bastante esse número.

Tendo em pauta a possibilidade referida, foi feita uma estimativa de qual é o diâmetro externo $\mathrm{D}$ de um catavento que possa, sozinho, atender a demanda diária de $11111 \mathrm{~m}^{3} /$ dia em R1. Supõe-se que esse catavento tenha um diâmetro interno $\mathrm{d}=1 \mathrm{~m}$. Para a demanda, é necessário que o suposto catavento tenha um diâmetro externo aproximadamente igual à 14,81 m (resultado da célula M31). As equações que geram esse resultado resultam da manipulação algébrica das Eqs. 4.14 e 4.17.

Assim, a partir da Eq. 4.14, e tendo em conta que $A=\pi / 4\left(D^{2}-d^{2}\right)$, obtém-se:

$D=\sqrt{\left(4 * P_{b}\right) /\left(2,79 * V^{3}\right)+1}$

e $\mathrm{P}_{\mathrm{b}}$ é obtido a partir da Eq. 4.17, ou seja,

$$
P_{b}=Q_{m} * 2,79 * H_{m}
$$

Sendo o caudal horário $\mathrm{Q}_{\mathrm{m}}$ dado pelo quociente da demanda diária por 24 . $\mathrm{O}$ valor da velocidade usado na Eq. 6.8 é a média anual 8,08 m/s (célula C15). Com a Eq. 6.9 determina-se a potência de bombeamento necessária (resultado da célula M17) cujo valor é usado para se obter o diâmetro (Eq. 6.8 na célula M31).

Para demandas inferiores a $11111 \mathrm{~m}^{3} /$ dia é possível que seja mais fácil achar no mercado um catavento com o diâmetro que for obtido pela Eq. 6.8, ou então pode-se encomendar um com as dimensões pretendidas.

Através de uma pesquisa na Internet, achou-se referência a um catavento com o diâmetro aproximado de 16 metros. O referido catavento é produto de uma empresa canadense DELTX WINDPUMP CORPORATION e apresenta as seguintes caráterísticas (WORLD WINDMILL COMPANIES ): 
"WINDPUMP 50 WINDMILL: Catavento capaz de bombear 109000 litros por minuto com diâmetro de rotor de 52,5 ft. 7-30 rpm e altura de 39,6 metros"

Usando esse valor $(52,5 \mathrm{ft}=16,002 \mathrm{~m})$ na planilha da tabela 6.9 , verificou-se que:

- um único catavento desses (resultado da célula $K 31=0,81$ ), com uma torre de 25 metros, é suficiente para bombear, a partir do nível do mar, em média, cerca de $11111 \mathrm{~m}^{3}$ de água por dia, até o reservatório $\mathrm{R} 1$ situado a uma altura de 7 metros.

Se o uso do terreno for uma variável que encareça muito uma intalação da $\mathrm{CPH}$ em virtude de um número elevado de cataventos, cabe citar que a alternativa de turbinas eólicas de eixo vertical é uma solução a ser considerada. Isso porque nesse tipo de turbinas, a área varrida pode ser aumenta na direção vertical sem que isso implique aumento consideravel do espaço usado. Além da solução sugerida, é de realçar que o uso de cataventos com diâmetro de rotor de 16 metros, como o WINDPUMP 50 WINDMILL, ameniza consideravelmente o problema do uso do terreno.

A análise do consumo específico da CPH com base no volume de $11111 \mathrm{~m}^{3}$ no reservatório $\mathrm{R} 1$ e a quantidade de água dessalinizada $5000 \mathrm{~m}^{3} /$ dia conduziu à seguinte conclusão:

o volume de água a ser bombeado para R1 tem que ser superior a $11111 \mathrm{~m}^{3} / \mathrm{dia}$ porque nele terá que estar diariamente a massa $\mathbf{m}_{\mathbf{1}}$ de água da qual se consegue $5000 \mathrm{~m}^{3}$ /dia dessalinizada, mas também uma massa $\mathbf{m}_{2}$ de forma que haja suficiente energia potencial gravitacional (EPG) necesssária para o processo.

Em termos fisico-matemáticos tem-se EPG $=\left(\mathbf{m}_{\mathbf{1}}+\mathbf{m}_{\mathbf{2}}\right) \mathbf{g} \mathbf{H}_{\mathbf{m}}$, sendo que de $\mathbf{m}_{\mathbf{1}}$, com base na taxa de conversão, se tem a quantidade de água dessalinizada pretendida, e com $\mathbf{m}_{1}+\mathbf{m}_{2}$ colocados à altura $\mathbf{H}_{\mathrm{m}}$ se tem a energia necessária correspondente ao consumo específico da CPH. Assim, a segunda abordagem é a mais apropriada.

- Segunda abordagem: determinação do volume de água a ser bombeado com base no consumo específico da $\mathrm{CPH}$. 
O consumo específico é dado por $\mathbf{E} / \mathbf{V}\left[\mathrm{kWh} / \mathrm{m}^{3}\right]$ sendo $\mathbf{E}$ a energia consumida pela CPH e V o volume de água dessalinizada. A dedução detalhada desse parâmetro para a CPH encontra-se no anexo B. Nesse anexo está demonstrado que:

- O consumo específico de energia teórico da CPH não depende de como se consegue a subida do êmbolo.

Naturalmente, o consumo específico real será maior do que o teórico devido às irreversibilidades, sendo tanto maior quanto menos eficiente for a máquina usada e/ou o processo usado para elevar o êmbolo.

Para a CPH, concluiu-se que o consumo específico é dado por (anexo B):

$\mathbf{E} / \mathrm{V}=\mathbf{P}$

O resultado encontrado na relação 6.10 sugere que ,

A energia específica consumida na dessalinização por osmose reversa, através da CPH, com a utilização da energia potencial gravitacional, caráteriza-se pelos seguintes aspectos:

- Só depende da pressão P exercida pelo êmbolo especial, necessária para que ocorra a osmose reversa, e é numericamente sempre igual a ela.

- Não depende das dimensões do reservatório, que contém o volume de água por dessalinizar (Reservatório R3, na CPH).

- Não depende, nem das dimensões do êmbolo (êmbolo especial E1, na CPH), nem do material de que ele é feito (não computando o atrito).

Para avaliar o volume mínimo necessário, teremos em conta a relação $6.10(\mathbf{E} / \mathbf{V}=\mathbf{P})$ segundo a qual, o consumo específico teórico do modelo é igual à pressão exercida pelo êmbolo especial que é de 67 bar. Assim, tem-se: 
$1,861 \mathrm{kWh}$ equivale à energia mínima necessária para se dessalinizar cada metro cúbico de água do mar se a CPH usar um êmbolo cuja pressão na base seja 67 bar. Então para se dessalinizar $5000 \mathrm{~m}^{3}$, a energia mínima será $9305 \mathrm{kWh}$. O volume de água do mar a $7 \mathrm{~m}$ de altura em relação ao nível do mar (cota do reservatório R1) que equivale à uma energia potencial gravitacional de $9305 \mathrm{kWh}$ (33 $498 \mathrm{MJ}$ ) é dado pela equação $\mathbf{V}=\mathbf{E p} /\left(\boldsymbol{\rho g} \mathbf{H}_{\mathrm{m}}\right)$. Consequentemente, o volume mínimo de água que deverá ser bombeado até R1 diariamente, será:

$\mathbf{V}_{\text {min }}=\operatorname{Ep} /\left(\rho g H_{m}\right)=33498 \times 10^{6} /(1025 \times 9,8 \times 7)=\mathbf{4 7 6} 399,1 \mathbf{m}^{3}$.

O volume equivale ao consumo de energia teórico sem contabilizar as ineficiências dos sub-sistemas da CPH e as inevitáveis "perdas". Assim, assumindo valores dentro de limites atingíveis na prática de acordo com alguns trabalhos, tais como:

- rendimento de $\mathbf{7 5 \%}$, para o mecanismo de elevação do êmbolo (aceitável).

- as "perdas" no bastidor de membranas de 5\% ( segundo A SMALL-SCALE[...]).

- bomba Clark capaz de recuperar 93\% da energia da salmoura (segundo $A$ SMALL-SCALE[...]).

tem-se um rendimento global do sistema de recuperação de energia equivalente a $66,26 \%(0,75 \times 0,95 \times 0,93)$.

Com base nesse pressuposto, deduz-se que o consumo específico "real" tendo em conta a degradação de 33,74\% da energia potencial gravitacional "colocada" no reservatório R1 será de:

$\mathbf{E} / \mathbf{V}=1,861 / 0,662=\mathbf{2 , 8 1 1} \mathbf{k W h} / \mathbf{m}^{\mathbf{3}} . \quad$ (consumo especifico "real")

Apesar de se poder na prática operar com uma pressão de 55 bar, será determinado o número de cataventos para um consumo "real" de $\mathbf{2 , 8 1 1} \mathbf{k W h} / \mathbf{m}^{\mathbf{3}}$. Assim, a EPG necessária para a dessalinização de $5000 \mathrm{~m}^{3}$ é $14055 \mathrm{kWh}$. Consequentemente, o 
volume a ser bombeado até R1 a 7 metros de altura que corresponde a essa energia de 50598 MJ será,

$\mathbf{V}=\mathrm{Ep} /\left(\rho g \mathrm{H}_{\mathrm{m}}\right)=50598 \times 10^{6} /(1025 \times 9,8 \times 7)=\mathbf{7 1 9 5 9 0 , 4} \mathbf{~ m}^{\mathbf{3}}$.

$\mathrm{Na}$ tabela 6.5 encontram-se os resultados obtidos para o número de cataventos necessário para bombear essa quantidade de água do mar até o reservatório superior R1.

Tabela 6.5: Número de cataventos (Fortuna, Kenya e Farroupilha, altura da torre igual a $25 \mathrm{~m}$ ) necessário para bombear $719590,4 \mathrm{~m}^{3}$ /dia de água do mar até uma altura manométrica de 7 m (na célula B20 $\mathrm{Hm}=7$ ).

\begin{tabular}{|c|c|c|c|c|c|c|c|c|c|c|c|}
\hline 4 & A & $B$ & C & $\bar{D}$ & $\mathrm{E}$ & $\mathrm{F}$ & G & $\mathrm{H}$ & 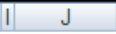 & K & $\bar{M}$ \\
\hline 1 & \multicolumn{2}{|c|}{ Velocidade média } & V. a alt. da Torre & \multicolumn{2}{|c|}{ Potencial eólico [W/m2] } & \multicolumn{5}{|c|}{ Pot. Hidráulico, Phidr $=0,1 \pi / 4\left(\mathrm{D}^{\wedge} 2-\mathrm{d}^{\wedge} 2\right) \mathrm{V}^{\wedge} 3$ [W] } & \multirow{2}{*}{$\begin{array}{c}\text { Dimensões } \\
\text { prováveis }\end{array}$} \\
\hline 2 & Mês & Vo $[\mathrm{m} / \mathrm{s}]$ & $\mathrm{V}=\mathrm{V}_{0}\left(\mathrm{H} / \mathrm{Ho}_{0}\right)^{n} \mathrm{n}$ & $\mathrm{Pe} / \mathrm{A}=\mathrm{k}^{*} \mathrm{~V}^{\wedge} 3$ & $\mathrm{Pe}^{\prime}=0,3^{*} \mathrm{Pe}$ & $\mathrm{A} 1=\mathrm{B} 22$ & $\mathrm{~A} 2=\mathrm{B} 23$ & A3=B24 & $A^{\prime}=M 7$ & $A^{\prime \prime}=M 8$ & \\
\hline 3 & Janeiro & 7,25 & 7,95 & 323,56 & 97,07 & 322,16 & 315,82 & 337,46 & 24572,55 & 10041,67 & $\mathrm{D}^{\prime}[\mathrm{m}]=$ \\
\hline 4 & Fevereiro & 8,31 & 9,11 & 487,24 & 146,17 & 485,13 & 475,58 & 508,18 & 37003,20 & 15121,50 & $d^{\prime}[\mathrm{m}]=$ \\
\hline 5 & Março & 8,31 & 9,11 & 487,24 & 146,17 & 485,13 & 475,58 & 508,18 & 37003,20 & 15121,50 & $\mathrm{D}^{\prime \prime}[\mathrm{m}]=$ \\
\hline 6 & Abril & 8,07 & 8,84 & 446,23 & 133,87 & 444,30 & 435,55 & 465,41 & 33888,85 & 13848,81 & $\mathrm{~d}^{\prime \prime}[\mathrm{m}]=$ \\
\hline 7 & Maio & 9,06 & 9,93 & 631,43 & 189,43 & 628,69 & 616,32 & 658,56 & 47953,56 & 19596,41 & $\mathrm{~A}^{\prime}[\mathrm{m} 2]=$ \\
\hline 8 & Junho & 8,26 & 9,05 & 478,50 & 143,55 & 476,42 & 467,05 & 499,06 & 36339,29 & 14850,19 & $\mathrm{~A}^{\prime \prime}[\mathrm{m} 2]=$ \\
\hline 9 & Julho & 6,6 & 7,23 & 244,10 & 73,23 & 243,04 & 238,26 & 254,59 & 18538,22 & 7575,72 & \\
\hline 10 & Agosto & 6,01 & 6,59 & 184,32 & 55,30 & 183,52 & 179,91 & 192,24 & 13997,80 & 5720,25 & \multirow{2}{*}{\begin{tabular}{|c|} 
Demanda \\
diária $[\mathrm{m} 3 / \mathrm{d}]$
\end{tabular}} \\
\hline 11 & Setembro & 6,94 & 7,61 & 283,81 & 85,14 & 282,57 & 277,01 & 296,00 & 21553,34 & 8807,86 & \\
\hline 12 & Outubro & 7,01 & 7,68 & 292,48 & 87,74 & 291,21 & 285,48 & 305,05 & 22212,13 & 9077,07 & \\
\hline 13 & Novembro & 6,91 & 7,57 & 280,14 & 84,04 & 278,92 & 273,44 & 292,18 & 21275,04 & 8694,13 & \multirow{3}{*}{$\mathbf{R} 1$} \\
\hline 14 & Dezembro & 5,73 & 6,28 & 159,74 & 47,92 & 159,04 & 155,91 & 166,60 & 12131,10 & 4957,42 & \\
\hline 15 & MÉDIA & 7,37 & 8,08 & 358,23 & 107,47 & 356,68 & 349,66 & 373,62 & 27205,69 & 11117,71 & \\
\hline 16 & \multicolumn{4}{|c|}{ PARÂMETROS PARA O DIMENSIONAMENTO } & & \multicolumn{5}{|c|}{ Vazão, Qm = Phidr $/\left(2,79^{*} \mathrm{Hm}\right)[\mathrm{m} 3 / \mathrm{h}]$} & Phidr. necessá. \\
\hline 17 & $\mathrm{H}[\mathrm{m}]=$ & 25 & \multicolumn{2}{|c|}{ Altura da Torre do Catavento } & Mês & Fortuna & Kenya & Farroup. & Prováv. & Prováv. & $\mathrm{p} / 1 \mathrm{ca}$ \\
\hline 18 & $\mathrm{Ho}[\mathrm{m}]=$ & 10 & \multicolumn{2}{|c|}{ Altura da colheita dos dados } & Janeiro & 16,50 & 16,17 & 17,28 & 1258,20 & 514,17 & \\
\hline 19 & $\mathrm{n}=$ & 0,1 & \multicolumn{2}{|c|}{ Fator de rugosidade do terreno } & Fevereiro & 24,84 & 24,35 & 26,02 & 1894,69 & 774,27 & \multirow{11}{*}{ H } \\
\hline 20 & $\mathrm{Hm}[\mathrm{m}]=$ & 7 & \multicolumn{2}{|c|}{ Altura manométrica } & Março & 24,84 & 24,35 & 26,02 & 1894,69 & 774,27 & \\
\hline 21 & $\mathrm{k}=$ & 0,645 & \multicolumn{2}{|c|}{ Constante eólica } & Abril & 22,75 & 22,30 & 23,83 & 1735,22 & 709,10 & \\
\hline 22 & $\mathrm{~A} 1[\mathrm{~m} 2]=$ & 6,42 & \multicolumn{2}{|c|}{ Área varrida (Cat. Fortuna) } & Maio & 32,19 & 31,56 & 33,72 & 2455,38 & 1003,40 & \\
\hline 23 & $\mathrm{~A} 2[\mathrm{~m} 2]=$ & 6,30 & \multicolumn{2}{|c|}{ Área varrida (Cat. Kenya) } & Junho & 24,39 & 23,91 & 25,55 & 1860,69 & 760,38 & \\
\hline 24 & $\mathrm{~A} 3[\mathrm{~m} 2]=$ & 6,73 & \multicolumn{2}{|c|}{ Área varrida (Cat. Farroupilha) } & Julho & 12,44 & 12,20 & 13,04 & 949,22 & 387,90 & \\
\hline 25 & $\mathrm{D} 1[\mathrm{~m}]=$ & 3,03 & \multicolumn{2}{|c|}{ Diâmetro externo do rotor } & Agosto & & & 9 , & 716,73 & 292,90 & \\
\hline 26 & $\mathrm{~d} 1[\mathrm{~m}]=$ & 1 & \multicolumn{2}{|c|}{ Diâmetro interno do rotor } & Setembro & 14,47 & 14,18 & 15,16 & 1103,60 & 450,99 & \\
\hline 27 & $\mathrm{D} 2[\mathrm{~m}]=$ & 3 & \multicolumn{2}{|c|}{ Diâmetro externo do rotor } & Outubro & 14,91 & 14,62 & 15,62 & 1137,33 & 464,78 & \\
\hline 28 & $\mathrm{~d} 2[\mathrm{~m}]=$ & 0,99 & \multicolumn{2}{|c|}{ Diâmetro interno do rotor } & Novembro & 14,28 & 14,00 & 14,96 & 1089,35 & 445,17 & \\
\hline 29 & $\mathrm{D} 3[\mathrm{~m}]=$ & 3,1 & \multicolumn{2}{|c|}{ Diâmetro externo do rotor } & Dezembro & 8,14 & 7,98 & 8,53 & 621,15 & 253,84 & \\
\hline 30 & $\mathrm{~d} 3[\mathrm{~m}]=$ & 1,02 & \multicolumn{2}{|c|}{ Diâmetro interno do rotor } & MÉDIA & 18,26 & 17,90 & 19,13 & 1393,02 & 569,26 & D [m] necessár. \\
\hline 31 & NUM. DE C & CATAVEN & OS PARA ATENDE & R A DEMAND & élula M12) & 1641,72 & 1674,68 & 1567,26 & 21,52 & 52,67 & $\mathrm { c } / \mathrm { d } = 1 \mathrm { m } \longdiv { 1 6 0 , 8 3 }$ \\
\hline
\end{tabular}

Pelos resultados da tabela 6.5, nota-se que o aumento em número de cataventos Kenya, Fortuna e Farroupilha é significativo (cerca de 1600). Tem-se em média 1 catavento desses para a dessalinização de três metros cúbicos de água do mar por dia. Recorrendo aos cataventos WINDPUMP 50 WINDMILL, a situação é amenizada dado que precisa-se de 53 deles (resultado da célula K31) para atender a demanda. Pelo resultado da célula $\mathbf{J 3 1}$ verifica-se que se necessita de 22 cataventos que tivessem 25 metros de diâmetro. 
Em suma, usando dados de uma unidade convencional, e com valores teóricos (dentro dos limites possíveis de se conseguir na prática) para os rendimentos dos mecanismos do modelo proposto, pode-se inferir que:

- O consumo específico "real" é próximo do mínimo teórico apontado em "Reverse Osmosis" (SOURIRAJAN, 1970) para dessalinização de água do mar com $100 \%$ de taxa de conversão.

- O consumo específico "real" de um modelo da CPH que se propõe construir futuramente venha a ser inferior ao da unidade convencional da cidade Praia, que é em torno de $4,12\left[\mathrm{kWh} / \mathrm{m}^{3}\right]$.

Apesar do elevado número de cataventos com diâmetro de $3 \mathrm{~m}$, em contrapartida, se for feita a análise do benefício social que se consegue com a dessalinização de $5000 \mathrm{~m}^{3}$ de água por dia, distribuindo-os pela população da ilha de São Vicente, por exemplo, tem-se:

$5000000[1 / \mathrm{dia}] / 70000[\mathrm{hab}]=71,42$ litros por habitante por dia .

Compare-se esse valor com os 20 litros, recomendados pela OMS e as Nações Unidas para o consumo diário de uma pessoa em zonas semi-áridas.

\section{Dimensionamento do sistema de elevação do êmbolo especial}

Para este item, considere-se as caráterísticas do êmbolo representado na Fig. 6.9. O peso do êmbolo sem o volume de água contido em R2 será determinado em função da pressão que ele exerce na sua base. Para elevá-lo usar-se-á um sistema de roldanas como o ilustrado na Fig. 6.9. O êmbolo dispõe de ganchos que distribuem o seu peso. 


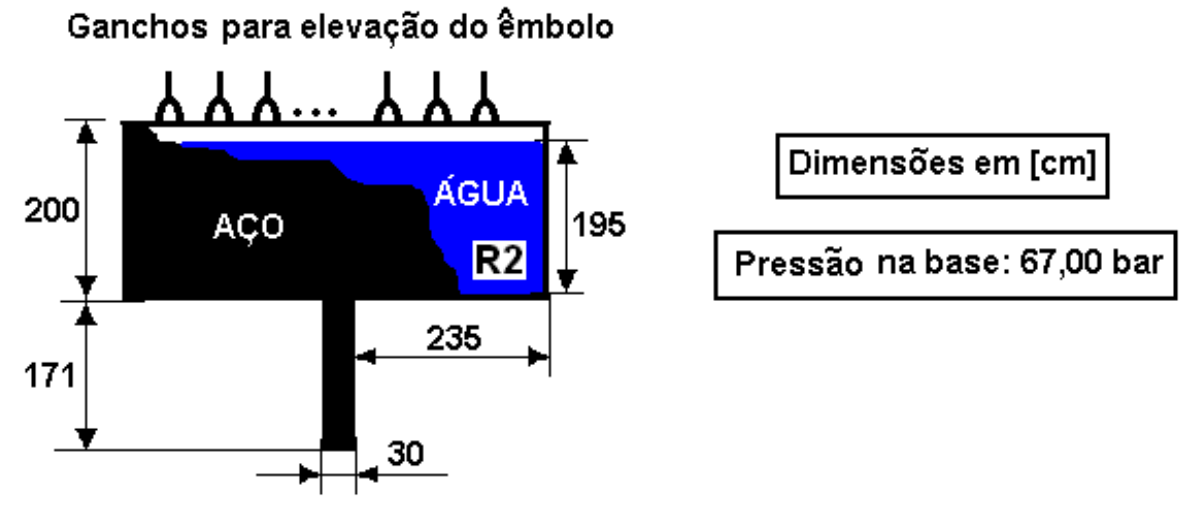

Fig. 6.9: Êmbolo especial A munido de ganchos para a sua elevação.

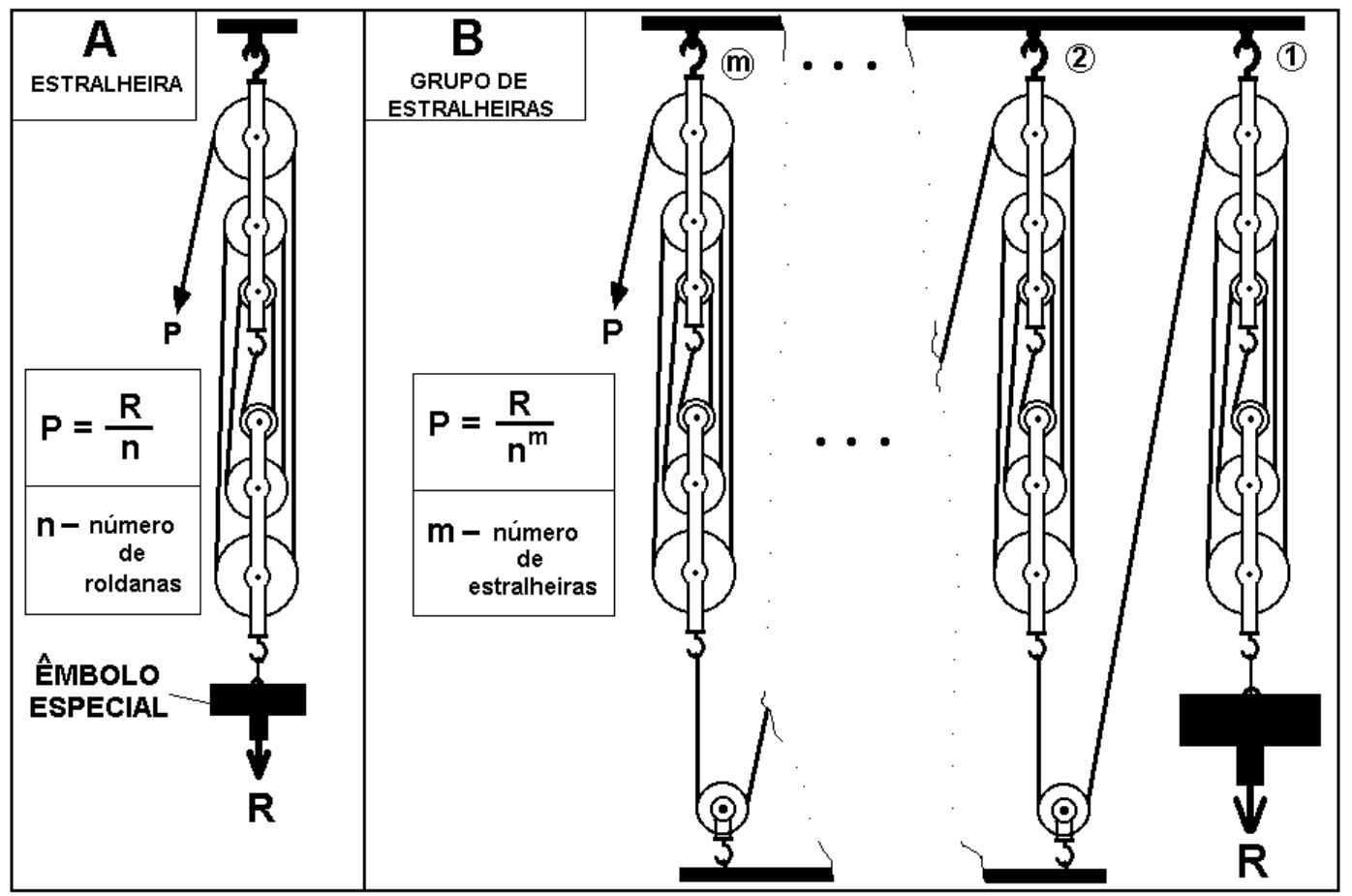

Fig. 6.10: Associação de roldanas. A: estralheira, B-grupo de estralheiras.

A pressão na base do êmbolo $\mathrm{P}_{\mathrm{op}}$ é dada por:

$\mathrm{P}_{\mathrm{op}}=4\left(\mathrm{P}_{\mathrm{ev}}+\mathrm{P}_{\mathrm{agua}}\right) /\left(\pi \mathrm{d}_{\mathrm{e}}^{2}\right)$

sendo,

$\mathbf{P}_{\text {op }}$ a pressão de operação $\left[\mathrm{N} / \mathrm{m}^{2}\right]$

$\mathbf{P}_{\mathbf{e v}}$ o peso correspondente à massa sólida do êmbolo (peso do êmbolo vazio) [N], 
$\mathbf{P}_{\text {agua }}$ o peso da água contida em R2 [N],

de o diâmetro da base do êmbolo [m].

Resolvendo a Eq. 6.11 para $\mathrm{P}_{\mathrm{ev}}$,obtém-se

$\mathrm{P}_{\mathrm{ev}}=\left(\mathrm{P}_{\mathrm{op}} \pi \mathrm{d}_{\mathrm{e}}^{2}-4 \mathrm{P}_{\text {agua }}\right) / 4$

O peso da água contida em R2 é dado por $\boldsymbol{\rho}_{\text {agua }} \mathbf{V}_{\text {agua }} \mathbf{g}$, sendo o volume de água dado por:

$\mathrm{V}_{\text {agua }}=\pi \mathrm{Di}^{2} / 4 \mathrm{n}$

sendo,

Di é o diâmetro interno de R2.

n é o nível de água em R2.

Logo o peso da água contida em R2 é dado por,

$\mathrm{P}_{\text {agua }}=\rho_{\text {agua }} \pi \mathrm{Di}^{2} / 4 \mathrm{ng}$

Substituindo a Eq. 6.14 na Eq. 6.12 vem,

$\mathrm{P}_{\mathrm{ev}}=\left(\mathrm{P}_{\mathrm{op}} \mathrm{d}_{\mathrm{e}}^{2}-\rho_{\mathrm{agua}} \mathrm{Di}^{2} \mathrm{ng}\right) \pi / 4$

$\mathbf{P}_{\text {ev }}$ corresponde ao peso que terá de ser elevado pelo sistema de elevação do êmbolo, que será designado por $\mathbf{R}$ para que fique em conformidade com o esquema da Fig. 6.10.

Com os seguintes dados:

$$
\begin{aligned}
& P_{o p}=67 \times 10^{5} \mathrm{~N} / \mathrm{m}^{2} \\
& \mathrm{~d}_{\mathrm{e}}=0,3 \mathrm{~m} \\
& \text { Di }=4,97 \mathrm{~m} \\
& \mathrm{n}=1,95 \mathrm{~m}
\end{aligned}
$$


$\rho_{\text {agua }}=1025 \mathrm{~kg} / \mathrm{m}^{3}$

$\mathrm{g}=9,8 \mathrm{~m} / \mathrm{s}^{2}$,

$\pi=3,14$

inseridos na Eq. 6.15 tem-se,

$P_{\mathrm{ev}}=\left(67 \times 10^{5} \times 0,3^{2}-1025 \times 4,97^{2} \times 1,95 \times 9,8\right) \times 3,14 / 4=93544,48 \mathrm{~N}=93,54 \mathrm{kN}$.

Consequentemente, o peso que o sistema constituído por roldanas e contrapeso terá que elevar será $\mathrm{R}=93,54 \mathrm{kN}$.

Para que o contrapeso não tenha que percorrer uma distância $\mathbf{D}_{\mathbf{p}}$ (veja-se no esquema da tabela 6.6) bastante grande, o sistema de roldanas proposto deverá ser constituído por um conjunto de roldanas idêntico ao da Fig. 6.10- B sendo que a extremidade de cada um, que suporta o peso R, deverá ser presa aos ganchos para elevação do êmbolo ilustrados na Fig. 6.9.

O peso do contrapeso capaz de elevar o êmbolo é dado por $\left(\mathbf{P}=\mathbf{R} / \mathbf{n}^{\mathbf{m}}\right)$. Distribuindo o peso do êmbolo por 8 ganchos distanciados entre si por cerca de $60 \mathrm{~cm}(500 / 8=62,5)$, tem-se $\mathbf{R}^{\prime}=\mathbf{1 1 , 6 9} \mathbf{k N}$. Se o sistema proposto tiver 3 grupos de estralheiras com quatro roldanas cada $(n=4$ e $m=3)$ o peso do contrapeso será igual a:

$\mathbf{P}=11690 / 4^{3}=\mathbf{1 8 2 , 6 6} \mathbf{N}$

Esse valor corresponde à massa de 18,64 $\mathrm{kg}$ de água do mar, que equivale à $0,018 \mathrm{~m}^{3}$ desse líquido. Tendo um contrapeso cilíndrico com o diâmetro interno igual a 1 metro, o nível $\mathbf{N}$ de água que equivale a $0,018 \mathrm{~m}^{3}$ de água nele contido é dado por:

$\mathbf{N}=0,018 /\left(3,14 \times 0,5^{2}\right)=0,0229 \mathrm{~m}=\mathbf{2 , 3} \mathbf{~ c m}$ (nível baixo $\rightarrow$ contrapesos pequenos)

A distância $\mathbf{D}_{\mathbf{p}}$ percorrida pelo contrapeso será $\mathbf{D}_{\mathbf{p}}=\mathbf{R} \times \mathbf{D}_{\mathbf{r}} / \mathbf{P}$, sendo $D_{\mathrm{r}}$ a distância percorrida pelo êmbolo durante a sua subida (veja-se no esquema da tabela 6.6). Dado que, pelas dimensões do êmbolo (veja-se a Fig. 6-6), dispõe-se de no máximo $171 \mathrm{~cm}$ para a distância $D_{r}$, considere-se $D_{r}=160 \mathrm{~cm}$. Assim sendo, tem-se: 
$\mathbf{D}_{\mathbf{p}}=11690 \mathrm{~N} \times 1,6 \mathrm{~m} / 182,66 \mathrm{~N}=\mathbf{1 0 2 , 3 9} \mathbf{~ m}$ (demasiado para se usar contrapesos ).

O valor determinado corresponde à distância que 8 contrapesos de 18,64, kg cada teriam que percorrer ou que um só contrapeso de massa 8 × 23,8 $\mathrm{kg}$ teria que percorrer para elevar o êmbolo de 93, $54 \mathrm{kN}$ até 1,6 metros de altura.

Uma das alternativas para se ter uma distância menor é aumentar a massa do contrapeso (mais água no contrapeso) ou/e diminuir a massa do êmbolo especial. A esse respeito, convém recordar que a pressão na base do êmbolo ilustrado na Fig. 6.9 é de 67 bar e que se pode operar com uma pressão de 55 bar, podendo-se assim ter um êmbolo com menos massa. Outra delas seria reduzir o número de roldanas da estralheira.

As tabelas 6.6 e 6.7 resumem o dimensionamento do sistema de elevação do êmbolo. Se por exemplo usarmos somente $2(\mathrm{n}=2)$ roldanas ao invés de 4 , a distância $\mathbf{D}_{\mathbf{p}}$, a ser percorrida pelo contrapeso reduz-se para $\mathbf{1 2 , 8} \mathbf{~ m ~}\left[D_{p}=14900 \times 1,6 /\left(14900 / 2^{3}\right)\right]$ como se pode confirmar pela célula E2 da tabela 6.6

Tabela 6.6: Resultados do dimensionamento do sistema de elevação do êmbolo especial, cuja massa sem água é $9545,35 \mathrm{~kg}(=93544,43 / 9,8)$.

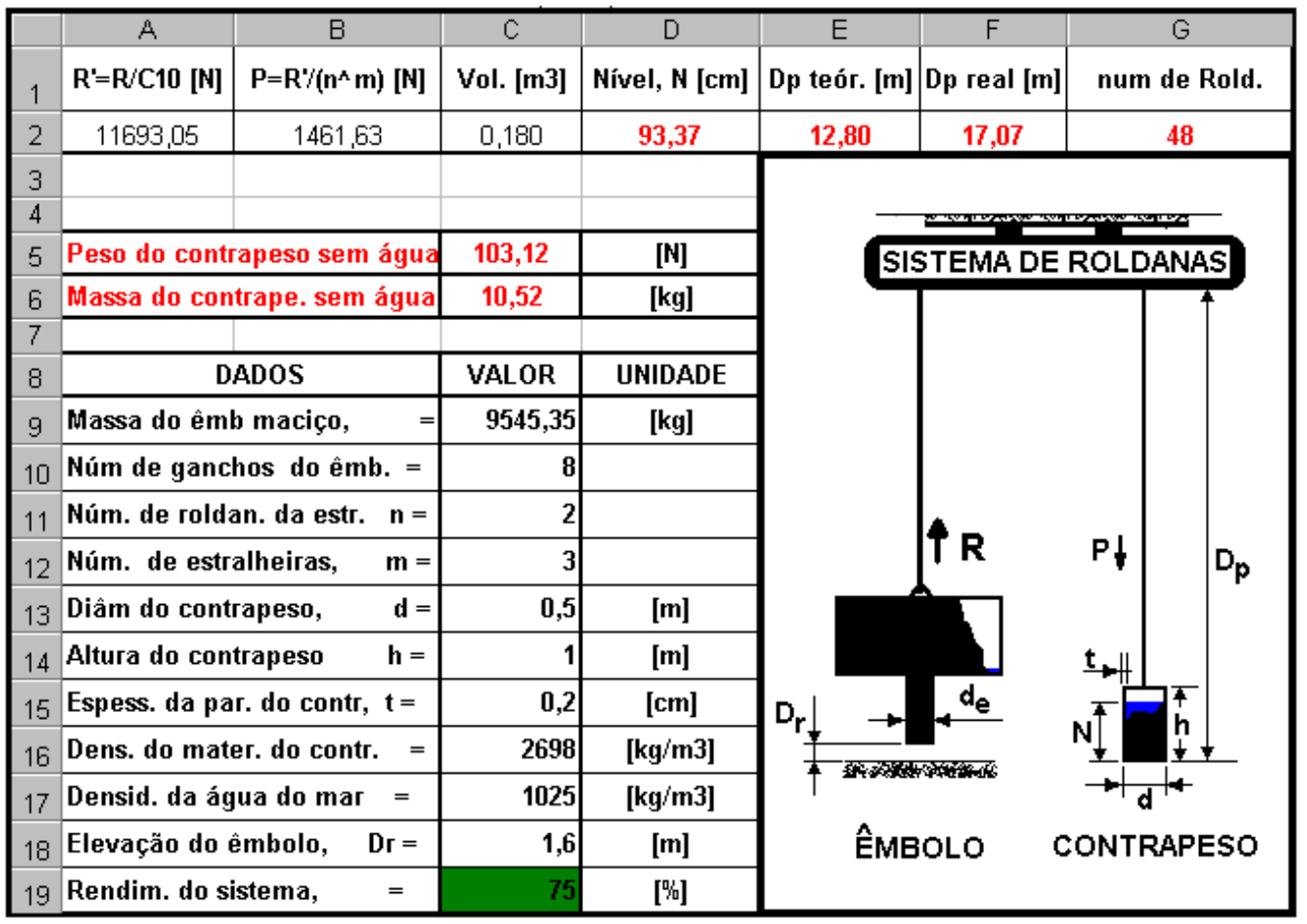


Se o contrapeso for de alumínio e tiver as dimensões indicadas nas células C13, C14 e $\mathrm{C} 15$, seu peso sem água será $103,12 \mathrm{~N}$, célula $\mathrm{C} 5=\rho \mathrm{g} \pi\left[\mathrm{hd}^{2} / 4-(\mathrm{d} / 2-\mathrm{t})^{2}(\mathrm{~h}-2 \mathrm{t})\right]$, e o nível de água do mar para que tenha o peso necessário deverá ser 93,37 cm (célula D2). Se for assumido um rendimento de $75 \%$ para o sistema, a distância real a ser percorrida pelo contrapeso será $17,07 \mathrm{~m}$ (célula F2). Se a preferência for por manter os 12,8 metros, tem-se a alternativa de compensar a ineficiência através do aumento do peso do contrapeso, o que poderá ser feito aumentado o nível $\mathbf{N}$ de água ou/e a espessura $\mathbf{t}$ da parede.

Fazendo o dimensionamento com os dados do êmbolo representado Fig. 6.8-B, obtem-se os resultados da tabela 6.7, que confirmam a possibilidade de redução de custos do sistema de elevação do êmbolo, se este tiver menores dimensões. O peso desse êmbolo $\mathbf{P}_{\mathbf{e v}}$ pela Eq. 6.15 é dado por:

$\mathbf{P}_{\mathrm{ev}}=\left(55 \times 10^{5} \times 0,3^{2}-1025 \times 4,47^{2} \times 1,928 \times 9,8\right) \times 3,14 / 4=84807,24 \mathrm{~N}=\mathbf{8 4}, \mathbf{8 1} \mathbf{k N}$

Tabela 6.7: Resultados do dimensionamento do sistema de elevação do êmbolo especial cuja massa sem água é $8653,8 \mathrm{~kg}$.

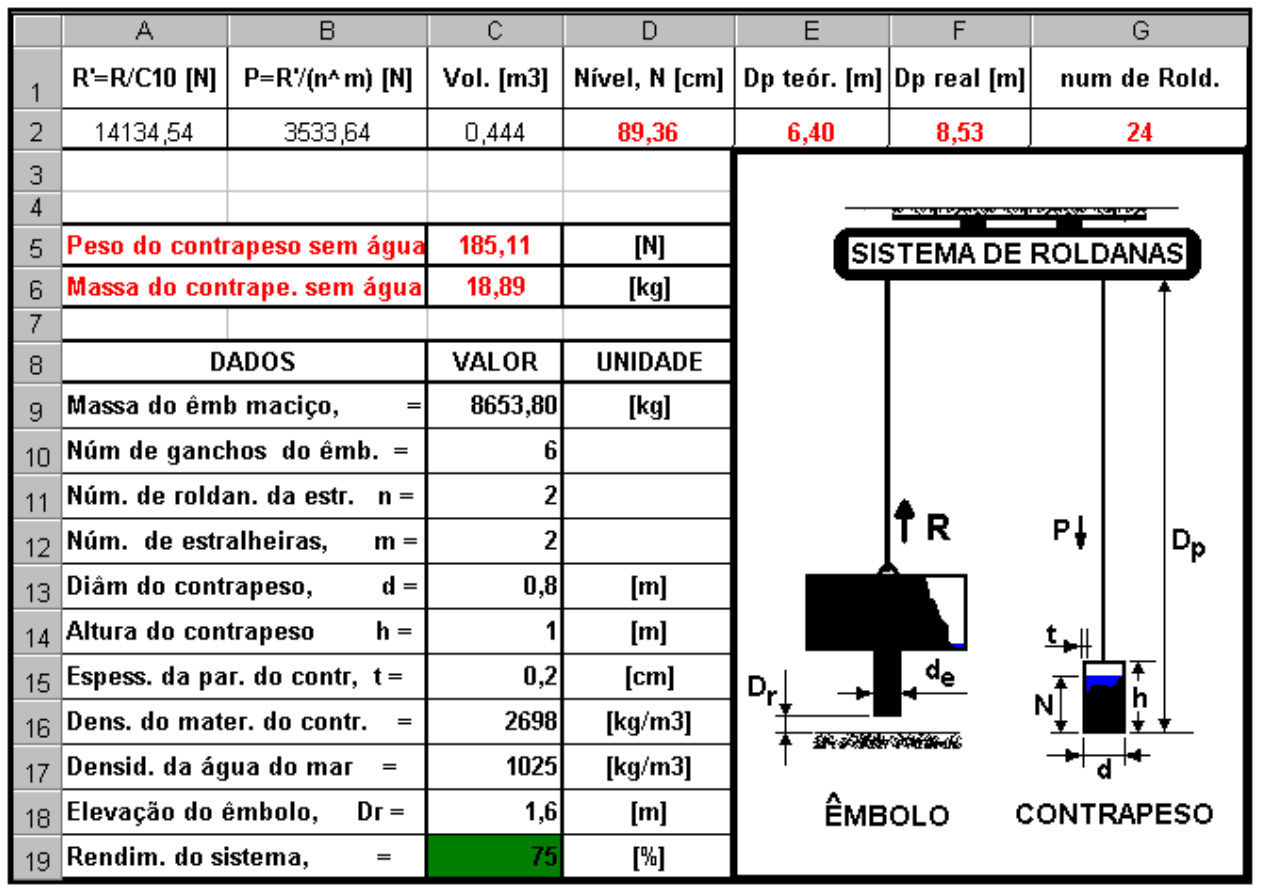

Assim, da comparação dos resultados das tabelas 6.6 e 6.7, verifica-se que se pode usar um sistema com 24 roldanas ao invés de 48 (células G2) e com redução do percurso 
teórico do contrapeso de 12,80 para 6,40 metros (células E2), às custas de um pequeno aumento da massa do contrapeso sem água (diferença entre as células C6) que corresponde ao custo de mais 8 x $8,37 \mathrm{~kg}$ de alumínio. Esse valor é provavelmente inferior ao custo de 24 roldanas pelo fato de se poder usar alumínio reciclado, ou até outro material para desempenhar a função de contrapeso como foi feito na terceira fase de construção do protótipo.

Como já tinha sido colocado na seção 3.11, uma alternativa para ultrapassar a dificuldade prática de se ter um percurso longo $D_{p}$ do contrapeso, na vertical, é a utilização de um eixo e uma roda Pelton para a elevação do êmbolo (anexo E). Para o valor de $D_{p}=102,4 \mathrm{~m}$, um eixo com o raio de 1 metro teria que dar cerca de 16 rotações para elevar o êmbolo a 1, $5 \mathrm{~m}$ de altura $[102,4 /(2 \pi \mathrm{r})]$. Com esta possibilidade, podese, em função do tempo disponível, reduzir infinitamente o esforço para elevar o êmbolo, às custas de um número maior de roldanas e um número elevado de rotações do eixo da roda Pelton, que seria posta em movimento pelo fluxo da salmoura.

\section{Determinação do número de módulos de membrana}

Tendo em conta que o procedimento adotado para o dimensionamento foi o de conseguir um determinado volume de água por dia passando pelo reservatório superior $\mathrm{R} 1$, que garanta $5000 \mathrm{~m}^{3} /$ dia de água dessalinizada, obtida através de um bastidor de módulos já conhecido de uma unidade convencional, não há necessidade de se determinar o número e o tipo de módulos necessários, por se tratar de informações de que se dispõe. Sabe-se que o bastidor da unidade em questão, Fig. 6.3-D, contém 560 módulos do tipo espiral.

No entanto, se se começa o dimensionamento pelo conhecimento dos módulos e respectivas caráterísticas principais, tais como, pressão de operação, vazão de água dessalinizada e taxa de conversão, o procedimento é o inverso do que foi seguido. Nesse caso a seqüência é:

- A partir da vazão de água dessalinizada fornecida por módulo, determina-se o número de módulos necessários para se atender a demanda de água potável. 
- Dimensiona-se o(s) êmbolo(s) para a pressão especificada no catalogo dos módulos. Esse valor é geralmente igual a 55 bar (célula H23 da tabela 6.1).

- A partir da taxa de conversão, determinar-se o volume de água do mar necessário, e consequentemente o número de cataventos necessário para o bombeamento.

Em relação a essa abordagem, tenha-se em conta que, o número de módulos determinado por essa via, é inferior aos 560 que constituem o bastidor da unidade convencional em estudo, como será mostrado na sequência através de simples cálculos. Isso explica-se pelo fato de haver a possibilidade de se ter uma distribuição dos módulos mais favorável em torno das CPH's. Recorde-se a esse respeito que a disposição em série dos módulos faz com que os últimos da série tenham uma produção inferior à especificada no catálogo devido à queda de pressão.

Para demonstrar o que foi colocado, considere-se os dados de módulos de membranas comerciais, apresentados em (PAREKH, 1988), cujo extrato se vê a seguir, na tabela da Fig. 6.11 (fac símile).

\begin{tabular}{|c|c|c|c|c|c|c|c|c|}
\hline $\begin{array}{l}\text { 104 } \\
\text { Table 9. Searal }\end{array}$ & ter Spirals & Allegreses & Commerciol & RO Mombrones & and Modicies & & & 105 \\
\hline \multirow[b]{2}{*}{ Manuf'ncturer } & \multirow[b]{2}{*}{$\begin{array}{c}\text { Module } \\
\text { nomenolature }\end{array}$} & \multirow[b]{2}{*}{$\begin{array}{c}\text { Module } \\
\text { dismeter } \\
\text { (min/in. })\end{array}$} & \multirow[b]{2}{*}{$\begin{array}{c}\text { Moxtule } \\
\text { lengtin } \\
\text { (mm/in.) }\end{array}$} & \multirow[b]{2}{*}{$\begin{array}{l}\text { Module } \\
\text { productivity } \\
\text { (mpdigpd) }\end{array}$} & \multirow{2}{*}{$\begin{array}{l}\text { Percent } \\
\text { l'ujuclion } \\
\text { (ninimum/ } \\
\text { avernee) } \\
\end{array}$} & \multicolumn{2}{|c|}{ Teat conditions } & \multirow[b]{2}{*}{ 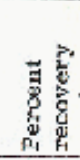 } \\
\hline & & & & & & $\begin{array}{c}\text { Salt } \\
\text { concont:ation } \\
\text { (ppu NuCl) }\end{array}$ & $\begin{array}{l}\text { Pres- } \\
\text { sure } \\
\text { (psi) }\end{array}$ & \\
\hline \multirow[t]{8}{*}{ FilmTee } & Si $30 \mathrm{HR}-4014$ & $99.1 / 3.9$ & $294.6 / 11.6$ & $0.7: 200$ & $00.2 / 90.5$ & $35,000^{2}$ & 300 & 3.5 \\
\hline & Siv $30 H R-4021$ & $99.1 / 3.9$ & 177.5:18.t: & $1 . \pi / 400$ & $99.2 / 99.5$ & $35,000^{a}$ & sob & 5.0 \\
\hline & Sw30 1040 & $99,1 / 3.9$ & $965.2 / 38$ & $5.7 / 1500$ & 98.6je!s. 1 & $35,000^{2}$ & 800 & 10.0 \\
\hline & $8 W 30 \mathrm{BO} 4 \mathrm{U}$ & $200 . i / 7.9$ & $1016 / 40$ & $23 / 6000$ & $98.6 / 99.1$ & $35,000^{a}$ & 800 & 10,0 \\
\hline & SW38 8536 & $215.4 / 8.48$ & $914.4 / 36$ & $35 / 6500$ & $98.6 ; 99.1$ & $35, n_{n} n^{a}$ & 800 & 10.0 \\
\hline & SW 30[]R-2514 & fi1. $0 / 2.4$ & $294.6 / 11.6$ & $0.25 / \quad 65$ & $99.2 / 09.5$ & $35, n \cap 0^{a}$ & 800 & 3.5 \\
\hline & SWI $300 \mathrm{HR}-2521$ & 61. $12 / 2.4$ & $477.5 / 18.6$ & $0.50 / 130$ & $99.2 / 99.5$ & $35.000^{\AA 9}$ & 800 & 5.4 \\
\hline & SW30HR - 4021 & $61.0 / 2.4$ & $965.2 / 39$ & $1.3 / 380$ & $99.2 / 99.5$ & $35,000^{\mathrm{B}}$ & 800 & 10.0 \\
\hline \multirow[t]{4}{*}{ Toray } & $\mathrm{SC} 8100$ & $|100.51 / 3.96|$ & $1016 \quad ; 40$ & $3.2 / 680$ & $55.0 / 06.0$ & $33,000^{\mathrm{b}}$ & 800 & - \\
\hline & $8 \mathrm{c} 8200$ & $201 / 7.817$ & $9016 \quad 860$ & $8.8 ; 2320$ & $95.0 / 96.0$ & $33,000^{\mathrm{b}}$ & 860 & - \\
\hline & SP-110 & $100.5 / 3.9 B$ & $1016 \quad: 10$ & $2.25 i \quad 585$ & $90.5 / 34.7$ & $33,000^{b}$ & 810 & - \\
\hline & $S P-120$ & $201 \quad / 7.91$ & $1016 \quad / 40$ & $0.0 ; 2380$ & $99.5 / 90,7$ & $33,000^{b}$ & $8 \mathrm{Co}$ & - \\
\hline
\end{tabular}

Fig. 6.11: Caráterísticas de módulos comerciais. Fonte: (PAREKH, 1988). 
O módulo do tipo espiral que foi destacado na Fig. 6.11, foi testado com água do mar (concentração de 35000 ppm) a uma pressão de 800 psi (cerca de 55 bar) e apresentou uma produção de $25 \mathrm{~m}^{3}$ por dia, com uma taxa de conversão de $10 \%$ e rejeição dos sais da ordem de $99,5 \%$.

Assim, para se ter $5000 \mathrm{~m}^{3}$ por dia de água dessalinizada com módulos SW38 $8536 \mathrm{da}$ FilmTec, precisa-se de cerca de 200 deles, ao invés dos 560 que compõem o bastidor da unidade da Praia. Atendendo às condições de teste do fabricante, é necessário um fluxo de $50000 \mathrm{~m}^{3} /$ dia ( taxa de conversão de $10 \%$ ) de água do mar, com uma pressão de 55 bar. É aconselhável não ultrapassar a taxa de conversão indicada pelo fabricante, através do aumento da pressão, sob pena de se comprometer a vida dos módulos devido à sua compactação. Contudo, há que ressalvar dois aspectos:

- A taxa de conversão de 10\% ( última coluna da tabela na Fig. 6.11), apresentada não é apontada como limitação do módulo, tanto que na mesma página, para o fabricante Toray, não se indica qualquer taxa de conversão.

- Com a CPH, é possível aumentar a taxa de conversão sem aumentar a pressão de operação, usando um limitador de vazão da salmoura.

Deduz-se assim que o dimensionamento com base nos dados do módulo da FilmTec proporciona uma redução do número de módulos superior à $50 \%$ em relação ao bastidor de 560 módulos, e uma redução nas dimensões do êmbolo especial (menor pressão de operação), o que implica redução do sistema para sua elevação.

No que toca ao investimento inicial, um êmbolo com menores dimensões terá consequentemente menos aço, logo menor custo. Além disso, permitirá ter $\mathrm{CPH}$ s com menores dimensões, possibilitando uma redução substancial da quantidade de material para as construir e ocupação de menor área. Como consequência da redução das dimensões do êmbolo, o custo do sistema usado para elevá-lo será menor. 


\section{Determinação da capacidade do reservatório $R 1$}

O volume de água no reservatório superior R1, Fig. 6.12, é função da vazão mássica ṁ1 de entrada, e m6 de saída. A vazão mi 1 é suprida pelos cataventos (S1) ou pela bomba alimentada pelos aerogeradores (S2), e m6 é correspondente à energia necessária para que o contrapeso eleve o êmbolo especial durante o funcionamento da $\mathrm{CPH}$. Em termos matemáticos, o volume de água no reservatório $\mathrm{R} 1, \mathrm{~V}_{\mathrm{aR} 1}$, varia com o tempo de acordo com a seguinte expressão:

$\mathbf{V}_{\mathrm{aR} 1}(\mathbf{t})=\mathbf{V}_{\mathbf{0}}+\left(\mathbf{V}_{\mathbf{1}}-\mathbf{V}_{\mathbf{6}}\right) \mathbf{t} \quad \mathrm{em}\left[\mathrm{m}^{3}\right]$

sendo:

$\mathbf{V}_{\mathbf{0}}$ é o volume inicial em R1 para a partida da $\mathrm{CPH}\left[\mathrm{m}^{3}\right]$

$\mathbf{V}_{1}$ é o volume correspondente à m $1 \mathrm{em}\left[\mathrm{m}^{3}\right]$. Sendo $\mathrm{V}=\mathrm{m} / \rho$.

$\mathbf{V}_{6}$ é o volume correspondente à ṁ6 em $\left[\mathrm{m}^{3}\right]$. (m6 está associado aos ciclos do $\mathrm{CP}$ ).

t é o tempo em [s]

$\mathrm{O}$ volume inicial $\mathrm{V}_{0}$ será determinado com base nos ciclos do contrapeso de tal forma que a CPH possa operar ininterruptamente durante um determinado período (ex: $24 \mathrm{~h}$ ) sem a entrada m1. Esses ciclos permitem calcular o volume de água que sai de R1.

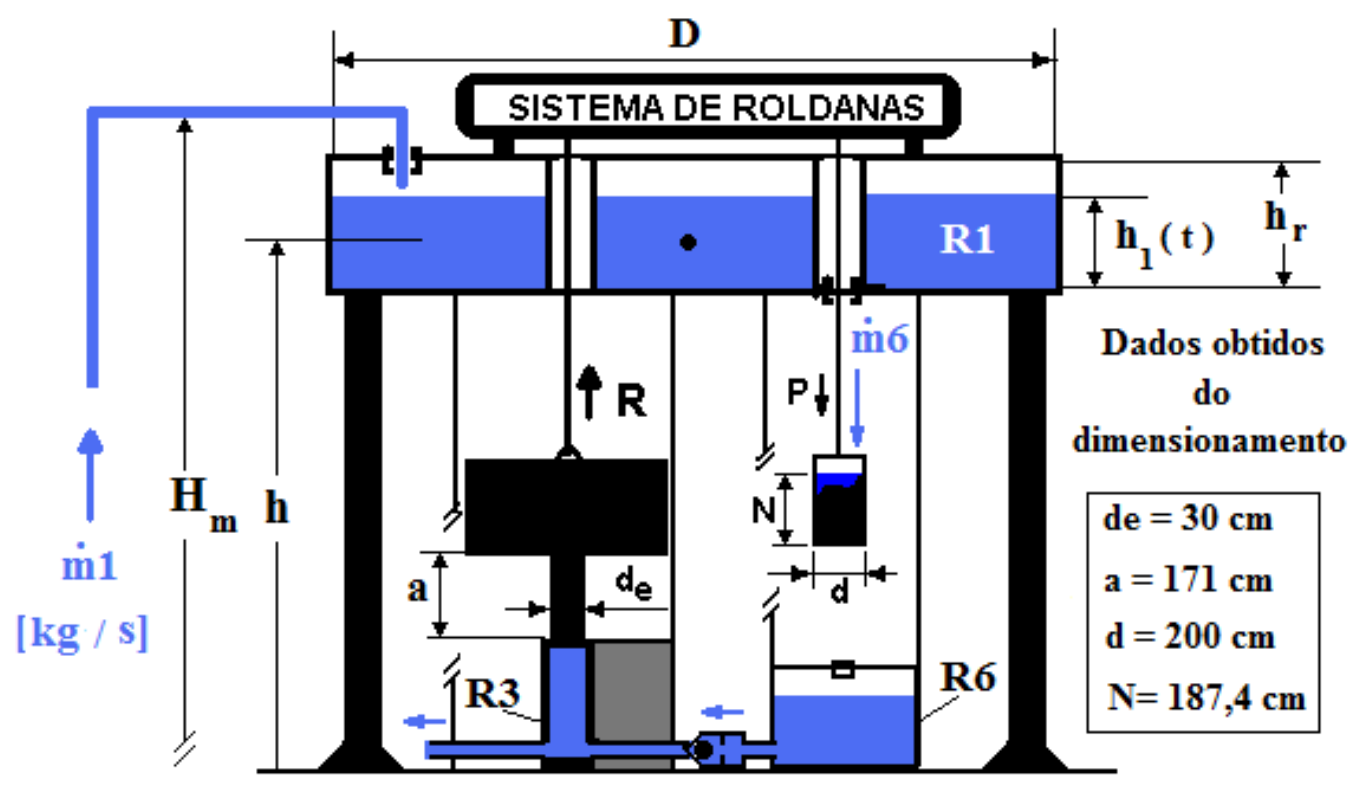

Fig. 6.12-CPH sob o reservatório R1. 
Por conveniência, será adotada a terminologia automobilística para se referir ao volume da câmara de compressão (R3 na Fig. 6.12). Assim, esse volume será designado pela cilindrada da câmara de compressão, ou cilindrada de R3, $\mathrm{C}_{\mathrm{R} 3}$.

Para o caso da geração de eletricidade é conveniente dimensionar o reservatório R1 para que haja uma reserva de $\mathbf{n}_{\mathbf{d}}$ dias para quando não houver vento suficiente. Entretanto, se o sistema é usado para a dessalinização, a reserva pode ser dispensável. Isso porque geralmente a água dessalinizada pode ser armazenada tanto na própria unidade de dessalinização quanto nas residências dos consumidores.

Se se considar que $\mathrm{R} 1$ é cilíndrico, a sua capacidade $\mathrm{V}_{\mathrm{R} 1}$ é dada por:

$$
V_{R 1}=h_{r} \pi D^{2} / 4
$$

sendo,

$\mathbf{h}_{\mathbf{r}}$ é a altura do reservatório $\mathrm{R} 1 \mathrm{em}[\mathrm{m}]$.

D é o diâmetro de $\mathrm{R} 1 \mathrm{em}[\mathrm{m}]$.

Se for fixado um valor para $\mathbf{D}$ na Eq. 6.17, de forma que a área da base do reservatório seja suficiente para acomodar as CPH's, determina-se a altura do reservatório por:

$$
h_{r}=4 V_{R 1} /\left(\pi D^{2}\right)
$$

Analogamente, o nível de água em $\mathrm{R} 1, \mathbf{h}_{\mathbf{1}}(\mathbf{t})$ na Fig. 6.12, oscila de acordo com a função:

$$
\mathbf{h}_{\mathbf{1}}=4 \mathrm{~V}_{\mathrm{aR} 1} /\left(\pi \mathrm{D}^{2}\right)
$$

Substituindo o valor de $\mathrm{V}_{\mathrm{aR} 1}$ da Eq. 6.16, obtém-se:

$$
h_{1}(t)=4 /\left(\pi D^{2}\right)\left[V_{0}+\left(V_{1}-V_{6}\right) t\right]
$$


Da observação da Fig. 6.12, constata-se que $\mathbf{h}_{\mathbf{r}}$ deve ser maior do que $\mathbf{h}_{\mathbf{1}}(\mathbf{t})$, caso contrário, haverá "perda" de energia potêncial gravitacional (água tranbordando).

Nas Eqs 6.16 e 6.20, volume $\mathbf{V}_{\mathbf{6}}$ é definido pela demanda de água dessalinizada ou/e pela demanda de potência elétrica. $\mathrm{O}$ volume $\mathbf{V}_{\mathbf{1}}$, de acordo com o dimensionamento, é função do número de cataventos (ou aerogeradores e bomba elétrica), da capacidade de bombeamento, da altura manométrica e do regime dos ventos. Daí que, o nível de água $\mathbf{h}_{1}(\mathbf{t})$ em R1 é oscilante. Para contornar essa oscilação, e garantir que a CPH funcione ininterruptamente, há que determinar o volume mínimo $\mathbf{V}_{\mathbf{0}}$ de água que garanta essa condição, ou seja há que garantir a energia firme em R1. Para tal, procede-se assim:

1) Com base na taxa de conversão da unidade da Praia de $45 \%$, determina-se o volume $\mathbf{V}_{\text {bomb }}$ de água do mar que os êmbolos deverão bombear diariamente para os módulos de membrana.

2) $\mathbf{V}_{\text {bomb }}$ corresponde a um número ( $\left.\mathbf{n}_{\text {cil }}\right)$ de cilindradas de R3. Assim $\mathbf{n}_{\mathbf{c i l}}=\mathbf{V}_{\mathbf{b o m b}} / \mathbf{C}_{\mathbf{R} 3}$. A cilindrada de R3, determinada a partir dos dados gemétricos do êmbolo (ver Fig. 6.12), é dada por $\mathbf{C}_{\mathbf{R} 3}=\mathbf{a} \boldsymbol{\pi} \mathbf{d}_{\mathbf{e}}{ }^{2} / 4$.

3) Associado à $\mathbf{n}_{\text {cil }}$ estão as descidas do contrapeso que despeja água em R6, Fig. 6.12, e consequentemente, ao volume de água $\mathbf{V}_{6}$ que sai de R1. Assim, o volume $\mathbf{V}_{6}$ é dado pelo produto do número de cilindradas pelo volume de água do contrapeso $\mathbf{V}_{\mathbf{a C P}}$, ou seja, $\mathbf{V}_{\mathbf{6}}=\mathbf{n}_{\text {cil }} \mathbf{x} \mathbf{V}_{\mathrm{aCP}}$.

Observando o contrapeso na Fig. 6.12, conclui-se que $\mathbf{V}_{\mathbf{a C P}}=\mathbf{N} \boldsymbol{\pi} \mathbf{d}^{\mathbf{2}} \mathbf{4}$. Entretanto, para se chegar aos valores de $\mathbf{N}$ e d, para poder determinar $\mathbf{V}_{\mathbf{a C P}}$ (volume de água que eleva o êmbolo), há que calcular o peso do êmbolo e levar em conta a redução de força proporcionada pelo sistema de roldanas.

O peso do êmbolo é dado por $\mathbf{F}=\mathbf{P}_{\mathbf{o p}} \mathbf{A}_{\mathbf{b}}$, sendo $\mathbf{A}_{\mathbf{b}}$, a área na sua base e $\mathbf{P}_{\mathbf{o p}}$, a pressão que exerce. Tendo em conta a redução proporcionada pelas roldanas, calcula-se o peso do contrapeso capaz de elevar o êmbolo que é dado por $\left(\mathbf{P}_{\mathbf{C P}}=\mathbf{F} / \mathbf{n}^{\mathbf{m}}\right)$. Consulte-se a Fig. 6.10 e tabela 6.6 para identificar $\mathbf{n}$ e m. 
4) Com $\mathbf{V}_{\mathbf{6}}$ e conhecendo a média para $\mathbf{V}_{\mathbf{1}}$, determina-se $\mathbf{V}_{\mathbf{0}}$ que permite dimensionar $\mathrm{R} 1$ através da Eq. 6.17.

Seguintes passos são definidos:

1) $\mathbf{V}_{\text {bomb }}=\mathbf{1 1} 111 \mathbf{m}^{3}$. Note-se que $45 \%$ de $11111 \mathrm{~m}^{3}=4999,95 \mathrm{~m}^{3}$.

2) $\mathbf{C}_{\mathbf{R 3}}=\mathrm{a} \pi \mathrm{d}_{\mathrm{e}}^{2} / 4=1,71 \times 3,14 \times 0,3^{2} / 4=\mathbf{0 , 1 2 1} \mathbf{m}^{\mathbf{3}}$.

$\mathbf{n}_{\text {cil }}=V_{\text {bomb }} / C_{R 3}=V_{\text {bomb }}=11111 / 0,121=91827$.

Com esse número de ciclos, divididos por dois contrapesos (duas $\mathrm{CPH}^{\prime}$ s) faz-se o seguinte raciocínio em relação ao ciclo de bombeamento dos êmbolos:

Cada êmbolo deverá efetuar 45914 ciclos de bombeamento. Então, no período de um dia, cada um deles demoraria 0,53 segundos (45 914/ 86400 s) para completar um ciclo.

3) O peso do êmbolo e o do contrapeso são dados por:

$\mathbf{F}=\mathbf{P}_{\text {op }} \mathbf{A}=6700000 \times 3.14 \times(0,15)^{2}=\mathbf{4 7 3} 355 \mathbf{N}$.

$\mathbf{P}_{\mathbf{C P}}=\mathbf{F} / \mathbf{n}^{\mathbf{m}}=473355 / 2^{3}=\mathbf{5 9} \mathbf{1 6 9}, \mathbf{3 8} \mathbf{N}$.

Tendo em conta que a densidade da água do mar é $\boldsymbol{\rho}=\mathbf{1 0 2 5} \mathbf{~ k g} / \mathbf{m}^{\mathbf{3}}$ e que, $\mathbf{m}=\boldsymbol{\rho V}$ e $\mathbf{F}=\boldsymbol{\rho} \mathbf{V} \mathbf{g}$, esse valor $(59169,38 \mathrm{~N}$ ) corresponde ao peso de $6031,54 \mathrm{~kg}$ de água do mar que equivale à 5,884 $\mathrm{m}^{3}$ desse líquido. Então, $\mathrm{V}_{\mathrm{aCP}}$ será igual a 5,884 $\mathrm{m}^{3}$.

Tendo um contrapeso cilíndrico com o diâmetro interno igual a 2 metros, o nível $\mathbf{N}$ de água que equivale a $5,884 \mathrm{~m}^{3}$ de água nele contido é dado por:

$\mathbf{N}=5,884 /\left(3,14 \times 1,5^{2}\right)=\mathbf{1 , 8 7 4} \mathbf{m}$

$\mathbf{V}_{\mathrm{aCP}}=\mathrm{N} \pi \mathrm{d}^{2} / 4=1,874 \times 3,14 \times 2^{2} / 4=\mathbf{5 , 8 8 4} \mathbf{~ m}^{\mathbf{3}}$ 
$\mathbf{V}_{\mathbf{6}}=\mathbf{n}_{\text {cil }} \times \mathbf{V}_{\mathrm{aCP}}=91827 \times 5,884=\mathbf{5 4 0 ~ 3 1 0 ,} \mathbf{1} \mathbf{~ m}^{\mathbf{3}}$

Considerando o rendimento do sistema de roldanas de $75 \%$, tem-se,

$\mathbf{V}_{6}=540310,1 / 0,75=\mathbf{7 2 0} \mathbf{4 1 3 , 5} \mathbf{~ m}^{3}$

4) Relembrando, com o volume $\mathbf{V}_{6}$ de água que sai e conhecendo a média para $o$ volume $\mathbf{V}_{\mathbf{1}}$ bombeado pelos cataventos determina-se o volume inicial $\mathbf{V}_{\mathbf{0}}$ que permite dimensionar R1 através da Eq. 6.17.

De acordo com o valor determinado previamente, os cataventos devem bombear $719590,4 \mathrm{~m}^{3}$ por dia até $\mathrm{R} 1$, A diferença diária entre $\mathbf{V}_{6}$ e $\mathbf{V}_{\mathbf{1}}$ é de $823,1 \mathrm{~m}^{3}$ correspondente à cerca de $34 \mathrm{~m}^{3}$ por hora. Pelos cálculos feitos com a tabela 6.5, essa diferença é superada com mais 2 cataventos Kenya.

Superada essa diferença, conclui-se que no balanço de massa aplicado ao reservatório $\mathrm{R} 1$, tem-se a entrada $\dot{\mathbf{m}} \mathbf{1}$ igual à saída $\dot{\mathbf{m} 6}$ a menos das variações de $\dot{\mathrm{m}} 1$ devidas ao caratér intermitente do vento.

Para nortear o dimensionamento de R1, retome-se a Eq. 6.16 que dá o volume de água oscilante em R1:

$V_{\mathrm{aR} 1}(t)=V_{0}+\left(V_{1}-V_{6}\right) t$

$\Delta \mathbf{V}_{\mathbf{1 - 6}}=\mathrm{V}_{1}-\mathrm{V}_{6}$ é o declive da reta que representa graficamente a função $\mathbf{V}_{\mathrm{aR1}}(\mathbf{t})$. Esse declive $\Delta \mathbf{V}_{\mathbf{1}^{-6} \mathbf{6}}$ varia de acordo com a entrada $\dot{\mathbf{m} 1}$ e saída $\dot{\mathbf{m} 6}$ e com as seguintes consequências representadas nos gráficos da Fig. 6.8-B pelas retas A, B e C:

A) Se $\dot{\mathbf{m}} \mathbf{1}=\dot{\mathbf{m}} \mathbf{6}$, o nível de água em R1, $\mathbf{h}_{\mathbf{R} 1}(\mathbf{t})$, mantém-se no nível $\mathbf{h}_{\mathbf{0}}$ correspondente à $\mathrm{V}_{0}$ como ilustra a reta A na Fig. 6.18.

B) Se $\dot{\mathbf{m} 1}>$ m6, o nível $\mathbf{h}_{\mathbf{R} 1}(\mathbf{t})$ aumenta proporcionalmente à diferença $\left(\mathrm{V}_{1}-\mathrm{V}_{6}\right)$.

C) Se $\dot{\mathbf{m}} \mathbf{1}<\dot{\mathbf{m} 6}$, o nível $\mathbf{h}_{\mathbf{R} 1}(\mathbf{t})$ diminui proporcionalmente à diferença $\left(\mathrm{V}_{1}-\mathrm{V}_{6}\right)$. 

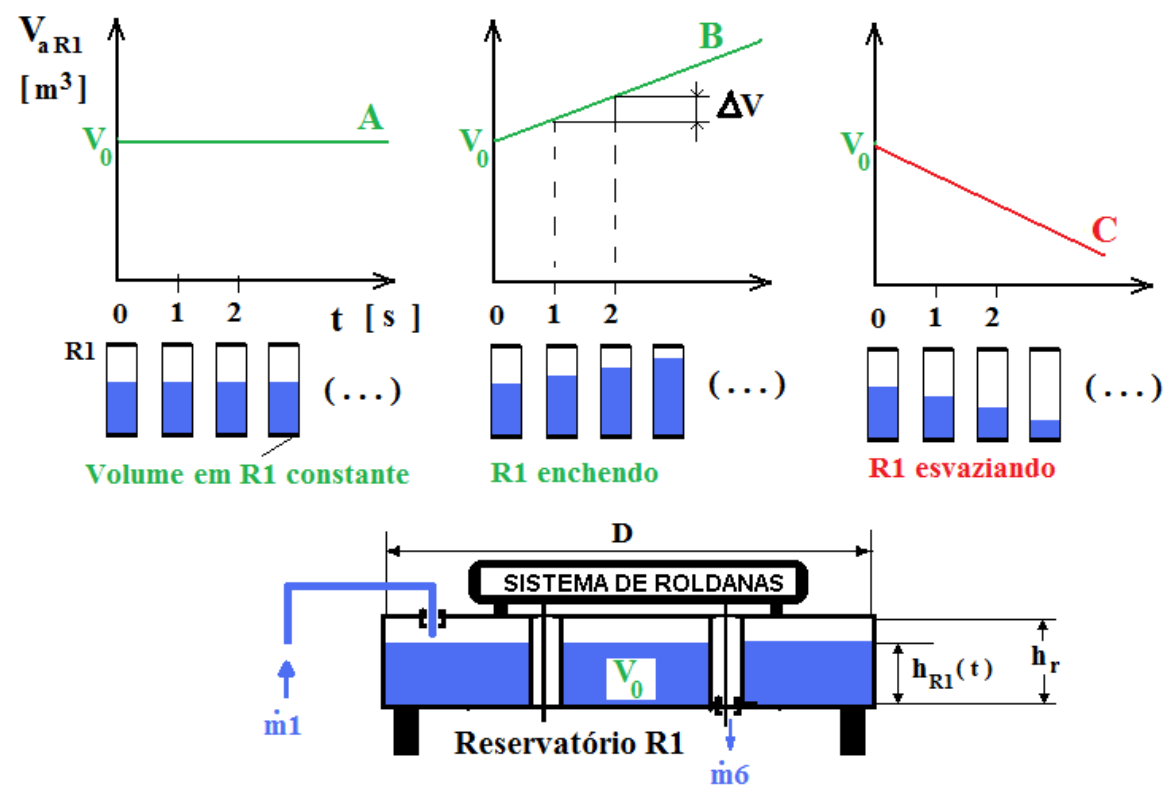

Fig. 6.18: Gráficos da variação do volume de água no reservatório R1

Tendo em mente as consequências apontadas, dimensiona-se R1 com base num determinado volume inicial $\mathrm{V}_{0}$ de tal forma que haja reserva e não se tenha $\mathrm{R} 1$ com dimensões colossais a ponto de inviabilizar o projeto. Entretanto, caso a ocupação de terreno seja um fator preocupante, cabe cogitar a montagem dos cataventos ou aerogeradores no topo de $\mathrm{R} 1$.

A altura do reservatório $\mathrm{R} 1$ como função do diâmetro e do volume $\mathrm{V}_{0}$ que deverá comportar é dado por :

$h_{r}=4 V_{0} /\left(\pi D^{2}\right)$

Se se quiser uma reserva de 1 dia, $V_{0}$ deverá ser igual a $720413,5 \mathbf{~ m}^{3}$ que corresponde à V6 que sai diariamente através do contrapeso. Se o diâmetro de R1 for $200 \mathrm{~m}$ na Eq. 6.21, tem-se:

$\mathbf{h}_{\mathbf{r}}=4 \times 720413,5 /\left(3,14 \times 200^{2}\right)=\mathbf{5 , 7 4} \mathbf{~ m}$

Então, para a produção diária de $5000 \mathrm{~m}^{3}$ de água, com taxa de conversão de $45 \%$, com uma reserva de 1 dia de funcionamento sem vento, o reservatório R1 deverá ter, no mínimo, $200 \mathrm{~m}$ de diâmetro e 5,74 m de altura. 
Pelas dimensões de R1, justifica-se pensar em usar a área ocupada para a instalação das máquinas eólicas. Entretanto, há que referir que no caso da construção de uma unidade de dessalinização, a área sob o reservatório é útil para acomodar todas as instalações da $\mathrm{CPH}$ entre as quais salas, escritórios, reservatórios de água potável etc.

Para atenuar a questão das dimensões de R1, recorde-se que se pode operar a $\mathrm{CPH}$ com uma reserva bem menor e com um sistema de "back-up" para abastecer R1 (bombeamento à Diesel por exemplo). Outra alternativa é aumentar o número de máquinas eólicas de forma que, geralmente, a entrada $V_{1}$ seja maior do que a saída $V_{6}$. Nessa condição, apesar de se correr o risco de ter perda de energia potencial gravitacional, é possível ter um reservatório relativamente pequeno, com uma reserva mínima para suprir alguns ciclos do contrapeso.

Devido à versatilidade da $\mathrm{CPH}$, pode-se ainda sugerir outras soluções. Uma delas é dessalinizar com uma pressão de operação inferior à 67 bar (com 55 bar por exemplo), donde, pelas equações expostas, deduz-se que R1 seria menor. Outra é aumentar a taxa de conversão para por exemplo $70 \%$ já que isso não acarreta para a $\mathrm{CPH}$ aumento do consumo específico. Assim, por cada $\mathrm{m}^{3}$ de água potável bombea-se menos água até R1.

\subsection{2-Resumo do dimensionamento da CPH para produção de $5000 \mathrm{~m}^{3} / \mathrm{dia}$}

As etapas percorridas até este ponto para o dimensionamento do modelo, para a produção de $5000 \mathrm{~m}^{3}$ de água dessalinizada por dia, sugerem que seja composto por:

- 53 cataventos WINDPUMP 50 WINDMILL com uma torre de 25 metros cujo rotor tem um diâmetro de 16 metros para bombear a água até o reservatório superior R1. Alternativa a esses cataventos são 1675 cataventos Kenya de diâmetro do rotor igual a $3 \mathrm{~m}$ (resultados da tabela 6.8). Em relação ao número de cataventos é possível reduzi-lo tendo em conta que a pressão de operação pode ser reduzida (menos do que 67 bar) e ainda assim se conseguir os $5000 \mathrm{~m}^{3}$ de água dessalinizada.

- Émbolos especiais com as dimensões indicadas na Fig. 6.9 cuja pressão na base é de 67 bar. 
- CPH's que abrigam os êmbolos com altura de 7 metros.

- Um contrapeso cilíndrico de alumínio com 1,1 m de altura, 1,2 m de diâmetro e 2 mm de espessura, que será usado para elevar o êmbolo através de um sistema mecânico com 48 roldanas (dados e resultados da tabela 6.9-A, com o número de ganchos igual a 1). Note-se que as dimensões do contrapeso para o caso de elevação do êmbolo maciço, são diferentes como se constata na Fig. 6.8.

- Reservatório R1 com diâmetro de $200 \mathrm{~m}$ e altura de 5, $74 \mathrm{~m}$ com reserva de 1 dia sem vento. $\mathrm{R} 1$ ocupa uma área de $31400 \mathrm{~m}^{2}$.

Os êmbolos (êmbolo especial A ou B) terão a função de bombear água do mar a uma pressão de 67 bar, para um bastidor de osmose reversa composto por 560 módulos de membrana do tipo espiral (bastidor igual ao da unidade da cidade da Praia), no qual se dá a dessalinização (produção de água potável). Alternativamente, o bastidor de membranas poderá ter 200 módulos SW38 8536 da FilmTec (de acordo com dados da tabela na Fig. 6.11).

\subsection{3: Comparação da unidade convencional de Cabo Verde com a CPH}

Na tabela 6.8 apresenta-se alguns parâmetros que permitem comparar as unidades.

Em relação à área ocupada pelos cataventos e o reservatório R1, pode-se optar por outros conceitos de cataventos como os ilustrados no anexo G. Entre esses, a opção de cataventos semelhantes à turbina Maglev, possibilita uma redução significativa da área ocupada. À propósito dessa alternativa, a Fig. 6.14 dá uma visão de como o reservatório R1 pode ser combinado com um catavento de eixo vertical idêntico à turbina Maglev. Note-se ainda que se a ocupação do terreno for um fator limitador, a área ocupada pelo reservatório R1 pode ser usada para se instalar cataventos. Esses poderiam ser instalados sobre ou sob R1. 


\begin{tabular}{|c|c|c|c|c|c|c|}
\hline 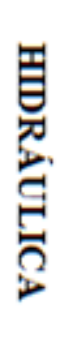 & 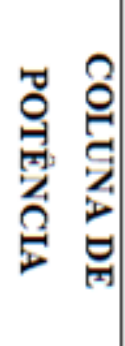 & 雨 & 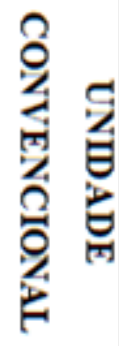 & & 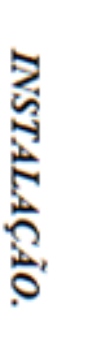 & \\
\hline & $\underset{\stackrel{\leftrightarrow}{\circ}}{\stackrel{\zeta}{\circ}}$ & & 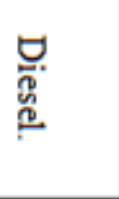 & 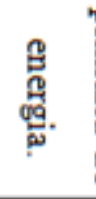 & 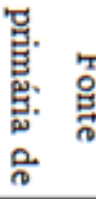 & \\
\hline $\begin{array}{l}\overrightarrow{0} \\
\stackrel{0}{0} \\
0 \\
0 \\
\stackrel{\circ}{\circ} \\
3\end{array}$ & 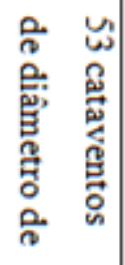 & 气ू. & 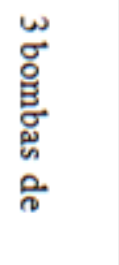 & 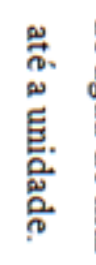 & 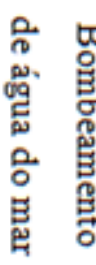 & \\
\hline & 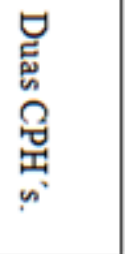 & 㣽 & 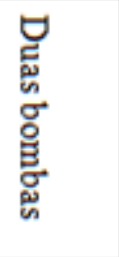 & 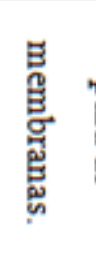 & 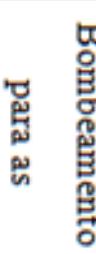 & \\
\hline 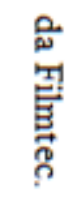 & 용 & & รั & 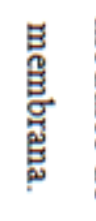 & 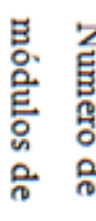 & \\
\hline & $\begin{array}{l}\text { ga } \\
\text { g్ }\end{array}$ & & $\begin{array}{l}\text { gે } \\
\text { ్ㅗㄹ }\end{array}$ & 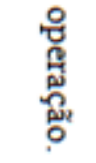 & 응 & \\
\hline & $\begin{array}{l}\text { u } \\
\text { ठ } \\
\text { g. }\end{array}$ & & $\begin{array}{l}n \\
8 \\
8 \\
8 \\
3\end{array}$ & & 总: & \\
\hline & 兽 & & 壱 & 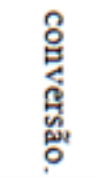 & 웅 & \\
\hline & 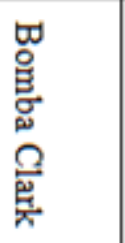 & & $\begin{array}{l}\mapsto \\
\text { 范 } \\
\stackrel{0}{\vec{g}}\end{array}$ & 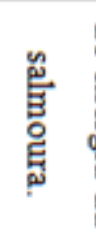 & 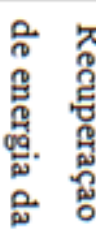 & \\
\hline & 点 & & 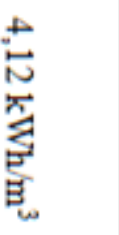 & & 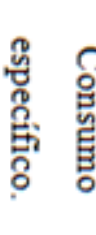 & \\
\hline
\end{tabular}




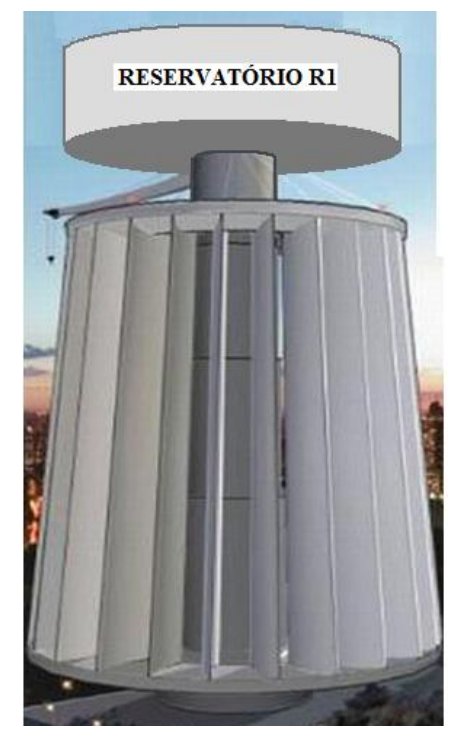

Fig. 6.14.: CPH alimentada com um catavento de eixo vertical.

Dado que a condição sine qua non para que $\mathrm{CPH}$ opere é ter água no reservatório superior R1, independentemente de como ele é alimentado, há a possibilidade de conduzir a água até R1 com outros modelos de cataventos. Esses podem até ser construídos com materias menos nobres tais como plástico, madeira, tecido etc.

\section{3- Caso 2: Dimensionamento da CPH para produzir $5 \mathrm{~m}^{3}$ de água por dia}

Neste estudo de caso pretende-se dimensionar a CPH para a produção de $5 \mathrm{~m}^{3}$ de água por dia, o que de acordo com o projeto "drinking with the wind" (RABINOVITCH, 2008), é suficiente para abastecer uma pequena vila de 500 habitantes em países em vias de desenvolvimento. $\mathrm{O}$ referido projeto foi objeto de dissertação de mestrado defendida na universidade Delft na Holanda. Decidiu-se avançar com este estudo de caso pela semelhança desse projeto com a CPH. Na Fig. 6.15, visualiza-se o esquema do primeiro protótipo construído e sua instalação em Curaçao para testes com água do mar.

Este estudo de caso será dividido em dois de acordo com o sistema usado para alimentar o reservatório superior $\mathrm{R} 1$ da $\mathrm{CPH}$. Assim, tem-se o primeiro, caso 2.1, que será a aplicação do sistema 1, S1 com cataventos e o segundo, caso 2.2, será com aerogeradores, S2. 


\subsection{1-Características do protótipo holandês}

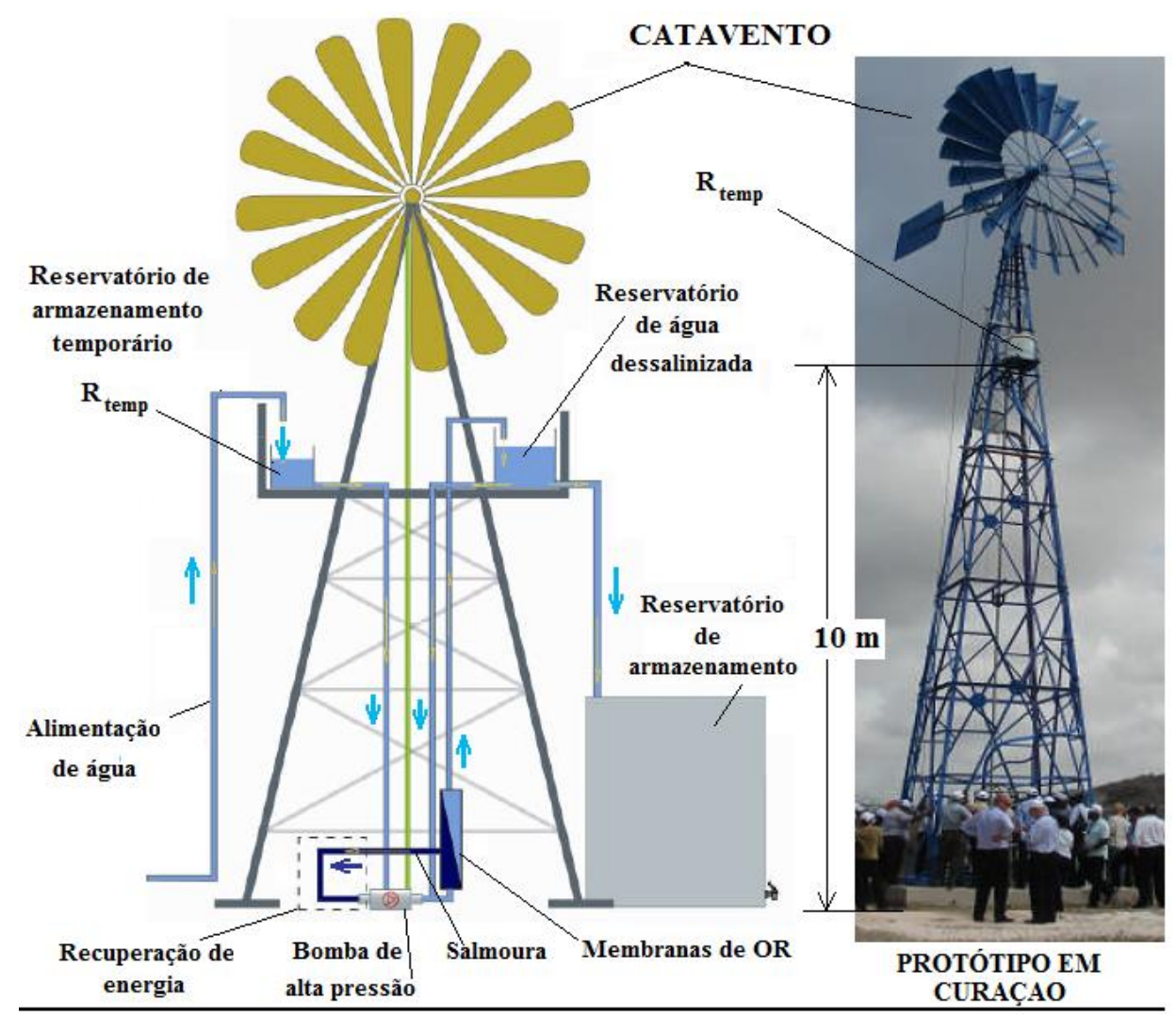

Fig. 6.15- Esquema do primeiro protótipo do projeto "drinking with the wind". Fonte: (RABINOVITCH, 2008) com edição nossa.

O dimensionamento da $\mathrm{CPH}$ com parâmetros iguais aos do protótipo que foi instalado em Curaçao (Ex-colônia holandesa) permite estabelecer comparações que permitam prever e antever a primeira instalação da CPH.

Antes do protótipo ser instalado em Curação, foi instalado num local próximo à cidade Delft na Holanda. Nessa etapa, foi testado com água contendo $\mathrm{NaCl}$ dissolvido com concentração de 35000 ppm. Os testes foram feitos com as seguintes caráterísticas:

- Pressão de operação: 60 bar

- Taxa de recuperação: $\mathbf{2 0 \%}$

- 4 membranas SWC1 ( 9,6 cm) da empresa Hydranautics colocadas em série.

- Diâmetro externo do rotor do catavento 5 m. Diâmetro interno 2 m (valor estimado com base na foto da Fig. 6.15). Rotor a $15 \mathrm{~m}$ de altura, Fig. 6.15. 
- A bomba de alta pressão é de pistão e é conectada diretamente ao eixo do catavento através de uma transmissão mecânica. O sistema de recuperação de energia é conectado ao mesmo eixo da bomba de alta pressão.

- A instalação foi dimensionada para uma produção máxima de $10 \mathrm{~m}^{3} / \mathrm{dia}$, com uma velocidade média do vento de $12 \mathrm{~m} / \mathrm{s}$.

Os seguintes resultados foram obtidos com o protótipo holandês:

- Produção nominal de $5 \mathbf{m}^{3} /$ dia com uma velocidade média do vento de $7 \mathrm{~m} / \mathrm{s}$.

- Consumo específico de $\mathbf{5 , 2} \mathbf{k W h} / \mathbf{m}^{3}$ de água dessalinizada.

- A produção inicia-se com velocidade do vento a partir de 4 m/s.

- Concentração da água dessalinizada inferior a $1200 \mathbf{p p m}$, porém superior a 500 ppm, logo suficiente para irrigação mas imprópria para beber.

A propósito da qualidade de água, comenta-se no trabalho que houve falha numa das membranas e que ultrapassando esse incidente, é possível produzir água com salinidade inferior a 500 ppm podendo chegar à valores menores do que 175 ppm.

\subsection{2- Caso 2.1: Dimensionamento da CPH com o sistema S1 (cataventos)}

Antes de se dimensionar a CPH para $5 \mathrm{~m}^{3} / \mathrm{dia}$, vai-se estabelecer algumas comparações qualitativas entre o projeto "drinking with the wind" e o projeto da coluna de potência hidráulica, CPH. Doravente os dois projetos serão denominados respectivamente por "DWW" e "CPH".

1- Apesar do DWW operar com a pressão de 60 bar e isso implicar uma limitação no arranque do catavento ( $\mathrm{V}>4 \mathrm{~m} / \mathrm{s}$ ), o CPH pode operar com a pressão de 67 bar sem que isso afete o catavento. Caso o êmbolo especial fosse dimensionado para 60 bar, ter-se-ia um reservatório R1 de menores dimensões e um consumo específico menor.

2- No CPH, as membranas não são submetidas a uma variação do fluxo de água como acontece no DWW. Nas conclusões de (RABINOVITCH, 2008) com base no DWW, 
recomenda-se a investigação da operação com fluxo variável dado que geralmente isso não é recomendável.

3- No DWW, para evitar que a bomba de alta pressão funcione sem água, há uma tubulação que a alimenta com água proveniente do reservatório de água dessalinizada (Fig. 6.10) através de um controle automático. No CPH esse controle é dispensável, visto que não havendo água no reservatório R1, não haverá ciclos do contrapeso e, consequentemente, o êmbolo especial não trabalha.

4- Verifica-se semelhança entre a existência do reservatório temporário $R_{\text {temp }}$ do DWW na Fig. 6.10 e o reservatório $\mathrm{R} 1$ do $\mathrm{CPH}$. $\mathrm{R}_{\text {temp }}$ Tem a capacidade de 30 litros e serve como proteção contra o funcionamento da bomba de alta pressão em vazio. R1 serve como regulador da vazão e acumulador de energia.

Passando ao dimensionamento, no DWW, calculou-se a potência mecânica (potência do rotor $\mathrm{P}_{\mathrm{r}}$ na $\mathrm{CPH}$ ) fornecida pelo catavento partindo da seguinte expressão (RABINOVITCH, 2008):

$\mathbf{P}_{\text {mec }}=\eta_{\text {mec }} \times \mathbf{C}_{\mathbf{p}} \mathbf{x} \mathbf{P}_{\text {kin }}$,

sendo $\mathbf{P}_{\text {kin }}=1 / 2 \rho_{\text {air }} \mathrm{AV}^{3}$ é a potência cinética (kinetic $\boldsymbol{P}$ ower $)$.

Com os seguintes dados (RABINOVITCH, 2008):

$\boldsymbol{\rho}_{\text {air }}=1,2 \mathrm{~kg} / \mathrm{m}^{3}$ para a densidade do ar a 1 atm e $20^{\circ} \mathrm{C}$.

$\mathbf{C}_{\mathbf{p}}=0,35$ para o coeficiente de potência do catavento.

$\boldsymbol{\eta}_{\text {mec }}=88 \%$ para o rendimento mecânico da transmissão que conecta o rotor do catavento ao eixo da bomba de alta pressão.

Chegou-se à expressão:

$P_{\text {mec }}=0,185 \mathrm{AV}^{3}[\mathrm{~W}]$

onde $\mathbf{A}$ é a área varrida pelo rotor em $\left[\mathrm{m}^{2}\right]$ e $\mathbf{V}$ é a velocidade média do vento em $[\mathrm{m} / \mathrm{s}]$. 
Assim, para se fazer os cálculos com a mesma base, será empregada a mesma expressão ao invés de $\mathbf{P}=\mathbf{0 , 1} \mathbf{A V}^{\mathbf{3}}$ que foi utilizada no estudo de caso anterior na tabela 6.9.

O número de cataventos será determinado para um consumo "real" de $\mathbf{2 , 8 1 1} \mathbf{k W h} / \mathbf{m}^{\mathbf{3}}$. Assim, a energia potencial gravitacional necessária para a dessalinização de $5 \mathbf{~ m}^{3}$ /dia é 14,055 $\mathbf{k W h}(5 \times 2,811)$. Consequentemente, o volume a ser bombeado até R1 a 7 metros de altura que corresponde a essa energia de 50, 598 MJ (14 055 x 3600) será,

$\mathbf{V}=\operatorname{Ep} /\left(\rho g H_{m}\right)=50,598 \times 10^{6} /(1025 \times 9,8 \times 7)=\mathbf{7 1 9}, \mathbf{5 9} \mathbf{~ m}^{3}$.

$\mathrm{Na}$ tabela 6.9 encontram-se os resultados obtidos para o número de cataventos necessários para bombear essa quantidade de água do mar até o reservatório superior R1. Na tabela 6.9 designou-se por catavento DWW o que tem as dimensões do que foi usado no projeto DWW ( linha 22 da tabela) e, para se obter a velocidade média do vento idêntica uso-se $7 \mathrm{~m} / \mathrm{s}$ nas linhas 3 a 14 da coluna B.

Tabela 6.9: Número de cataventos (DWW, Kenya e Farroupilha, altura da torre igual a $12 \mathrm{~m}$ ) necessário para bombear $719,59 \mathrm{~m}^{3} /$ dia de água do mar até uma altura manométrica de $7 \mathrm{~m}$.

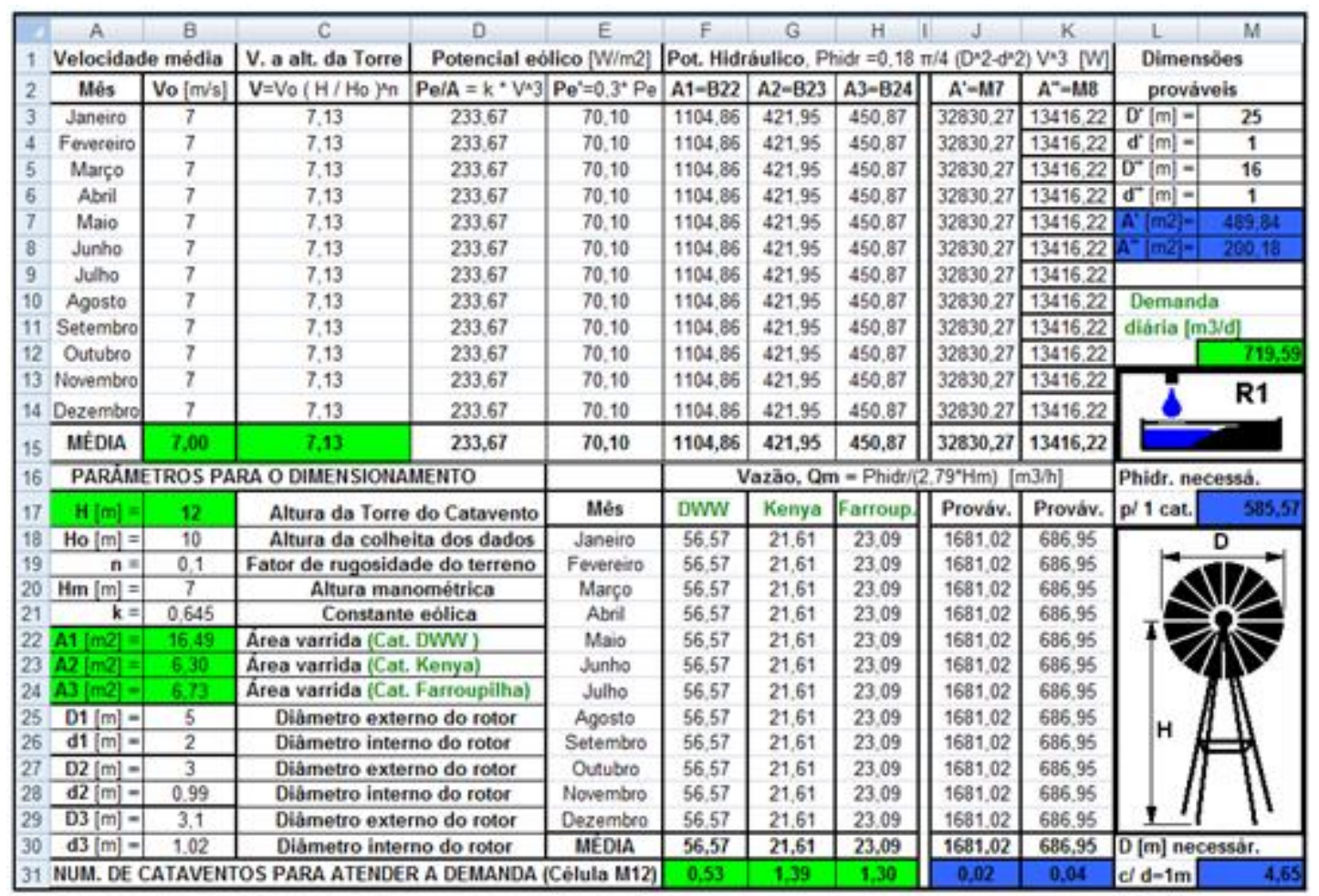


Pelos resultados da tabela 6.9 (célula F31), tem-se em média 1 catavento desse tipo para a dessalinização de cinco metros cúbicos de água do mar por dia.

O resultado da célula M31 indica que um catavento com o diâmetro externo de 4,65 m e interno de $1 \mathrm{~m}$ é o necessário para a dessalinização de $5 \mathrm{~m}^{3} /$ dia em condições idênticas às do projeto DWW.

O resultado obtido na célula F31 $(0,53)$ permite deduzir que com o catavento DWW é possível dessalinizar cerca de $10 \mathrm{~m}^{3}$ de água por dia com a velocidade média de $7 \mathrm{~m} / \mathrm{s}$. A propósito, recorde-se que no projeto DWW, a instalação foi dimensionada para uma produção máxima de $10 \mathrm{~m}^{3} /$ dia, com uma velocidade média do vento de $12 \mathrm{~m} / \mathrm{s}$. Percebe-se que, teoricamente, com o CPH tem-se mais água dessalinizada do que com DWW em condições semelhantes de operação. Isso justifica-se pela diferença do consumo específico em torno de $5,2 \mathrm{kWh} / \mathrm{m}^{3}$ para DWW e $2,811 \mathrm{kWh} / \mathrm{m}^{3}$ para CPH.

\section{Determinação da capacidade do reservatório $R I$}

Analogamente ao que se fez no estudo de caso anterior, inicia-se a análise através da taxa de conversão de $20 \%$ usada pelo DWW. Assim, seguindo os mesmos passos:

1) O volume de água que deve ser bombeado para as membranas é :

$\mathbf{V}_{\text {bomb }}=\mathbf{2 5} \mathbf{m}^{\mathbf{3}}$ dado que $20 \%$ de $25 \mathrm{~m}^{3}=5 \mathrm{~m}^{3}$

2) A cilindrada da câmara de compressão é:

$\mathbf{C}_{\mathbf{R} 3}=\mathrm{a} \pi \mathrm{d}_{\mathrm{e}}^{2} / 4=1,71 \times 3,14 \times 0,3^{2} / 4=\mathbf{0 , 1 2 1} \mathbf{~ m}^{\mathbf{3}}$.

Então, o número de ciclos do êmbolo é, $\mathbf{n}_{\text {cil }}=V_{\text {bomb }} / C_{R 3}=V_{\text {bomb }}=25 / 0,121=\mathbf{2 0 6}, \mathbf{6}$

Tendo um contrapeso cilíndrico com o diâmetro interno d, igual a 2 metros, o nível de água $\mathbf{N}$ necessário para elevar o êmbolo será $\mathbf{1 , 8 7 4} \mathbf{m}$ e seu volume será:

$\mathbf{V}_{\mathrm{aCP}}=\mathrm{N} \pi \mathrm{d}^{2} / 4=1,874 \times 3,14 \times 2^{2} / 4=\mathbf{5 , 8 8 4} \mathbf{~ m}^{\mathbf{3}}$ 
Determina-se, o volume de água que sai através do contrapeso com,

$\mathbf{V}_{6}=\mathbf{n}_{\text {cil }} \times \mathbf{V}_{\mathrm{aCP}}=206,6 \times 5,884=\mathbf{1 2 1 5 , 6 3} \mathbf{m}^{3}$

A altura do reservatório $\mathrm{R} 1$ como função do diâmetro e do volume de água $\mathrm{V}_{0}$ que o mesmo deverá comportar é dado por :

$h_{r}=4 V_{0} /\left(\pi D^{2}\right)$

Se se quiser uma reserva de 1 dia, $V_{0}$ deverá ser igual a $1215,63 \mathbf{m}^{3}$ que corresponde a $\mathrm{V}_{6}$ que sai diariamente através do contrapeso. Se o diâmetro de $\mathrm{R} 1$ for $15 \mathrm{~m}$ tem-se:

$\mathbf{h}_{\mathbf{r}}=4 \times 1215,63 /\left(3,14 \times 15^{2}\right)=\mathbf{6 , 8 8} \mathbf{~ m}$

Então, para a produção diária de $5 \mathbf{~ m}^{\mathbf{3}}$ de água com taxa de conversão de $20 \%$, e com uma reserva de 1 dia de funcionamento sem vento, o reservatório cilíndrico R1 deverá ter, no mínimo, 15 m de diâmetro e 6,88 m de altura.

Durante o dimensionamento do reservatório com base na taxa de conversão, verificamse interligações entre decisões a tomar. Nas próximas linhas, tendo em mente o esquema da Fig. 6.16, e a título ilustrativo, apresentam-se duas soluções possíveis para quando se depara com um número elevado de ciclos do êmbolo para bombear um determinado volume de água (função da taxa de conversão). Uma é ter um número maior de êmbolos especiais, e outra é ter êmbolos especiais com maior área da base (aumentando $d_{e}$ ) para poderem bombear mais água a cada ciclo.

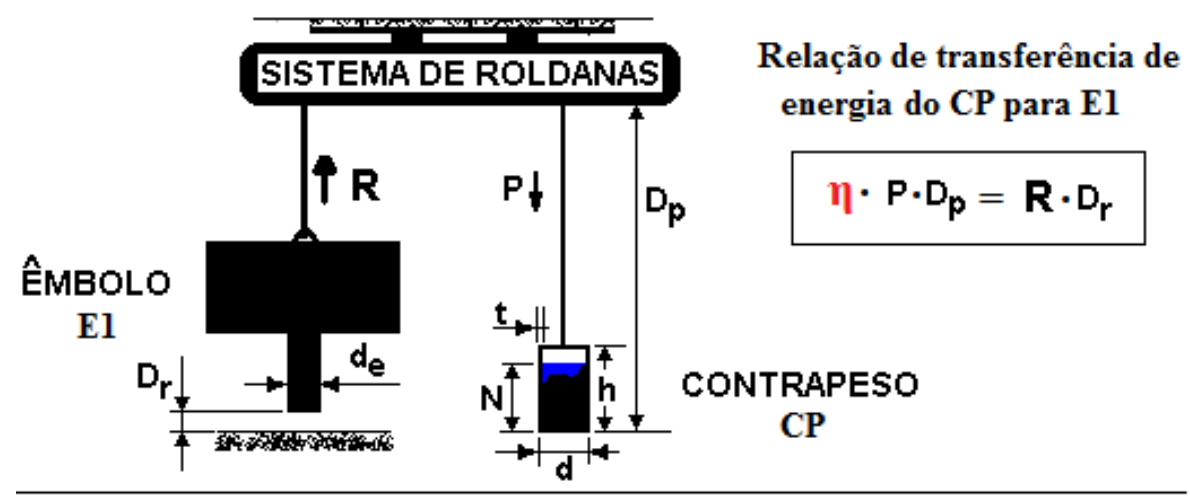

Fig. 6.16: Sistema de elevação do êmbolo. 
A segunda solução acarreta ter contrapesos maiores ou maior número de roldanas para a elevação do êmbolo que, mantendo a pressão de operação, seria necessariamente mais pesado. Porém, o aumento do número de roldanas implica que o contrapeso percorra maior distância $D_{p}$. Mas, maior distância $D_{p}$ significa ter o reservatório R1 a uma altura maior, o que faz aumentar o número de cataventos para bombear a mesma quantidade de água.

A interligação entre uma atitude e outras no dimensionamento incita uma avaliação em termos de otimização do sistema. Com esse objetivo, será investigado o seguinte:

1) Qual é a altura $\mathrm{H}_{\mathrm{m}}$ a que $25 \mathrm{~m}^{3}$ de água do mar deverão ser bombeados, de forma que a respectiva energia potencial seja equivalente à energia necessária para dessalinização de $5 \mathrm{~m}^{3}$ dessa água?

2 ) Que resultado se obtem, se o contrapeso for dimensionado de forma que o volume de água que o mesmo despeja seja igual ao volume da camâra de compressão R3? Se for exequível, sem acarretar transformações significativas, tem-se um sistema em que toda a água despejada pelo contrapeso segue para a câmara de compressão no próximo ciclo não havendo portanto acúmulo no reservatório que recebe essa água.

Veja-se os resultados:

1) $\mathbf{E P G}=\mathbf{m g H}_{\mathbf{m}}=5\left[\mathrm{~m}^{3}\right] \times 2,811\left[\mathrm{kWh} / \mathrm{m}^{3}\right]=\mathbf{1 4 , 0 5 5} \mathbf{k W h}=14,055 \times 3600=$ $=50598 \mathrm{~kJ}$

Sendo $\mathrm{m}=\rho \mathrm{V}$, com $\rho=1025 \mathrm{~kg} / \mathrm{m}^{3}$ e $\mathrm{V}=25 \mathrm{~m}^{3}$, tem-se:

$\mathbf{H}_{\mathbf{m}}=50598000 /(1025 \times 25 \times 9,8)=\mathbf{2 0 1 , 5} \mathbf{~ m}$

Conclui-se que é impraticável, a menos que se use o sistema de elevação do êmbolo proposto no anexo E. É preferível que a altura $\mathbf{H}_{\mathbf{m}}$ seja definida em função das dimensões do êmbolo especial porque quanto menor for, tem-se um menor número de cataventos para o mesmo volume de água bombeado. Passe-se à segunda indagação. 
2) O volume de água no contrapeso é dado por :

$\mathbf{V}_{\mathrm{aCP}}=\mathrm{N} \pi \mathrm{d}^{2} / 4=1,71 \times 3,14 \times 0,3^{2} / 4=\mathbf{0 , 1 2 1} \mathbf{~ m}^{\mathbf{3}}$.

Segue-se a condição de igualdade entre o volume de água no contrapeso e o volume de câmara de compressão:

$\mathbf{V}_{\mathbf{a C P}}=\mathbf{C}_{\mathbf{R} 3} \leftrightarrow \mathrm{a} \pi \mathrm{d}_{\mathrm{e}}^{2} / 4=\mathrm{N} \pi \mathrm{d}^{2} / 4$

$\mathrm{N} \pi \mathrm{d}^{2} / 4=0,121 \mathrm{~m}^{3}$

Se se fixar $\mathrm{d}=2$ tem-se $\mathrm{N}=38 \mathrm{~cm}$.

Entretanto, relembra-se que o volume necessário para elevar o êmbolo foi calculado como sendo 5,884 $\mathrm{m}^{3}$ que é cerca de 48 vezes maior do que $0,121 \mathrm{~m}^{3}$. Seria necessário aumentar o número de roldanas para se conseguir maior redução. Assim a distância percorrida pelo contrapeso seria cerca de 48 vezes maior como será provado em breve no texto com a generalização do problema.

Se por outro lado se fizer com que o volume da câmara de compressão seja $5,884 \mathrm{~m}^{3}$, é necessário aumentar a área de base do êmbolo (aumentando $d_{e}$ ) o que implica ter um êmbolo mais pesado para se manter a pressão de operação $\mathrm{P}_{\mathrm{op}}$.

No entanto, ter um êmbolo mais pesado implica, pretendendo manter o volume do contrapeso em $0,121 \mathrm{~m}^{3}$, compensar na distância $\mathrm{D}_{\mathrm{p}}$ percorrida pelo mesmo aumentado-a cerca de 48 vezes. Isso porque a relação $\mathrm{R} \times \mathrm{D}_{\mathrm{r}}=\mathrm{P} \times \mathrm{D}_{\mathrm{p}}$ deve ser mantida, Fig. 6.16.

Generalizando o problema, considere-se duas situações. Uma situação 1, Sit1, e outra Sit2 tais que:

1) $\mathrm{Na}$ Sit1, o dimensionamento do contrapeso CP é feito somente com base no peso do êmbolo especial E1 que o mesmo terá que elevar. Nesse processo, enquanto o contrapeso, ao descer, percorre a distância $D_{p}$, o êmbolo percorre a distância $D_{r}$ subindo. 
A menos da ineficiência do sistema de roldanas, a relação de transferência de energia de CP cujo peso é $\mathrm{P}$, para E1 cujo peso é R, é dada por $\mathbf{R} \times \mathbf{D}_{\mathbf{r}}=\mathbf{P} \times \mathbf{D}_{\mathbf{p}}$.

2) $\mathrm{Na}$ Sit2, buscando a otimização, CP é dimensionado de forma que o volume de água que o mesmo despeja em R6 seja igual ao volume de água que entra na câmara de compressão R3. Essa decisão tem como objetivo não "desperdiçar” parte da água que já tinha sido bombeada até o reservatório superior R1. Em princípio, agindo assim, evita-se a degradação da energia potencial gravitacional que a água desperdiçada já possuía.

O trabalho realizado pelo contrapeso na descida é dado por $\mathbf{W}_{\mathbf{C P}}=\boldsymbol{\eta} \mathbf{P} \mathbf{D}_{\mathbf{p}}$. Considerando que o peso $\mathrm{P}$ é atribuído somente ao volume de água que enche o contrapeso até o nível N, tem-se:

$\mathrm{W}_{\mathrm{CP}}=\boldsymbol{\eta} \rho \mathrm{V}_{\mathrm{aCP}} \mathbf{g} \mathbf{D}_{\mathrm{p}}$

Usando na Eq. 6.22 os índices 1 e 2 para as situações respectivas, obtem-se o trabalho realizado pelo contrapeso na Sit1 e na Sit2:

$\mathrm{W}_{\mathrm{CP1}}=\eta \rho \mathrm{V}_{\mathrm{aCP1}} \mathbf{g} \mathbf{D}_{\mathrm{p} 1}$

$\mathrm{W}_{\mathrm{CP2}}=\eta \rho \mathrm{V}_{\mathrm{aCP2}} \mathrm{g} \mathrm{D}_{\mathrm{p} 2}$

Se na passagem da Sit1 para a Sit2, não se alterar a pressão de operação $\mathrm{P}_{\mathrm{op}}$, mantendo-a por exemplo em 67 bar, o peso do êmbolo será mantido, logo o trabalho do contrapeso deverá ser o mesmo para elevá-lo. Isso significa que $\mathbf{W}_{\mathbf{C P 1}}=\mathbf{W}_{\mathbf{C P 2}}$ ou seja,

$$
\eta \rho V_{\mathrm{aCP} 1} g D_{\mathrm{p} 1}=\eta \rho V_{\mathrm{aCP} 2} \mathrm{~g} \mathrm{D}_{\mathrm{p} 2}
$$

Resolvendo a Eq. 6.23 para a distância percorrida pelo CP na Sit 2 tem-se:

$$
D_{\mathrm{p} 2}=\mathrm{V}_{\mathrm{aCP} 1} / \mathbf{V}_{\mathrm{aCP} 2} \quad \mathbf{x} \quad \mathbf{D}_{\mathrm{p} 1}
$$


Verifica-se pela Eq. 6.24 que ao se diminuir o volume de água do contrapeso para que seja igual ao da câmara de compressão (passagem da Sit1 para a Sit 2), "paga-se" na mesma proporção da redução, com o aumento da distância percorrida pelo CP. Como mencionado já, isso implica ter R1 a uma altura maior, que por sua vez implica aumentar o número de cataventos ou/e o diâmetro do (s) rotor (es).

Concluindo, a relação custo-benefício não abona a favor dessa "otimização" exceto se a razão $\mathbf{V}_{\mathrm{aCP1}} / \mathbf{V}_{\mathrm{aCP2}}$ não a inviabilize em termos econômicos ou/e práticos.

Pode-se ainda indagar: e a questão da possível degradação de energia potencial gravitacional devida ao desperdício de água? A respeito disso, provou-se que (DIAS,2004):

Desprezando as perdas no sistema de roldanas, o trabalho realizado pelo contrapeso na descida é integralmente transferido ao êmbolo, que por sua vez, o tranfere à água que será bombeada para o módulo de membranas. Ou seja, cada $\mathrm{m}^{3}$ de água bombeado até $\mathrm{R} 1$, contém a respectiva energia potencial gravitacional que será na íntegra aproveitada pelo contrapeso. Assim, quando a água é despejada em R6, já terá cumprido o seu trabalho além de na sequência ser usada para a obtenção de um ou dois produtos.

Com o recurso ao diagrama de corpo livre do sistema de elevação do êmbolo ilustrado na Fig. 6.17, serão desenvolvidas as equações que permitem avaliar a aceleração do conjunto contrapeso e êmbolo quando este é elevado preparando-se para mais um ciclo de compressão, bem como o tempo para percorrer a distância $\mathrm{D}_{\mathrm{p}}$.

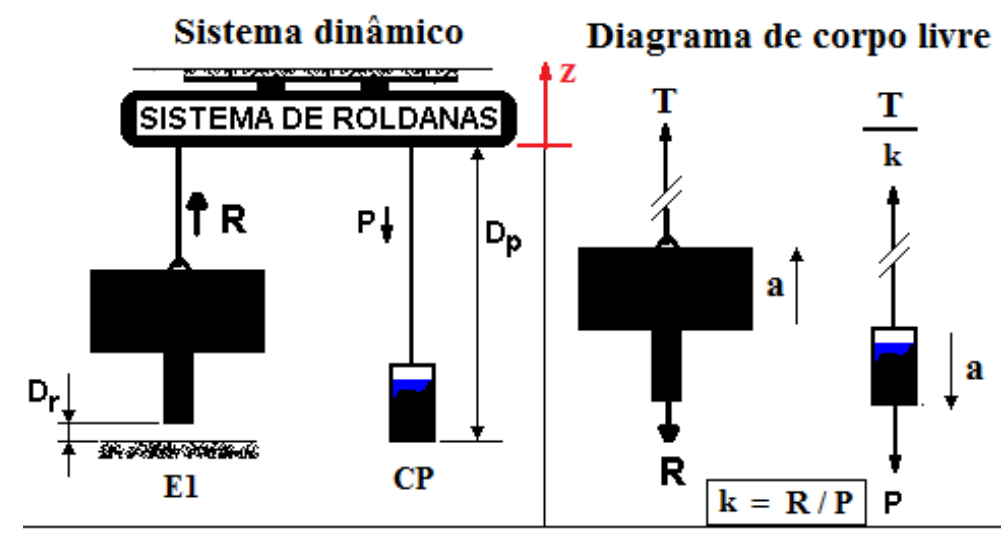

Fig. 6.17: Diagrama de corpo livre do sistema de elevação do êmbolo. 
A posse de tais equações permite estimar quantos êmbolos são necessários para bombear de forma contínua com uma determinada vazão a partir do conhecimento do número de ciclos necessários $\left(\mathbf{n}_{\text {cil }}=\mathrm{V}_{\mathrm{bomb}} / \mathrm{C}_{\mathrm{R} 3}\right)$.

Designando a massa do contrapeso $\mathrm{CP}$ por $\mathrm{m}_{\mathrm{CP}}$, e a do êmbolo $\mathrm{E} 1$ por $\mathrm{m}_{\mathrm{E} 1}$, e aplicando a $2^{\mathrm{a}}$ lei de Newton ( $\Sigma \mathrm{F}_{\mathrm{z}}=\mathrm{ma}$ ) aos corpos livres $\mathrm{CP}$ e E1 obtém-se as seguintes equações:

$\mathrm{T} / \mathrm{k}-\mathrm{P}=-\mathrm{m}_{\mathrm{CP}} \mathrm{x} \mathrm{a}$

$\mathrm{T}-\mathrm{R}=\mathrm{m}_{\mathrm{E} 1} \mathrm{x}$ a

Eliminado a tensão $\mathrm{T}$ nas duas equações e resolvendo para determinar a aceleração tem-se:

$\mathrm{a}=(\mathrm{kP}-\mathrm{R}) /\left(\mathrm{k} \mathrm{m}_{\mathrm{CP}}+\mathrm{m}_{\mathrm{E} 1}\right)$

Na Eq. 6.27, os pesos do $\mathrm{CP}$ e do $\mathrm{E} 1$ são dados por $\mathrm{P}=\mathrm{m}_{\mathrm{CP}} \times \mathrm{g}$ e $\mathrm{R}=\mathrm{m}_{\mathrm{E} 1} \mathrm{x}$. Substituindo-os na Eq. 6.27, obtem-se:

$\mathbf{a}=\mathbf{g}\left(\mathbf{k} \mathbf{m}_{\mathrm{CP}}-\mathbf{m}_{\mathbf{E 1}}\right) /\left(\mathbf{k} \mathbf{m}_{\mathrm{CP}}+\mathbf{m}_{\mathbf{E} 1}\right) \quad \mathrm{em}\left[\mathrm{m} / \mathrm{s}^{2}\right]$

sendo,

$\mathbf{g}=9,81 \mathrm{~m} / \mathrm{s}^{2}$

$\mathbf{m}_{\mathbf{C P}}$ é a massa do contrapeso

$\mathbf{m}_{\mathbf{E 1}}$ é a massa do êmbolo

Aplicando a equação do movimento uniformemente variado (MUV) ao CP partindo da posição zero (Fig. 6.17), tem-se

$D_{p}=a t^{2} / 2$

Resolvendo a equação anterior para determinar o tempo de descida do CP vem, 
$t=\left(2 D_{p} / a\right)^{1 / 2}$

Substituindo na Eq. 6.30 o resultado da aceleração obtida na Eq. 6.28, e usando o valor da aceleração da gravidade de $9,81 \mathrm{~m} / \mathrm{s}^{2}$, obtem-se:

$t=\left[0,204\left(k m_{C P}+m_{E 1}\right) /\left(k m_{C P}-m_{E 1}\right)\right]^{1 / 2} \quad[s]$

Na prática, o tempo de descida do contrapeso, pode ser menor do que o valor dado pela Eq. 6.30, se a camâra de compressão R3 for alimentada com água recebida diretamente do reservatório superior R1, ou se o nível de água em R6 estiver acima da sua entrada para R3. Isso explica-se porque no diagrama de corpo livre do êmbolo, Fig. 6.17, não se considerou a pequena força exercida pela água, de baixo para cima, na sua base devida à pressão da coluna de água. No primeiro caso, tal força teria uma magnitude equivalente à $\left(\mathrm{P}_{0}+\rho g \mathrm{H}\right)\left(\pi \mathrm{de}^{2} / 4\right)$.

A Eq. 6.31 é útil no processo de dimesionamento do sistema de elevação principalmente quando se tenta a otimização pelas variações das massas do contrapeso e do êmbolo.

Resolvendo a Eq. 6.26 para a tensão $\mathrm{T}$ do cabo, e substituindo nela o resultado da aceleração, tem-se :

$\mathbf{T}=\mathbf{g}\left(\mathbf{k} \mathbf{m}_{\mathrm{CP}} \mathbf{m}_{\mathrm{E} 1}-\mathbf{m}_{\mathrm{E1}}{ }^{2}\right) /\left(\mathbf{k} \mathbf{m}_{\mathrm{CP}}+\mathbf{m}_{\mathrm{E} 1}\right)+\mathbf{R} \quad[\mathrm{N}]$

Com a Eq. 6.32, e com recurso aos conhecimentos de resistência dos materiais, tem-se condições para dimensionar o cabo de elevação do êmbolo especial. No entanto, nesta tese, não se dedicará a essa etapa, por sair do escopo dos objetivos preconizados até aqui. 


\subsection{3- Caso 2.2: Dimensionamento da CPH com o sistema S2 (Aerogeradores)}

A diferença fundamental entre S1 e S2 para a dessalinização, consiste na forma de bombear a água até R1. Por esse motivo, praticamente todas as considerações feitas no caso 2.1 são válidas para o caso 2.2. Pelo estado da arte, conforme foi colocado quando da comparação qualitativa dos dois sistemas, há indicações de que, com um aerogerador alimentando uma bomba elétrica (S2), é possível bombear quatro vezes mais água até $\mathrm{R} 1$ do que com um catavento (S1) nas mesmas condições de vento.

\section{Determinação do número de aerogeradores}

Apesar do exposto no parágrafo anterior, neste estudo de caso, para trabalhar com parâmetros semelhantes, usa-se a planilha que gerou a tabela 6.9, porém para o potencial hidráulico recorreu-se à Eq. $4.30\left(\mathbf{P}_{\mathrm{elm}}=\mathbf{0 , 3 2 9} \mathbf{A V}_{\mathbf{m}}{ }^{\mathbf{3}}\right)$, que indica a potência elétrica média $\mathbf{P}_{\text {elm }}$ suprida pelo aerogerador. Na conversão dessa potência elétrica em potência de bombeamento $\mathrm{P}_{\mathrm{b}}$, e usou-se o valor de $80 \%$ para o rendimento da bomba elétrica. Com esse rendimento computado obtem-se:

$\mathbf{P}_{\mathbf{b}}=0,8 \times 0,329$ A. $\mathrm{V}_{\mathrm{m}}{ }^{3}=\mathbf{0 , 2 6 3} \mathbf{A} \cdot \mathbf{V}_{\mathbf{m}}{ }^{3}$.

Note-se que este procedimento de usar a Eq. 6.33 para avaliar o desempenho do sistema $\mathrm{S} 2$, é útil e rápido porém, tendo-se os dados estatísticos da velocidade do vento e a curva de potência da turbina eólica a ser usada, recomenda-se recorrer ao método exposto na seção 4.6.1.2 (produtividade real de uma turbina usando a distribuição de Weibull)

719, $59 \mathrm{~m}^{3}$ é o volume de água que deve ser bombeado até R1 (calculado no caso 2.1 ).

Na tabela 6.10 encontram-se os resultados obtidos para o número de aerogeradores necessário para bombear essa quantidade de água do mar até o reservatório superior R1 situado a $7 \mathrm{~m}$ de altura. 
Tabela 6.10: Número de aerogeradores ( altura da torre igual a $12 \mathrm{~m}$ ) necessário para bombear $719,59 \mathrm{~m}^{3} /$ dia de água do mar até uma altura manométrica de $7 \mathrm{~m}$.

\begin{tabular}{|c|c|c|c|c|c|c|c|c|c|c|c|}
\hline 9 & A & B & $\bar{C}$ & D & $E$ & $F$ & $G$ & $\mathrm{H}$ & $J$ & $\mathrm{~K}$ & $\bar{M}$ \\
\hline 1 & \multicolumn{2}{|c|}{ Velocidade média } & V. a alt. da Torre & \multicolumn{2}{|c|}{ Potencial eolice [W/m2] } & \multicolumn{5}{|c|}{ Pot. Hidráulico. Phidr $=0.1 \pi / 4\left(D^{*} 2-d * 2\right) V^{*} 3[\mathrm{~W}]$} & Dimensōes \\
\hline 2 & Mês & Vo $[\mathrm{m} / \mathrm{s}]$ & $\mathrm{V}=\mathrm{V}_{0}(\mathrm{H} / \mathrm{Ho}) \mathrm{m}$ & $\mathrm{Pe} / \mathrm{A}=\mathrm{k} * \mathrm{~V} \cdot 3$ & $P_{e}=0.3^{*} P_{e}$ & $A 1-822$ & $A 2-B 23$ & A3-824 & $A^{2}-1.97$ & $A^{*}-1.48$ & prováveis \\
\hline 3 & Janeiro & 7 & 7.13 & 233.67 & 70.10 & 1869.88 & 673,16 & 718.78 & 46747,02 & 1914758 & $\sigma^{\prime}(m)=$ \\
\hline 4 & Fevereico & 7 & 7,13 & 233,67 & 70,10 & 1869,88 & 673,16 & 718,78 & 46747,02 & 19147.58 & $f(m)=$ \\
\hline 5 & Março & 7 & 7.13 & 233.67 & 70.10 & 1869.88 & 673,16 & 718.78 & 46747.02 & 1914758 & $\sigma^{-1}[m]=$ \\
\hline 6 & Abril & 7 & 7,13 & 233,67 & 70,10 & 1869.83 & 673,16 & 718,78 & 46747,02 & 19147.58 & $\sigma^{\prime}(m)=$ \\
\hline 7 & Maso & 7 & 7,13 & 233.67 & 70,10 & 1869.88 & 673.16 & 718.78 & 46747.02 & 1914758 & $A^{2}(\ln 2)=$ \\
\hline 8 & Junho & 7 & 7,13 & 233,67 & 70.10 & 1869,88 & 673,16 & 718,78 & 46747,02 & 1914758 & $A^{-1}(m 2)=$ \\
\hline 9 & Juthe & 7 & 7,13 & 233.67 & 70.10 & 1869.88 & 673.16 & 718.78 & 46747,02 & 1914758 & \\
\hline 10 & Agosto & 7 & 7,13 & 233.67 & 70.10 & 1859.88 & 673,16 & 718.78 & 46747,02 & 19147.58 & \multirow{2}{*}{$\begin{array}{l}\text { Demanda } \\
\text { diarria [m } 3 / d]\end{array}$} \\
\hline 11 & Setembro & 7 & 7,13 & 233.67 & 70,10 & 1869.83 & 673,16 & 718,78 & 46747,02 & 1914758 & \\
\hline 12 & Outubro & 7 & 7,13 & 233.67 & 70,10 & 1869.88 & 673,16 & 718.78 & 46747,02 & 19147.58 & \multirow{3}{*}{ R1 } \\
\hline 13 & Novembro & 7 & 7,13 & 233.67 & 70,10 & 1869.88 & 673,16 & 718,78 & 46747,02 & 19147.58 & \\
\hline 14 & Dezembro & 7 & 7.13 & 233.67 & 70.10 & 1869.88 & 673,16 & 718.78 & 46747,02 & 19147.58 & \\
\hline 15 & MEEOAA & 7,00 & 7,13 & 233,67 & 70,10 & 1869,88 & 673,16 & 718,78 & 46747,02 & 19147,58 & \\
\hline $15^{\circ}$ & \multicolumn{4}{|c|}{ PARAMEIROS PARA O DIMENSIONAMENTO } & & \multicolumn{5}{|c|}{ Vazào, Om = Phidr $\left(2.79{ }^{\circ} \mathrm{Hm}\right)[\mathrm{m} 3 \mathrm{~h}]$} & Phidt, necessa. \\
\hline 17 & $\mathrm{H}[\mathrm{m}]=$ & 12 & \multicolumn{2}{|c|}{ Altura da Torre do Catavento } & Més & Aerog 1 & Aerog 2 & Aerog 3 & Prováv. & Provalv. & \multirow[t]{2}{*}{585,57} \\
\hline 13 & $\mathrm{Ho}[\mathrm{m}]=$ & 10 & \multicolumn{2}{|c|}{ Altura da colheita dos dados } & Janeiro & 95,74 & 34,47 & 36,80 & 2393,60 & 900.42 & \\
\hline 19 & $n=$ & 0.1 & \multicolumn{2}{|c|}{ Fator de rugosidade do terreno } & Fevereiro & 95,74 & 34,47 & 36,80 & 2393,60 & 980,42 & D \\
\hline 20 & $\mathrm{Hm}[\mathrm{m}]=$ & 7 & \multicolumn{2}{|c|}{ Altura manométrica } & Março & 95,74 & 34,47 & 36,80 & 2393.60 & 980.42 & \\
\hline 21. & $k=$ & 0.645 & \multicolumn{2}{|c|}{ Constante eólica } & Abril & 95.74 & 34,47 & 36.80 & 2393.60 & 960.42 & \\
\hline 22 & A1 $(m 2)=$ & 1963 & \multicolumn{2}{|c|}{ Area varrida (Aerogerador 1) } & Maio & 95,74 & 34,47 & 36.80 & 2393.60 & 980,42 & \\
\hline 23 & $A 2 \ln 2]=$ & 707 & \multicolumn{2}{|c|}{ Área varrida (Aetegerador 2$)$} & Junho & 95,74 & 34,47 & 36.80 & 2393,60 & 980,42 & 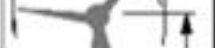 \\
\hline 24. & A3 $\ln 2 i=$ & 7.54 & \multicolumn{2}{|c|}{ Área varrida (Aerogerador J) } & Juhs & 95,74 & 34,47 & 36,80 & 2393,60 & 960,42 & \multirow{4}{*}{$\searrow_{H}^{\prime}$} \\
\hline 25 & D1 $[m]=$ & 5 & \multicolumn{2}{|c|}{ Dismetro externo do rotor } & Agosto & 95,74 & 34,47 & 36,80 & 2393,60 & 960,42 & \\
\hline 26 & $d 1(m)=$ & 0 & \multicolumn{2}{|c|}{ Diametro interno do rotor } & Setembro & 95.74 & 34,47 & 36,80 & 2393.60 & 980.42 & \\
\hline 27 & $\mathrm{D} 2[\mathrm{~m}]=$ & 3 & \multicolumn{2}{|c|}{ Diametro externo do rotor } & Outubro & 95,74 & 34,47 & 36,80 & 2393,60 & 980,42 & \\
\hline 28 & $d 2(m)=$ & 0 & \multicolumn{2}{|c|}{ Diametro interno do rotor } & Novembro & 95.74 & 34,47 & 36.80 & 2393.60 & 900.42 & \\
\hline 29 & $03(\mathrm{~m})=$ & 3.1 & Diàmetro exter & the do rotor & Dezembro & 95.74 & 34.47 & 36.80 & 2393.60 & 980.42 & \\
\hline 30. & $d 3[\mathrm{~m}]=$ & 0 & Diàmetro inter & no do rotor & MEDIA & 95,74 & 34.47 & 36.80 & 2393,60 & 980.42 & D(m) necessar. \\
\hline 31$]$ & NUM. DE A & EEROGER & . PARA ATENDER & RA DEMANDA & (Célula M12) & 0,31 & 0.87 & 0.81 & 0,01 & 0.03 & $d d=0$ \\
\hline
\end{tabular}

$\mathrm{Na}$ tabela 6.10, designamos por Aerogerador 1 o que tem as dimensões do catavento que foi usado no projeto DWW ( linha 22 da tabela), e nas células B 26, B28 e B30, fez-se $\mathrm{d}=0$ visto que nos aerogeradores não há esse parâmetro.

Como era de prever, com S2, é possível dessalinizar bem mais do que $5 \mathrm{~m}^{3}$ de água nas mesmas condições do DWW. Pelo resultado da célula F31 (0,31), estima-se que com um aerogerador de diâmetro de rotor igual a $5 \mathrm{~m}$ tem-se cerca de $16,1 \mathrm{~m}^{3}(5 / 0,31)$ de água dessalinizada.

\section{Determinação da capacidade do reservatório $R I$}

Se a opção com S2 for de dessalinizar $5 \mathrm{~m}^{3}$ de água por dia ainda que a capacidade seja de $16 \mathrm{~m}^{3}$, as dimensões de $\mathrm{R} 1$ teriam que ser aumentadas para não se correr o risco de haver transbordo de água já que o volume bombeado é maior. No entanto, aproveitando a capacidade, seguindo o mesmo procedimento feito no estudo de caso 2.1, obtem-se:

$\mathbf{V}_{\text {bomb }}=\mathbf{8 0} \mathbf{m}^{\mathbf{3}}(20 \%$ de $80=16)$ 
$\mathbf{n}_{\text {cil }}=V_{\text {bomb }} / C_{R 3}=80 / 0,121=\mathbf{6 6 1 , 2} \mathbf{m}^{3}$.

$\mathbf{V}_{\mathbf{6}}=\mathbf{n}_{\text {cil }} \times \mathbf{V}_{\mathrm{aCP}}=661,2 \times 5,884=\mathbf{3 8 9 0 , 5} \mathbf{~ m}^{\mathbf{3}}$

Se se quiser uma reserva de $\mathbf{1}$ dia, $V_{0}$ deverá ser igual a $3890,5 \mathrm{~m}^{3}$ que corresponde à $\mathrm{V}_{6}$ que sai diariamente através do contrapeso. Se o diâmetro de $\mathrm{R} 1$ for $20 \mathrm{~m}$ tem-se:

$\mathbf{h}_{\mathbf{r}}=4 \times 3890,5 /\left(3,14 \times 20^{2}\right)=\mathbf{1 2 , 3 9} \mathbf{~ m}$

Então, para a produção diária de $16 \mathrm{~m}^{3}$ de água com taxa de conversão de $20 \%$, e com uma reserva de 1 dia de funcionamento sem vento, o reservatório cilíndrico R1 deverá ter, no mínimo, $20 \mathrm{~m}$ de diâmetro e 12,39 m de altura.

\subsection{4: Comparação entre o protótipo holandês e a CPH (Sistemas 1 e 2)}

A Tabela 6.11 apresenta alguns parâmetros que permitem estabelecer uma comparação entre o protótipo DWW e a CPH. 


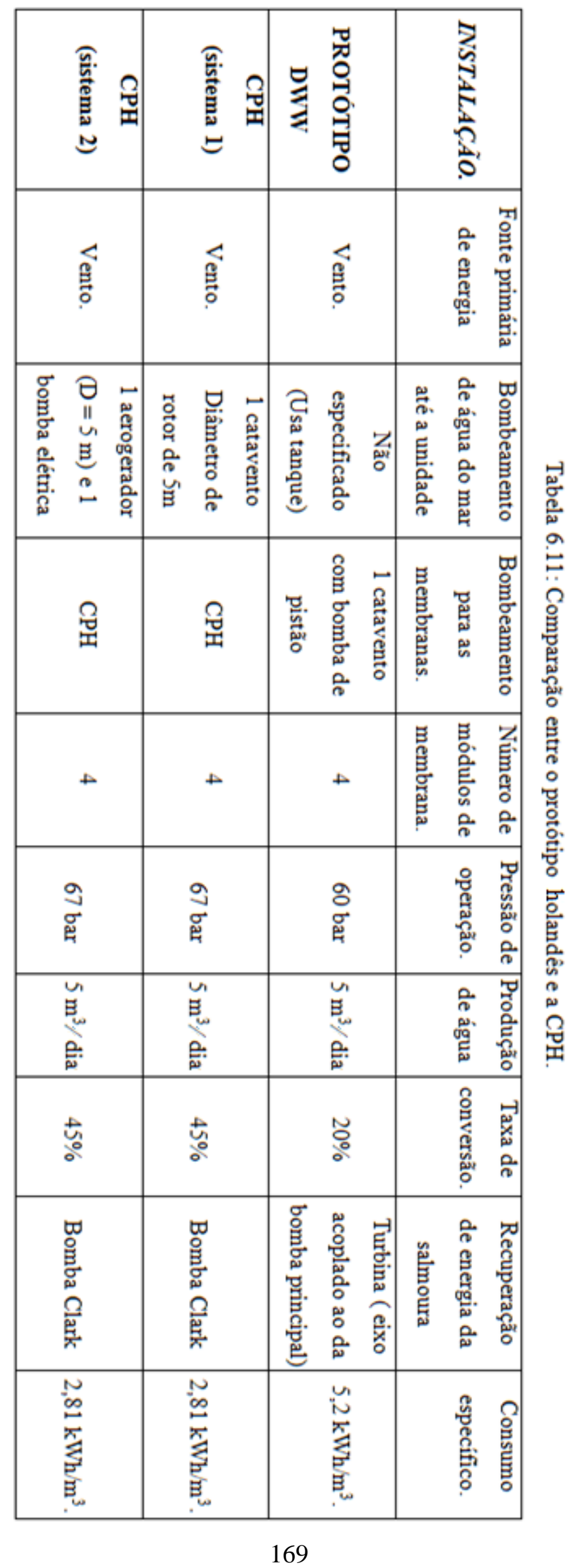




\section{4-Caso 3: Dimensionamento da CPH para atender uma demanda de $1000 \mathrm{~kW}$}

Neste estudo de caso dimensiona-se os dois sistemas S1 e S2 para a geração de eletricidade. Em relação à aplicação do sistema S2 para a produção de eletricidade, é pertinente salientar que, pelo fato de à saída do aerogerador já se ter a geração de eletricidade, parece ser um retrocesso a conversão da potência elétrica em potência mecânica, e novamente, em potência elétrica devido às perdas de energia associadas.

Entretanto, como foi comentado na seção 4.8, a CPH permite a regularização da energia eólica e seu armazenamento com menor custo do que o armazenamento em baterias, como convencionalmente é feito para sistemas isolados. Além disso, em relação ao sistema S1, há a vantagem de se colocar o aerogerador no local de maior potencial eólico, conduzir a potência elétrica para armazená-la na CPH que estaria junto ao local de consumo da eletricidade. Esta versatilidade do S2, ainda que para determinadas distâncias seja possível de se fazer com cataventos, S1 é mais complicada tecnicamente e, provavelmente mais dispendiosa.

Como apresentado no capítulo 5 , a potência do jato que sai da $\mathrm{CPH}$ é dada pelo produto

$\mathbf{P}_{\mathrm{g}}=\boldsymbol{\eta}_{\mathrm{T}} \boldsymbol{\eta}_{\mathbf{G}} \mathbf{P}_{\mathbf{o p}} \mathbf{A} \mathbf{v}_{\mathbf{j}} \quad[\mathrm{W}]$

sendo,

$\boldsymbol{\eta}_{\mathbf{T}}$ é o rendimento da turbina Pelton (TP)

$\boldsymbol{\eta}_{\mathbf{G}}$ é o rendimento do gerador

$\mathbf{P}_{\mathbf{o p}}$ é a pressão exercida pelo êmbolo $\left[\mathrm{N} / \mathrm{m}^{2}\right]$

A é a area do bico do injetor em $\left[\mathrm{m}^{2}\right]$

$\mathbf{v}_{\mathbf{j}}$ é a velocidade do jato de água que se dirige às conchas da TP em $[\mathrm{m} / \mathrm{s}]$.

Entretanto, o produto $\mathbf{A} \mathbf{x} \mathbf{v}_{\mathbf{j}}$ representa a vazão volumétrica de água bombeada pelo êmbolo expressa em $\left[\mathrm{m}^{3} / \mathrm{s}\right]$. A velocidade do jato é regulável através do bico do injetor da turbina Pelton. 
O dimensionamento pode ser feito a partir das caráterísticas da turbina Pelton ou a partir das caráterísticas da $\mathrm{CPH}$. No primeiro caso, a $\mathrm{CPH}$ teria que ser dimensionada para alimentar a turbina com a vazão e velocidade de jato adequadas à turbina escolhida. Estes dois parâmetros são controláveis através do bico injetor. No segundo caso, fixando uma determinada demanda, inicia-se com o dimensionamento da $\mathrm{CPH}$ e o reservatório R1, e escolhe-se, ou constrói-se, uma turbina que se adequa à capacidade da $\mathrm{CPH}$ de fornecer o fluxo constante com uma deteminada vazão e velocidade que atenda a demanda.

Retomando a Eq. 6.34 com $\eta_{\mathrm{T}}=0,9$ e $\eta_{\mathrm{G}}=0,6$, (valores possíveis) tem-se:

$\mathbf{P}_{\mathbf{g}}=\mathbf{0 , 5 4} \mathbf{P}_{\mathbf{o p}} \mathrm{A} \quad \mathbf{v}_{\mathbf{j}} \quad[\mathrm{W}]$

Partindo da Eq. 6.35, vamos dimensionar a $\mathrm{CPH}$ para atender uma demanda de $1000 \mathrm{~kW}$ que corresponde a uma pequena central, de acordo com a classificação da Eletrobrás (FARRET,1999).

Para que se tenha um volume maior de água na câmara de compressão, o diâmetro da base do êmbolo será fixado em 1,2 m (igual ao do SEARASER 1200), e a pressão de operação em 40 bar que equivale a uma altura de queda de $400 \mathrm{~m}$ (adequada ao funcionamento de uma turbina Pelton). Além dessas adaptações, o diâmetro de 1,2 m permite que, a cada descida do êmbolo, se tenha uma maior cilindrada de R3. Assim, no dimensionamento, consegue-se um menor número de ciclos do êmbolo, e consequentemente o mesmo pode trabalhar mais lentamente evitando vibrações.

Com a pressão de operação de 40 bar, a vazão volumétrica necessária será:

$$
\text { A } \quad \mathbf{v}_{\mathbf{j}}=\mathrm{P}_{\mathrm{g}} /\left(0,54 \mathrm{P}_{\mathrm{op}}\right)=1000000 /(0,54 \mathrm{x} 4000000)=\mathbf{0 , 4 6 2 9} \mathbf{~ m}^{\mathbf{3}} / \mathbf{s}
$$

Logo, o volume de água a ser bombeado em 24 horas é dado por:

$$
\mathbf{V}_{\mathbf{b}}=24 \times 3600 \times 0,4629=\mathbf{4 0} \mathbf{0 0 0} \mathbf{~ m}^{\mathbf{3}}
$$


O volume da câmara de compressão (cilindrada $\mathbf{C}_{\mathbf{R} 3}$ ) é calculado com base no volume da parte inferior cilíndrica do êmbolo especial B cuja altura a será fixada em $\mathbf{2}$ m.

$\mathbf{C}_{\mathbf{R 3}}=\mathrm{a} \pi \mathrm{d}_{\mathrm{e}}^{2} / 4=2 \times 3,14 \times 1,2^{2} / 4=\mathbf{2 , 2 6 1} \mathbf{~ m}^{\mathbf{3}}$.

O número de ciclos $\mathbf{n}_{\text {cil }}$ do êmbolo (ou do contrapeso) é dado por:

$\mathbf{n}_{\text {cil }}=V_{\text {bomb }} / C_{R 3}=40000 / 2,261=17692$

Para garantir esse número de ciclos, de forma que a $\mathrm{CPH}$ funcione perenemente, o volume de água que sai através do contrapeso, a cada elevação do êmbolo $\mathrm{V}_{\mathrm{aCP}}$, deve ser calculado para que se saiba quanta água deverá estar no reservatório R1. Assim, seguindo os passos para determinar $\mathrm{V}_{\mathrm{aCP}}$, comece-se pelo peso do êmbolo $\mathrm{F}$, e o do contrapeso $\mathrm{P}_{\mathrm{CP}}$, dados por:

$\mathbf{F}=\mathbf{P}_{\mathbf{o p}} \mathbf{A}=4000000 \times 3.14 \times(1,2 / 2)^{2}=\mathbf{4 5 2 1 6 0 0 ~ \mathbf { N }}$.

$\mathbf{P}_{\mathbf{C P}}=\mathbf{F} / \mathbf{n}^{\mathbf{m}}=4521600 / 2^{3}=\mathbf{5 6 5 2 0 0} \mathbf{N}$. (mesmo sistema de roldanas do caso 1 )

A massa de água do mar correspondente a esse peso é dado por:

$\mathbf{m}_{\mathbf{a}}=\mathbf{P}_{\mathbf{C P}} / \mathbf{g}=565200 / 9,81=\mathbf{5 7 6 1 4 , 6 8} \mathbf{~ k g}$

Então volume de água do mar $\left(\rho=1025 \mathrm{~kg} / \mathrm{m}^{3}\right)$ que o contrapeso deverá ter para elevar o êmbolo será:

$\mathrm{V}_{\mathrm{aCP}}=\mathrm{m}_{\mathrm{a}} / \rho=\mathbf{5 7 6 1 4 , 6 8} / 1025=\mathbf{5 6 , 2 1} \mathrm{m}^{\mathbf{3}}$

Tem-se agora os dados para calcular o volume V6:

$\mathbf{V}_{6}=\mathbf{n}_{\text {cil }} \times \mathbf{V}_{\mathrm{aCP}}=17692 \times 56,21=\mathbf{9 9 4} \mathbf{4 6 7 , 3 2} \mathbf{m}^{\mathbf{3}}$ 
Esse volume de água deverá ser bombeado até o reservatório R1 situado a uma altura, que será determinado após ser calculada a distância que o contrapeso deverá percorrer para elevar o êmbolo. Esse dimensionamento é feito em seguida.

\section{Dimensionamento do sistema de elevação do êmbolo}

No processo de transferência de energia potencial gravitacional do contrapeso para o êmbolo, deve verificar-se a relação $\eta \mathbf{P} \times \mathbf{D}_{\mathbf{p}}=\mathbf{R} \times \mathbf{D}_{\mathbf{r}}$ (ver Fig. 6.18).
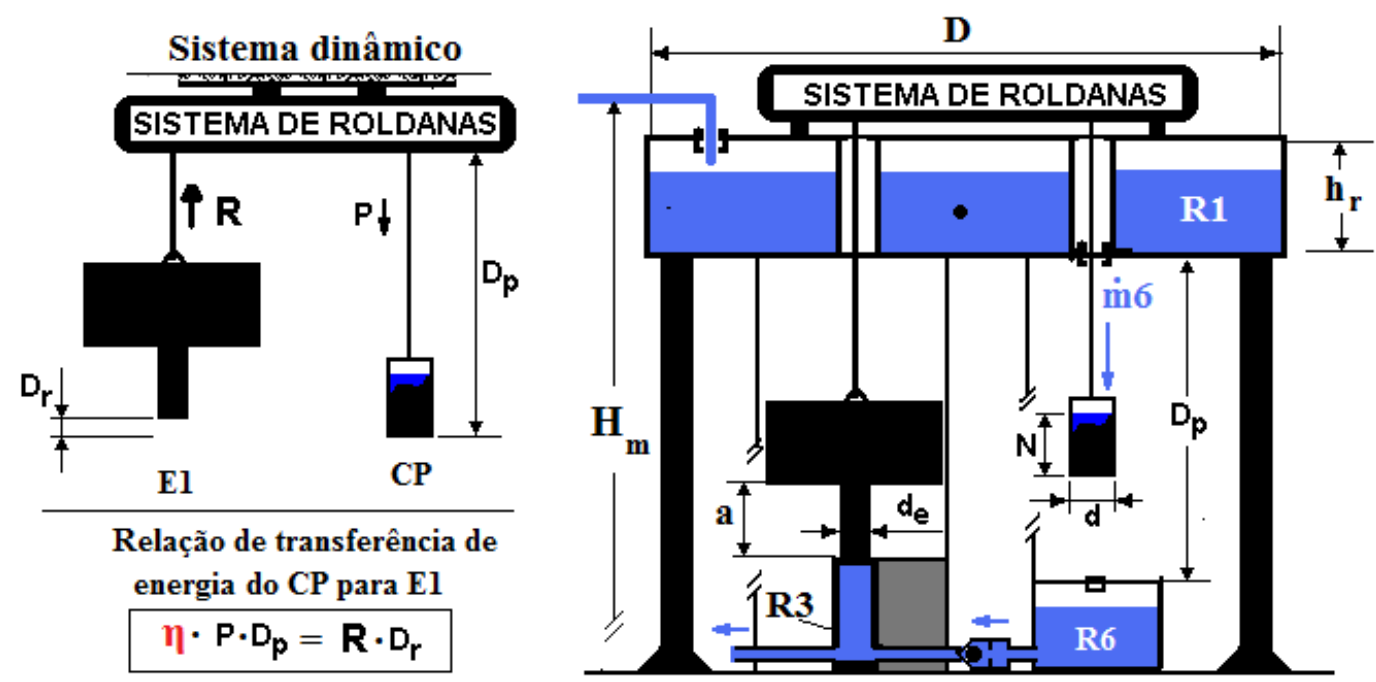

Fig. 6.18-Transferência de energia potencial gravitacional do contrapeso para o êmbolo através do sistema de elevação.

Adaptando essa relação à nomenclatura aqui usada, e com rendimento do sistema de roldanas de $75 \%$, (valor aceitável que tem sido usado na $\mathrm{CPH}$ ) tem-se:

$\eta P_{C P} \times D_{p}=F \times D_{r}$

Tendo em conta a altura $\left(\mathrm{a}=2 \mathrm{~m}\right.$ ) do cilindro inferior do êmbolo, fixe-se a distância $\mathbf{D}_{\mathbf{r}}$ em 1, $99 \mathrm{~m}$. Note-se que o cálculo de $C_{R 3}$ poderia ou deveria ser refeito porém para fins teóricos não há essa necessidade devido à pequena diferença de $0,011 \mathrm{~m}^{3}$.

Da relação de transferência de energia, calcula-se a distância $\mathbf{D}_{\mathbf{p}}$ percorrida pelo contrapeso para elevar o êmbolo 1,19 m de altura: 
$D_{p}=F \times D_{r} / \eta P_{C P}=4521600 \times 1,99 /(0,75 \times 565200)=21,23 \mathbf{m}$

Esta-se em condições de poder seguir um caminho alternativo para determinar (e com isso comprovar) o volume de água que deverá ser bombeado diariamente até o reservatório R1. A lógica é que em R1, tem que haver diariamente energia potencial gravitacional suficiente para a elevação do êmbolo tantas vezes quantas o número de ciclos $\mathbf{n}_{\text {cil }}=17$ 692. A energia consumida pelo contrapeso para realizar esse trabalho é dada por:

$$
\mathbf{E}=\mathbf{n}_{\text {cil }} \times \mathbf{P}_{\mathbf{C P}} \times \mathbf{D}_{\mathbf{p}}=17692 \times 565200 \times 21,23=\mathbf{2 1 2} \mathbf{2 8 9} 775 \mathbf{6 3 2} \mathbf{J}
$$

Essa energia sob forma de água armazenada em R1 a 21,23 m de altura corresponde a uma determinável massa $\mathrm{m}_{\mathrm{a}}$ de água do mar:

$$
\mathrm{m}_{\mathrm{a}}=\mathrm{E} /(\mathrm{g} \mathrm{H})=212289775632 /(\text { 9,81 x 21,23) = } 1019318 \text { 899, } 08 \text { kg }
$$

Valor que em volume de água bombeado até R1 equivale à:

$$
\mathbf{V}_{\mathbf{6}}=\mathbf{m} / \boldsymbol{\rho}=1019318899,08 / 1025=\mathbf{9 9 4} \mathbf{4 5 7 , 4 6} \mathbf{~ m}^{\mathbf{3}}
$$

\section{Dimensionamento do êmbolo}

Como vito no capítulo 3, a pressão $\mathbf{P}_{\mathbf{B}}$ exercida pelo êmbolo B maciço de aço é dada por:

$$
P_{B}=g \rho_{\text {aço }} / \operatorname{de}^{2}\left(D_{e}{ }^{2} b+d_{e}{ }^{2} a\right)
$$

Dado que já assumimos o valor de $2 \mathrm{~m}$ para a dimensão a, e 1,2 $\mathrm{m}$ para $\mathbf{d}_{\mathbf{e}}$, resta determinar $\mathbf{D}_{\mathbf{e}}$ e b. Resolvendo a Eq. 6.36 para $\mathrm{D}_{\mathrm{e}}$ obtem-se:

$$
D_{e}=\left[1 / b\left(P_{B} d_{e}^{2} /\left(g \rho_{\text {aço }}\right)-d_{e}^{2} a\right)\right]^{1 / 2}
$$

Com os seguintes dados: $\mathbf{d}_{\mathbf{e}}=1,2 \mathrm{~m} ; \mathbf{a}=2 \mathrm{~m} ; \mathbf{P}_{\mathbf{B}}=4000000 \mathrm{~N} / \mathrm{m}^{2} ; \mathbf{g}=9,81 \mathrm{~m} / \mathrm{s}^{2} \quad$ e $\boldsymbol{\rho}_{\text {aço }}=7800 \mathrm{~kg} / \mathrm{m}^{3}$, obtem-se o seguinte resultado parcial da Eq. 6.37: 
$D_{e}=[1 / b(5760000 / 76518-2,88)]^{1 / 2}$

Fazendo $\mathbf{b}=\mathbf{5} \mathbf{~ m}$, acha-se $\mathbf{D}_{\mathbf{e}}=\mathbf{3 , 8 1} \mathbf{m}$.

\section{Dimensionamento do contrapeso}

Como mostrado, o volume de água que o contrapeso deverá comportar é $\mathrm{V}_{\mathrm{aCP}}=56,21 \mathrm{~m}^{3}$

Tendo um contrapeso cilíndrico com o diâmetro interno igual a 4 metros, o nível $\mathbf{N}$ de água que equivale a $\mathbf{5 6 , 2 1} \mathbf{~ m}^{3}$ de água nele contido é dado por:

$\mathbf{N}=56,21 /\left(3,14 \times 2^{2}\right)=\mathbf{4 , 4 6} \mathbf{m}$

Na Fig. 6.19 dá-se uma visão das proporções do êmbolo e do contrapeso.

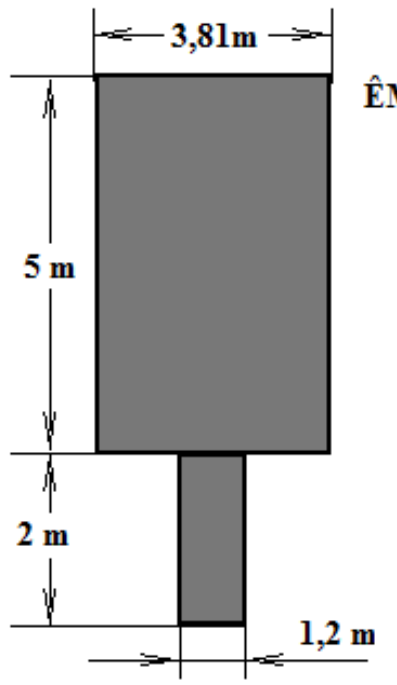

ÊMBOLO

CONTRAPESO

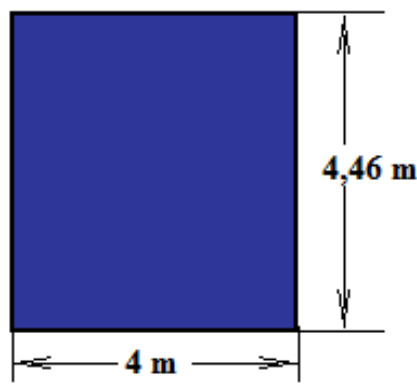

Fig. 6.19- Dimensões do êmbolo e do contrapeso.

\section{Determinação da capacidade de RI}

Se se quiser uma reserva de $\mathbf{1}$ dia, o volume inicial $\mathbf{V}_{\mathbf{0}}$ deverá ser igual a $V_{6}=994457,46 \mathrm{~m}^{3}$, correspondente ao volume de água que sai diariamente através do contrapeso. Se o diâmetro de R1 for 300 m tem-se: 
$\mathbf{h}_{\mathbf{r}}=4 \times 994457,46 /\left(3,14 \times 300^{2}\right)=\mathbf{1 4 , 0 8} \mathbf{~ m}$.

Concluindo, para a autonomia do sistema para o caso de um dia sem vento, o reservatório $R 1$ deverá ter, no mínimo, $300 \mathrm{~m}$ de diâmetro e altura de 14,08m.

\subsection{1-Determinação do número de cataventos necessários (S1)}

$\mathrm{O}$ volume de água $\mathrm{V}_{6}=994$ 467,32 $\mathrm{m}^{3}$ deverá ser bombeado diariamente e acumulado num reservatório $\mathrm{R} 1$ cuja base estará situada à $21,23 \mathrm{~m}$ de altura. A tabela 6.12 apresenta os resultados para o número de cataventos necessários para cumprir essa tarefa. Consideramos $\mathrm{H}_{\mathrm{m}}=35,31 \mathrm{~m}$ porque somou-se a altura de $\mathrm{R} 1$ aos 21,23 $\mathrm{m}$. Na célula M3 introduziu-se o diâmetro de 60 m que é indicado (MANWELL et al, 2002) como sendo o de uma turbina de $1000 \mathrm{~kW}$ e na B17, $70 \mathrm{~m}$ correspondente à altura da torre.

Tabela 6.12: Número de cataventos ( altura da torre igual a $70 \mathrm{~m}$ ) necessário para bombear $994467,32 \mathrm{~m}^{3}$ /dia de água do mar até uma altura manométrica de $35,31 \mathrm{~m}$.

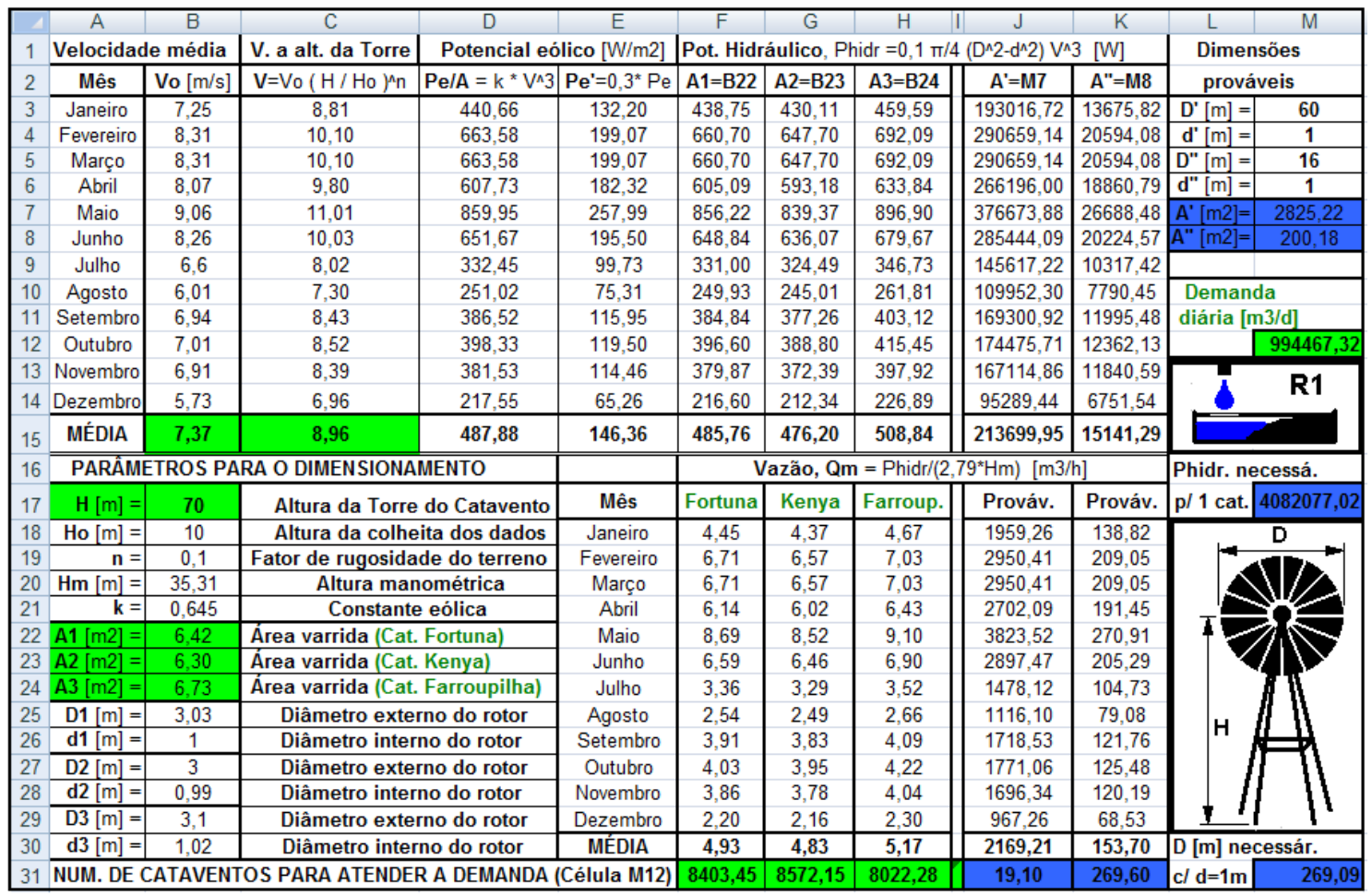

Pelos resultados das células da linha 31 colunas F,G e H da tabela 6.12, conclui-se que é inviável implementar o projeto de geração de $1000 \mathrm{~kW}$ com cataventos cujo diâmetro 
de rotor seja cerca de 3 metros. Aumentando consideravelmente o diâmetro, verifica-se, pelo resultado da célula J31, que cerca de 19 cataventos de diâmetro de rotor de $60 \mathrm{~m}$ seriam capazes de atender a demanda de potêncica elétrica de $1000 \mathrm{~kW}$, com uma reserva de um dia sem vento. Essa afirmação é válida se a velocidade média do vento for em torno de $7,5 \mathrm{~m} / \mathrm{s}$.

\subsection{2-Determinação do número de aerogeradores necessários (S2)}

Usando os mesmos dados da tabela 6.12, porém com as equações do sistema de bombeamento com aerogeradores e bomba elétrica, gerou-se os resultados da tabela 6.13. Pelo mesmo motivo anteriormente citado, as linhas 4 e 6 da coluna M têm o valor zero para os diâmetros internos.

Tabela 6.13: Número de aerogeradores ( altura da torre igual a $70 \mathrm{~m}$ ) necessário para bombear 994 467,32 $\mathrm{m}^{3}$ /dia de água do mar até uma altura manométrica de $35,31 \mathrm{~m}$.

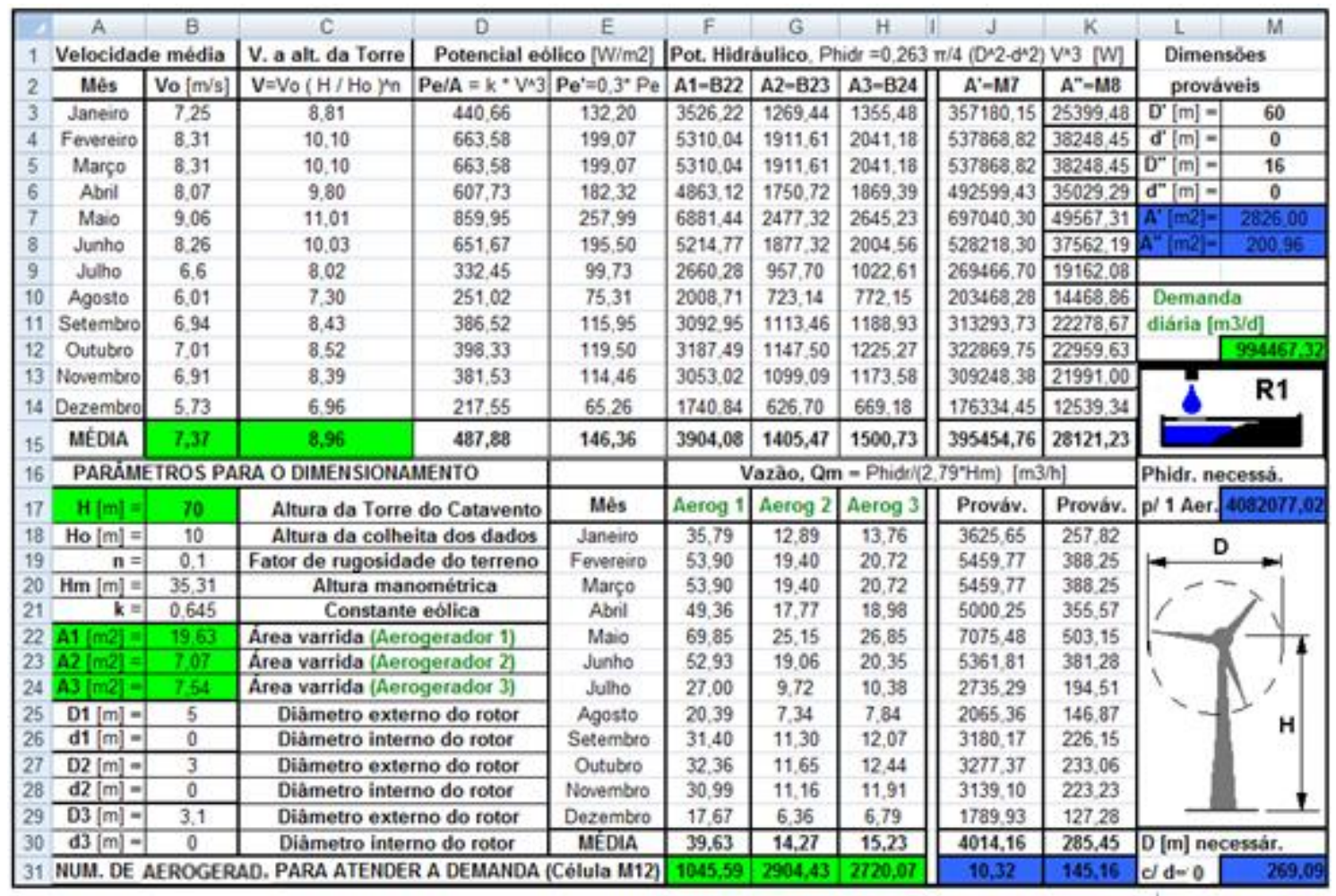

Em relação aos resultados da tabela 6.13, pode-se tecer comentários idênticos aos feitos para os da tabela anterior. Pelo resultado da célula $\mathrm{J} 31$, conclui-se que cerca de 10 aerogeradores com diâmetro de rotor de $60 \mathrm{~m}$, nas mesmas condições de vento, são 
suficientes para suprir a demanda de potência elétrica de $1000 \mathrm{~kW}$, com uma reserva de um dia sem vento.

Pelo consumo médio mensal de uma família de quatro pessoas no Brasil, (220 kWh), a potência de $1000 \mathrm{~kW}$, para que foi dimensionada a $\mathrm{CPH}$, atende as necessidades domésticas de 3273 residências de famílias com 4 pessoas.

Terminamos dizendo que, caso se quisesse usar a energia do mar ao invés da do vento para bombear água até o reservatório da $\mathrm{CPH}$, o SEARASER seria uma das alternativas possíveis. Pelos nossos cálculos, (ver tabela do anexo D) oito SEARASERS 1200 (vejase o anexo D) seriam capazes de alimentar R1 com o volume diário de $994467,32 \mathrm{~m}^{3}$ de água necessário para a CPH suprir os $1000 \mathrm{~kW}$.

\subsection{3- Comparação dos sistemas 1 e 2 para geração elétrica}

A tabela 6.14 resume a comparação entre o sistema 1 e sistema 2.

Tabela 6.14: Comparação entre os dois sistemas.

\begin{tabular}{|c|c|c|c|c|c|c|}
\hline $\begin{array}{c}\text { INSTALA- } \\
\text { Çत्A. }\end{array}$ & $\begin{array}{c}\text { Fonte } \\
\text { primária } \\
\text { de energia }\end{array}$ & $\begin{array}{c}\text { Bombeamento } \\
\text { de água do mar } \\
\text { até a unidade }\end{array}$ & $\begin{array}{c}\text { Bombeamento } \\
\text { para a turbina } \\
\text { Pelton. }\end{array}$ & $\begin{array}{c}\text { Número de } \\
\text { turbinas }\end{array}$ & $\begin{array}{c}\text { Pressão de } \\
\text { operação. }\end{array}$ & $\begin{array}{c}\text { Produção } \\
\text { diária. }\end{array}$ \\
\hline $\begin{array}{c}\text { CPH } \\
\text { (sistema 1) }\end{array}$ & Vento. & $\begin{array}{c}19 \text { cataventos } \\
\text { de diâmetro de } \\
\text { rotor de } 60 \mathrm{~m} .\end{array}$ & $\mathrm{CPH}$ & $\begin{array}{c}\text { Dependente da } \\
\text { configuração } \\
\text { desejada. }\end{array}$ & $40 \mathrm{bar}$ & $1 \mathrm{MW}$ \\
\hline $\begin{array}{c}\text { CPH } \\
\text { (sistema 2) }\end{array}$ & Vento. & $\begin{array}{c}10 \text { aeroger. de } \\
\text { diâmetro de } \\
\text { rotor de } 60 \mathrm{~m} .\end{array}$ & $\mathrm{CPH}$ & idem & 40 bar & $1 \mathrm{MW}$ \\
\hline
\end{tabular}

Em relação à área ocupada, não há uma diferença significativa em relação ao reservatório R1 porque o diâmetro pode ser mantido. Pelo número de máquinas eólicas necessárias para cada sistema (tabela 6.14) deduz-se que a área ocupada com o sistema 1 (19 cataventos) é, no mínimo o dobro da ocupada pelo sistema 2 (10 aerogeradores). 


\section{5-Diagramas de Sankey do modelo proposto}

Nesta seção retoma-se a interpretação dos processos que ocorrem nos sistemas através do diagrama de Sankey Fig. 6.21. Como referido no capítulo anterior, para simplificar tal interpretação, optou-se por usar a configuração da Fig. 6.20 com um êmbolo maciço e o reservatório superior R1 a uma altura de 12,8 metros em relação ao nível do mar.

Apresenta-se os diagramas de Sankey do sistema 1 (cataventos) para a dessalinização por osmose reversa e para a geração de eletricidade, e o diagrama de Sankey do sistema 2 (aerogeradores) para geração de eletricidade. Podem ser tiradas ilações em relação ao diagrama de Sankey do sistema 2 para dessalinização por OR, com base no diagrama do sistema 1 para a mesma aplicação e a potência de bombeamento dos dois sistemas.

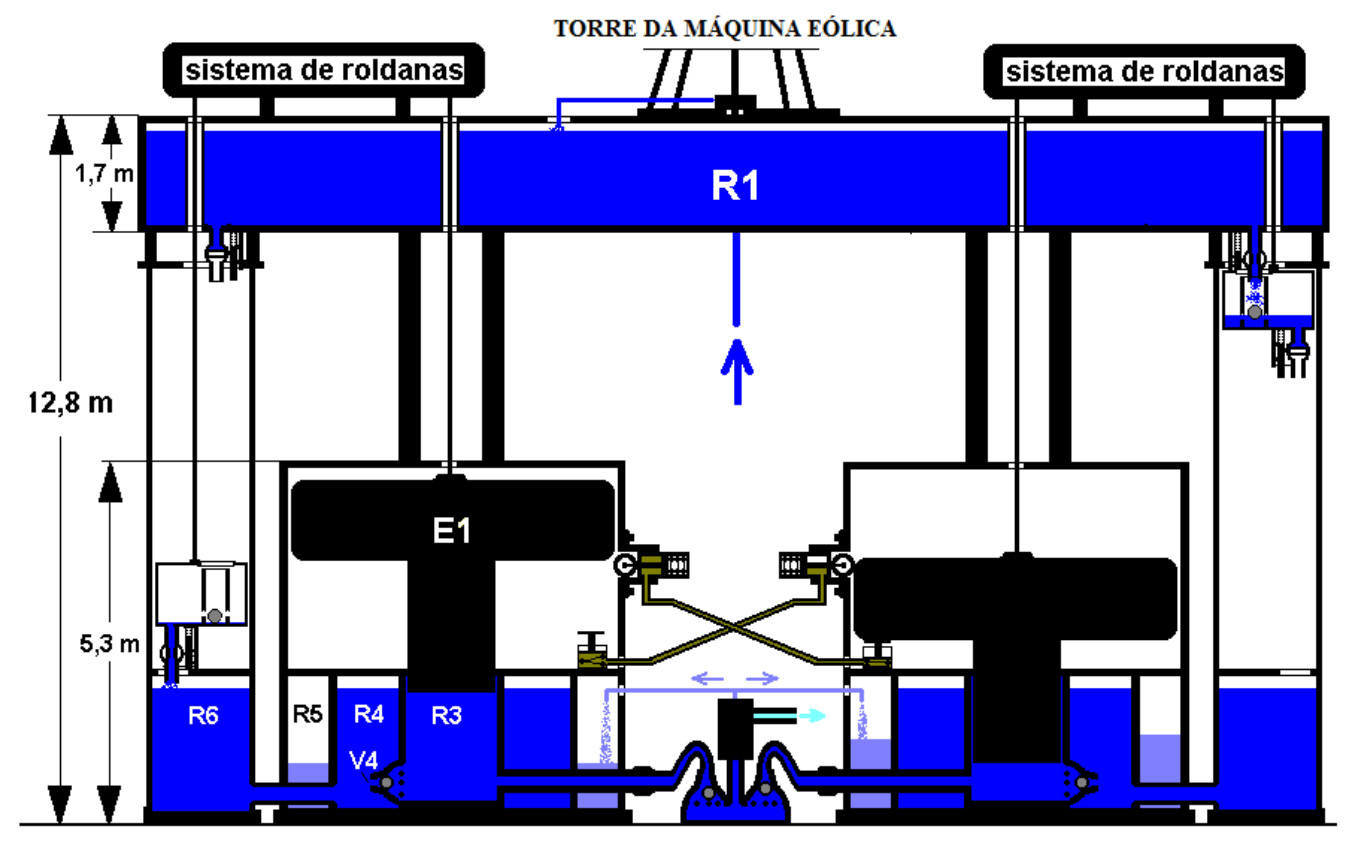

Fig. 6.20: CPH com êmbolos maciços.

Os valores indicados no diagrama foram obtidos com base nas equações previamente usadas ao longo do dimensionamento do sistema e assumindo valores teóricos para os rendimentos dos subsistemas. 


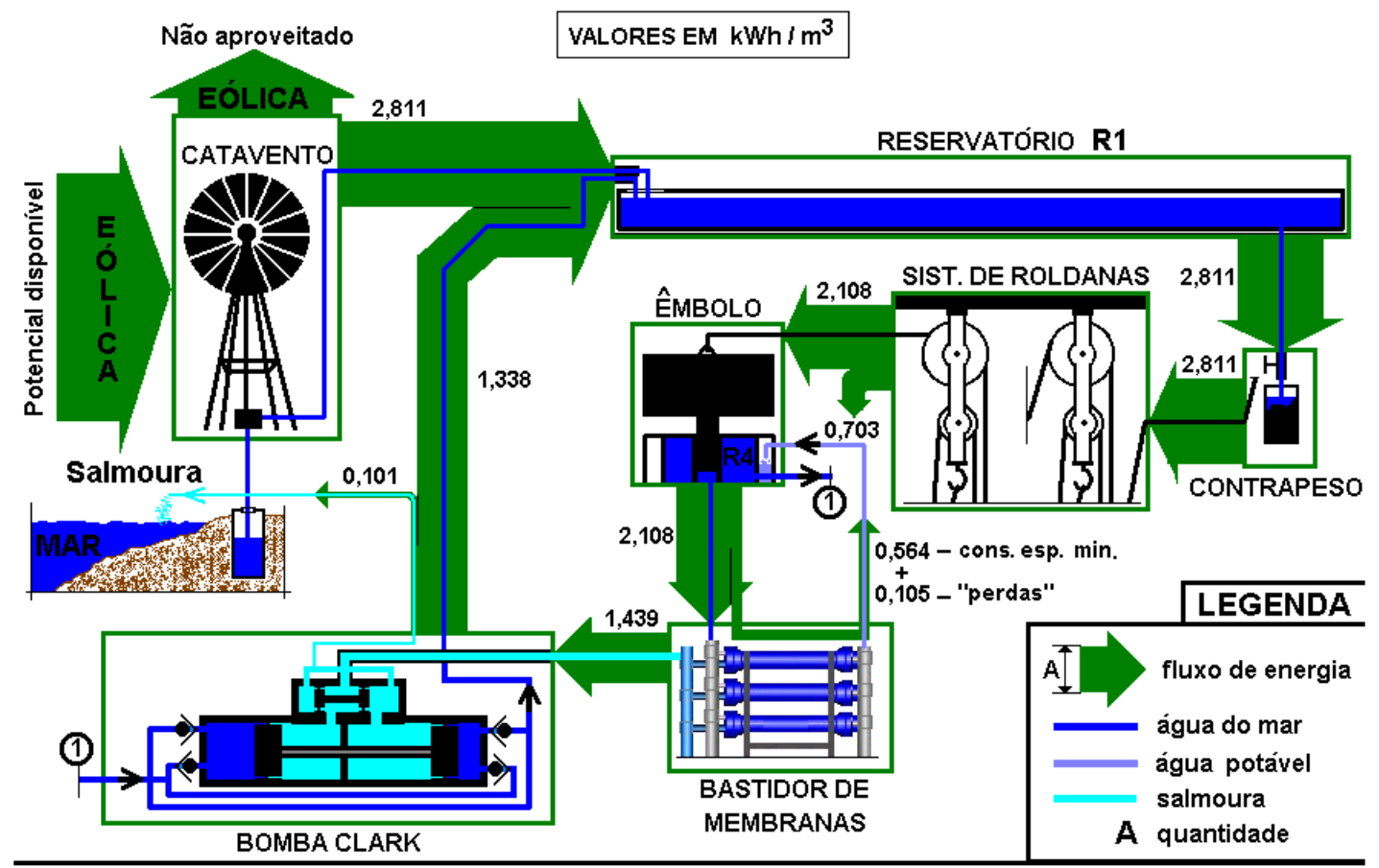

Fig. 6.21: Diagrama de Sankey do modelo proposto com base na configuração da Fig. 6.20 com R1 a 12,8 m, êmbolo maciço, e valores teóricos para os rendimentos dos diversos componentes do sistema.

De acordo com o exposto, o consumo específico isentrópico do modelo depende exclusivamente da pressão de operação do modelo, ou seja,

$E / \mathrm{V}=\mathbf{P}_{\text {op }}\left[\mathrm{kWh} / \mathrm{m}^{3}\right]$

Sendo 67 bar a pressão exercida pelo êmbolo na respectiva base, pela Eq. 6.38 obtém-se para o consumo específico isentrópico o valor de $\mathbf{1 , 8 6 1}\left[\mathrm{kWh} / \mathrm{m}^{3}\right]$. Analogamente ao que foi demonstrado anteriormente, o volume mínimo que os cataventos têm que colocar diariamente no reservatório superior R1, a 12,80 metros de altura em relação ao nível do mar, é de:

$\mathbf{V}_{\text {min }}=\operatorname{Ep} /(\rho g H)=33498 \times 10^{6} /(1025 \times 9,8 \times 12,8)=\mathbf{2 6 0 5 3 0 , 7 4} \mathbf{~ m}^{\mathbf{3}}$.

A energia entregada diariamente ao modelo pelos cataventos através do bombeamento do volume de água $\mathrm{V}_{\min }$ até o reservatório $\mathrm{R}$ 1, dividida pelo volume de água dessalinizada por dia de $\mathrm{V}_{\text {dess }}=5000 \mathrm{~m}^{3}$ corresponde ao consumo específico isentrópico, consequentemente teórico, do modelo é dado por: 
$\mathbf{m g H} / \mathbf{V}_{\text {dess }}=\rho \mathbf{V}_{\min } \mathbf{g H} / \mathbf{V}_{\text {dess }}=1025 \times 260530,74 \times 9,8 \times 12,8 / 5000=$ $=6699600,1 \mathrm{~J} / \mathrm{m}^{3}$

$6699600,1 \mathrm{~J} / \mathrm{m}^{3}$ equivale à $1,861 \mathrm{kWh} / \mathrm{m}^{3}$. No entanto, se se tiver em conta o caso mais realístico, pode-se assumir um rendimento global do modelo de 66,26 \% como anteriormente em que:

- O mecanismo de elevação do êmbolo tenha um rendimento de $75 \%$.

- As "perdas" no bastidor de membranas são de 5\%.

- Que se dispõe de uma bomba Clark capaz de recuperar 93\% da energia da salmoura.

Assim sendo, o consumo específico "real" tendo em conta a degradação de 33,74\% da energia potencial gravitacional "colocada" no reservatório R1 é de:

$\mathbf{E} / \mathrm{V}=1,861 / 0,662=\mathbf{2 , 8 1 1} \mathbf{k W h} / \mathbf{m}^{\mathbf{3}}$

O valor obtido corresponde no diagrama de Sankey, Fig. 21 ao que é entregue pelos cataventos.

Os cataventos obtêm essa energia do total de energia eólica disponível a 25 metros de altura no local em estudo (ilha de São Vicente em Cabo Verde) de acordo com o potencial aí existente. A percentagem da energia eólica captada pelos cataventos é de aproximadamente $10 \%$ desse potencial eólico.

A energia colocada em R1 (2,811 kWh / $\mathrm{m}^{3}$ do diagrama de Sankey - d.S.) é aproveitada pelo contrapeso para que o mesmo eleve o êmbolo maciço, através do sistema de roldanas, até o fim de curso superior. $25 \%$ dessa energia $\left(0,703 \mathrm{kWh} / \mathrm{m}^{3}\right.$ no d.S.) é destinada para vencer as irreversibilidades desse sistema. Portanto, $75 \%$ da energia $\left(0,75 \times 2,108 \mathrm{kWh} / \mathrm{m}^{3}\right)$ que o contrapeso obtém do reservatório R1 é convertida em energia potencial gravitacional do êmbolo no seu fim de curso superior.

O êmbolo, a partir do fim de curso superior, desce exercendo a pressão de 67 bar fornecendo energia à agua do mar forçando-a em direção ao bastidor de membranas. 
Desprezando o atrito entre o êmbolo e as paredes do reservatório R3, toda a energia potencial gravitacional do êmbolo $\left(2,108 \mathrm{kWh} / \mathrm{m}^{3}\right.$ no d.S.) é entregue à água que segue para as membranas.

Assumiu-se que $26,8 \%\left(0,564 \mathrm{kWh} / \mathrm{m}^{3}\right.$ no d.S.) dessa energia é usada para a dessalinização e $5 \%\left(0,105 \mathrm{kWh} / \mathrm{m}^{3}\right.$ no d.S.) dela converte-se em "perdas" viscosas e “perdas" de pressão que ocorrem no bastidor de membranas. Conseqüentemente, $62,8 \%$ $\left(1,439 \mathrm{kWh} / \mathrm{m}^{3}\right)$ da energia potencial do êmbolo fica contida na salmoura que sai do bastidor em direção à(s) bomba(s) Clark.

A(s) bomba(s) Clark recupera $(m) 93 \%\left(1,338 \mathrm{kWh} / \mathrm{m}^{3}\right.$.) da energia da salmoura e a convertem em energia potencial gravitacional da água que bombeia (m) até R1.

A Fig. 6.22 apresenta o diagrama de Sankey do modelo cujo êmbolo especial A, ao invés de ser maciço, contém o reservatório R2. No diagrama dispensou-se a quantificação dos fluxos de energia dado que a análise difere da anterior somente pelo fato do contrapeso precisar de menos energia para elevar o êmbolo (A4 $<2,861 \mathrm{kWh} / \mathrm{m}^{3}$ no d.S.). Em contrapartida essa quantidade a menos de energia é entregue ao reservatório R2 (A3 no d.S.) através da água que o mesmo contém durante a descida.

Por motivos relacionados com a semelhança dos diagramas dispensou-se a apresentação do que representa a dessalinização com o sistema de bombemento aerogerador bomba elétrica (sistema 2). Frisa-se entretanto que a diferença fundamental entre esse diagrama e o anterior da Fig. 6.21, é que a quantidade de água bombeada para R1 pelo sistema 2 é maior do que a bombeada por S2. Como foi demonstrado, o consumo específico é o mesmo porque só depende da pressão exercida pelo êmbolo especial. 


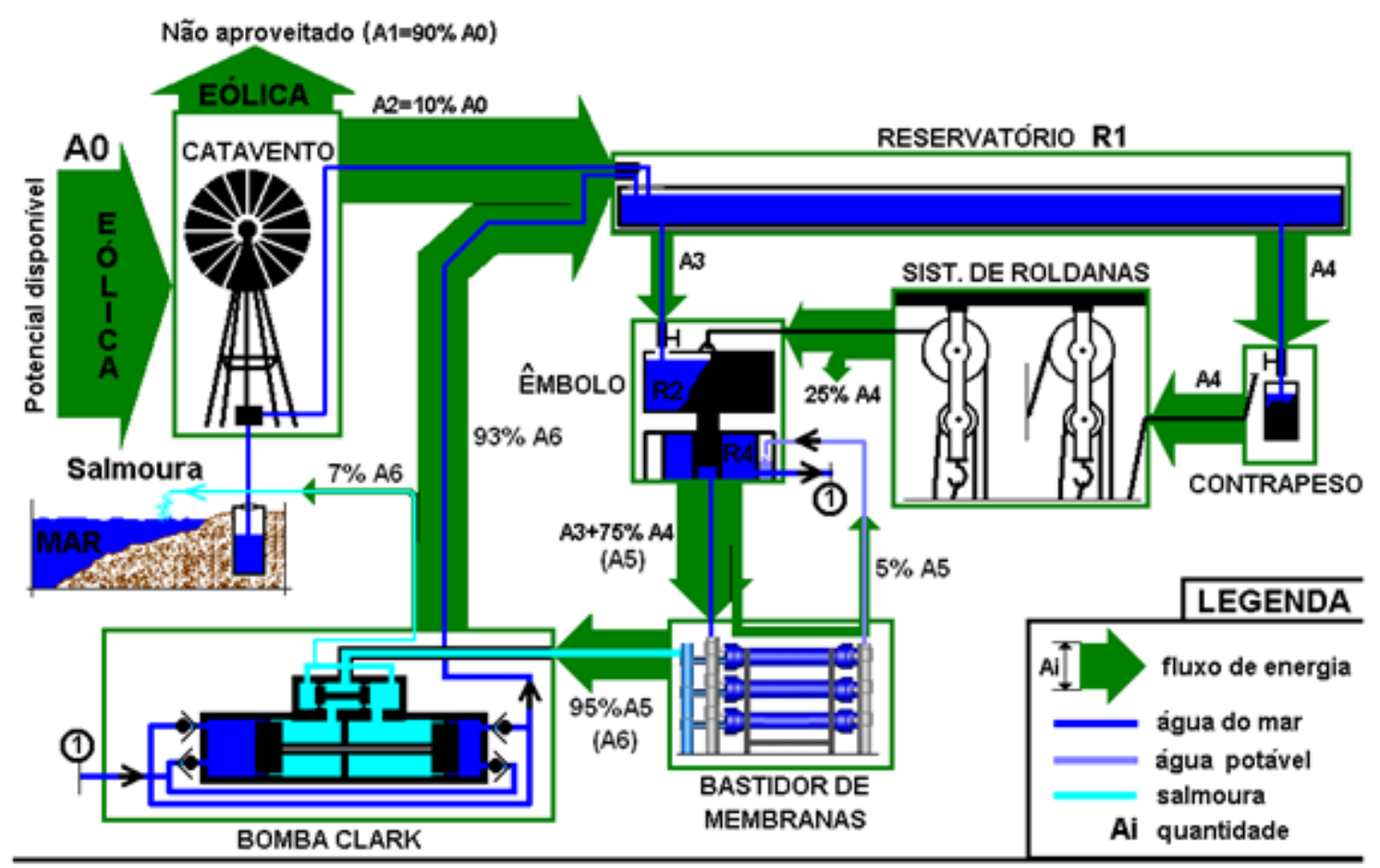

Fig. 6.22: Diagrama de Sankey do sistema S1 para dessalinização com base na configuração da Fig. 6.20, porém com êmbolo especial B, e valores teóricos para os rendimentos dos diversos componentes do sistema.

Dispondo de um protótipo completo do sistema, estar-se-á em condições de ter valores reais para os fluxos de energia, podendo-se assim, com eles, elaborar um diagrama de Sankey obtido a partir do desempenho prático do mesmo. Entretanto, tendo recentemente construído um pequeno protótipo da coluna de potência hidráulica, está-se em condições de abordar algumas questões relacionadas com a viabilidade técnica do modelo na seção seguinte.

A Fig. 6.23 ilustra o diagrama de Sankey correspondente à geração de energia elétrica através do sistema 1 (cataventos) e a Fig. 6.24 o mesmo diagrama correspondente à geração de energia elétrica através do sistema 2 (aerogeradores). Os valores indicados nos diagrama foram obtidos com base nas equações previamente usadas ao longo do dimensionamento do sistema e assumindo valores teóricos para os rendimentos dos subsistemas bem como da turbina Pelton (85\%) e do gerador $(60 \%)$. 


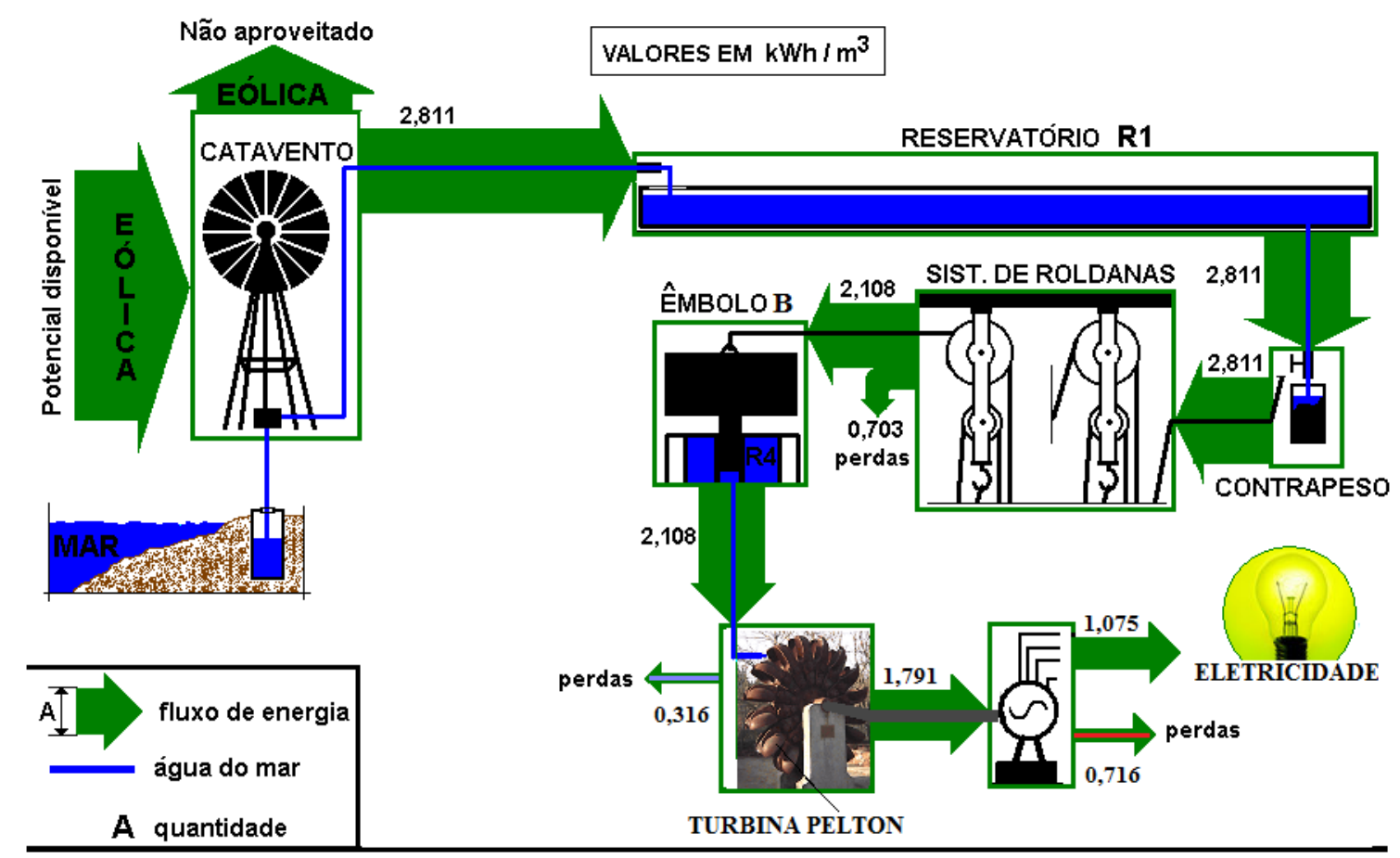

Fig. 6.23: Diagrama de Sankey do sistema S1 para geração de energia elétrica com base na configuração da Fig. 6.20 com R1 a 12,8 m, êmbolo maciço, e valores teóricos para os rendimentos dos diversos componentes do sistema.

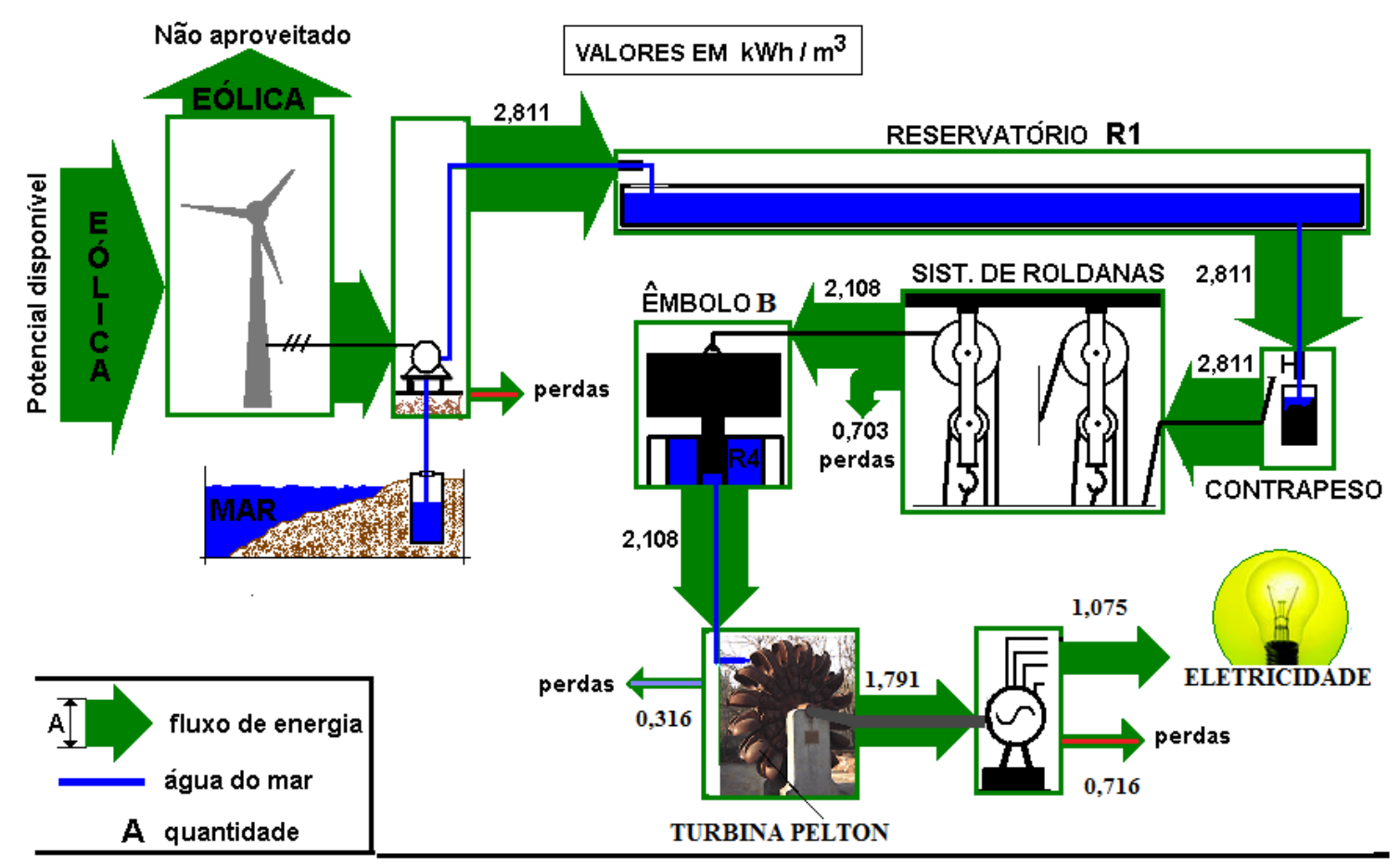

Fig. 6.24: Diagrama de Sankey do sistema S2 para geração de energia elétrica com base na configuração da Fig. 6.20, e valores teóricos para os rendimentos dos diversos componentes do sistema. 


\section{6-Considerações sobre a viabilidade técnica, ambiental e social do uso da CPH}

Em termos tecnológicos, o modelo da $\mathrm{CPH}$ não apresenta dificuldades de implementação por se basear essencialmente em sistemas simples que não apresentam "segredos" para a engenharia. Tanto os cataventos quanto as roldanas e a roda Pelton são dispositivos que a humanidade utiliza há mais de um século. Igualmente os subsistemas propostos para a automação hidráulica, baseiam-se em componentes mecânicos que são do domínio da humanidade décadas tais como a mola, roda dentada a cremalheira. A construção do protótipo confirmou o que que foi colocado.

Relativamente ao aspecto ambiental, tem-se que ressalvar que há unidades convencionais de osmose reversa cuja energia elétrica provém de fontes renováveis e que, portanto, estão nas mesmas condições que o modelo apresentado neste trabalho. Essa não é a situação da unidade da cidade da Praia cuja origem primária da energia elétrica que alimenta as bombas é o óleo combustível usado nas termelétricas da ilha havendo, consequentemente, emissão de $\mathrm{CO}_{2}$.

Um aspecto que torna a CPH economicamente interessante é a manutenção simples e pouco onerosa. $\mathrm{O}$ anexo $\mathrm{B}$ demonstra isso.

Os benefícios que podem advir, da adoção do modelo proposto tanto para a dessalinização como para a geração de eletricidade, não se limitam ao campo econômico. Tais benefícios entram nos domínios social e ambiental.

Quanto ao domínio social, a solução mesmo que parcial do problema da falta de água, e acesso à eletricidade possibilita às populações, melhor qualidade de vida. Aspectos contemplados nessa melhoria são, por exemplo, a saúde e a educação.

No que diz respeito à saúde, pode-se referir o fato da ingestão de água de pouca qualidade acarretar problemas para o organismo. No que diz respeito à educação, além de ser afetada pela possível saúde deficitária, também o é, pelo tempo gasto em busca de água em regiões com escassez. O estudo à noite é deficitário se não houver eletricidade. 
Quanto ao domínio econômico, é inegável a sua cumplicidade com a saúde e educação. Além dos benefícios econômicos provenientes indiretamente dos da saúde e educação, tem-se os diretos devido à redução dos custos de produção, pela adoção do modelo em plantas de dessalinização convencionais e para a geração eletrica. Essa redução é devida ao uso de fontes de energia "gratuita" em processos que são energeticamente onerosos. O beneficio é muito maior, em países que não dispõem de recursos minerais e que precisam dessalinizar água, como é o caso de Cabo Verde. Ainda nesse domínio, é pertinente frisar que, em meios rurais, o modelo oferece a possibilidade de se ter água para a agricultura a partir da dessalinização de águas salobras e eletricidade para ajudar nos trabalhos do campo.

Os benefícios ambientais são relativos, dado que consiste em não agredir o meio ambiente, tanto quanto os restantes modelos industriais. Comparativamente, o modelo proposto é menos agressivo para com o ambiente já que não necessita de combustíveis fósseis. Pelo fato de não recorrer ao uso de combustíveis fósseis, tem-se um modelo que além de ser economicamente competitivo, também o é ecologicamente dado que não tem emissão de $\mathrm{CO}_{2}$ para a atmosfera.

Em relação ao modelo apresentado, o que pode constituir agressão ao meio ambiente, é o rejeito da salmoura que é comum a todos os processos de dessalinização. Contudo, em Plantas de dessalinização de água do mar, a salmoura é geralmente rejeitada para o oceano, tendo um impacto ambiental reduzido se o processo não for térmico como é o caso da osmose reversa. O impacto comum é devido essencialmente aos produtos químicos usados na fase de pré-tratamento. A esse respeito, lembramos que se a taxa de conversão for suficientemente baixa, pode-se dispensar o uso de químicos no pré-tratamento.

No entanto, pensa-se que, para mitigar os efeitos prejudiciais da salmoura, é possível dar-lhe pelo menos dois destinos diferentes. Um deles é a construção de uma piscina solar para a geração de eletricidade, e o outro, com caráter de lazer, é a construção de uma piscina com as caráterísticas do mar morto (elevada salinidade), na qual o banhista não faz esforço nenhum para flutuar. 
Além dos destinos citados no parágrafo anterior, é interessante cogitar a possiblidade de uso da salmoura para piscicultura ou /e irrigação. Existem espécies animais e vegetais que se adaptam a água com elevado teor de salinidade. São exemplos o camarão de salmoura e a tilápia. As plantas adequadas podem ter a função de ornamentar o entorno da unidade de dessalinização. Essas ações, além de serem mitigadoras, têm o potencial de trazer benefícios financeiros. 


\section{CAPÍtUlo 7:}

\section{CONCLUSÕES}

As primeiras conclusões que se tiram deste trabalho, é que a materialização da idéia apresentada é tecnicamente viável. Por outras palavras, a dessalinização de água e a geração de eletricidade, usando a energia eólica e a coluna de potência hidráulica, tem custo operacional competitivo tanto pela sua simplicidade como pelo recurso a energia renovável.

A partir das deduções com fundamentos da Termodinâmica, da Mecânica Newtoniana e da Mecânica dos Fluídos, chegou-se à conclusão que o consumo específico de energia do modelo proposto, considerando processos isentos de irreversibilidades, é sempre igual à Pressão Osmótica da água por dessalinizar. Em relação à geração de eletricidade, a potência gerada é função do peso do êmbolo especial, da área da respectiva base e da área do bico do injetor.

Em relação às unidades que usam Osmose Reversa, a competitividade do modelo é justificada não só pelo uso de recurso energético "gratuito", mas também, pela sua versatilidade para atingir economias de escala. $\mathrm{O}$ aumento de produção pode, teoricamente, ser conseguido sem limites. Em relação à geração de eletricidade, deduzse que a $\mathrm{CPH}$ apresenta competitividade devido essencialmente ao uso de energias "gratuitas" e do custo de manutenção e operação.

Como limitações do modelo, dependendo do porte da instalação, aponta-se a necessidade de uma grande área para a instalação de cataventos e a de furar vários poços. Chegou-se ao valor de aproximadamente 2 cataventos com diâmetro de rotor de $3 \mathrm{~m}$ por metro cúbico de água dessalinizada. Assim, essas limitações ganham maiores proporções com o aumento da quantidade de água a ser dessalinizada ou da potência gerada. No entanto, a possibilidade de se usar turbinas de eixo vertical gigantes ou cataventos bem maiores proporciona economia de terreno ocupado.

O funcionamento da coluna de potência hidráulica não depende do uso do sistema 1 (cataventos) ou do sistema 2 (aerogeradores). No entanto, em relação ao uso do terreno, 
é conveniente decidir pelo sistema 2 (aerogeradores) dado que permite ter uma instalação com um menor número de máquinas eólicas. Além disso, o sistema 2 apresenta a vantagem de se poder instalar os aerogeradores num local onde o potencial eólico é maior e furar poucos poços de captação de água.

\section{Considerações finais, perspectivas e propostas futuras.}

Apesar de ao longo deste trabalho, em relação à dessalinização, se ter dado mais ênfase à água do mar, recorde-se que o modelo pode igualmente ser usado para a dessalinização de águas subterrâneas com custos inferiores devido à sua menor pressão osmótica, além de outros possíveis fatores. Outras possíveis aplicações do modelo, além das duas principais são:

1) Despoluição de riachos e lagos com o uso de filtros apropriados ao invés de membranas de RO, à semelhança duma das maiores unidades de osmose reversa, com capacidade nominal de $270000 \mathrm{~m}^{3} /$ dia, usada para diminuir a salinidade do rio Colorado em Yuma, EUA. Nesse caso, também se sugere a configuração de colunas submersas.

2) Uso como fonte de água para a agricultura em meios rurais. Nesse campo, dado que já se usa em Cabo Verde o sistema de rega gota-a-gota que rentabiliza a utilização da água na agricultura, não é mirabolante pensar em usar terrenos da ilha de Santa Luzia que é deserta, e transformá-los em terrenos produtivos.

3) Produção de gelo para conserva de peixe em zonas de pesca (uso da CPH como compressor de em um ciclo de refrigeração).

4) Obtenção de sucos concentrados como alternativa à destilação.

5) Obtenção de água com elevado grau de pureza para uso medicinal, etc.

6) A CPH pode ser usada como uma bomba de alta pressão para colocar água do mar num reservatório situado num monte à beira-mar por exemplo, para posterior uso da EPG para geração de eletricidade. Algumas ilhas em Cabo Verde têm condições para 
esta aplicação por serem montanhosas. Ainda nesta aplicação, o reservatório R1 da CPH que poderia estar a $10 \mathrm{~m}$ do nível do mar, poderia ser alimentado a partir de outras fontes de energia, além da eólica, tais como as ondas do mar e o sol.

Um dos aspectos práticos a ser explorado é a utilização de um regulador de vazão para limitar a vazão da salmoura. Um regulador de vazão é um aparelho intercalado numa canalização para manter constante sua vazão qualquer que seja a pressão a montante.

Um outro aspecto é a utilização de um sistema de elevação do êmbolo aproveitando a energia da salmoura como mostrado no anexo E. Essa alternativa é interessante caso a distância $\mathrm{D}_{\mathrm{p}}$ percorrida pelo contrapeso, para elevar o êmbolo, seja muito grande.

Além dos aspectos técnicos dessa etapa prática, poder-se-á aprofundar o estudo da viabilidade econômica (feita durante o mestrado) por se dispor, nessa altura, de custos relacionados com a construção do protótipo e seu desempenho real. Esse estudo poderá ser aprimorado através da otimização do modelo teórico. Assim, em função da demanda, e dos custos para atingí-la, o modelo otimizado poderá indicar as dimensões ideais para as $\mathrm{CPH}^{\prime}$ s, a melhor combinação de fontes para o bombeamento bem como o número de dispositivos. A propósito de fontes alternativas para abastecer o reservatório superior R1, apresenta-se no anexo F a sugestão do uso de carneiros hidráulicos. 
ANEXOS 


\section{ANEXO A-Pressão de Operação do Sistema}

\section{1) êmbolo especial $A$}

A pressão $\mathrm{P}_{\mathrm{A}}$ exercida pelo êmbolo especial A na sua base cujo diâmetro é $\boldsymbol{d e}$, é função dos parâmetros geométricos ilustrados na Fig. A.1.

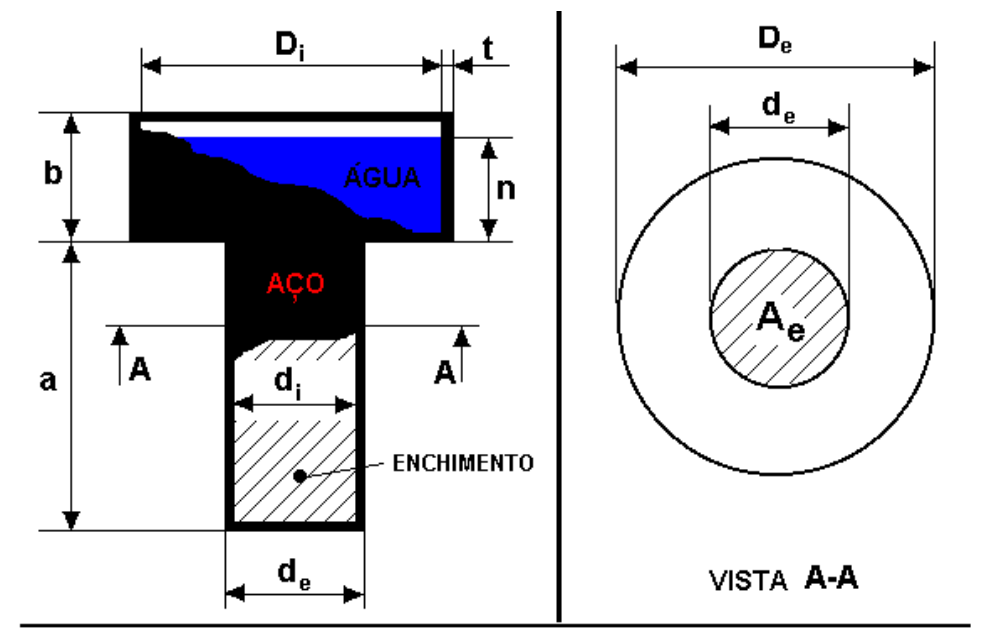

Fig. A.1: Esquema do Êmbolo especial A.

A pressão é dada pelo peso total $\boldsymbol{P t}$, do êmbolo dividido pela área circular $\mathbf{A}_{\mathbf{e}}$.

$\mathrm{P}_{\mathrm{A}}=\boldsymbol{P t} / \mathbf{A}_{\mathrm{e}}$

Sendo $\mathbf{A}_{\mathbf{e}}=\pi / 4 \boldsymbol{d} \boldsymbol{e}^{2}$ vem,

$\mathrm{P}_{\mathrm{A}}=4 P t /\left(\pi d e^{2}\right)$

O peso total é dado pela soma dos pesos da estrutura de aço $\boldsymbol{P}_{\boldsymbol{a c ̧}}$, da água do mar contida no reservatório do êmbolo $\boldsymbol{P}_{\text {agua }}$ e do enchimento $\boldsymbol{P}_{\text {ench }}$, ou seja,

$P t=P_{\text {aço }}+P_{\text {agua }}+P_{\text {ench }}$

A massa do aço é dada pelo produto do volume que ocupa pela sua densidade, ou seja,

$\mathrm{M}_{\text {aço }}=\rho_{\text {aço }} \times \mathrm{V}_{\text {aço }}$ 
Pela geometria do êmbolo verifica-se que o volume de aço é dado por:

$\mathrm{V}_{\text {aço }}=\pi / 4\left[\left(D e^{2} b+d e^{2} a\right)-\left[D i^{2}(b-2 t)+d i^{2} a\right]\right.$

Substituindo a Eq. A.5 na A.4 e, dado que o peso do aço é igual à g x $\mathrm{M}_{\text {aço, }}$, tem-se

$P_{\text {aço }}=g \rho_{\text {aço }} \pi / 4\left[\left(D e^{2} b+d e^{2} a\right)-\left[D i^{2}(b-2 t)+d i^{2} a\right]\right.$

Analogamente, obtém-se para o peso da água e do material de enchimento as seguintes igualdades:

$\mathrm{P}_{\text {água }}=\mathrm{g} \rho_{\text {água }} \pi / 4 \mathrm{Di}^{2} \mathrm{n}$

$\mathrm{P}_{\text {ench }}=\mathrm{g} \rho_{\text {ench }} \pi / 4 \mathrm{di}^{2} \mathrm{a}$

Voltando à Eq. A.2 e tendo em conta a Eq A.3, obtém-se para a pressão exercida na base do êmbolo a seguinte igualdade:

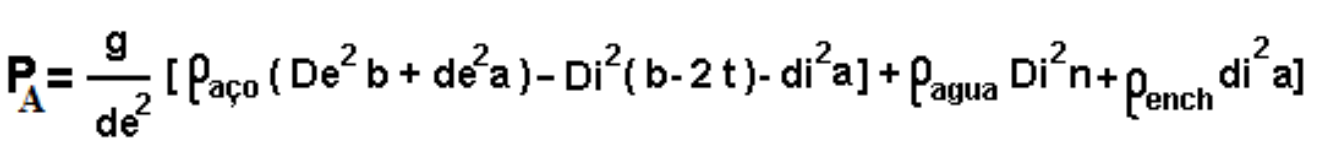

onde

g é a aceleração da gravidade em $\left[\mathrm{m} / \mathrm{s}^{2}\right]$

$\boldsymbol{\rho}_{\text {aço }}$ é a densidade do aço em $\left[\mathrm{kg} / \mathrm{m}^{3}\right]$

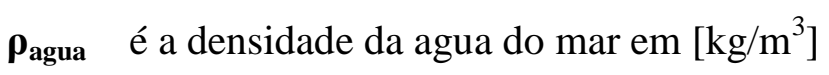

$\boldsymbol{\rho}_{\text {ench }}$ é a densidade do material de enchimento em $\left[\mathrm{kg} / \mathrm{m}^{3}\right]$

e, Di=De-2t em [m].

a, b, De , de, Di, di, n são os parâmetros geométricos da Fig. A1 expressos em [m]

O gráfico da Fig. A2 espelha a sensibilidade da pressão em função dos diferentes parâmetros. Para a elaboração do gráfico, usou-se valores unitários $(\boldsymbol{a}=\boldsymbol{b}=\ldots=\boldsymbol{n}=1)$ para todos os parâmetros, mantendo-se a espessura $t$ constante e igual à $0,01 \mathrm{~m}$. 


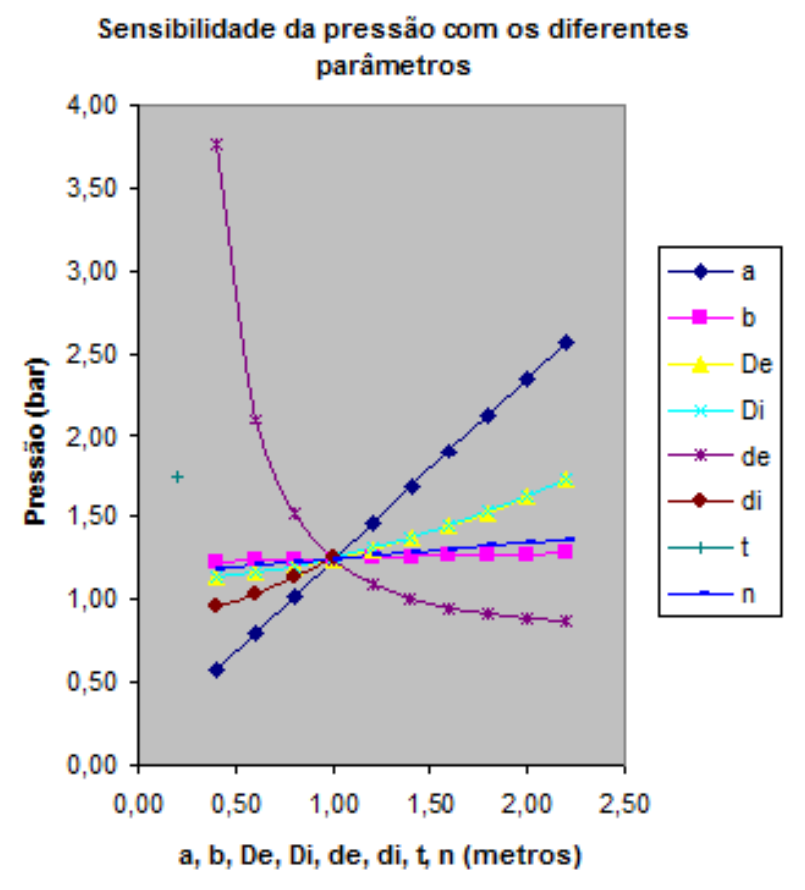

Fig. A2: Gráfico da sensibilidade da pressão exercida pelo êmbolo especial.

\section{2) êmbolo especial B}

Em relação ao êmbolo especial B (êmbolo maciço) a pressão exercida por ele na sua base é função dos parâmetros geométricos ilustrados na Fig. A.3. Para facilitar os cálculos decompos-se o êmbolo em dois cilindros cujos volumes são V1 e V2.

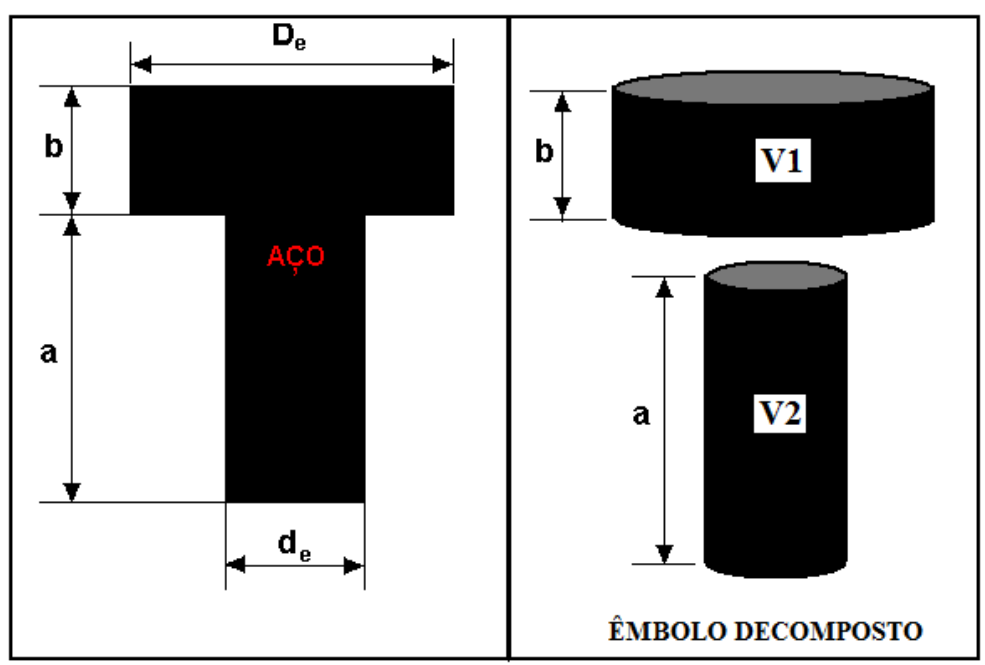

Fig. A.3: Esquema do Êmbolo especial B.

A pressão é dada pelo peso total $\boldsymbol{P t}$, do êmbolo dividido pela área circular $\mathbf{A}_{\mathbf{e}}$. 
$\mathrm{P}_{\mathrm{B}}=\boldsymbol{P t} / \mathbf{A}_{\mathrm{e}}$

Sendo $\mathbf{A}_{\mathrm{e}}=\pi / 4 \boldsymbol{d} \boldsymbol{e}^{2}$ vem,

$\mathrm{P}_{\mathrm{B}}=4 P t /\left(\pi d e^{2}\right)$

$\mathrm{O}$ peso total é dado pela soma dos pesos $\mathrm{P} 1$ e $\mathrm{P} 2$ correspondentes aos volumes $\mathrm{V} 1$ e V2 dos dois cilindros maciços, ou seja,

$P t=P 1+P 2$

A massa do aço é dada pelo produto do volume que ocupa pela sua densidade, ou seja,

$\mathrm{M}_{\text {aço }}=\rho_{\text {aço }} \times \mathrm{V}_{\text {aço }}$

Pela geometria do êmbolo decomposta verifica-se que o volume de aço é dado por:

$\mathrm{V}_{\text {aço }}=\pi / 4\left(\operatorname{De}^{2} b+\operatorname{de}^{2} \mathrm{a}\right)$

Substituindo a Eq. A.14 na A.13 e, dado que o peso do aço é igual à g x $\mathrm{M}_{\text {aço }}$, tem-se

$\mathrm{P}_{\mathrm{aço}}=\mathrm{g} \rho_{\mathrm{aço}} \pi / 4\left(\mathrm{De}^{2} \mathrm{~b}+\mathrm{de}^{2} \mathrm{a}\right)$

Voltando à Eq. A.10 e tendo em conta a Eq A.12, obtém-se para a pressão exercida na base do êmbolo a seguinte igualdade:

$$
P_{B}=\frac{g}{d e^{2}} \rho_{a c ̧ o}\left(D e^{2} b+d e^{2} a\right)
$$

sendo $\boldsymbol{g}$ a aceleração da gravidade, $\boldsymbol{\rho}_{\text {aço }}$ a densidade do aço, e $\boldsymbol{a}, \boldsymbol{b}, \boldsymbol{D} \boldsymbol{e}, \boldsymbol{d e}$ os parâmetros geométricos da Fig. A3 com as mesmas unidades da Eq. A.9. 


\section{ANEXO B-Consumo específico da CPH}

Vamos supor que $1 \mathrm{~m}^{3}$ a água está contido num reservatório cilíndrico de diâmetro de e altura $\boldsymbol{a}$, ilustrado na Fig. 3.22.
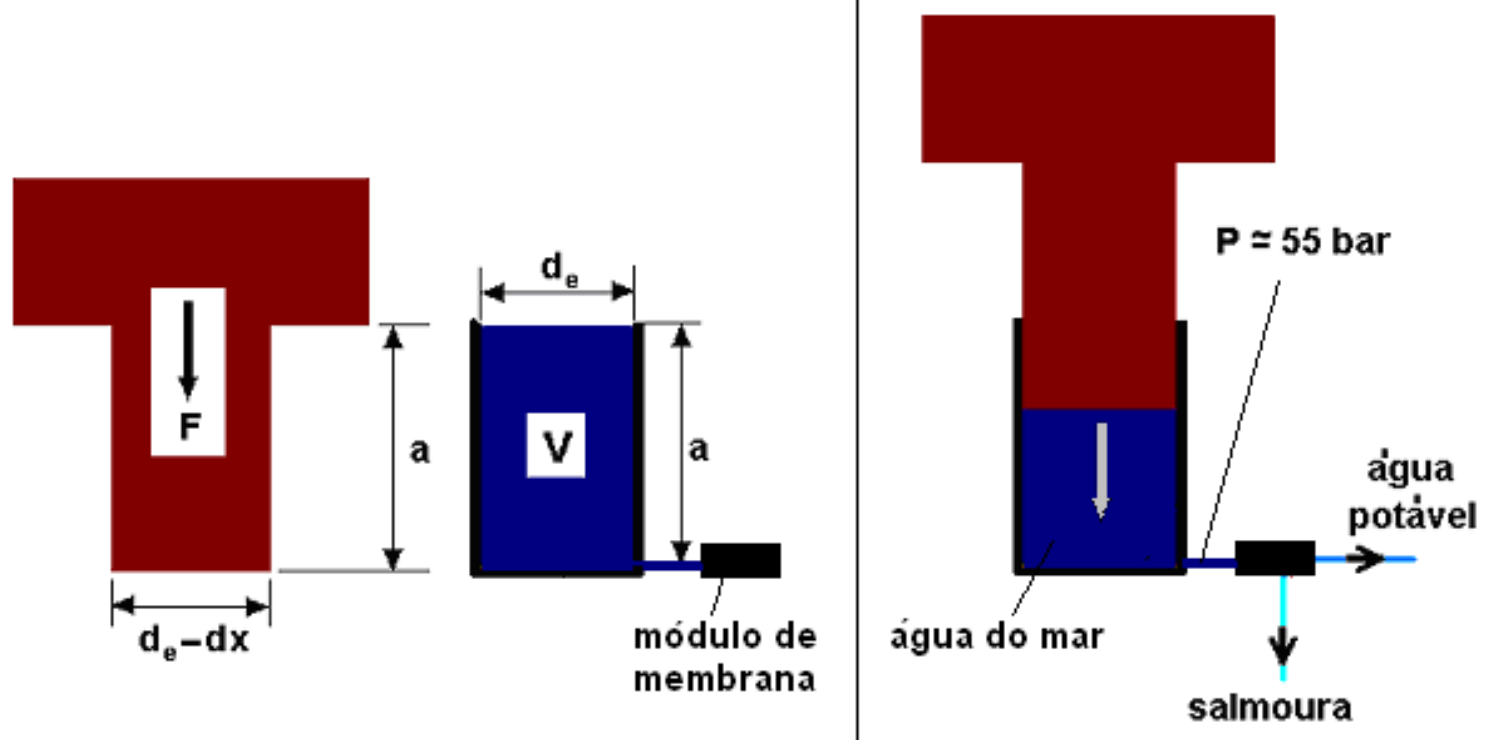

Fig. B1: Dessalinização por Osmose Reversa com o uso do Êmbolo Especial

Para dessalinizar a água dispomos de um módulo de membrana acoplada ao reservatório cilíndrico. Para exercer a pressão necessária para a dessalinização, dispomos de um êmbolo maciço, com a forma sugerida no projeto.

Recordemos que

- A pressão mínima para se conseguir a dessalinização por osmose reversa é igual à pressão osmótica da solução que se quer dessalinizar.

No entanto, sem prejuízo para as conclusões a que chegaremos, no decorrer das análises feitas neste anexo, usaremos valores diferentes para a pressão tais como:

55 bar, que corresponde à pressão usadas em testes dos módulos de membranas para dessalinização de água do mar.

A pressão $\mathbf{P}$ de dessalinização é dada pelo peso $\mathbf{F}$ do êmbolo dividido pela área $\mathbf{A}_{\mathbf{b}}$ da sua base, 
$\mathrm{P}=\mathrm{F} / \mathrm{A}_{\mathrm{b}}$

Como a área da base do cilindro é,

$\mathrm{A}_{\mathrm{b}}=\pi \mathrm{de}^{2} / 4$

Substituindo a Eq. B2 na Eq. B1, resulta,

$\mathrm{P}=\mathrm{F} /\left(\pi \mathrm{de}^{2} / 4\right)$

O volume de água é dado por,

$\mathrm{V}=\left(\pi \mathrm{de}^{2} / 4\right) \mathrm{a}$

donde,

$\mathrm{a}=4 \mathrm{~V} /\left(\pi \mathrm{de}^{2}\right)$

Resolvendo a Eq. 3.12 para de com $\pi=3,14$ tem-se:

$d e=\sqrt{4 A_{b} / 3,14}$

Fixando a área da base $\mathrm{A}_{\mathrm{b}} \mathrm{em} 1 \mathrm{~m}^{2}$, tem-se $d e=1,128 \mathrm{~m}$.

Com esse valor do parâmetro de, inserido na Eq. 3.15 e, fazendo $V=1 \mathrm{~m}^{3}$, tem-se:

$\mathrm{a}=4 /\left(3,14 \times 1,128^{2}\right)=1 \mathrm{~m}$

Assim, temos $\mathbf{1 m}^{\mathbf{3}}$ de água contido num reservatório cilíndrico cujo diâmetro da base $d_{e}=1,128 m$, e altura $a=1 m$

Da Eq B1, com a área da base $A_{b}=1 \mathrm{~m}^{2}$, resulta, 
A relação B7 significa que o peso do êmbolo deve ser numericamente igual à pressão de dessalinização. Como visto anteriormente, para a água do mar precisa-se de uma pressão igual a 800 psi ou 55 bar que corresponde à $55 \times 10^{5} \mathrm{~N} / \mathrm{m}^{2}$. Para que o êmbolo exerça pressão suficiente para dessalinizar o metro cúbico de água contida no reservatório, seu peso terá que ser igual a $55 \times 10^{5} \mathrm{~N}$.

Colocando esse êmbolo no topo do cilindro, ele forçará a água a atravessar a membrana plana. Dado que a membrana é semipermeável, ela permite a passagem da água, mas impede a dos sais dissolvidos. Assim, consegue-se dessalinizar o metro cúbico de água contido no cilindro.

A quantidade de energia usada para o processo, equivale ao trabalho realizado para elevar o êmbolo até a altura a, já que a sua descida se faz por ação da força de atração gravitacional.

Tendo em conta que no modelo proposto sugeriu-se pelo menos três formas diferentes para elevar o êmbolo, pela expansão de ar comprimido, por roldanas e macaco hidráulico, é importante frisar que:

- O trabalho teórico para elevar o êmbolo não depende do processo usado. O seu valor corresponde ao produto do peso do êmbolo pelo deslocamento do seu centro de gravidade. Conseqüentemente,

- O consumo específico de energia teórico do modelo, não depende de como se consegue a subida do êmbolo. Naturalmente, o consumo específico real será maior do que o teórico devido às irreversibilidades, sendo tanto maior quanto menos eficiente for a máquina usada elou o processo usado para elevar o êmbolo.

O trabalho W, para se conseguir subir o êmbolo até a altura a é dado por, 
Onde, $\mathbf{F}$ é o peso do êmbolo e a, é altura do reservatório cilíndrico. Com os valores de a e $\mathbf{F}$ obtidos anteriormente tem-se:

$\mathrm{W}=55 \times 10^{5} \mathrm{~N} \times 1 \mathrm{~m}=55 \times 10^{5} \mathrm{~J}=5500 \mathrm{~kJ}$

O consumo específico de energia é dado por

$\mathrm{E} / \mathrm{V}=5500 \mathrm{~kJ} / 1 \mathrm{~m}^{3}=5500 \mathrm{~kJ} / \mathrm{m}^{3}$.

Sendo que $1 \mathrm{~kJ}=1 / 3600 \mathrm{kWh}$, vem

\section{$\mathrm{E} / \mathrm{V}=1,528 \mathrm{kWh} / \mathrm{m}^{3}$}

A resolução analítica do problema anterior conduz-nos a uma solução geral. Assim, vamos generalizar o referido problema (Fig. B1).

A pressão $\mathrm{P}$, exercida pelo êmbolo na sua base é

$\mathrm{P}=\mathrm{F} /\left(\pi \mathrm{de}^{2} / 4\right)$

Donde o peso do êmbolo F é dado por,

$\mathrm{F}=\mathrm{P} \pi \mathrm{de}^{2} / 4$

$\mathrm{O}$ volume de água $\mathrm{V}$, contida no reservatório é dado por,

$\mathrm{V}=\left(\pi \mathrm{de}^{2} / 4\right) \mathrm{a}$

O trabalho realizado $\mathrm{W}$, para elevar o êmbolo até a altura do reservatório cilíndrico é,

$\mathrm{W}=\mathrm{F}$ a

Esse trabalho equivale a energia E usada para dessalinizar o volume V de água, ou seja, 
Por conseguinte, a energia específica usada na dessalinização será,

$\mathrm{E} / \mathrm{V}=\mathrm{W} / \mathrm{V}=\mathrm{F}$ a/ $\left(\pi \mathrm{de}^{2} / 4 \mathrm{a}\right)$

Substituindo o valor de F da Eq. B10 na Eq. B14, tem-se,

$\mathrm{E} / \mathrm{V}=\mathrm{P} \pi \mathrm{de}^{2} / 4 \mathrm{a} /\left(\pi \mathrm{de}^{2} / 4 \mathrm{a}\right)$, ou seja

$\mathbf{E} / \mathrm{V}=\mathbf{P}$

O resultado encontrado na relação B15 sugere que:

-A energia específica consumida na dessalinização por osmose reversa, através do modelo proposto, com a utilização da energia potencial gravitacional caráteriza-se pelos seguintes aspectos:

- É, numericamente, sempre igual a pressão $P$, necessária para que ocorra o processo de dessalinização (cerca de 55 bar para água do Mar, ou 20,3 bar isentropicamente).

- Não depende das dimensões do reservatório, que contém o volume de água por dessalinizar (Reservatório $R 3$, no modelo proposto).

- Não depende, nem das dimensões do êmbolo (êmbolo especial E1, no modelo proposto), nem do material de que ele é feito.

Se o cálculo para $E / V=P$ for feito considerando $\mathbf{P}=\mathbf{2 0 , 3}$ bar para dessalinização isentrópica (que equivale ao trabalho mínimo), de acordo com ISENTROPIC [...] obtém-se o seguinte $\left(1\right.$ bar $\left.=10^{5} \mathrm{~N} / \mathrm{m}^{2}\right)$ :

$\mathrm{E} / \mathrm{V}=2030 \mathrm{~kJ} / 1 \mathrm{~m}^{3}=5500 \mathrm{~kJ} / \mathrm{m}^{3}$. 
dado que $1 \mathrm{~kJ}=1 / 3600 \mathrm{kWh}$, vem,

$\mathrm{E} / \mathrm{V}=0,564 \mathrm{kWh} / \mathrm{m}^{3}$

Esse resultado confere com o apresentado pelo referido trabalho como sendo a quantidade mínima de energia necessária para dessalinizar cada metro cúbico de água do mar como se pode ver no extrato do mesmo apresentado na figura B2.

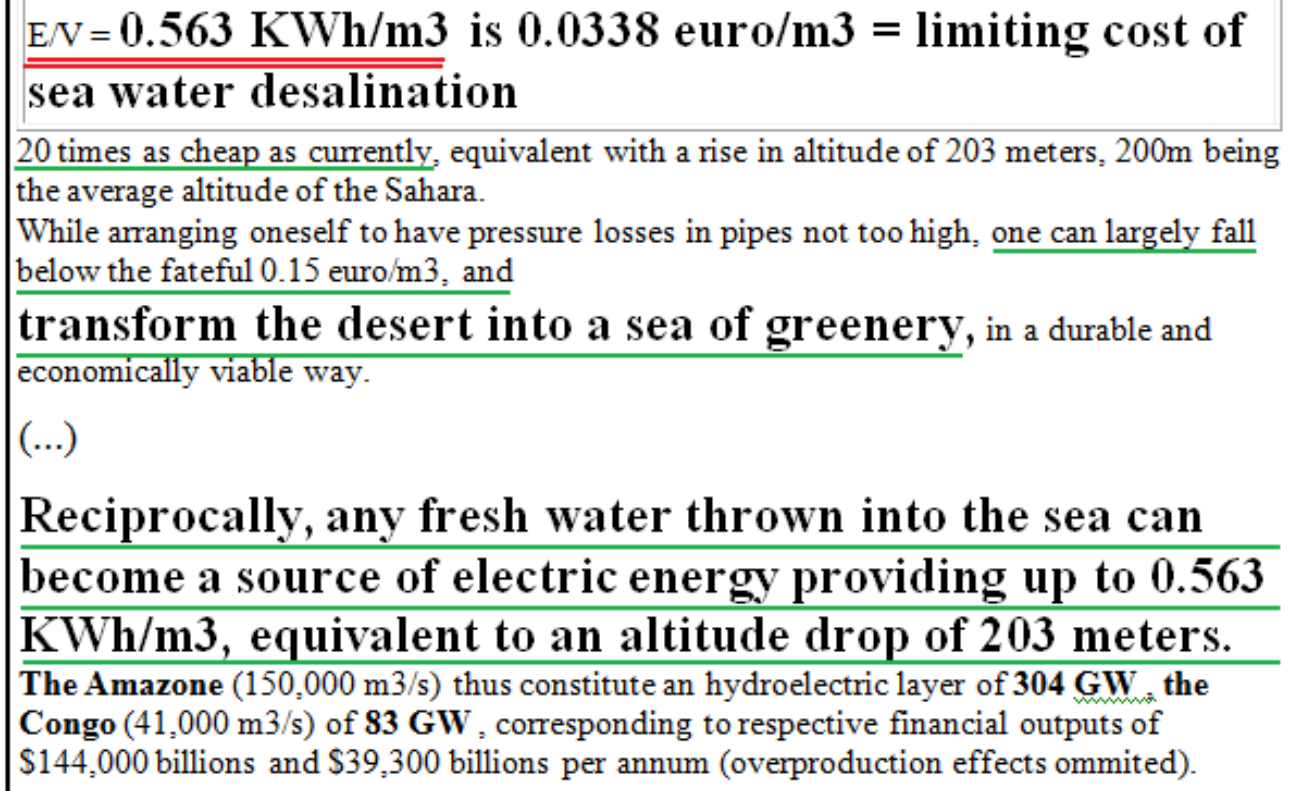

Fig. B2: extracto do texto original. Fonte ISENTROPIC [...] com grifo nosso

$\mathrm{Na}$ Fig. B2 destacamos aspectos econômicos interessantes relacionados com a dessalinização e com a geração de eletricidade. Conclui-se que a CPH é um sistema promissor para a dessalinização por osmose reversa. Quanto à geração de eletricidade, além de o fluxo de água com alta pressão poder ser direcionado diretamente para a turbina Pelton, ele poderá ser encaminhado para um reservatório à uma altura correspondente à alta pressão (203 m por exemplo) e posteriormente, por gravidade, acionar uma turbina. Ter-se-ia, isentropicamente, uma geração de $0,563 \mathrm{kWh}$ por cada $\mathrm{m}^{3}$ de água armazanado no reservatório sob forma de energia potencial gravitacional. 
ANEXO C- PRÁTICAS DE MANUTENÇÃO APLICADAS A UMA BOMBA DE DESLOCAMENTO POSITIVO (modelo proposto) DE UMA UNIDADE DE DESSALINIZAÇÃO DE ÁGUA POR OSMOSE REVERSA

\section{ANÁliSE DOS MODOS E EFEITOS DE FALHA E PRÁTICAS DE MANUTENÇÃO ADOTADAS}

Decidimos neste trabalho isolar do sistema todo (unidade de dessalinização) um dispositivo que será o foco do nosso estudo relacionado tanto com o diagrama funcional como com a análise dos modos e efeitos de falha (FMEA- Failure Mode and Effect Analysis). O dispositivo foco está representado na Fig. C.1.

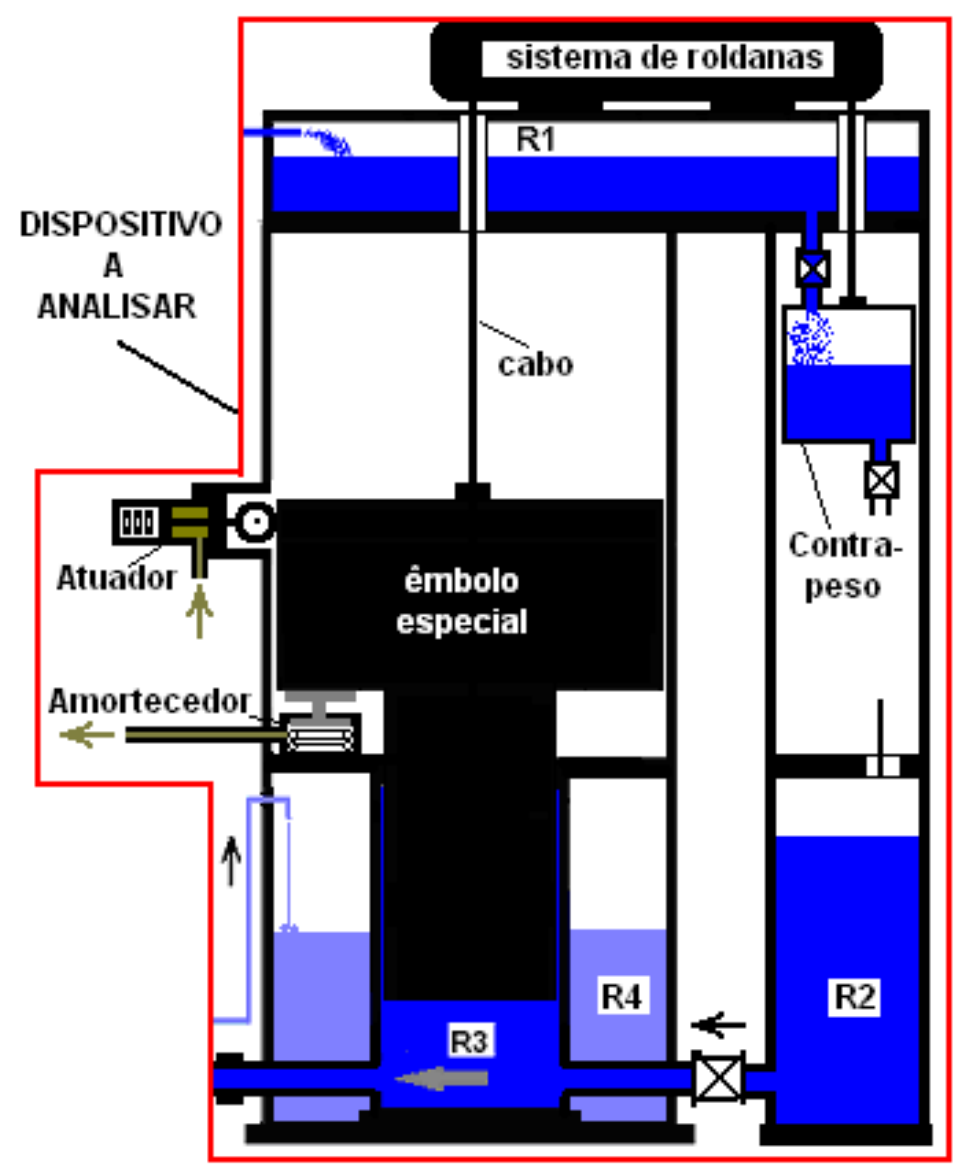

Fig. C.1: Dispositivo foco da análise e seus elementos. 


\section{C.1-diagrama funcional do dispositivo}

Após a identificação do dispositivo a ser analisado e conhecendo bem o funcionamento da bomba, torna-se fácil esboçar o diagrama funcional do mesmo. A figura C.2 apresenta uma versão simplificada do "diagrama funcional" no qual pode-se identificar as interligações entre os vários elementos do dispositivo.

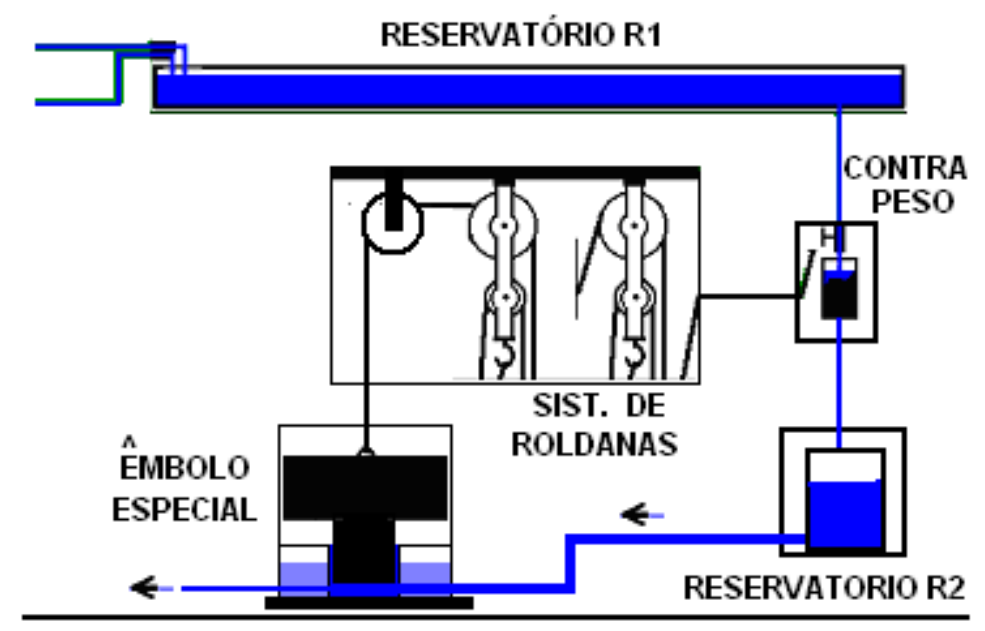

Fig. C.2: "diagrama funcional" do dispositivo.

As conexões funcionais são:

1) A água do reservatório R1 (energia potencial gravitacional acumulada) passa para o contrapeso (fornecimento de energia) e este, através do sistema de roldanas e cabo, eleva o êmbolo.

2) O êmbolo ao subir suga água do reservatório $R 2$ para dentro da câmara de compressão (reservatório R3). O êmbolo, no seu fim de curso superior, detém energia potencial gravitacional que lhe foi transmitida pelo contrapeso através do cabo.

3) O contrapeso, ao se esvaziar (água que cai em R2), possibilita a descida do êmbolo. Ao descer, o êmbolo bombeia a água contida na câmara de compressão. 
O referido "diagrama funcional" é obtido diagrama de Sankey (veja-se a Fig. C.3) do modelo de unidade de dessalinização que usa a bomba premente. No diagrama de Sankey representa-se todos os fluxos de energia entre os vários dispositivos do sistema.

Do diagrama, constata-se que o consumo específico "real" da unidade (energia fornecida pelo(s) catavento(s)) é em torno de $2,81 \mathrm{KWh} / \mathrm{m}^{3}$. Esse valor é cerca de metade do consumo de unidades convencionais de osmose reversa.

A bomba Clark presente no diagrama de Sankey é um dispositivo usado para recuperar a energia contida na salmoura. Ele bombeia água de R2 para R1 a partir da conversão do fluxo da salmoura em trabalho de um pistão.

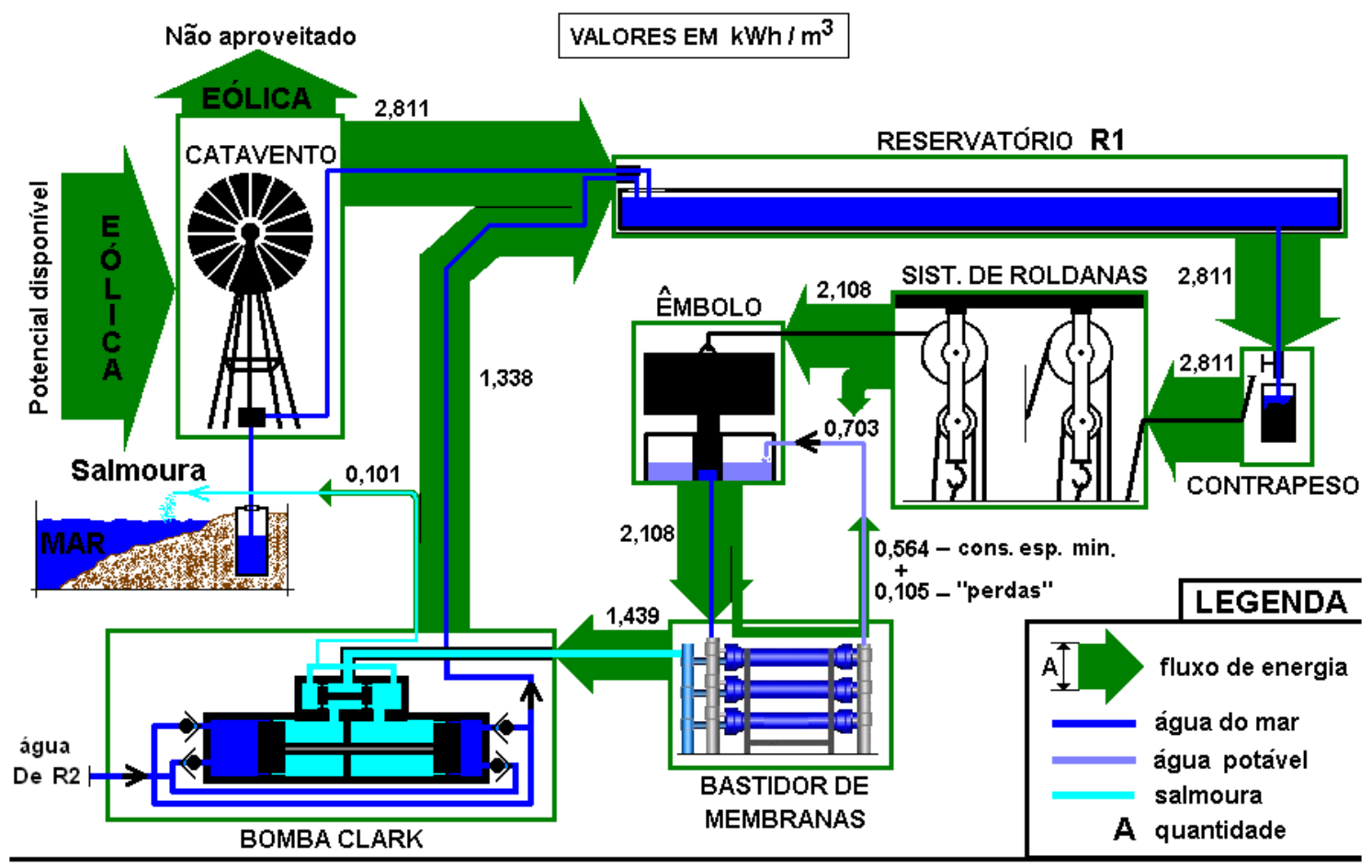

Fig. C.3: Diagrama de Sankey do sistema proposto.

\section{FMEA (Failure Mode and Effect Analysis).}

O fato de se estar numa fase de construção de um protótipo da bomba aspirantepremente, possibilita-nos apresentar algumas fotos de alguns elementos já construídos bem como algumas etapas de sua construção. Essa fase foi de extrema importância para este trabalho dado que a vivência na oficina com os técnicos, e o contato com as peças, 
são uma experiência rica que nos facultou uma boa "visão" dos modos e efeitos de falha.

\section{C.2.1- Dispositivos e suas funções}

Apresentaremos de seguida, os elementos do dispositivo e citaremos as suas funções. Na seqüência apresentaremos o FMEA do cabo e do sistema de roldanas cuja falha tem conseqüência perigosa. Dispensou-se aqui a apresentação do FMEA completo.
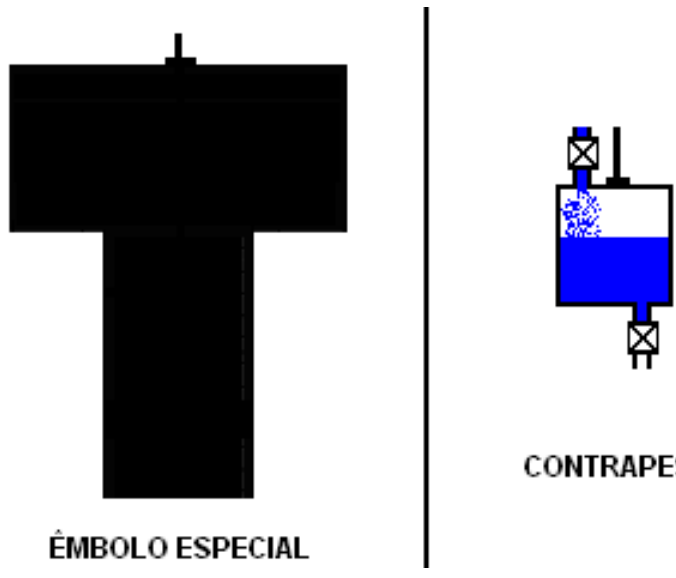

CONTRAPESO

Fig. C.4: Êmbolo especial e contrapeso.

A função principal do êmbolo especial é bombear água a uma determinada pressão. A função principal do contrapeso é armazenar água para elevar o êmbolo especial.

2) Reservatórios R1, R2, R3 (câmara de compressão), R4 e a carcaça.

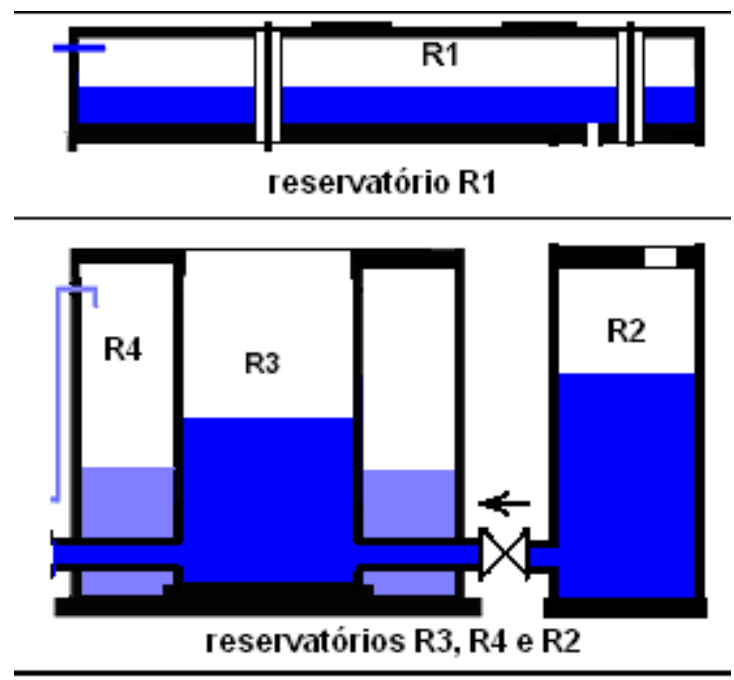

Fig. C.5: Reservatórios R1, R2, R3 e R4. 
-As funções de R1 são armazenar água e suportar (função estrutural) o sistema de roldanas

-As funções de R2 são armazenar água despejada pelo contrapeso e alimentar R3.

-A função de R3 (câmara de compressão) é receber água de R2 para ser bombeada.

-A função de R4 é armazenar a água dessalinizada.

- As funções da carcaça são guiar o êmbolo e formar as paredes do reservatório R4.

A função do sistema de roldanas é multiplicar a força exercida pelo contrapeso para elevar o êmbolo. Nos testes efetuados com o protótipo, provou-se que essa função é efetiva.

A função do cabo é transmitir a força exercida pelo contrapeso. Obviamente que também, com os testes ficou provada essa função.

4) Amortecedor-atuador, válvulas e tubulações.

Esses dispositivos já foram apresentados anteriormente pelo que passamos diretamente às suas funções:

-As funções do amortecedor são amortecer o impacto do êmbolo ao chegar ao fim de curso inferior e enviar um sinal (pressão hidráulica) para o atuador

-As funções do atuador são travar e destravar o êmbolo quando ele estiver no fim de curso inferior.

Considerando o amortecedor e o atuador como um único dispositivo a sua função será de automação hidráulica.

-As funções das válvulas são impedir ou/e direcionar o fluxo de água.

-A função das tubulações é conduzir a água para os pontos a que ela se destina.

\section{B.2.2- FMEA do cabo e do sistema de roldanas.}

Da análise que foi feita dos modos e efeitos de falhas, identificou-se dois elementos cuja falha pode ter conseqüências perigosas. Na tabela C.1 pode-se ver o FMEA desses 
elementos (cabo e sistema de roldanas). Reiteramos que o FMEA de todos os elementos encontra-se no anexo 2.

Tabela C.1: FMEA do sistema de roldanas e do cabo.

\begin{tabular}{|c|c|c|c|c|c|c|c|c|}
\hline & \multicolumn{2}{|c|}{ FUNÇÖES } & PADRÄO & $\begin{array}{l}\text { PARÂME- } \\
\text { TRO }\end{array}$ & $\begin{array}{l}\text { MODOS DE } \\
\text { FALHA }\end{array}$ & CAUSA & $\begin{array}{l}\text { CONSE- } \\
\text { QUÊNCIA }\end{array}$ & PROAÇÄO \\
\hline \multirow[t]{2}{*}{$\begin{array}{l}\text { S } \\
\text { I } \\
\text { S } \\
\text { T. }\end{array}$} & \multirow[t]{2}{*}{ Principal } & \multirow{2}{*}{$\begin{array}{c}\text { Multiplicaçäo } \\
\text { de força }\end{array}$} & \multirow{2}{*}{ Absoluto } & Sim/näo & Desmontagem & Oxidação & $\begin{array}{l}\text { Queda do } \\
\text { Contrapeso } \\
\text { e do pistäo } \\
\text { (Perigosa) }\end{array}$ & Lubrificação \\
\hline & & & & Sim/näo & Lubrificaçäo & $\begin{array}{l}\text { Falta de } \\
\text { Lubrificação }\end{array}$ & $\begin{array}{l}\text { Polia gripa } \\
\text { ou oxidaçăo }\end{array}$ & Lubrificação \\
\hline $\begin{array}{l}0 \\
\text { L } \\
\text { D }\end{array}$ & \multirow{2}{*}{ Secundária } & \multirow{2}{*}{$\begin{array}{l}\text { Reduçäo de } \\
\text { atrito }\end{array}$} & \multirow{2}{*}{ Absoluto } & \multirow{2}{*}{ Sim/näo } & \multirow{2}{*}{ Deterioraçäo } & Oxidaçäo & \begin{tabular}{|c|}
$\begin{array}{c}\text { Aumento } \\
\text { do atrito } \\
\text { (Näo perigosa) }\end{array}$ \\
\end{tabular} & Lubrificação \\
\hline $\begin{array}{l}\text { N } \\
A \\
S\end{array}$ & & & & & & Lubrificação & $\mid \begin{array}{c}\text { Aumento } \\
\text { do atrito } \\
\text { (Näo perigosa) }\end{array}$ & Lubrificaçäo \\
\hline $\begin{array}{l}\text { C } \\
\text { A } \\
\text { B } \\
0 \\
\text { S }\end{array}$ & Principal & \begin{tabular}{|c|} 
Tranmitir \\
força exercida \\
pelo \\
contrapeso
\end{tabular} & Absoluto & Sim/näo & Deterioraçäo & $\begin{array}{l}\text { Oxidação do } \\
\text { cabo de aço }\end{array}$ & $\begin{array}{l}\text { Queda do } \\
\text { Contrapeso } \\
\text { e do pistäo } \\
\text { (Perigosa) }\end{array}$ & Lubrificaçäo \\
\hline
\end{tabular}

\section{C.2.3- Práticas de manutenção adotadas}

Em função da simplicidade do sistema, e da análise do FMEA (tabela C.3) dos elementos, decidiu-se que as práticas de manutenção corretiva e preventiva são suficientes para garantir à bomba aspirante-premente uma alta disponibilidade. A Tabela C. 2 resume a nossa decisão em relação a esse aspecto.

Tabela C.2: práticas de manutenção aplicadas aos elementos.

\begin{tabular}{|l|l|}
\hline PRÁTICA & DISPOSITIVOS \\
\hline MANUTENÇÄO & $\begin{array}{l}\text { Contrapeso } \\
\text { Roldanas } \\
\text { R2 } \\
\text { Carcaça } \\
\text { CabEVENTIVA }\end{array}$ \\
\hline & Êmbolo \\
& Amortecedor \\
& Atuador \\
MANUTENÇÄO & Válvulas \\
CORRETIVA & R1, R3, R4 \\
& Tubulaçöes \\
\hline
\end{tabular}


No que se refere à manutenção preventiva recomenda-se que testes sejam feitos para se determinar o tempo entre as intervenções. A manutenção preditiva não foi contemplada na nossa decisão pelo fato de se ter um sistema que, além de ser simples, poderá ser utilizado em locais remotos onde haja carência de pessoal qualificado.

Tabela C.3: FMEA da bomba (CPH).

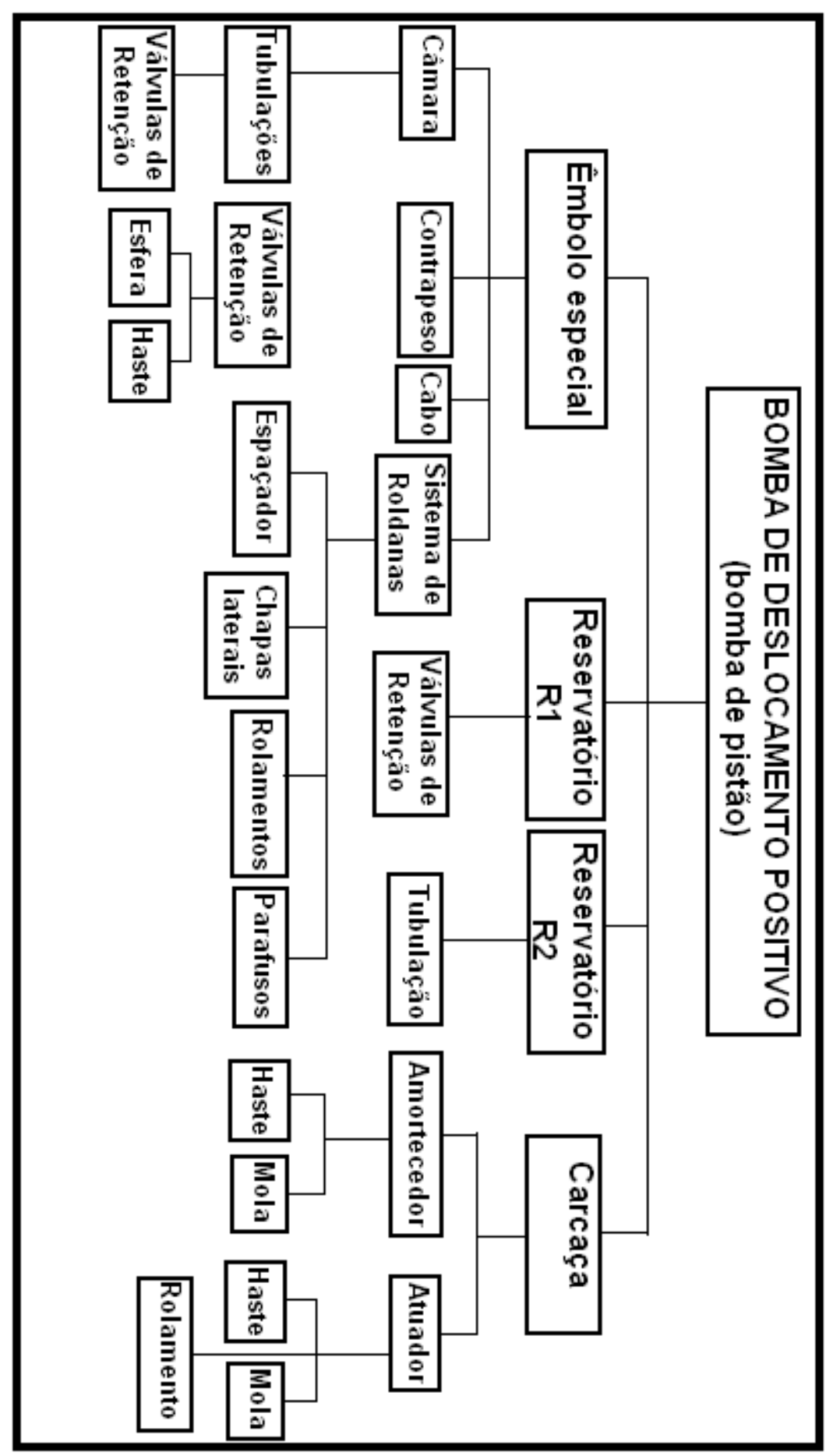


ANEXO D: extrato da divulgação do SEARASER. Fonte:http//searaser.com

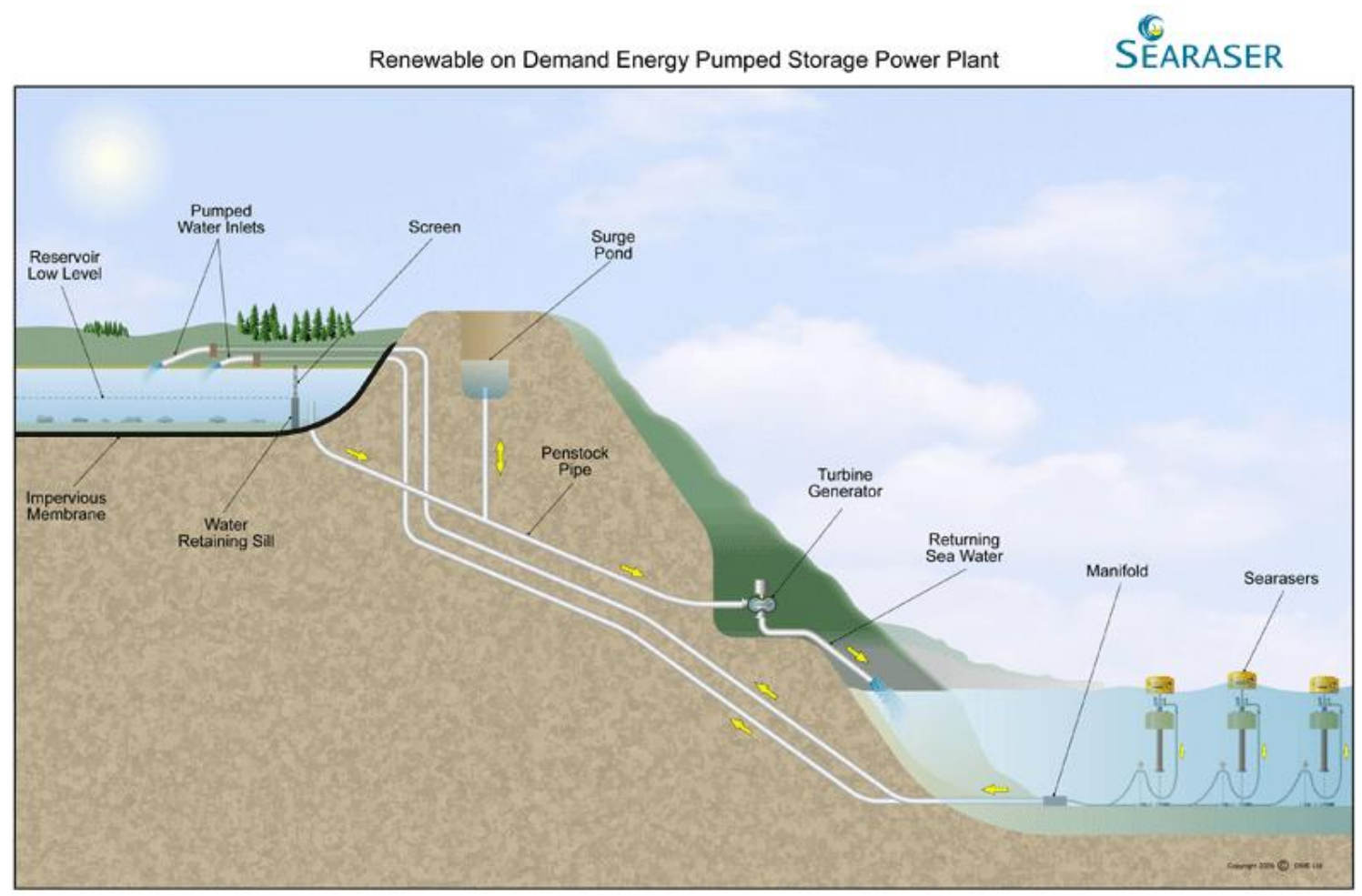

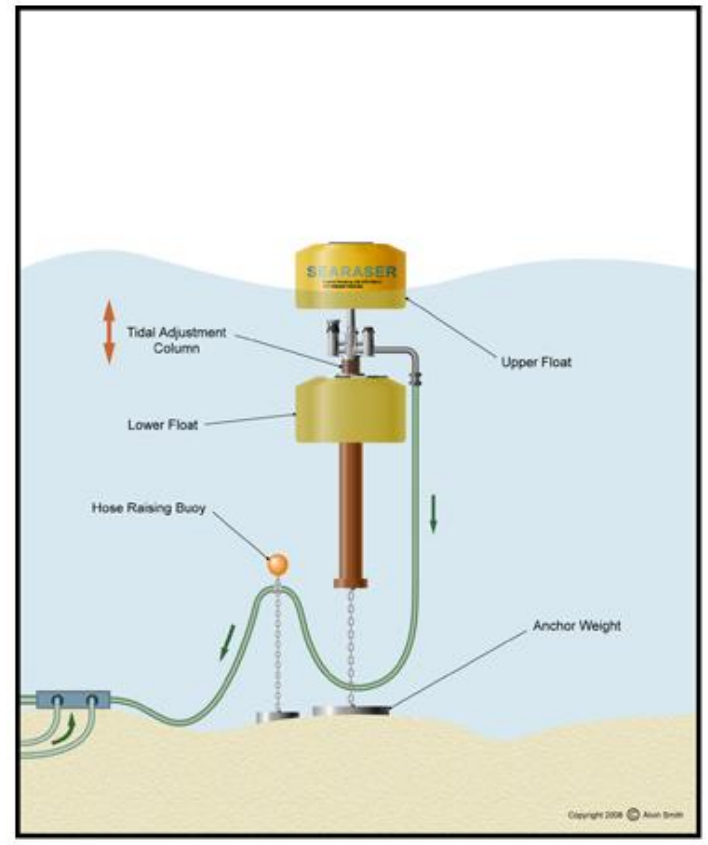

Upper float lowered in trough of wave

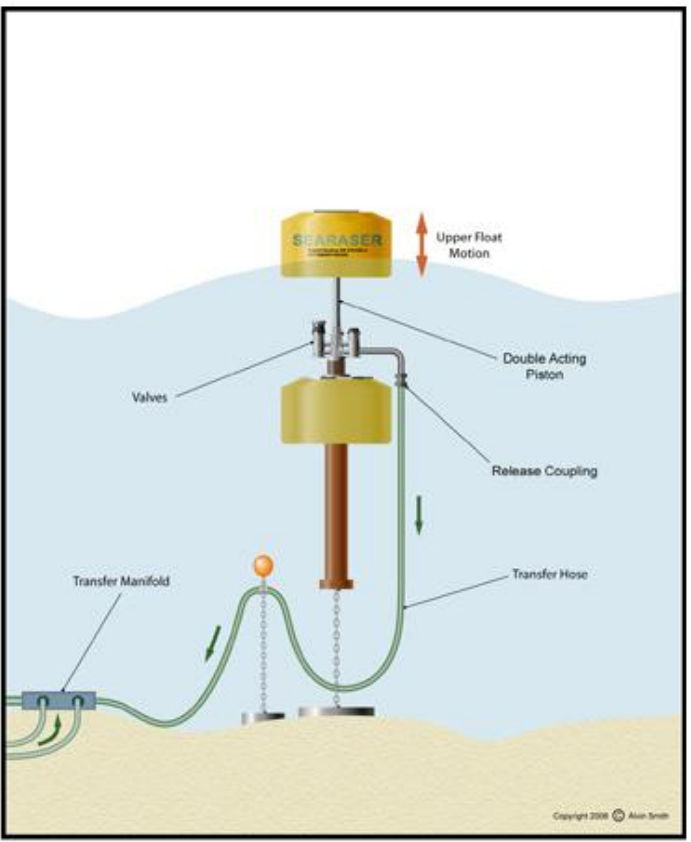

Upper float elevated on crest of wave

\section{Exciting new British invention}

Wave energy converter providing clean renewable energy on demand

NOTA: O sublinhado foi feito para destacarmos alguns aspectos do SEARASER que o colocam como uma efectiva alternativa para bombeamento de água para posterior 
geração de eletricidade a apartir da energia potencial gravitacional. É evidente que esta tecnologia pode ser usada para bombear água do mar atér o reservatótio R1 da coluna de potência hidráulica.

SEARASER could be one of the most efficient sources of renewable energy. It could also be one of the cheapest methods of producing electricity this includes nuclear, gas or coal as it does not attract a carbon levy.

11,000 full size SEARASER's could power the whole of the UK domestic demand.

The thinking behind the "SEARASER" by its British Inventor ALVIN SMITH.

Nuclear energy is by far the most reliable form of electricity production, but the clean-up over subsequent decades might outweigh the early fruitful years of production.

Hydro energy for the production of electricity is the next most efficient energy source and has advantages over direct wind systems in being storable and controllable. However, most hydro systems in the western world have been exploited to their full potential, which means that future demand will not be satisfied by hydro unless new hydro energy forms become available.

SEARASER represents that new, sustainable energy form. If we move water to higher ground or to a hilltop we would have a controllable hydro system similar to the Welsh and Scottish pumped storage systems but utilising RENEWABLE ENERGY and not fossil fuels to pump the water up to the head.

\section{So how do we get water to run up hill?}

SEARASER uses wave displacement to lift a float attached to a piston and uses gravity in the wave's following trough to push the piston back down. It is different from other wecs as it is tethered to a weight on the seabed by a single flexible tether, but utilises a double acting piston, thereby producing volumes of pressurised water in both directions of the piston.

Performance data from April 2009 sea trial

\begin{tabular}{|l|r|r|r|}
\hline SEARASER & $\begin{array}{r}\text { Maximum } \\
\text { Output } \\
\text { Prototype } \mathbf{8 3}\end{array}$ & $\begin{array}{r}\text { April Sea Trial } \\
\text { Actual } \\
\text { Prototype } 83\end{array}$ & $\begin{array}{r}\text { Forecast Output } \\
\text { Large Scale } \\
\mathbf{1 2 0 0}\end{array}$ \\
\hline Piston Diameter & $83 \mathrm{~mm}$ & $83 \mathrm{~mm}$ & $1200 \mathrm{~mm}$ \\
\hline Water volume per day (Litres) & $136,515 \mathrm{ltrs}$ & $112,800 \mathrm{ltrs}$ & $136,820,272 \mathrm{ltrs}$ \\
\hline Output & $0.93 \mathrm{~kW}$ & $0.77 \mathrm{~kW}$ & $932 \mathrm{~kW}$ \\
\hline Cost to produce electricity per kWh & & & 1.5 pence \\
\hline
\end{tabular}

Patented

GB 2445951

PCT / GB 2007 / 004366

Alvin Smith

Inventor of SEARASER

Dartmouth Wave Energy Limited

NOTA $: 1$ pence $=1 / 100$ libra $($ libra é a unidade monetária do Reino Unido $)$

Pela cotação do dia 13/01/2010, 1 libra $=1,62$ USD e 1 USD $=1,74$ Reais. Consequentemente, nesse dia, 1,5 pence $=0,042$ Reais, ou seja, o custo de produção de eletricidade com o SEARASER é de $\mathbf{0 , 0 4 2}$ Reais /kWh. 
SEQUÊNCIA DE IMAGENS DOS TESTES COM O PROTÓTIPO DO SEARASER $83 \mathrm{~mm}$.

(imagens "congeladas" e legendadas pelo autor)

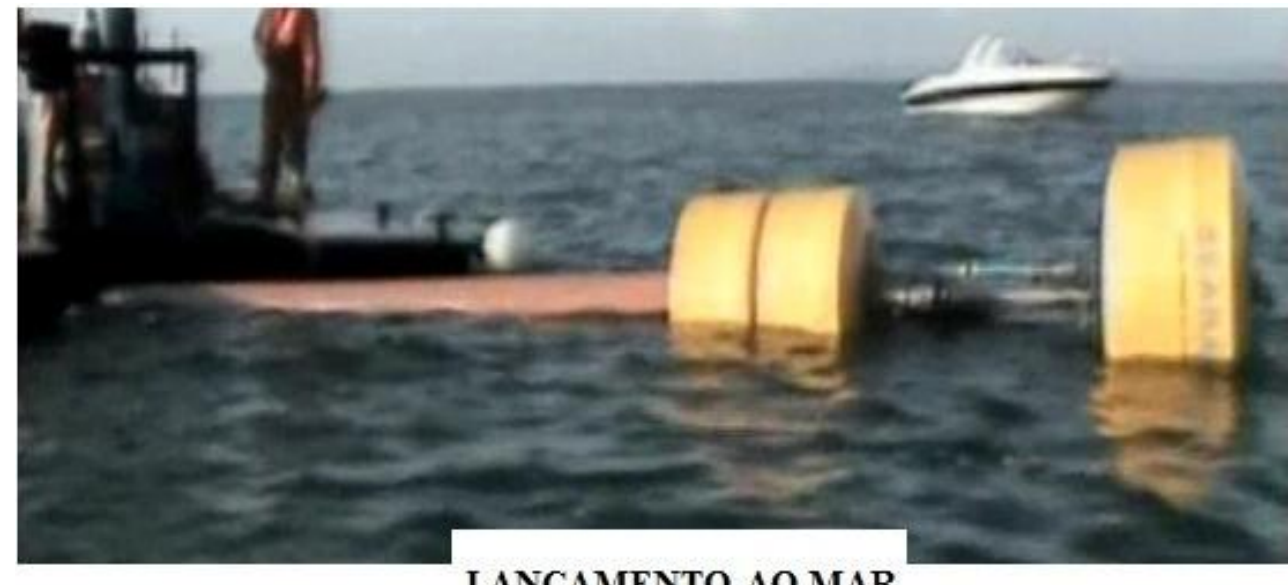

LANÇAMENTO AO MAR

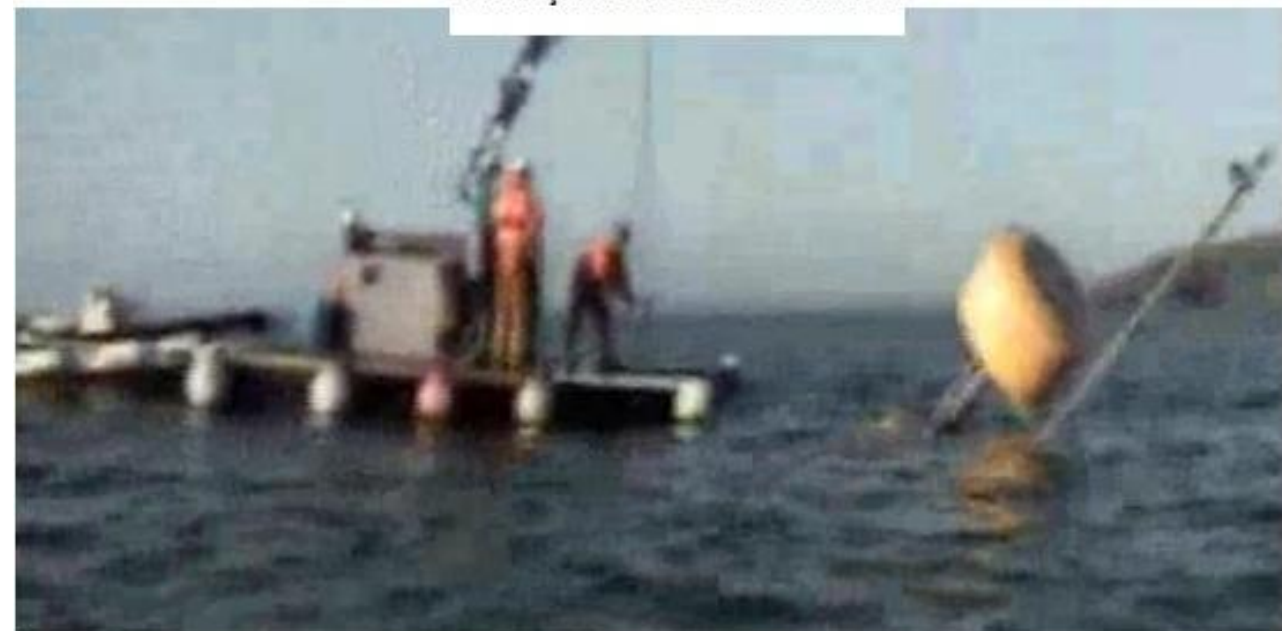

SEARASER BOMBEANDO

ELUCIDANDO SOBRE A PRESSÃO DA AGUA BOMBEADA PARA O ALTO DA COLINA
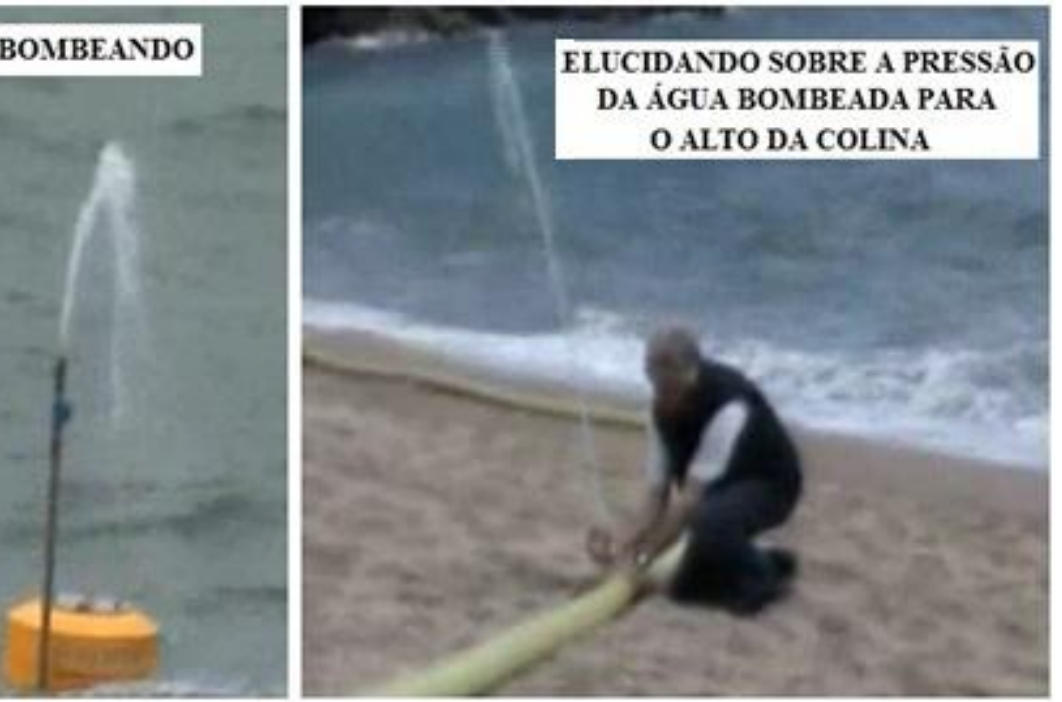


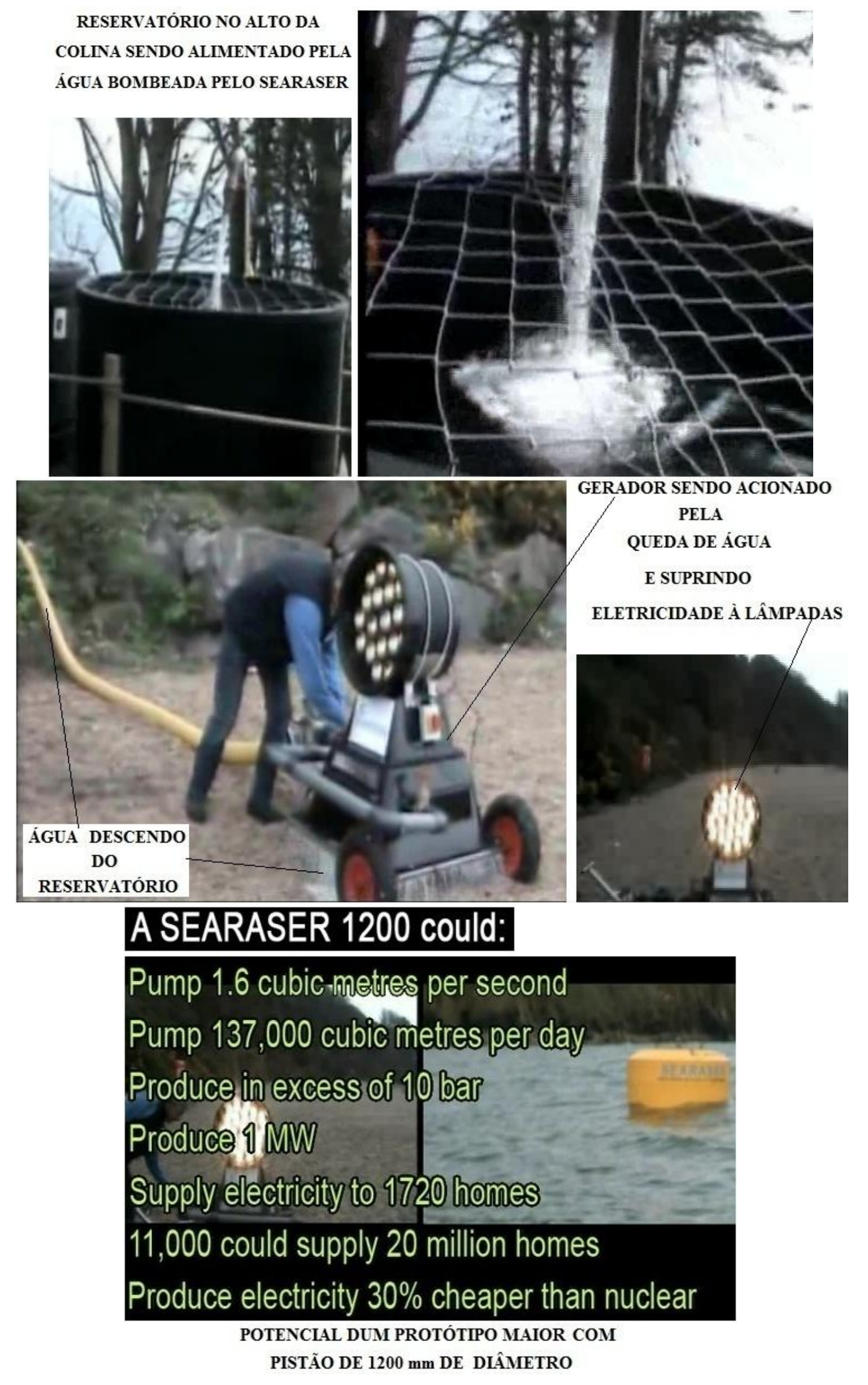




\section{ANEXO E-Uso de uma roda Pelton para a elevação do êmbolo especial}

O recurso à roda Pelton para elevação do êmbolo especial, poderá revelar-se de grande utilidade para o modelo em situações em que a distância que os contrapesos tivessem que percorrer fosse demasiado grande. A Fig. E.1 ilustra o mecanismo idealizado para incorporação da roda Pelton no sistema.

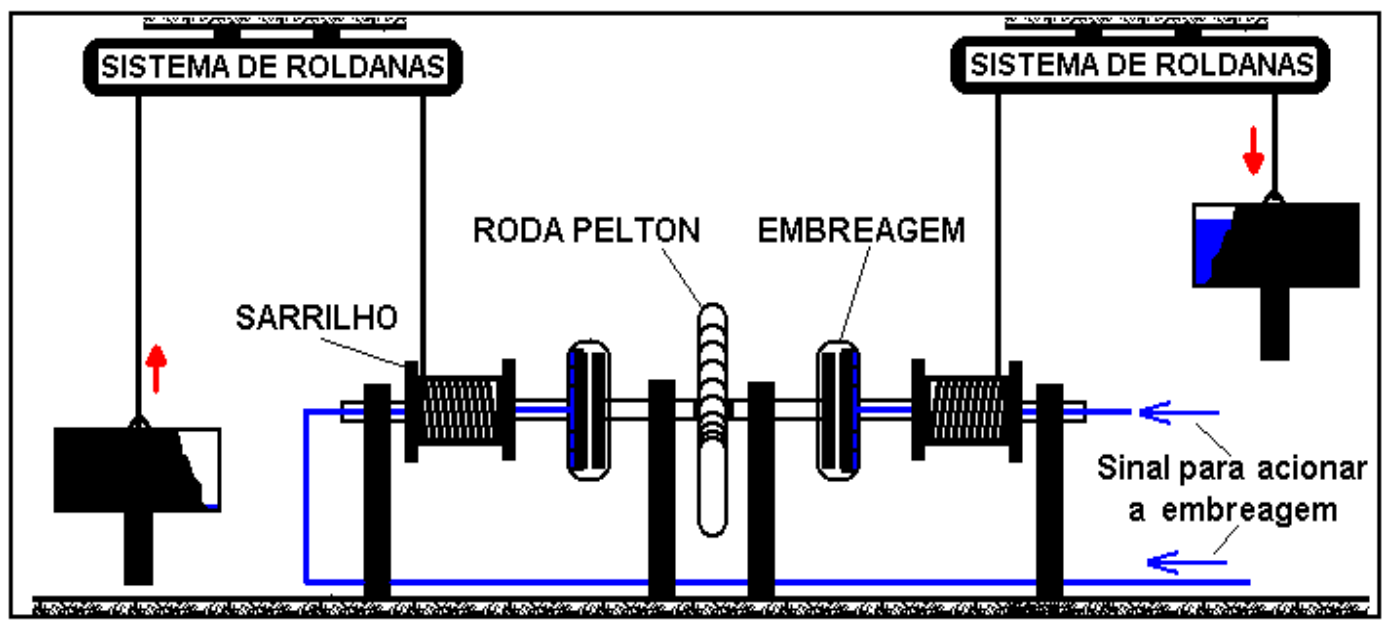

Fig. E.1: Sistema de elevação dos êmbolos através duma roda Pelton.

Quanto à utilização da roda Pelton, haverá a necessidade de se alterar parte do automatismo hidráulico para a sua incorporação no sistema. Uma das possibilidades é o uso de embreagem de discos para alternar a elevação dos êmbolos. A idéia está ilustrada na Fig. E.1 e descrita nas linhas seguintes:

- Tem-se um eixo, com uma roda Pelton no meio, cujas extremidades estão munidas de embreagens conectadas a dois eixos (um em cada extremidade), que têm os sarrilhos para elevar os dois êmbolos, alternadamente. O sinal de pressão para a ativação de cada embreagem poderá provir da ação do êmbolo da coluna oposta. Uma possibilidade seria ter uma linha de pressão, retirada do fluxo de água do mar, em direção aos módulos, proveniente duma coluna, para ativar a embreagem da outra coluna, cujo êmbolo estaria pronto para ser elevado.

A referida possibilidade está ilustrada na Fig. E.2 que apresenta o sistema de elevação através de roda Pelton e sarrilho incorporados no modelo de coluna de dessalinização. 
Quanto à embreagem, sabe-se que é tecnicamente viável o funcionamento preconizado para ela, descrito no parágrafo precedente, pelo que se dispensa a sua apresentação neste texto.

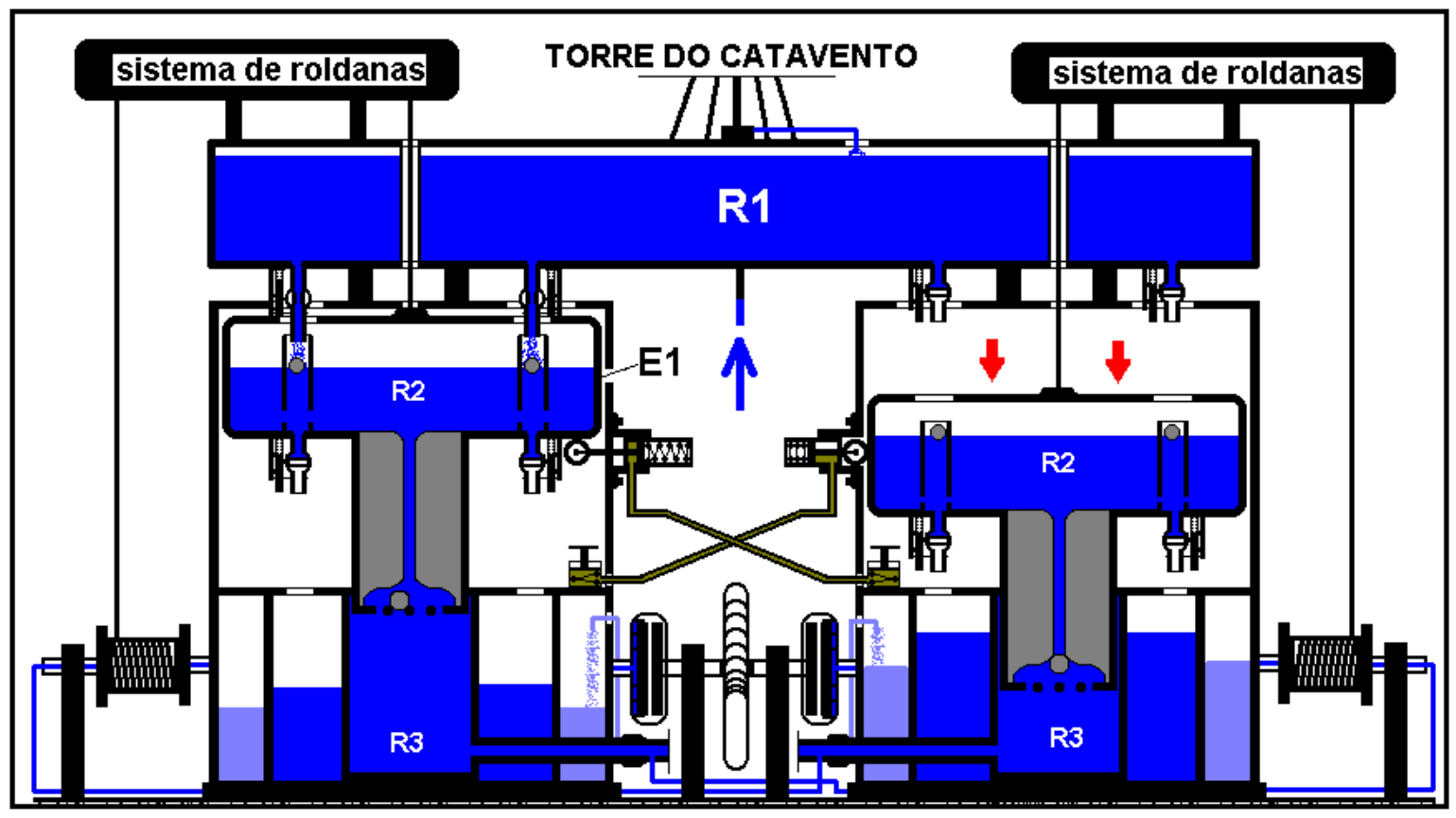

Fig. E.2: Sistema de elevação dos êmbolos através duma roda Pelton, incorporado no modelo. 


\section{ANEXO F: alimentação de R1 com carneiro hidráulico}

Seguem-se duas propostas para o uso do carneiro hidráulico para o abastecimento do reservatório R1 da Coluna de Potência Hidráulica.

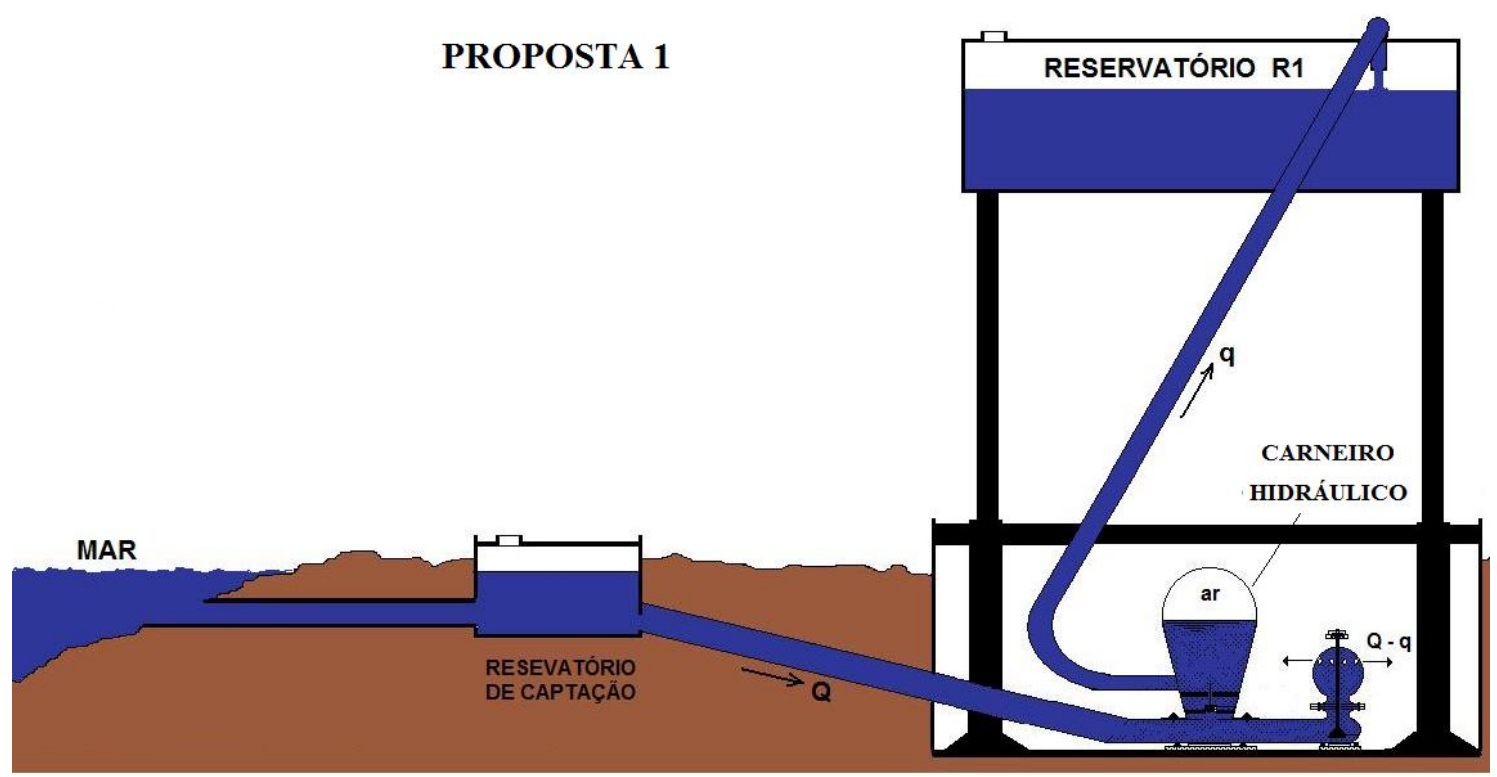

Fig. F1: Alimentação do carneiro através de um reservatório de captação

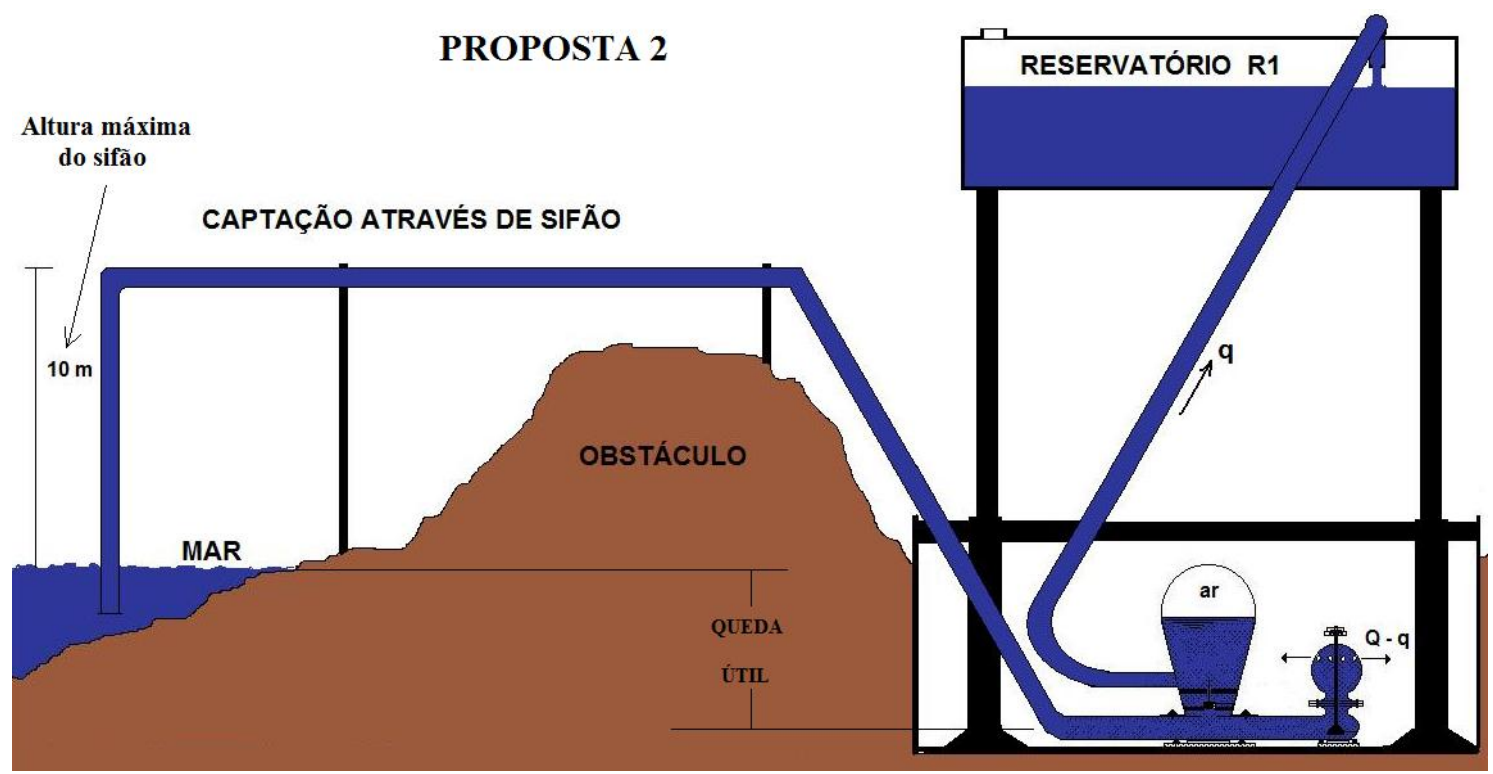

Fig. F2: Alimentação do carneiro através de um sifão.

A segunda proposta, Fig. F2, considera o levantamento da água do MAR até uma determinada altura inferior a $10 \mathrm{~m}$ ( altura que equilibra a pressão atmosférica), através de um sifão e o alimentar a bomba carneiro com a queda obtida. Nessa proposta a altura útil de queda até o carneiro corresponde ao diferença entre o nível do mar e a entrada da 
tubulação no carneiro. Como se constata, essa proposta permite ultrapassar pequenos obstáculos e vencer grandes distâncias sem a necessidade de escavações.

O caudal de água não bombeado (Q - q) cerca de $90 \%$ da água que chega ao carneiro hidráulico deverá retornar ao Mar, evaporar-se ou infiltrar-se. Pode-se ter uma combinação dessas três situações. Avançamos algumas soluções para resolver essa questão:

1-Bombeamento com a própria energia do mar (ondas e vagas). Aqui se adapta o SEARASER (invenção do Engenheiro Britânico), o SEARASER.

2-Dimensionamento do volume de água no vale onde se situa o carneiro em função das marés de forma que a água retorne ao mar na maré baixa.

Ainda para esse fim, outras tecnologias, tais como cataventos, máquina de Newcomen solar etc, podem ser usadas para o bombeamento do caudal (Q - q) de volta ao mar.

Com essas possibilidade de retornar o caudal não bombeado ao mar, prova-se que as propostas apresentadas não violam quaisquer leis da física e que, portanto, são factíveis. Sobre o potêncial de bombeamento há no mercado carneiros hidráulicos com capacidade de bombeamento até $\mathbf{5 0 0} 000$ litros por dia (ver Fig. F3).

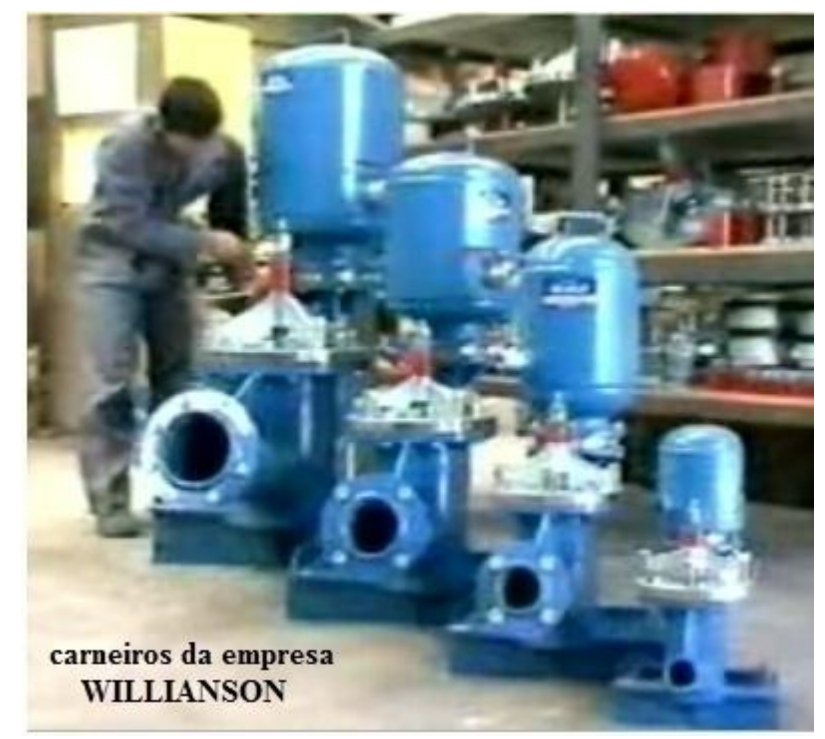

Fig. F3: Carneiros hidráulicos da empresa WILLIANSON 
Na Fig. G.1, apresenta-se alguns conceitos de turbinas que podem ser usados para obter a potência de bombeamento necessária para abastecer o reservatório R1 da CPH. Para tal, pode-se aproveitar ou a energia mecânica do rotor ou a energia elétrica do gerador.

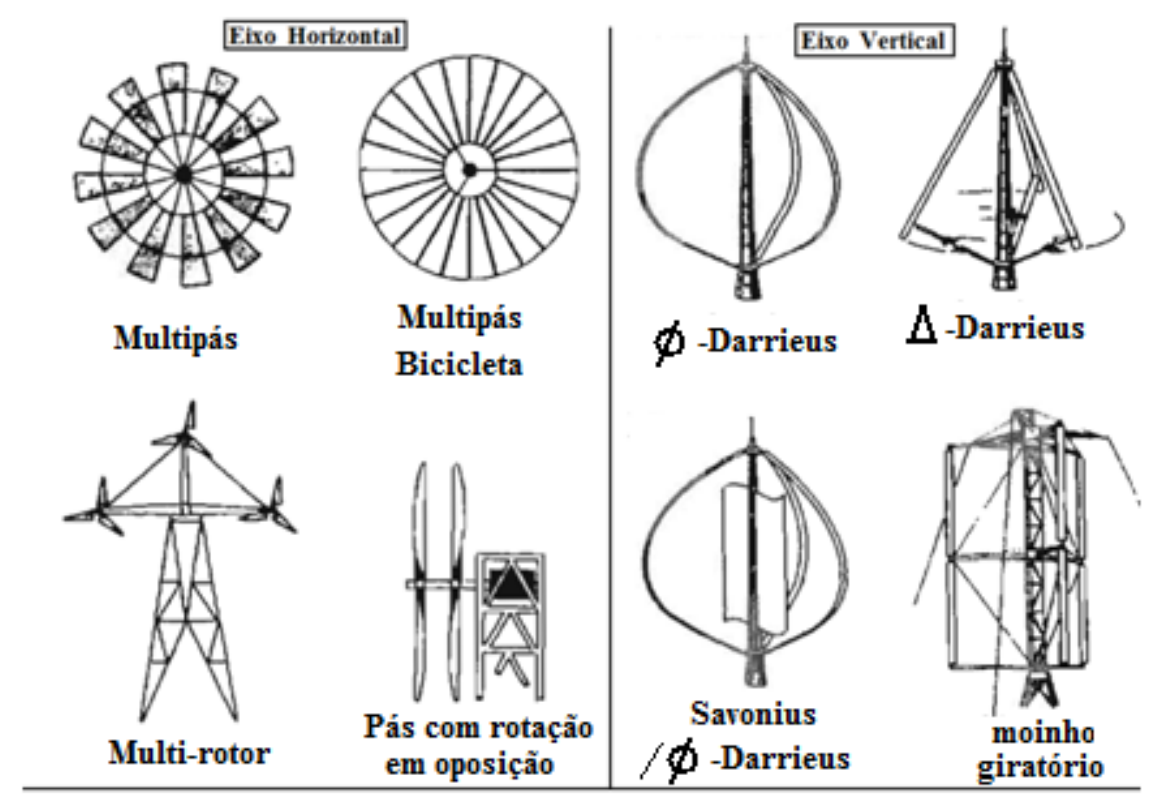

Fig. G.1: Vários conceitos de turbinas de eixo horizontal e vertical.

Fonte (MANWELL et al, 2002)

A possibilidade de se ter turbinas de eixo vertical com uma imensa variedade de desenhos é grande. Na Fig. G.2. estão algumas imagens extraídas de videos (www.youtube.com). Os videos comprovam que os perfis aerodinâmicos dos protótipos permitem que a turbina gire sempre no mesmo sentido independentemente da direcção do vento incidente. Tais turbinas não necessitamde sistema de orientação, o que é uma vantagem estrutural em relação às turbinas convencionais de eixo horizontal.
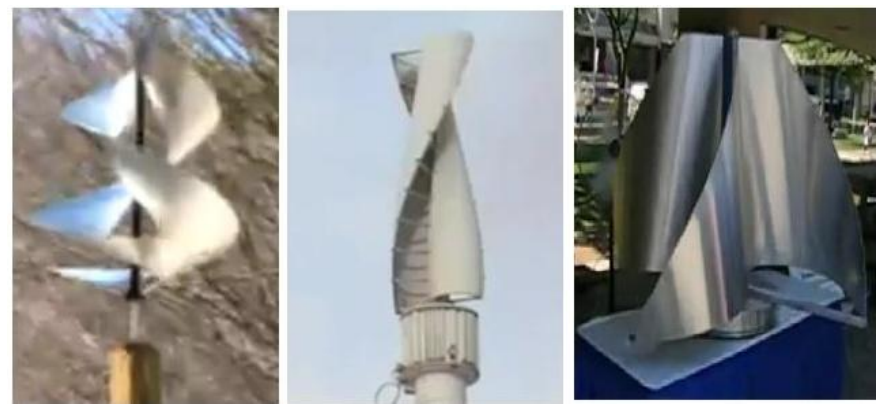

Fig. G.1: Turbinas de eixo vertical. Fonte: www.youtube.com. 
As turbinas de eixo vertical apresentam a facilidade de poderem ser montadas num eixo com levitação magnética. Essa alternativa reduz bastante o atrito além de dispensar a lubrificação, reduzir os custos de manutenção e aumentar a vida útil da turbina.

Sobre o potencial das turbinas eólicas com levitação magnética, cabe dizer que segundo a redação do site Inovação Tecnológia, a empresa MagLev apresentou na China a turbina maglev, Fig. G.3, que poderá produzir $1 \mathrm{GW}$. Na imagem seguinte pode-se ver a referida turbina e a sua comparação com as turbinas convencionais de eixo horizontal.

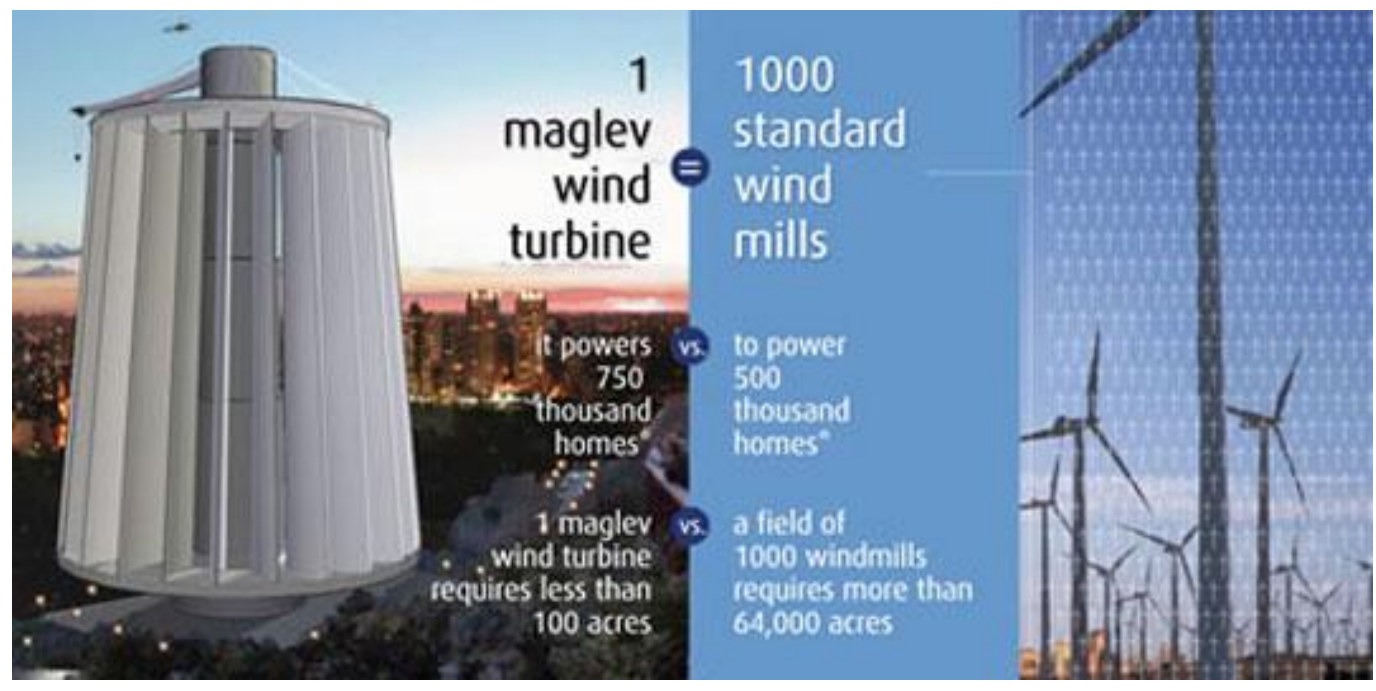

Fig.G.3 : Turbina maglev apresentada na China. Veja-se comparação com aerogeradores tradicionais: 1 turbina Maglev $=1000$ aerogeradores.

A Fig. G.4 sugere que tendo como requisito principal evitar as críticas relacionadas com a poluição visual, a CPH pode ser alimentada com cataventos de eixo vertical (com levitação magnética ou não) cujo aspecto seja agradável. Testes feitos pelo autor comprovaram a viabilidade técnica da proposta. Pode-se pensar numa "floresta eólica".

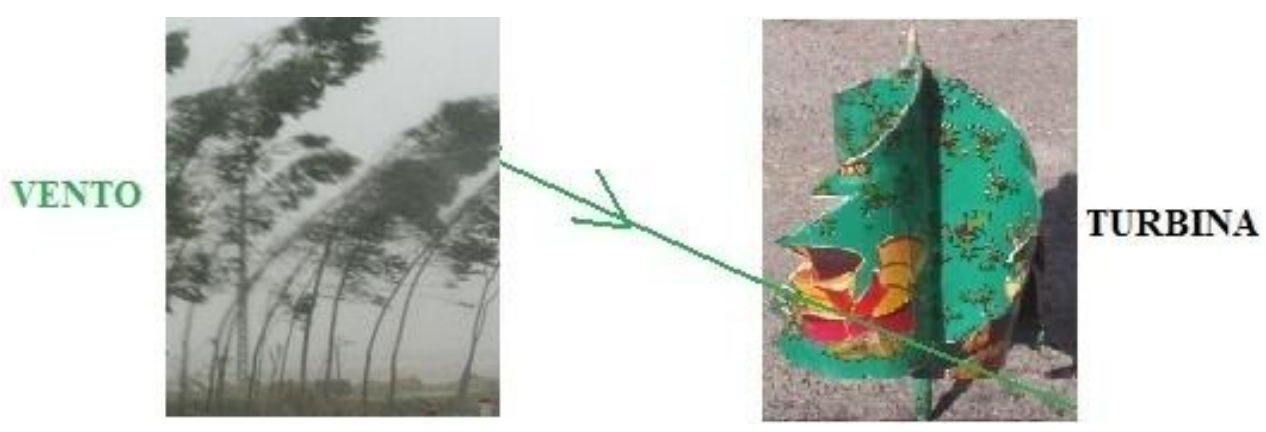

Fig. G4: Turbina de eixo vertical com perfil de árvore. 


\section{REFERÊNCIAS.}

ACIOLA, Jose de Lima. Fontes de energia. Editora: Universidade de Brasília, 1993.

A SMALL-SCALE seawater reverse-osmosis system with excellent energy efficiency over a wide operating range. Disponível em:

< http://www.desline.com/articoli/4925.pdf $>$. Acesso em: 20 Abr. 2010.

BATTERYLESS photovoltaic reverse osmosis desalination system. Disponível em: <http://test.netgates.co.uk/nre/pdf/SP200305.pdf $>$. Acesso em: 20 Abr. 2010.

CARVALHO, P. Geração Eólica. Fortaleza: Imprensa Universitária, 2003.

CREDER, H.. Instalações Hidráulicas e Sanitárias, $2^{\mathrm{a}}$ Edição, Livros técnicos e científicos Editora S.A., 1977.

DIAS, J. R. Dessalinização de água por osmose reversa usando energia potencial gravitacional e energia eólica. Dissertação de Mestrado, Escola Politécnica, Universidade de São Paulo, 2004.

FADIGAS, E.A.F.A; DIAS, J.R. Desalination of water by reverse osmosis using gravitational potential energy and wind energy. Department of Electrical Automation and Energy Engineering, São Paulo University. Desalination 237(2009) 140-146. Disponível online em: www.sciencedirect.com

FADIGAS, E. A. F. A. Energia eólica: Fundamentos, aplicações, viabilidade técnica e econômica. Escola Politécnica da Universidade de São Paulo. Apostila de Curso de produção de energia da Engenharia Elétrica, 2004.

FARRET, F.A . Aproveitamento de pequenas fontes de energia eólica, Ed. Ufsm, Rio Grande do Sul, 1999, 245p.

FIALHO, BUSTAMANTE., A. Automação hidráulica, 2a ed. São Paulo: Érica, 2004. 
FREE-WEATHER.COM. Disponível em:

<http://www.free-weather.com/Cape-Verde.php?nav=> . Acesso em: 20 Abr. 2010.

GOLDING, E. W. The generation of Electricity by wind power. E. \& F.N. Spon Ltd, 1976.

ISENTROPIC desalination (at minimal energy cost) of seawater. Disponível em:

<http://mshades.free.fr/isentropiques/desalination.html>. Acesso em: 20 Abr. 2010.

KENNETH, W. Jr. Termodynamics. 5.ed. New York: McGraw-Hill, 1988.

KHARABSHEH,S. Al. An innovative reverse osmosis desalination system using hydrostatic pressure. Desalination, 196 (2006) 210-214.

MANWELL, J.F; MCGOWAN, J.G. ; ROGERS, A.L..wind energy explained. University of Massachusetts, Amherst, USA JOHN WLEY \& SONS, LTD,2002

MEDINA, SAN JUAN, J.A. Desalación de aguas salobres y de mar: Osmosis Inversa.Madrid: Ediciones Mundi-Prensa, 2000.

PAREKH, B. Reverse osmosis tecnology: Aplications for high-purity-water Production- New York: Marcel Dekker Inc., 1988.

PATEL, M. R. Wind and solar power systems: design, analysis and operation. 2nd ed, 2006.

PROPERTIES of seawater. Disponível em:

<http://halibut.ims.uaf.edu/ musgrave/MSL620old/Properties\%20of\%20Seawater.htm>. Acesso em: 20 Abr. 2010.

RABINOVITCH E. Drinking with the wind: Small scale SWRO-installation mechanically driven by wind energy. Tese de mestrado defendida na Faculdade de Engenharia Civil e Geociências da universidade tecnológica Delft, 2008. 
REIS, L. B.; FADIGAS, E. A. F. A; CARVALHO C. E. Energia, Recursos Naturais e a Prática do Desenvolvimento Sustentável. Barueri, SP: Manole,2005.

REIS, L. B. Geração de Energia Elétrica. $3^{\text {a }}$ ed. Editora Manole, 2003.

SEARS, F.W; ZEMANSKY, M.W. Física: Mecânica - Hidrodinâmica, vol 1: Livros técnicos e científicos Editora, 1980.

SILVA, C.D.; SERAPHIM, O.J.; TEIXEIRA, N. M. Potencial eólico para bombeamento de água na fazenda lageado. In: ENCONTRO DE ENERGIA NO MEIO RURAL,3, 2000, Campinas. Anais eletrônicos...Disponível em:

$<$ http:/www.proceedings.scielo.php?script=sci_arttext\&pid=MSC000000002200000020 0032\&lng=pt\&nrm=abn>.Acesso em 20 Abr. 2010.

SOURIRAJAN, S. Reverse Osmosis. New York: Academic Press, 1970.

SPECTRA WATERMACHINES. Disponível em:

<http://www.spectrawatermakers.com>. Acesso em: 20 Abr. 2010.

VIABILIDADE económica da dessalinização. Disponível em:

<http://dequim.ist.utl.pt/iipi/TGrupos/Trabalho\%20T7.doc $>$. Acesso em: 20 Abr. 2010.

VISIBLE EARTH. Disponível em: < http://www.visibleearth.nasa.gov/>.

Acesso em: 20 Abr. 2010.

WORLD WINDMILL COMPANIES. Disponível em:

<http://members.westnet.com.au/caladenia/WorldCompanies.html $>$.

Acesso em: 20 Abr. 2010.

YUNUS, Ç.; MICHAEL, A.B. Termodynamics: An engineering approach. 3ed. New York: McGraw-Hill, 1998. 